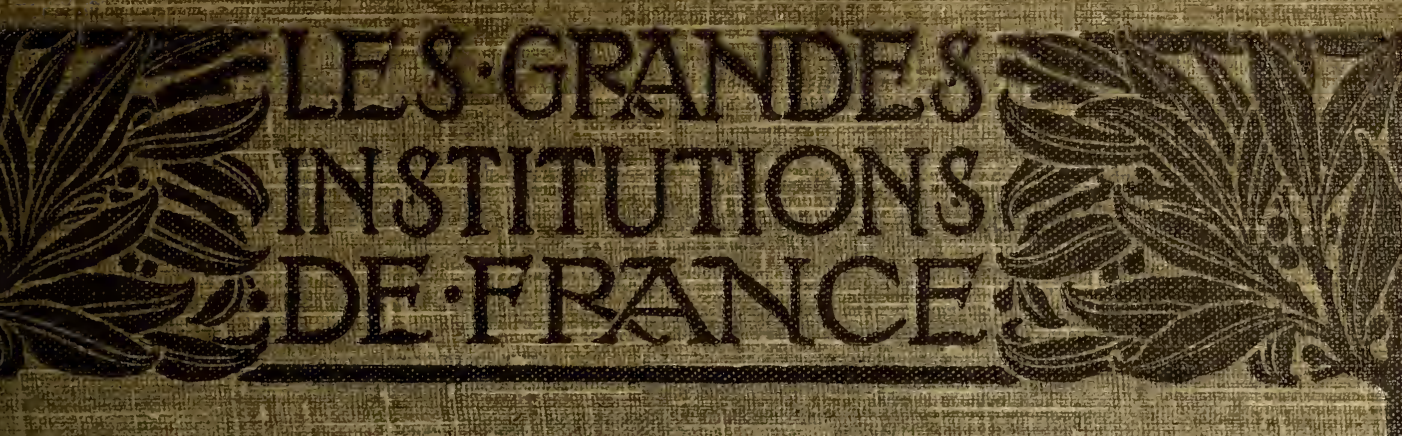

GeorgeS LECHEVALLIER-CHEVIGNARD

LA.

MANUFACTURE DE PORCELAINE DE

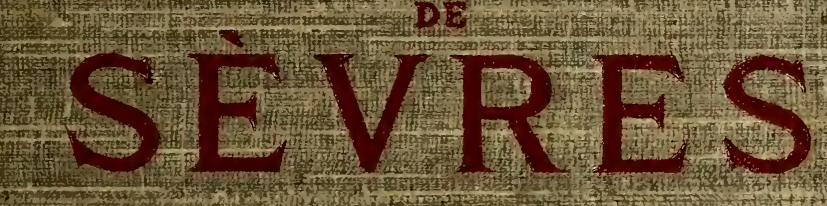

MISTOIRE DE LA MANUFACTURE

$1738-1876$
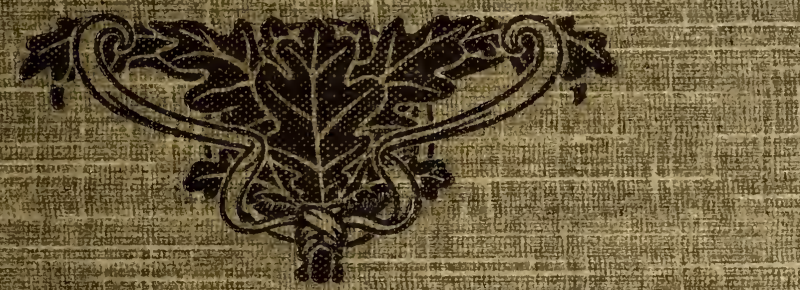

$H^{3}$

01004 


\section{La Manufacture de Porcelaine}

$$
\text { D E }
$$

$$
\text { S ̀̀VRES }
$$




\section{MEME COLLECTION}

Parus :

Les Gobelins et Beauvais. par Jules Gurfrey, de l'Institut.

La Monnaie, par Fernand Mazenolde, archiviste a la Monnaie.

Linstitut, 2 volumes, par Gaston Borssier. Gaston Darboux, Georges l'errot, Georges Picot, Henry Rouson, secrétaires perpétuels, et A. Fraxklis, administrateur honoraire de la Bibliotheque Mazarine.

La Bibliothèque Nationale, 2 volumes, par Ilenry MAcel, administrateur général, Henry Bouchor, Ernest Babeson, Paul MARChal et Camille Cocderc conservateurs et conservateur-adjoint.

\section{En preparation :}

L’Université de Paris, 2 volumes, par Louis Liakd, vice-recteur de l'Académie de Paris.

Le Musée de sculpture comparee du Trocadéro, par Camille ENLakT, directeur du Musée de sculpture comparée.

Le Louvre. La peinture, par Jean Guffrer, attaché au Musée du Louvre. 


\title{
La Manufacture de Porcelaine
}

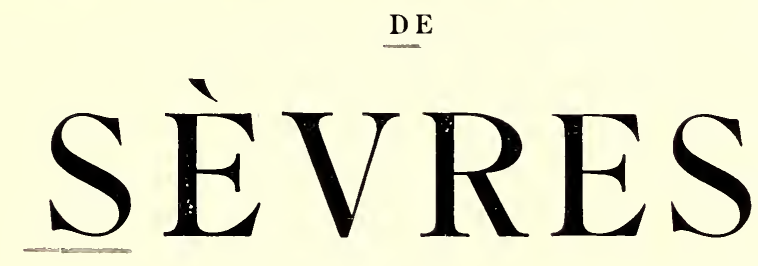

PAR

GEORGES LECHEVALLIER-CHEVIGNARD

Secrétaire archiviste de la Manufacture.

\begin{abstract}
HISTOIRE DE LA MANUFACTURE
I739-I876
\end{abstract}

Ouvrage illustré de 68 gravures

\section{PARIS}

LIBRAIRIE RENOUARD - H. LAURENS, ÉDITEUR

6 , RUE DE TOURNON, 6

$190 \mathrm{~s}$

Tous droits de traduction et de reproduction réservés pour tous pays. 


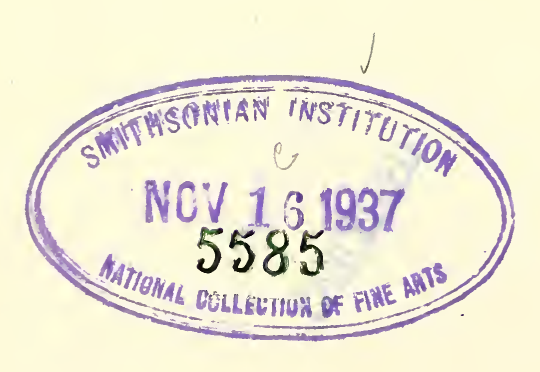




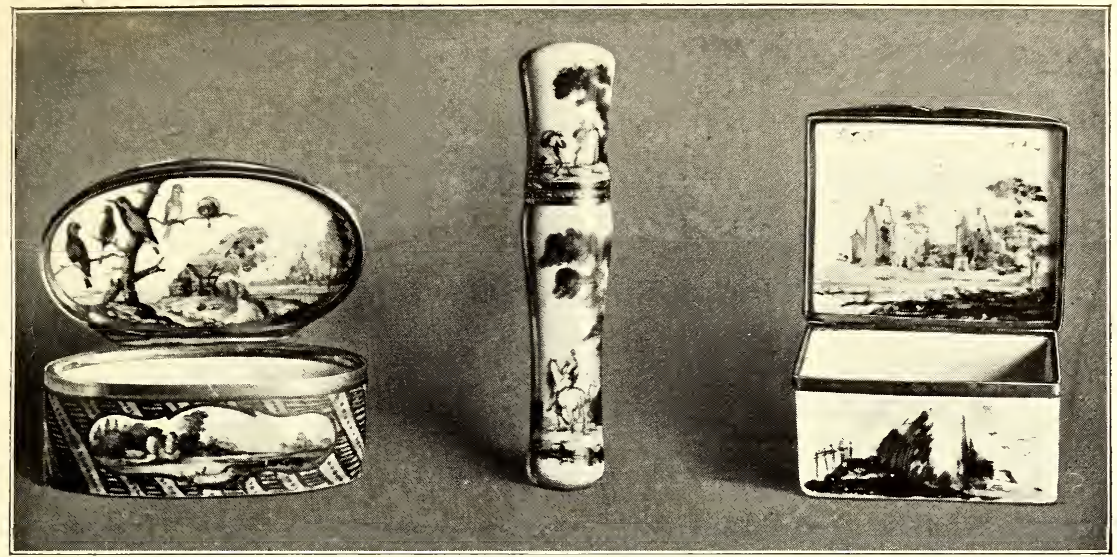

Porcelaine tendre do Vincennes, tre époque. (Collection de Chavagnac.)

LES PREMIÉRES MANUFAGTURES̃ FRANGGAISES DE PORGELAINE. LA FONDATION DE LA MANUFAGTURE DE VINGENNES. LA GOMPAGNIE GHARLES ADIM (1738-1752).

L'histoire de la fabrication de la porcelaine en Europe ne commence guère avant le jour où l’importation de plus en plus considérable des poreelaines orientales vint menacer le commerce florissant de la fä̈ence, et les fabricants de céramique ne paraissent a voir sérieusement cherché à rep̣roduire ou à imiter colte précieuse matière qu’à l'époque où la Compagnie des Indes entreprit de faire servir la porcelaine chinoise et japonaise aux usages journaliers de la table ef de la décoration courante : ainsi la découverte de la porcelaine en Europe fut, dans une certaine mesure, le résultat d'une situation eréée par la coneurrence commerciale.

Il y avait en effet bien longtemps que de somptueuses garnitures de porcelaine trouvaient leur place dans les palais des grands seigneur's ou des amateurs d'art : François I ${ }^{\text {er }}$ et Henri II manifestaient déjà un goùt très vif pour les luxueuses potiches chi- 
noises que les Portugais rapportaient de leurs lointaines excursions dans les mers d'Orient. Plus tard, au cours du xvir ${ }^{\mathrm{e}}$ siècle, les Hollandais monopolisìrent ce commerce et introduisirent sur le continent des pièces décorées d'émaux éclatants qui devinrent très vite objets de collections et atteignirent des prix considérables. La

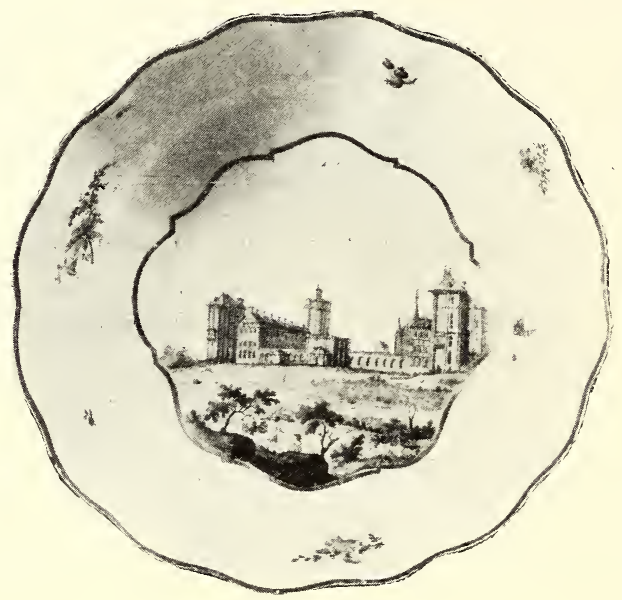

Porcelaine tendre de Vincennes. - Jatte décorée d’une vue du château de Vincennes. Diamètre 0,24. (Musée de Sèvres $11^{\circ} 36307$.)

Compagnie des Indes orientales, organisée par Mazarin en 1685, étendit encore le goût et augmenta le succès des porcelaines en faisant exécuter en Chine, d'après des dessins français, de grands services de table, aux armoiries des grandes maisons, services de France, de Penthièvre, etc.

G'est vers ce moment qu'apparut chez les fä̈enciers la préoccupation de fabriquer la porcelaine, ou tout au moins une matière offrant lès mêmes qualités de blancheur, de transparence et de solidité que celle dont le succìs leur eréait une dangereuse concurrence. Les céramistes rouennais, plus menacés encore que les autres par l'importation des produits orientaux, paraissent être parvenus, les premiers en France, à composer une matière présentant l'aspect 
et quelques-uns des caractères de la porcelaine. L’indication de de leur découverte se trouve dans un privilìge accordé en 1673 à Louis Poterat, où il est dit qu' " il a trouvé le secret de la véritable " porcelaine de la Chine ». Peu de pièces nous sont parvenues de cette fabrication qui n’eut sans doute, à aucune époque, un caraclère industriel : la pàte en est légèrement teintée, et le déeor est identique à celui des faïences rouennaises de la mème date.

En réalité, les Poterat restèrent avant tout des faïenciers, et il convient d'attribuer aux Chicaneau l'honneur d'avoir les premiers fabriqué d'une façon courante une matière céramique rappelant par son aspect la porcelaine chinoise. Ceux-ci, établis à Saint-Gloud, semblent bien avoir possédé le secret d'une composition de pâte dès avant 1678; mais, au témoignage de Martin Lister, ce serait seulement vers 1698 qu’ils en élablirent la fabrication régulière. Leur porcelaine, décorée d'ornements bleus dans le goùt de Bérain, eut un très grand succès; et l'estime dont les Chicaneau jouirent alors nous est connue par le Mercure de France qui raconte dans tous ses délails une visite de la duchesse de Bourgogne à leur manufacture, en l'an 1700.

A partir de cette époque, les essais se multiplièrent et les premières années du xvm siècle virent, à còté des fabricants, les plus illustres savants rechercher la eomposition de la véritable porcelaine : éest ainsi que Réaumur entreprit en 1717 la curieuse série d’analyses sur la transformation du verre en poreclaine dont il notait chaque jour les résultats sur un cahier conservé aujourd'hui eneore à Sèvres. Réaumur n’avait pas en de peine à reconnaitre que la matière fabriquée à Saint-Cloud, si brillante et si facile qu'elle fùt à décorer, n’était qu’une imitation de la véritable porcolaine, et que les deux eompositions, malgré leur similitude d'aspeet, étaient absolument différentes au point de vue de la conslitulion chimique. La découverte en Allemagne des matières premières nécessaires à 
la fabrication de la porcelaine chinoise, consacrée peu après par la fondation de la Manufacture de Meissen, devait lui donner pleinement raison et montrer clairement que le seeret de la porcelaine orientale échappail encore aux industriels français.

La création en 1722 de la Manufacture de Strasbourg par Hannong, à qui un ouvrier transfuge de la fabrique de Meissen, nommé Wankenfeld, avait apporté le secret de la fabrication saxonne, apparaît bien comme la première utilisation industrielle de la porcelaine naturelle dans notre pays : son succès devait ètre rapide et nous verrons dans la suite quelles causes toutes spéciales ameǹ̀rent en 17ö4 le transfert de cette fabrique à Frankenthal. Il semble extraordinaire, dans ces eonditions, que d'autres manufactures ne se soient pas organisées pour exploitèr les mèmes procédés : le secret de ceux-ci n’était certes pas impossible à pénétrer et la fondation mème de la fabrique Hannong prouve suffisamment qu’il était facile de découvrir un mécontent disposé à divulguer des secrets de cette nature. Aussi n’est-ce point là qu'il faut chercher la raison pour laquelle les Français se laissèrent à cette époque distancer par l'Allemagne, mais seulement dans ce fait que l'on ne soupçonnait pas la présence chez nous des matières premières utilisées pour la fabrication de la porcelaine à Meissen ou à Strasbourg. Et c'est pour ce motif que la Manufacture, fondée en 172:3 dans le domaine de Chantilly par Louis-Henri de Bourbon avee le coneours de Ciquaire Cirou, fut encore une fabrique de porcelaine tendre, e'est-à-dire d'une pereelaine dont la pâte était le résultat d'une préparation chimique, tandis que des produits naturels entraient seuls dans la composition de la porcelaine chinoise ou allemande. Cependant, malgré son infériorité apparente, cette création d'un grand seigneur amateur de belles choses apparaît bien dans l'histoire de l’industriè comme l'origine véritable de la porcelaine française, avec les qualités particulières qui devaient assurer sa réputation : en effet Rouen, Saint-Cloud, Stras- 
bourg n'avaient guère fait autre chose que transporter sur une matičre plus précieuse des décors déjà employés sur la fä̈ence; Chantilly, au conlraire, après quelques années frendant lespuelles l'imitation des décors chinois occupa encore une place prépondérante, sut trouver un genre de décoration emprunté à la flore et à la faunc nalurelles, merveilleusement approprié à la matiere nouvelle. Celle fabripue ne connut pas de concurrents jusqu'à l'époyue où s'ouvril à Paris la fabrigure de Frangois Barbin, rue de Charonne, fabrigue que son fondateur fut contraint de lransporler yuelques années plus tard à Mennecy sous la protec-

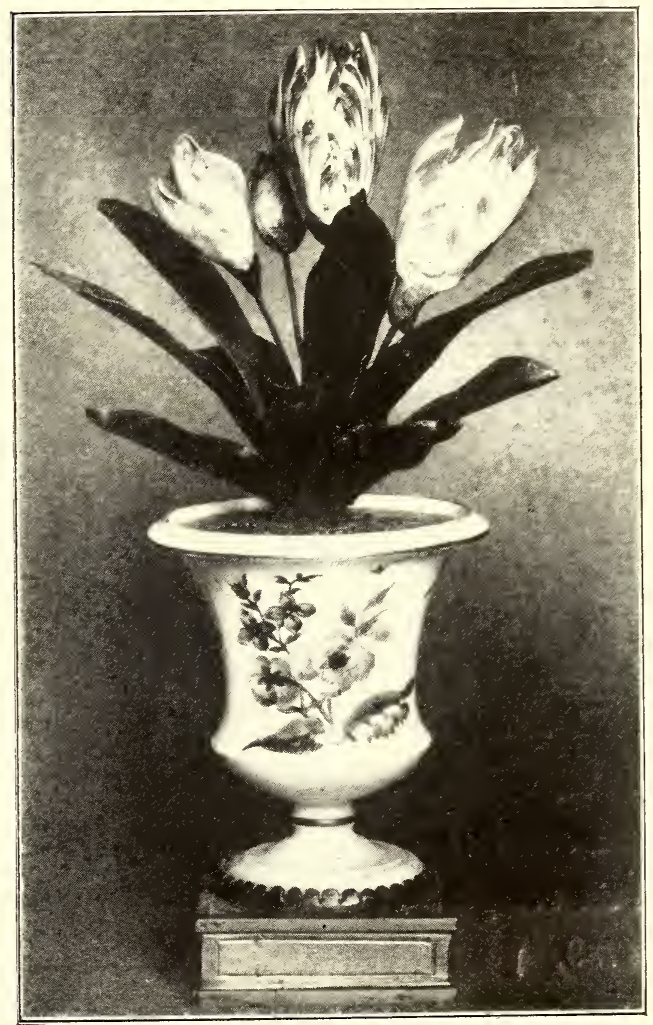

Fabrication de Vincennes, vers 1745-1750. Vase Médicis, avee bouquet de fleurs en porcelaine peinte (Collection de Charagnac). lion du duc de Villeroy.

Telle était la situation de l'industrie porcelainière en France au moment où commence l'histoire de la Manufacture qui, crééc à Vin. cennes en 1738, devait jeter un si vif éclat sur l'industrie de notre pays et faire donner à la porcelaine artidicielle le nom grlorieux de porcelaine française. L’idée de sa fondation nayuil du désir de protéger notre commerce contre le succès de la poreclaine allemande dont la concurrence immédiate devenail chaque jour plus redou- 
table; et de mème que les fabriques de Chantilly et de Mennecy durent leur établissement à de grands seigneurs comme Henri de Bourbon ou le duc de Villeroy qui s'honoraient de les posséder dans leurs domaines, la Manufacture de Vincennes fut fondée par un noble, Orry de Fulvy ${ }^{1}$, conseiller d'État et intendant des Finances.

A l'exemple de beaucoup des hommes de son milieu et de son temps, Orry de Fulvy s'intéressait depuis longtemps aux aris industriels et il avait vainement étudié la composition des pâtes à porcelaine, lorsqu'une occasion fortuite le mit à mème de reprendre ses essais arec l'espoir du succès. Trois contemporains, dont les noms restent liés à la période la plus brillante de la Manufacture, Bachelier, Millot et Gérin, nous ont conservé dans leurs mémoires l'histoire des débuts de la IIanufacture de Vincennes; et, si leur récit diffère parfois par des points de détail, il demeure cependant facile d'en dégager la part de vérité, en éliminant ce que chacun d'eux a pu ajouter, sous l'iníluence de préoccupations personnelles.

Deux ouvriers de Chantilly, les frères Gilles et Robert Dubois, l'un sculpteur, l'autre tourneur, durent quitter la manufacture en 1738, pour inconduite vraisemblablement. Millot raconte qu'ils emportèrent le secret de Ciquaire Cirou et qu'ils se réfugièrent au château de Vincennes dans la tour du Diahle, où ils restèrent pendant quelque temps à faire des essais et des pièces qu'ils allaient vendre en eachette à Paris : c'est là qu'au hasard d'une visite au marquis du Châtelet, gouverneur du donjon de Vincennes, Orry de Fulvy fut, dit-on, mis au fait des travaux des Dubois. Ceuxci eurent certainement le talent de faire renaître dans son esprit l'espoir abandonné de découvrir la composition de la porcelaine véritable, et ils oltinrent de Vignori, alors directeur général des Bâti-

${ }^{1}$ Orry de Fulvy, né à Paris en 1703, mort dans la mème ville en 17ö1, frère d’Orry, comte de Vignori, contrôleur général des Finances. 
ments, Arts ef Manufactures, la concession réguliere d'un emplacement dans le donjon de Vincemnes pour continuer leurs recherehes. En moins de lrois années. Ml de Fulvy leur avanga des sommes qui dépassèrent, si l'on en eroit Bachelier, cinquante mille lives ; le Roi lui-mème s’intéressa à leurs travaux par un don de dix mille lives. Cependant les mois passaient en infructueux essais et M. de Fulvy, découragé par l'absence de résultals, allail congédier les Dubois el abandonner sans doute définitivement l'idée de fabriquer la poreclaine, lorsquede nouvelles propositions vinrent raviver, encore une fois, ses espérances.

Auprès des Dubois travaillait un de leurs amis, Francois Gravant, d'abord fä̈encier dans l'oise, puis ayant fail de mauvaises affaires, marchand d'épices à Chantilly; témoin du mécontentement de II. de Fulry, il " conģut qu'en " restant fillèle à des maîtres qu'on

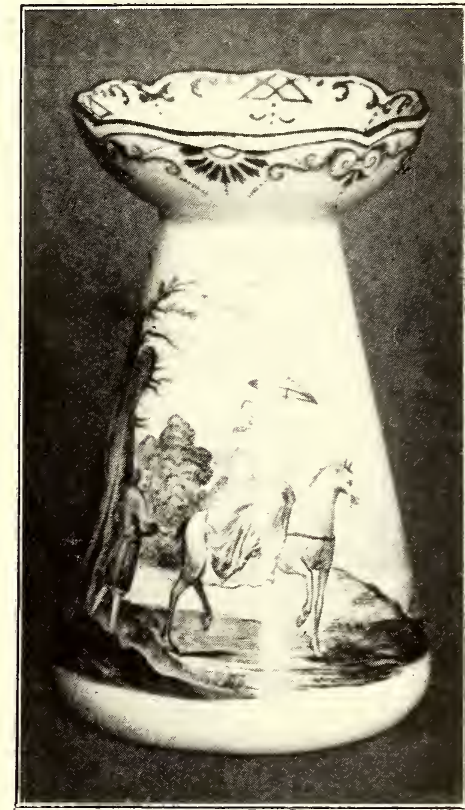

Fabrication de Vincennos, $1^{\text {re époyue. }}$ Vase à oignon. - Décor intité les Chinois. (Collection de Chavagnae.) " allail renvoyer, il perdait toutes res-

" sourees, au lieu qu'en servant M. de Fuby il aequerrait un puis"sant protecteur ; il résolut done de profiter des fréquentes ivresses " des Dubois pour copier ee qüils a vaient écrit sur la poreclaine et "remit le tout à Mi. de Fulyy. Les Dubeis furent ehassés. Gravant, " chargé du détail de loutes les compositions, devint le chef des ou"viers qu'il attira de Saint-Cloul" ".

Ces faits se passaient en mai 1741, el on peut considérer que la

\footnotetext{
${ }^{1}$ Bachelier. Mémoire historique sui. l'origine et le régime de la Manufacture royale de Sèvres, 1781.
} 
Manufacture eommença d'exister effectivement à celte date; cependant quatre années s'écoulèrent encore avant que la fabrication s'organisât d'une fạcon normale of devînt à peu près régulière. C'est en 1743 seulement que M. de Fulyy " parvint à sassurer de la com" position de la pâte, des moyens de former des pièces et de leur " donner une couverte qui pûl supporter la peinture ». Gravant en effet ne connaissail que la fabrication proprement dite et, si ses recherches l'amenèrent à composer une pâte et une courerte d'un blane satisfaisant, la cuisson des pièces donna longlemps de sérieux mécomptes. On en trouve l'aveu dans le mémoire de son collaborateur Millot qui, arrivé à Vincennes en 1740, devait y rester comme chel des fours jusqu'en 1786: il raconte que les fours employés alor's élaient d'une lauceur disproportionnée et que l'on devail se contenter de trouver, après la eaisson, 100 ou 1000 pièces réussies sur 600 ou 700 mises dans le four ; el il s'attribue l’idée d'avoir construit à mi-hauteur du four une seconde voûte grâce à laquelle les résultats furent beaucoup plus satisfaisants.

A cetle époque, d'ailleurs, l'organisalion de la Manufacture élait encore tout à fail rudimentaire. Les comptes de 1741 à $174 \%$ senblent établir qu'elle comprenait deux chefs d'atelier : d'un côté, Gravant avee une dizaine d'ouvriers venus pour la plupart de Chantilly, et de l'autre, Liot, qui resta quelque temps chef des peintres, avec un nombre à peu près égal de décorateurs. Ce personnel élait installé dans le donjon de Vineennes, d'abord dans les tours du Roi et du Diable, puis, un peu plus tard, dans les bàtiments de la Surintendance, extension devenue nécessaire, moins en raison de l'aecroissement du personnel que par suite de la construction des 9 fours que l'on essaya suceessivement, avant de parvenir à une ruisson régulière. Les années qui ront de 1741 à 1743 doivent done chre considérées encore comme une période d'essais nouveaux où des ouvriers tels que Gravant, Millot, Gérin ne firent guère autre 


\section{LA PÉRIODE DLS ESSAIS}

chose que perfectionner les secrets apportés de Clantilly. Toutefois lia Manufacture s'emrichissait en même lemps par l'arquuisition d'aulress

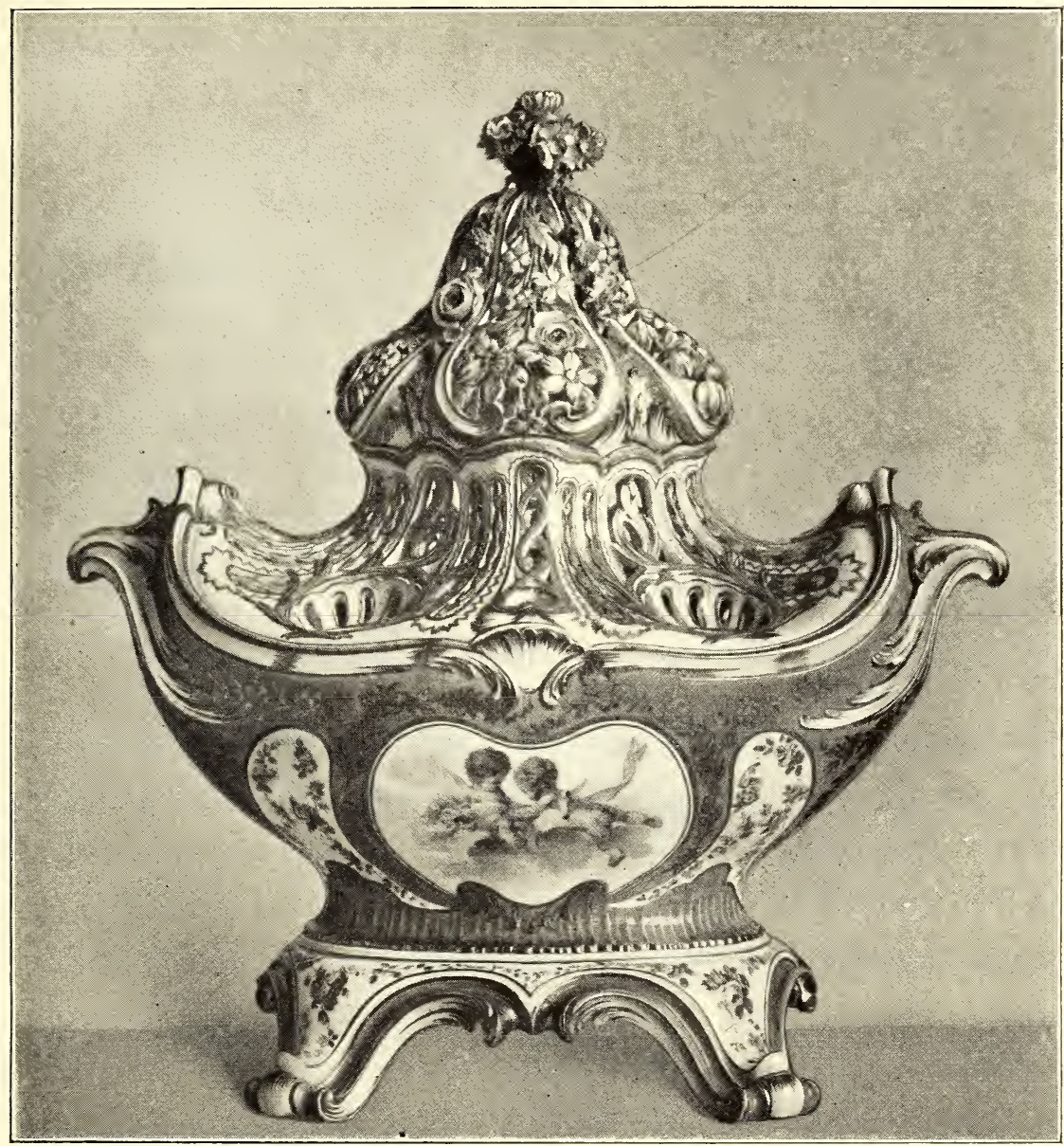

Fabrication de Vincennes, vers 17:5. - Vase a Pot-Pourri ) ovale, à fond rert et cartels décorés d’amours d’après Boucher. Couvercle orné de fleurs en relief. (Musée Wallace.)

procèdés: ainsi, dès 1741 , le comte d'Egmont vendit à M. de Fulvy un procédé pour dorer la porcelaine. Trois ans plus lard, un peintre de la maison, Taunay, déeouvrit les couleurs de carmin, de pourpre et de violet qu’il vendit plus lard à la Manufacture; en altendant, il devint, 
comme Gravant, le fournisseur de Vincennes qui lui achetait fort cher l'once de ses couleur's.

Au cours de ces quatre années, les dépenses étaient montées à près de 58000 livres et les comples de eette époque n’enregistrent aucune recette en regard de ce chiffre. Toutefois le but était atteint, et II. de Fulvy estima que le temps était venu de donner à son cuvre une existenee régulière et une organisation industrielle. C'est pour obtenir ce résultat que le Conseil du Commerce fut appeléen 1748 à statuer sur l'octroi d'un privilège exelusif " en faveur d'une manufacture de poreelaine, façon de Saxe et du Japon ", et, l'avis ayant été favorable, la demande de privilège fut adressée au Conseil d'État, sous le nom de Charles Adam qui était sans doute l'homme d'affaires ehargé, depuis plusieurs années déjà, de tout ce qui eoncernait la Manufaeture naissante.

Dans les considérants assez longs joints à sa requête, le demandeur, après avoir signalé les avantages que présentait l’installation en France d'une manufacture de poreelaines capable d'entrer en concurrence avec celles de la Saxe, et rappelé l'intérêt manifesté dès 1741 par le Roi aux tentatives des Dubois, exposait l'impossibilité où il se trouvait de pourvoir plus longtemps par lui-mème aux frais considérables qu'entraînaient les essais et les expériences grâce auxquels le suecès avait été atteint. Pour rembourser ses emprunts précédents et pour doter la France de l'industrie nouvelle de la poreelaine, il lui fallait faire appel à une compagnie : "à quoi il ne " pourrait parvenir s'il ne plaisait à Sa Majesté de lui aceorder un pri" vilège exelusif pour fabriquer de la poreelaine façon de Saxe, c'est" à-dire peinte et dorée, à figures humaines, et la concurrence, pour " tous les autres ouvrages, avec les autres manufactures de porcelaine “ blanche ou peinte façon du Japon. ” En outre, Charles Adam sollieitait pour l'installation de son usine l'autorisation d'oceuper, dans l'enceinte du chàteau de Vineennes, certains bàtiments inutilisés, 
entre autres " ceux de la cour de la Surintendance, du Manìge couvert et de la Ménagerie située à Bel-Air ». Il réclamait enlin le droit exclusif de fabriquer la poreelaine facgon de Saxe, sous peine pour les eontrevenants de la confiseation des objets fabriqués et de trois mille lives d'amende. Un privilìge, en date du 24 juillet 1749 , fut accordé dans les conditions demandées par Charles Adam, pour une durée de vingt années : il contenait mème une clause punissant de prison les ouvriers qui quitteraient la Manufarture sans un congé en bonne forme de Charles Adam et interdisant d'autre part aux fabrieants d'engager aucun ouvrier sorti de Vincennes sans l’agrément de la Compagnie privilégiée. Un témoignage plus précis encore de la protection royale fut enfin l'autorisation donnée aux nobles et aux officiers de s'associer, sans déroger, à l'entreprise. Une compagnie fut immédiatement constituée au eapital de 90300 livres, divisé en 21 actions : elle comprenait sept intéressés possédant ehacun deux actions, tandis que M. de Fulvy en aequérait sept pour sa part. Des 90300 livres formant le capital social, 58914 , montant des dépenses effectuées depuis 1741, furent remises à Charles Adam qui, à partir de ce moment, semble n’avoir plus été qu’un prète-nom.

C'est à cette époque que, forte de son privilège, la Manufacture s'organisa réellement et atteignit en quelques années un développement et une renommée considérables. Les associés rivalisèrent tout d'abord d'activité : une réunion arait lieu chaque semaine chez II. de Fulvy où l'on discutait des intérèts de l'établissement. Pour éviter de trop grands frais, chaque intéressé remplissait effectivement et à tour de ròle les fonctions de directeur pendant une semaine, tandis que l'un d'eux demeurait spécialement chargé de la tenue de la eaisse. Un seul agent suffisait alor's à assurer la marche des travaux : éétait, avec le titre de garde-magasin des matières premières, Boileau, qui devait ètre appelé cinq années plus tard à la 
direction de l'élablissement. Pourtant, malgré celte bonne volonté et ce zèle, la Compagnie Charles Adam eut à surmonter d’incessantes difficultés financières. Le capilal social arait été fixé, nous l’avons dit, à 90300 livres : dès l'année suivante on fut contraint de demander aux associés 56700 lives, 42000 en 1747, 1748 et 1749,

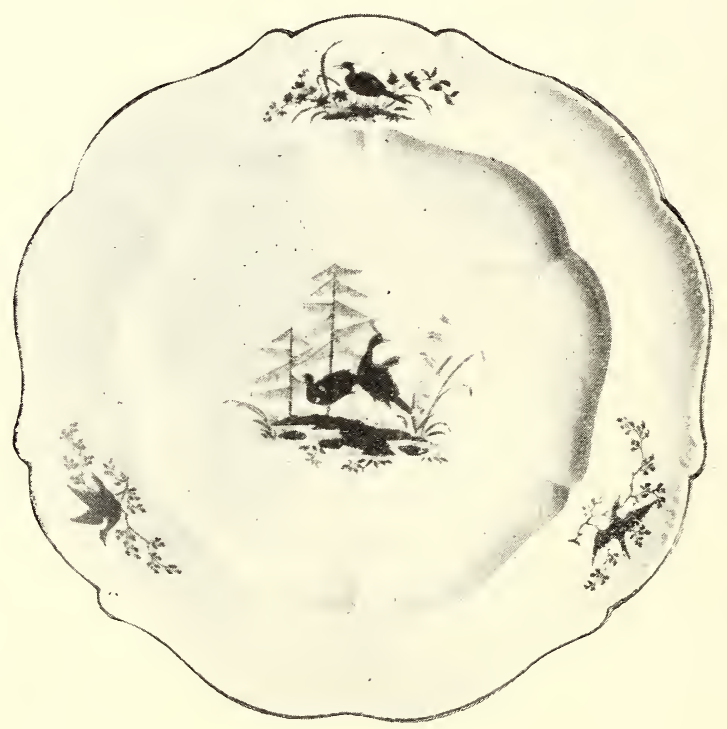

Fabrication de Vincennes, entre 1745 et 1733. - Assiette en porcelaine tendre décorée d'oiseaux et de lleurs en or. (Cullection de Charagnac.)

la moitié en 1750 el enfin 6.3000 en 1751, de sorte qu'au bout de six années, la valeur de chaque aclion, limitée primilivement à 4300 livres, représentait 14000 livres versées. De son côté le Roi, sollicilé par son entourage, encouragé par le Contrôleur général des finances de Nachault, qui avait remplacé en 174.̋ Orry de Vignori disgracié, donna en moins de deux années la somme de 133000 livres! Pour combler le déficit toujours croissant, les associés ne trouverent alor's rien de mieux que la création de neuf actions nouvelles au capital de 14000 livres. Peu après, ils transformèrent l'apport en 220 actions au porteur de 2800 livres chacune, 
confiant la direction à un ronseil de 8 membres que présidait M. de Fulvy; l'année suivante d'ailleurs, ils devaient, poussés par la crainte de voir leur échapper une affaire qui, improduclive en fait, avait pourtant l'avantage de leur assurer les sympathies du Roi et de $\mathbf{V}^{\mathrm{me}}$ de Pompadour, revenir sur leur décision el retirer de la circulation les actions au portem créés quelque mois plus tòt.

Au point de vue pratique, M. de Fulvy assumail à cefte époque la direction presque complète de la Manufaclure, et, jusquà sa mort. son activité suffit à maintenir l'établissement dans la voie qu il lui a vait tracée. Lorsqu'il disparut en 1781 , Boileau fut nommé inspecteur par une délibération où il est dit que " ce changement a semblé nécessaire par suite de la mori de M. de Fulvy, dont les connaissanees étaient si utiles à la Manufacture ». Il apparaì bien en effet que, poussé par son goùt pour l'établissement qui était son ouvre, M. de Fulvy avait su lui assurer très vite, au moyen de contrats régulierss, la propriété de tous les procédés capables de contribuer au succès de la fabrication. Ainsi une convention avait été passée en 174.̈, par laquelle Gravant avait pris l'engagement de donner par écrit le seeret de sa pàte, autorisant II. de Fulvy à en faire l'expérience; trois ans plus tard, les essais ayant paru satisfaisants, une nourelle convention régla définitivement la situation de Gravant, qui restait maître de ses secrets pendant huit années, à condition d'ètre en état de fabriquer sa pàte; puis, au bout de ce temps, moyennant le paiement d'une somme de 24000 lives et d'une rente annuelle de 1200 lirres, la Compagnie devenait propriétaire des procédés. Le prix de la pàte était fixé à 19 sols la livre, auxquels s’ajoutait une gratification de : 8 sols pour les premières 12000 livres fournies chaque année. En 1748 encore, M. de Fulvy acheta à un bénédictin de Saint-Nicolas, le frère Hippolyte, contre la somme de 9000 livres, le moven d'appliquer l'or sur la porcelaine: et peu après il acquit 
la recette des couleurs que fabriquait jusqu'alors le peintre Taunay. Une autre tàche, qui avait dès le début sollicité l'attention de la Compagnie, était l'obligation de donner à la Manufacture naissante une direction artistique, d'autant plus nécessaire que l'instruction des artistes employés dans les ateliers était plus limitée. Les associés s'adressèrent tout d'abord en octobre 1743̈ à Mathieu, l'émailleur du Roi, connu " surtoul sur la manière d'appliquer l'or sur les " ouvrages de porcelaine », qui promit de "s'appliquer à la perfec" tion des desseins, moules, peintures et dorures des ouvrages qui " seront fạbriqués ». Le choix n’était pas heureux, car, cinq mois plus tard, Mathieu fut contraint d'avouer " qu'il n'avait pas jusqu’à " présent exécuté sur la porcelaine de Vincennes les peintures et " dor'ures avec le mème succès que sur celle de Saxe " et d'abandonner la place. Celle-ci ne reçut sans doute pas immédiatement de nouveau titulaire, bien que Bachelier assure, dans le mémoire écrit trente ans plus tard pour sa justification, qu il fut appelé dès 1748 à la direction artistique de la Manufacture. Il est permis de penser qu’il s'attribue là le mérite d'une organisation qui ne semble, d'après les pièces comptables, lui avoir été confiée, officiellement du moins, qu'en $17 \%$, tandis que dans cette mème période le nom d'un autre artiste se retrouve tous les ans dans les livres de dépenses de la maison : celui de Duplessis, l'orfèvre du Roi. Dès 1747, celui-ci venait régulièrement à Vincennes chaque semaine pour surveiller les travaux des tourneurs, mouleurs et sculpteurs, et en même temps il fournissait à la Manufacture des modìles de pièces de service d'une forme remarquablement élégante. Ne peut-on admettre que le même homme ait étendu son influence jusqu'à donner à toute la partie artistique la sûreté de goût et l'originalité de création qui font le charme des produits de la Manufacture à cette époque? A côté de lui, d'ailleurs, d'autres artistes étaient appelés à créer des modèles pour les différents ateliers : on retrouve ainsi la trace de fréquentes 
acquisitions de gravures, d'estampes, de dessins destinés à servir de modèles aux décorateurs et à leur faire abandonner l’imitation persistante des décor's chinois. De mème, pour les sculpteur's qui " manquaient de modeles gracieux ", on demandait des 1746 a des artistes du dehors des modèles en terre d'une traduction facile dans la pâte de porcelaine : Depiereux fournit en une seule année six « divinilés $)$ et seize autres figures différentes; Gilles Dubois, chassé en 1741, reparut en 1750 pour eréer, lui aussi, quelques modèles.

Ainsi le travail s'organisail peu à peu, el si l'on considère le chemin parcouru en quatre années, l'on constale que dìs 17 0 la Manufacture comprenait les sept ateliers suivants, placés sous l’inspection de Boileau :

Fabrieation des pàtes: Gravant et huit manouvres.

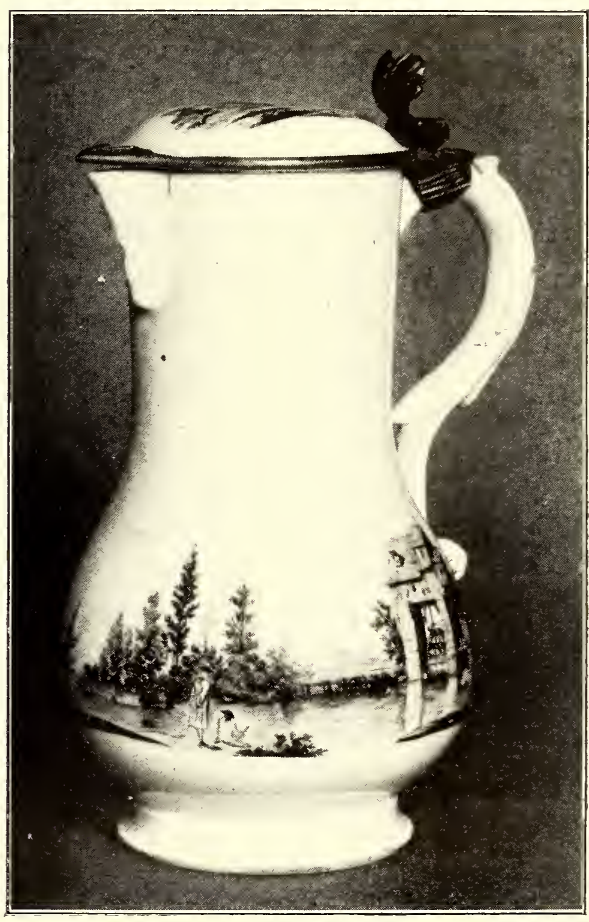

Porcelaine tendre de Vincennes, vers 1730. Broc à décol de paysages. (Collection de Chavagnac.)

Tourneurs : Corne et neuf ourriers.

Mouleurs: Chenot el dix ouvriers.

Anseurs et becteurs ${ }^{1}$ : Gérin el six ouvriers.

Seulpteurs : dix artistes.

Peintres : dix artistes.

\footnotetext{
${ }^{1}$ Les ouvriers chargés spécialcment de fabriquer les anses et les bees.
} 
Fleurs : II" Gravant et " quarante-cing femmes ou filles de tout âge " .

Ce personnel déjà considérable - 110 ouvriers environ - avait des orignines très diverses. Dans les ateliers de fabrication, à còté de quelques ouvriers débauchés dans les fabriques plus anciennes, Chantilly ou Hennecy-Villeroy, on rencontrait des gens ayant exercé les métiers les plus différents : soldats recrutés au donjon même de Vincennes, anciens domestiques, doreurs sur bois, etc. Dans les ateliers de peinture, il y avait des arlistes sortis des Manufactures de Saint-Cloud et de Sceaux, un peintre d'équipages, un peintre de tableaux, mais surtout des peintres d'éventails; et c'est sans doute à l'habilude des éventaillistes de peindre à la gouache, qu'il faut attribuer une certaine lourdeur dans l'emploi des couleurs qui se retrouve sur la plupart des pièces de cette époque.

On ronçoil sans peine qu'un personnel composé d'éléments aussi disparates ne devait pas toujours ètre d'un maniement très facile : la preuve en est dans les nombreuses contestations qui s'élevèrent presque aussitòt entre la Compagnie Charles Adam et les ouviers, prétendant à une liberté inconciliable avec la conservation des secrets dont la maison s'était assuré la propriété. Pour remédier à eet état de choses, II. de Fulvy demanda dès 1747 à II. de Machault de régler par un nouvel arrêt la situation des. ouviers de la Manufacture. La décision prise alors fut basée sur ce que " le Roy estant informé que, nonobstant les dispositions portées " par l’arrèt du Conseil du 24 juillet $174 \%$, par lequel Sa Majesté, en "areordant à Charles Adam, entrepreneur d'une Manufacture de por" celaine à l'imitation de celle de la Saxe, un privilège exclusif pour " l'imitation des dites porcelaines en peintures et dorures, aurait pris "toutes les préeautions qui avaient parues nécessaires pour, en " prévenant toute coneurrence entre cet établissement et ceux qui "élaient déjà formés tlans le royaume, assurer" au dit Charles Adam 
"la conservation des ouvriers qu’il avail formés ou pourait former " par la suite pour l'exploitation du privilège qui lui étail aceordé, "quelques-uns des ouvriers, dans l'espérance de trouver ailleurs " des condilions plus avantageuses que celles qui leur élaient " failes par ledit Charles Adam, se seraient absentés de ladite

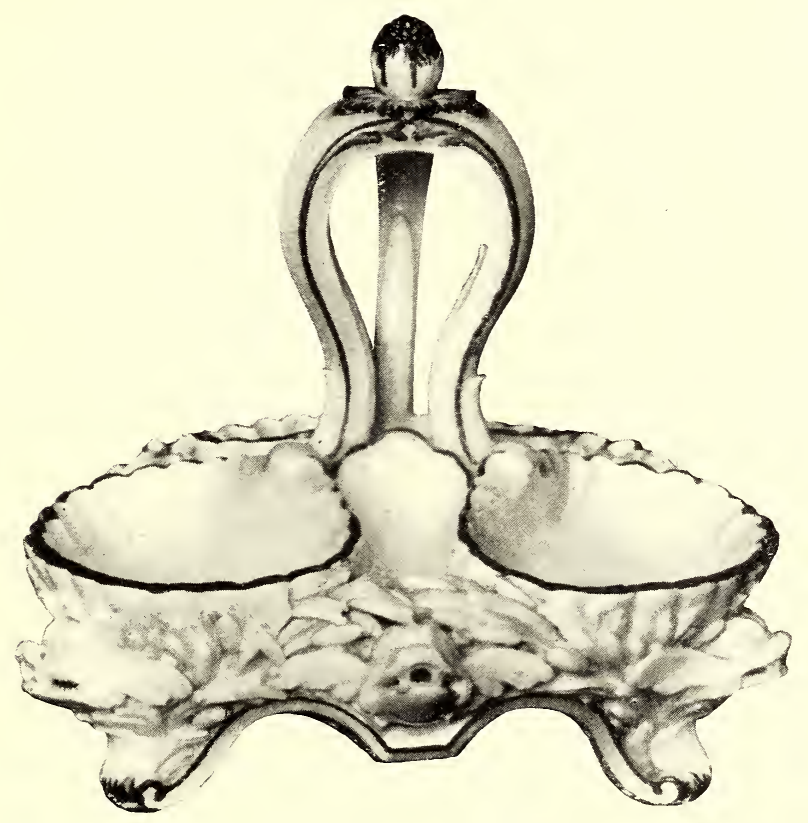

Porcelaine tendre de Vincemes. Salière trilobée à têtes de dauphin. (Collection de Charagnac.)

"Manufacture ou, pour se procurer la liberté d'aller ailleurs, ils "auraient... forcé ledit entrepreneur à les renvoyer ". S'appuyant sur ces motifs, le Contrôleur général fit défense à tous less ourriers, employés à Vincennes depuis plus d'un mois, de s'absenter aucun jour non férié, sous peine d'une relenue double du salaire et, en cas de réeidive, sous peine de prison et de 80 lives d'anende. Quant à ceux qui voudraient quiller définitivement l'élablissement, ils devaient sengager à ne jamais se servir des eonnaissances quils y auraient acquises : et iéi la première contravention ful taxée à 
1000 livres d'amende ou trois années de prison. Un article spécial édictait des pénalités contre les fabricants reconnus coupables, soit d'avoir accepté dans leurs ateliers un ouvrier sorti de Vincennes sans congé, soit d'avoir construit un four à porcelaine sans jouir d'un privilège particulier : dans l'un ou l'autre cas, c'étaient 3000 livres d'amende et la destruction immédiate des fours.

Ces dispositions rigoureuses ne restèrent point lettre morte, et les industriels furent bientôt renseignés sur la faveur dont la Manufacture jouissait à la Cour, par les poursuiles qu'ils subirent. Barbin, établi rue de Charonne, reçut défense de construire un four, et, à celle occasion, M. de Machault limita encore les genres de décoration sur porcelaine qu'il élait permis d'employer : "Il ne sera fait, disait-il, d'autres sortes d'ouvrages en porce" laines que celles qui peuvent servir pour la poterie ou la platerie, " lesquelles ne pourront ètre ornées de fleurs et de sculptures, ni " peintes autrement qu’enfacon de Japon sans, sous aucun prétexte, " y mêler des paysages, figures ou dorures dont Sa Majestéentend que " le travail soit exclusivement réservé à la Manufacture de Charles "Adam, ainsi que de toutes sortes et espèces d'ouvrages de porcelaine " en fleurs et en sculptures. " Après Barbin, la Manufacture de Sceaux dut fermer ses portes à la suite d'une contravention de même nature. Et les ouvriers connurent, eux aussi, les rigueurs des arrêts royaux, témoin le peintre Caillat qui, chargé de préparer certaines couleurs, eut le tort d'en communiquer la recette aux entrepreneurs de la fabrique de Chantilly : pour ce fait, il fut, après six mois de séjour à la Bastille, définitivement incarcéré au Mont Saint-Michel.

La protection si décidée de la Cour devait se manifester d'autre part par les aequisitions du Roi et de son entourage à la Manufacture, et c'est grâce à ee suecès que nous sommes renseignés sur les travaux qui s'exécutaient à Vineennes entre 174 et 1733. En l'absence des livres de vente de la Compagnie Charles Adam, le 
livre-journal de Lazare Duvaux, le marchand de la Cour, nous donne la précieuse nomenclature des pièces que les grands seigneurs achetaient alors à la Manufacture. En le parcourant, on constate avec un

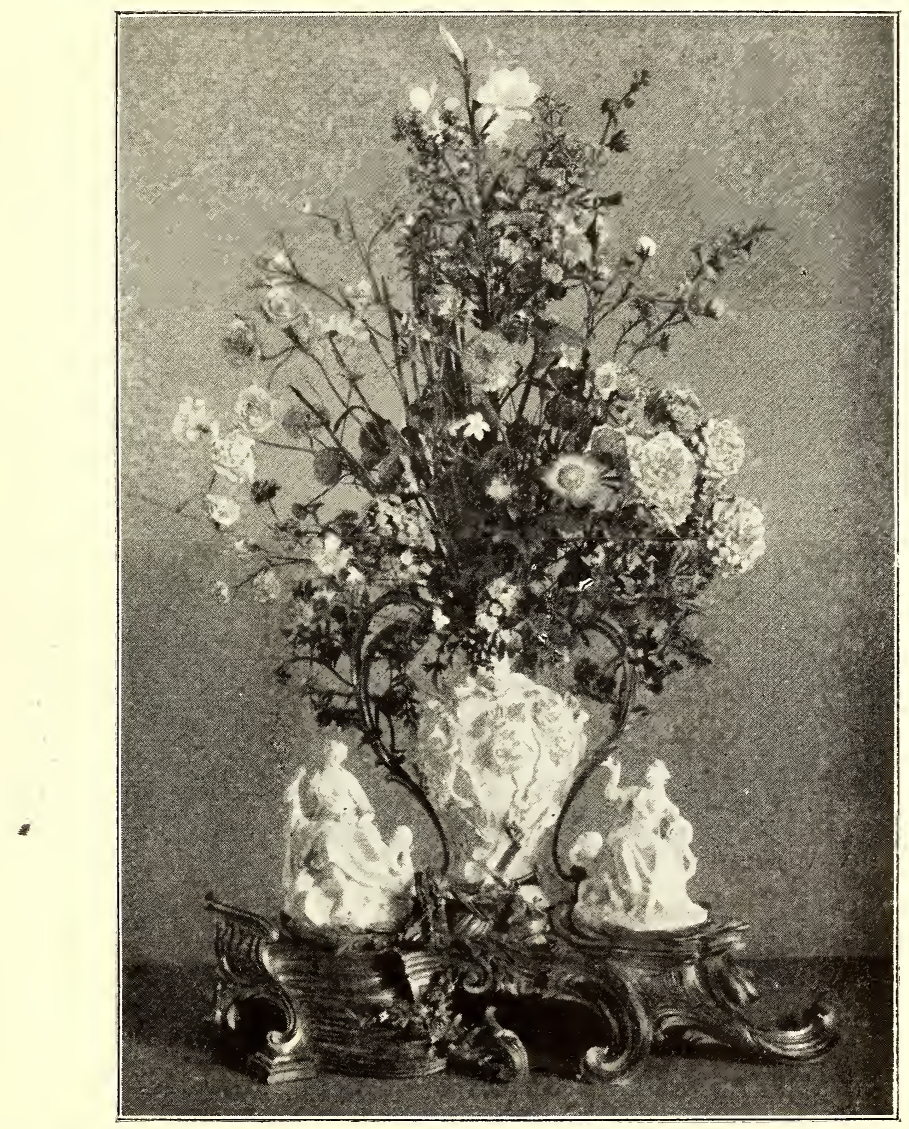

Porcelaine tendre de Vincennes. - Bouquet en porcelaine offert au Grand Electeur de Saxe, en 1748. (Musée Royal de Dresde.)

peu d'étonnement que les acquisitions portaient principalement, et presque uniquement au début, sur les fleurs de porcelaine "peintes au naturel ». $\mathbf{I}^{\mathrm{me}}$ de Pompadour ne se fil guìre livrer d'autres objets avant 1750 , et certainement c'est dans cette fabrication toute spéciale qu’il faut chercher l'origine du sucè̀s de la maison aux débuts de son existence. 
Ces fleurs, garnies de branchages en métal verni imitant la nature et assortis à chaque plante, étaient fabriquées dans un atelier qui occupait à lui seul, on l'a vu, la moitić du personnel de la Manufacture el qui était placé sous la direction de $\mathbf{M}^{\mathrm{me}}$ Gravant : c'était presque une entreprise personnelle de celle-ci, car elle revendait ses produits à la Compagnie, comme en témoigne l'accusation portée contre elle d'acheter simplement à d'autres fabricants des fleurs de façon médiocre pour les mélanger à ses livraisons courantes. Le succès de ces menus objets fut considérable, et tout de suite les préoceupations commerciales et les espérances des cautions de Charles Adam se reportìrent sur eux. Dès 1746, le registre des délibérations de la Compagnie relate l'ordre donné à Boileau de faire monter dans la Manufacture une quantité de bouquets « suffisante pour garnir un desserl, de façon à montrer au public l'usage des fleurs en porcelaine »; en 1748, les comptes enregistrent les frais de monlage des bouquets achetés par $\mathbf{I}^{\text {me }}$ de Pompadour, par le Roi et la Reine : 270 livres d'un côté, 4200 de l'autre; enfin, l'année suivante, lorsque la Dauphine voulut prouver à son père, le Roi de Saxe, que Vincennes surpassait déjà Meissen, e’est un énorme bouquet qu'elle lui lit parvenir avec des préeautions infinies, bouquet qui figure aujourd'hui encore au Musée Royal de Dresde. Et si l'on examine la valeur des objets vendus à cette époque à Vincennes, on constate que les fleurs en représentaient les quatre cinquièmes: en 1749 , par exemple, 36000 livres sur un ensemble de 44600, en 1750 , 26300 sur 32700 livres.

C'étaient d'ailleurs des objets tout à fait délicats, d'un travail et d'une élégance légìrement précieux, bien en harmonie d'ailleurs avec les tendances un peu mièvres du mobilier de l'époque. On les employait de mille façons différentes, lantôt sous forme de bouquets disposés dans des vases, tantôt accommodés en lustres, souvent aussi comme garnitures de slatuettes en porcelaine de Saxe el plus eneore comme 
bras de lunière. Pour bien définir le caractère de ces décorations dont s'ornaient les riches intérieurs d'alors, il nous suffira de citer celte deseription d'une pièce livrée en 1749 à la Dauphine : "Posé à " la eheminée de son cabinet, à Versailles, une parre de bras à trois " branches, composés de branchages vernis imitant la nature avec " les fleurs de porcelaine assorties à chaque plante : le haut de ces

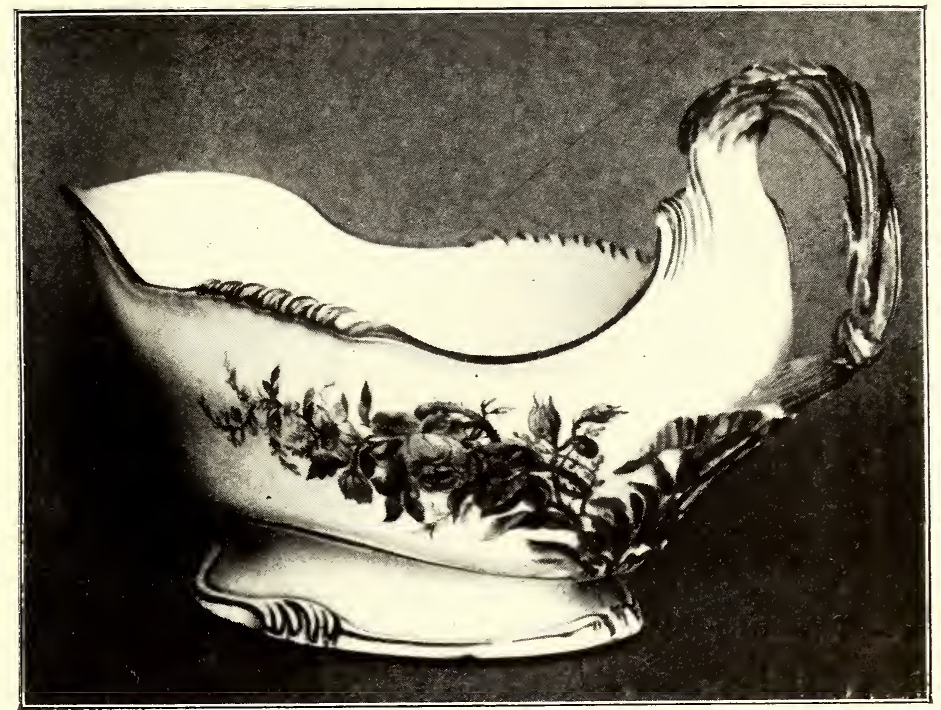

Porcelaine trndre de Vincennes, vers 1740̈-1750. - Saucière ornéc de fleurs en relief. (Collection de Chavagnac).

" bras d'une branche de lys, tulipes, jonquilles, nareisses et jacin" thes bleues, les branches du milieu de roses, celles en dehor's d'ané" mones et semi-doubles, celles en tedans de giroflées rouges et " violettes, la jonction des branches garnie de différentes fleurs, le bas " de boutons d'or et oreilles d'ours, les bassins de la mème poree"laine avec les binets dorés d'or moulu, ci, 1200 livres. "

Le nombre de fleurs qui composaient chaque bouquet était, on le voit, considérable. Il faut bien avouer que cette production si appréciée n’avait rien de très original : Meissen fabriquait des fleurs bien avant Vincennes et l'imitation était si flagrante que l'on peut 
trouver dans les comples de 1746 un paiement fait à deux peintres, Thévenet et Massue, "pour nourriture et dépenses à Paris pour " copier des fleurs de Saxe ".

Toulefois il ne faudrail pas, du fait que la part la plus grande des receltes provenait alors des ventes de fleurs, conelure que la Manufacture s'immolsilisail dans cetle fabrication. Malgré la rareté des doeuments sur les travaux de ce temps, les lives de vente nayant été conservés qu’à partir de $17 \% 33$, on trouve cependant dans les comptes annuels la trace d'acquisitions de modèles qui peuvent donner une idée assez exacte des créations qui, chaque année, s'ajoutaient aux modèles primilifs. Ainsi un grand effort semble avoir été fait en 17.00 : cette année-là, Duplessis toucha 26.92 livres pour divers modiles el d'autres artistes 2483 livres avec le même emploi. De telles sommes représentaient sans doute une quantité considérable de dessins, de formes, d'essais, que le petil nombre de modèles employés jusque-là rendait nécessaires. Comme vases, il n’y avait guère alors que celui qui a gardé le nom de vase de Vincennes, orné de deux anses enroulées, el les vases pots-pouris. Parmi les pièces de service, on fabriquait d'abord les seaux à 'rafrâichir qui semblent avoir obtenu dès le début un grand succìs, puis vers 1792 apparurent de nombreuses formes de gobelets, de tasses, de théières, d'écuelles, de compoliers en forme de coquilles, dont la composition élail due certainement à Duplessis. Le décor de tous ces objets, pièces d'ornement ou pièces d'usage, élait fréquemment encore formé de molifs rappelant les produclions chinoises et japonaises : M. de Machault avail lui-mème poussé la production dans cette voie en faisant copier des laques qui lui appartenaient, sur des morceaux de poreclaine dont il se servil pour orner des petits meubles ${ }^{1}$. Toutefois, dès ce moment, il est certain que l'on exéeutait les déeorations de fleurs of d'oiseaux qui restèrent pendant tant d'années

${ }^{1}$ Ces meubles font aujourd'hui partie de la collection de Rothschild. 
le motif caractéristique des produils de Vincennes, puis de Sirres. Toutes les pièces portaient, à n'en point douter, selon l'usage général des fabriques de faïences et de porcelaines, une marque, et celle-ci étail eertainement déjà les deux $\mathrm{L}$ entrelacées qui, à parlir de 1753, devinrent la marque officielle de la Manulaclure. Une opinion assez répandue veul que les deux $\mathrm{L}$ seules désignent les pièces fabriquées avant $174 \%$, tandis que le mème signe accompagné d'un

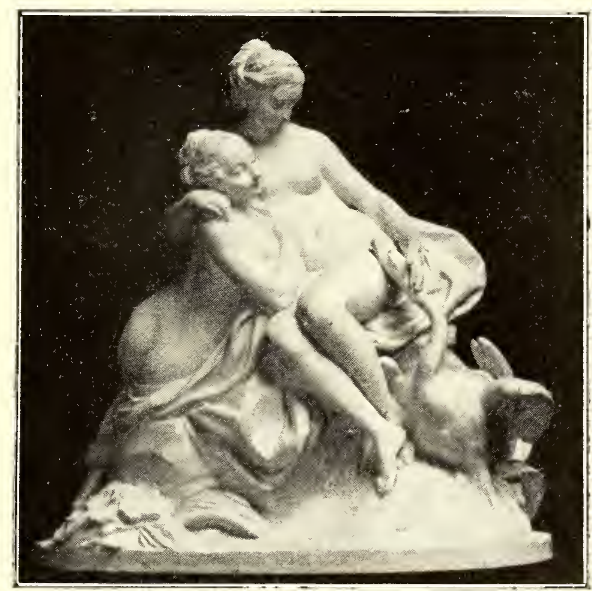

Groupe de Leda, d'après Boucher. - Modìle de 1743.

point indiquerait les pièces décorées sous la direction Charles Milam. En réalité, il n’a jamais été possible d'établir la légitimilé de celte allégation et le seul fail qui demeure certain est l'emploi des deux $\mathrm{L}$ bien avant 1753 : le earactère de certaines pièces revètues de cetle marque suffirait à le prouver.

La production de la Manufacture était eomplétée par la fabrieation de pièces en sculpture. On se rappelle en effet qu'un des arlicles du privilège de 1743 lui réservait le droit de reproduire en porcelaine des figures de personnages ou d'animaux. Dès le début, la Compagnie avait fait exécuter par des artistes du dehors un certain nombre de petits modieles, groupes d'enfants, figures de divi- 
nités, groupe de Léda, figure d'Hercule, ete... On modela aussi de nombreux types d'animaux, perroquets, perruches, moutons, chiens, qui se mèlèrent souvent aux décors de fleurs en porcelaine dout nous avons parlé. Toutes ces pièces étaient recouvertes d'un émail d'une réussite généralement médiocre, si l'on en eroit le récit de Bachelier qui raconte que "dans l'origine, jusqu'en 1749, la " sculpture étail luisante et colorée; l'impossibilité, dit-il, d’appro" ther des figures de Saxe par l'égalité d'emploi et l'éclat des " couleurs allait faire renoncer à cette partie quand le sieur "Bachelier proposa d'essayer la sculpture sans couverte, c'est" à-dire biscuit, mais il n’y arait pas d'exemple de ee gemre : aussi " fut-il rejeté conme impraticable et ridieule », et il ajoute que c'est seulement en 1798 que l'expérience fut tentée sur l'ordre de M. de Machault.

A dire vrai, la Manufacture, à cette date de 17301 où mourut M. de Fuly, n’avait pas encore trouvé son orientation délinitive: elle ne s'était pas alors suffisamment dégagée des préoccupations qui avaient amené sa fondation, mais qui ne pourraient justifier sa renommée. Trop souvent l'ambition d'égaler ou de surpasser les manufaetures allemandes apparaissait comme le seul but à atteindre; et d'autre part Vincennes ne possédait pas encore ces formes originales, ces déeors lıarmonieux qui plus tard donnèrent à ses produits un caractère si particulier. L’impulsion définitive allait, à cette époque, lui être donnée par Louis XV lui-mème, sous l'influenee de celle qui, dès le début, semble s'ètre passionnée pour les travaux de la Manufacture. $\mathrm{II}^{\mathrm{me}}$ de Pompadour, en effet, guidée sans doute par Lazare Duvaux, avait orné ses maisons d'une quantité de fleur's, de statuettes, de menus objets de Vincennes : sa fantaisie, surtout sa constante préoceupation de relenir le Roi, l'avaient par des motifs différents amenée à considérer la Manufacture comme aussi utile à sa domination qu'à son plaisir, et e'est probablement sous son inspiration 
que le Roi se décida, à l'époque ou nous sommes arrivés, à mettre la main sur l'administration de l'établissoment. Il désigna d'abora II. de Courteille, intendant des linances, "pour le rapport des aflaires concemant la régie et l'administration de la Manufacture ") puis, dérision qui devait elre lourde de conséquences, il chargea Hellot, membre de l'Académie des seiences " de faire les épreuves du

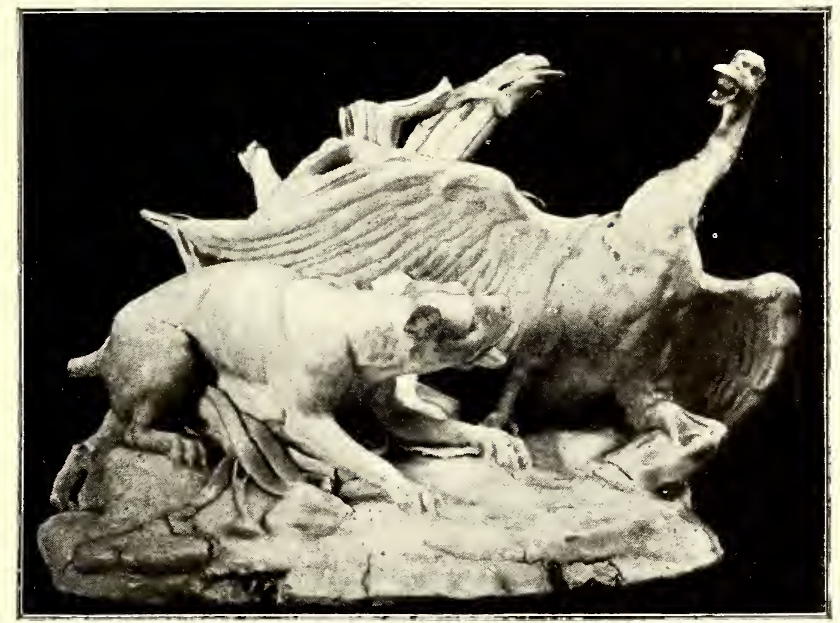

Groupe d'animaux, d'après Oudry. - Modelo de 17\%̈2.

Fabricalion de Vincennes. - Porcelaine tendre émaillée. Haut. 0,13. Larg. 0, „̇. Musce de sivres, no $80 \ddot{3}$ '.

" secret des composilions de la pàte et de la couverte, de la dorure, " des couleurs et émaux qui appartiennent à la Compagnie »; enlin un homme de goût, M. Ilulst, reçut la nission de " diriger ee qui concerne les ornements et la peinture ". C'était en fait une organisalion rationnelle des travaux, et il est probable que dès ce moment le Roi avait l’idée de racheler la Manufacture. Déjä il élait question de rapproeher l’établissement de la résidencede Versailles, et Louis XV avait mis à sa protection une condition significative, celle de devenir seul et unique possesseur des seerets de la fabricalion.

C'est pour répondre aux intentions royales qu Hellot se rendit en 1731 à Vincennes, et ses premiers travaux consistirent en une 
sorte de constat des procédés employés. Son cahier d'expériences a été conservé intact jusqu’à nos jours et c’est grâce aux précieuses indications qu'il contient, que l'on peut aujourd'hui connaître la composition exacte de l'ancienne pâte tendre. Hellot en avait lout d'abord demandé la formule à Gravant lui-même qui en fournit l'originale descripition suivante :

“Facon de faire 2020 l. de composition pour fre la porcelaine. " dont on se sert actuellement à Vincennes, sçavoir :

“ 440 l. cristal minéral,

" 146 l. sel marin,

“ 74 l. soude d'Espagne,

“ 74 l. gyps qui se prend à Montmartre,

“ $\overline{808} \mathrm{l}$.

"Il faut bien piler toutes ces drogues et, quand elles sont pilées " bien fines, y ajouter 1212 l. de sable, bien mesler le tout ensemble; " le fre cuire sous le four. Quand il sera bien cuit, l'éplucher, le " piler bien fin, voilà pour la composition. Le sable qui y sert est " dans la forest de Fontainebleau, dans le milieu de la montagne " sur le chemin de Paris. Quand vous voudrez faire la pâte dont “ on se sert actuellement, prenez 70 l. de la matière cy-dessus, ajou" tez-y le tiers ou $2 \% \mathrm{l}$. de corps, savoir : $12 \mathrm{l} .1 / 2$ de blane d'Espa"gne et $121.1 / 2$ de terre d'Argenteuil, mettez le tout dans un moulin " et le faites bien broyer et vous aurez $100 \mathrm{l}$. de pâte. " Telle était la composition de la pâte tendre en 1750 et, sauf les légères modifications que lui fit subir Hellot, la préparation en resta la même jusqu’à la fin du xrme siècle. Le défaut capital de cette pâte était un manque presque absolu de plasticité, qui en rendait le façonnage très difficile. On était forcé, pour l'employer par tournage ou par moulage, de lui incorporer un mélange de savon noir et de colle de parchemin qui portait le nom de "chimie ». Après une première cuisson qui atteignait environ 1200 degrés, 
cette pàte étail émaillée, soit par trempage pour les pièces unies, soit au pinceau pour les sculptures et les pièces ì relicfs. L'émail était fait d'un mélange de litharge, de sable de Fontainebleau et de silex calcinés, de carbonate de polasse et de rarbonate de soude

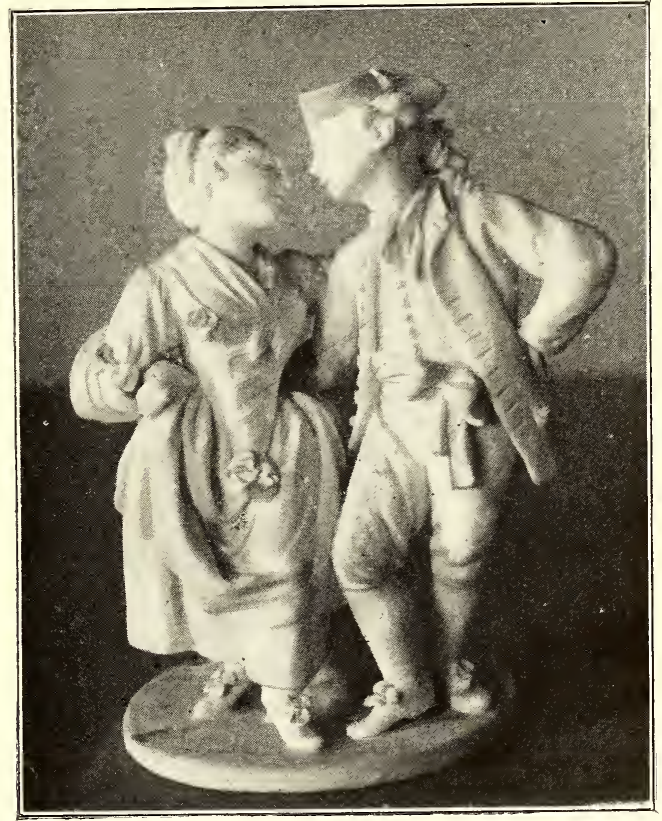

Groupe de danseurs. - Modèle de 1765 (Haut. 6,12). (Musée de Sèrres, no 5270.)

cristallisée : revêtues d'une certaine quantité de ce mélange, lés pièces subissaient une seconde euisson qui les mettait en état d'ètre décorées. La température de cuisson relativement peu élevée de cet émail permettait l'emploi d'un nombre considérable de couleurs et d'émaux, dont les formules furent, elles aussi, consignées dans les cahiers d'Hellot : on y retrouve tous les "secrets " - compositions de couleurs ou procédés de dorure - dont la Compagnie Charles Adam s'était peu ì peu assuré la propriété.

La direction artistique fut confiée, nous l'arons dit, ì M. Hulst, qui 
semble, si l'on en juge par les lettres qu'il échangea alors avec Boileau, avoir eu le sentiment très juste des besoins de la Manufacture et un goût raffiné pour toutes les belles choses. Il s'oceupa avec grand soin, pendant un certain temps au moins, de la direction dont il avait accepté la charge et nous le voyons donner son avis sur tous les dessins de formes et de déeors, sur tous les modèles nouveaux de Duplessis et de Bachelier. Ses lettres sont pleines d'aperçus spirituels sur les hommes et sur les choses, et il faut citer de lui ce passage où il s'efforçait de déterminer elairement les tendances que la Manufacture devait suivre : “La diversité des goùts, dit-il, est " l'ange tutélaire d'une manufacture qui roule sur des objets d'agré" ment : ce qui ne plaît pas aux uns plaît aux autres. En fait de "porcelaine surtout, les dessins les plus bizarres et les plus chi"mériques l'emporteront sur les dessins les plus élégants et les " mieux raisonnés. Que l'on fuie le lourd et le trivial, qu'on " donne du léger, du neuf et du varié, le sucè̀s est assuré. " Certes, si la Manufacture s'était toujours inspirée d'un éclectisme aussi rare, que de rrises fàcheuses elle aurait évitées!

A eòté de M. Hulst, Bachelier prit dans la maison le rôle qu’il conserva jusqu'à la Révolution et devint avant tout l'éducateur des jeunes artistes. Sa volonté patiente s'appliqua à former une génération de déeorateur's plus instruits que leurs devanciers et capables d'apporter dans leurs eompositions une variété aussi grande que possible. Lui-mème fournissait à Vineennes de nombreux dessins, d'après lesquels on exécutait les pièces importantes, le service à fond bleu antique et à cartouches peints et dorés qui fut présenté au Roi par Lazare Duvaux aux fètes te Noël en 1753, par exemple. Enfin une inspiration particulièrement heureuse fit adjoindre alors à Hulst et à Bachelier, Lazare Duvaux lui-mème, dont le nom reparaìt si souvent au cour's de cette première phase de l'existence de la Manufacture. Il venait à Vincennes ehaque semaine, et, avec ce sens 
particulier de l'homme qui veut diriger plutôt que suive le goût du public, il donnait son avis sur lous les modèles que l'on se proposait d'exéculer. Colte place laite à un marchand dans la direction d'art de la maison montre le souci du Roi, et plus encore de MI ${ }^{\text {me }}$ de Pompadour, de maintenir la production de la Manufacture en harmonie avec le goût et les tendanees de la Cour, et ce pelit fait est peut-être un des signes les plus précis de l’inlérêt suscité dans l’entourage de Louis XV par la eréation de M. de Fulyy.

Mais, à d'autres points de vue, rette organisation nouvelle fut tout d'abord pour la Compagnie Charles Adam une cause de sérieux embarras financiers. Un personnel coûteux de directeurs, d'artistes excellents eomme Bachelier ou Duplessis, les frais d'aménage-

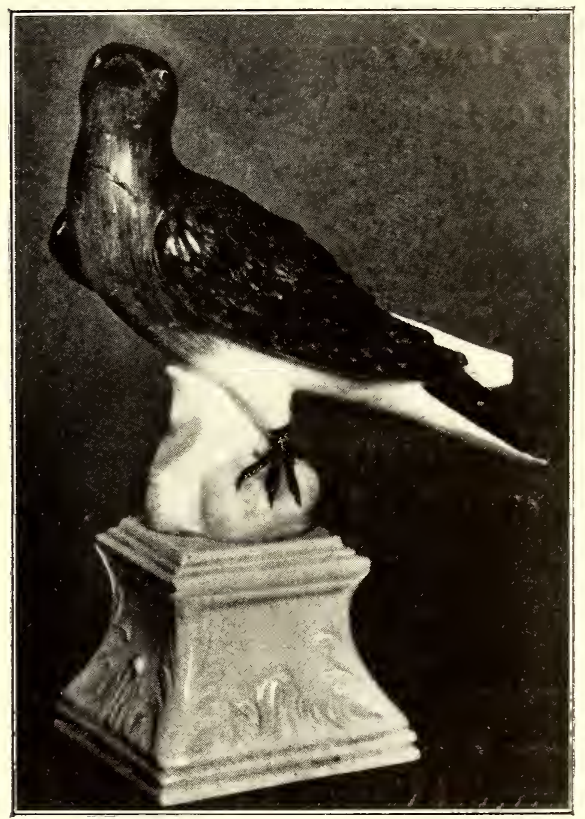

Fabrication de Vincennes, ver's 1753. - T'orcelaine tendre peints et imaillée. (Collection de Charagnac.)

ment du châleau de Vincennes qui avaient coûté 88000 livres, des achats fréfuents de modèles pour les divers ateliers, navaient fail qu'aggraver une situation difficile dès le début; el la Compagnie se trouvait d'autant plus ineapable de sortir par ses propres moyens de ces diflicultés qu'elle devait envisager comme une nécessité le transfert de la Manufacture en un lieu plus proche de Versailles que n’était Vincennes. On pourrait mème s'étonner de voir les associés consentir si longlemps des sacrilices d'argent, si leur intérèt ne s'était trouvé lié par bien des points au maintien de la Manu- 
facture : en effet ils avaient été choisis par M. de Fulvy parmi les fermiers généraux, et l'espoir de plaire au Ministre en subventionnant un établissement agréable au Roi explique la générosité et la patience dont ils firent preuve pendant plusieurs années. Un moment arriva pouriant où ils estimèrent ne pouvoir conserver plus longtemps cette trop lourde eharge; dans une délibération en date du 9 février 1792 , ils exposèrent l'embarras dans lequel ils se trouvaient et le secours qu ils sollicitaient. "La situation, est-il écrit au procès-verbal de " leur réunion, où se trouve la Compagnie, tant par rapport aux " fonds pour l'exploitation de la Nanufacture et fournir aux dépenses " nécessaires, qu’à cause de la translation, qu’il semble que le Roi " désire, de cette Manufacture dans un endroit plus à portée de "Versailles que n’est Vincennes, (force les associés à) prier MM. Bonfils " et Verdun d'agir près de M. de Courteille, intendant des finances, " pour l'engager à décider du sort de la Compagnie, soit par son rem" boursement, soit autrement... "Après d'assez longs pourparlers, une solution fut donnée à cette requète le 8 octobre de la mème année, sous la forme d'un arrêt du Conseil d'État révoquant le privilège accordé à Charles Adam et ordonnant le remboursement des cautions de celui-ei. La liquidation de la Compagnie dura jusqu'au mois de mai 17:33, et le procès-verbal de la dernière assemblée tenue par les associés nous fait connaître que ceux-ci touchèrent, tant en capital qu’en intérêts, tout près de 500000 livres : l'actif de la Manufacture dépassait à peine 210000 livres. 


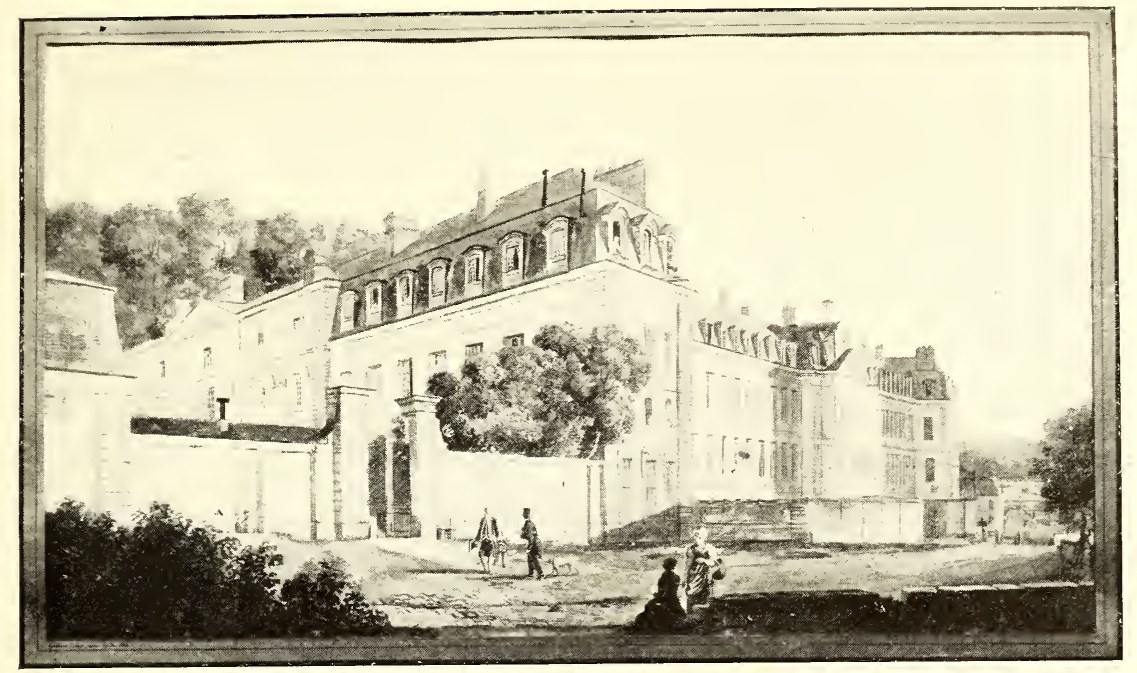

Vue de l'ancienne Nanufacturo do Sèvres (1756-1876). - Aquarelle de Troyon père, (Collections de la Manufacture.)

\section{LA MANUFAGTURE ROYALE DE PORGELAINE : LA GOMPAGNIE ÉLOY BRIGHARD (1752.1759)}

La Compagnie Charles Adam ayant cessé d'exister légalement au $1^{\text {er }}$ octobre 17:32, un laps de temps assez long sécoula avant qu'il fùt statué sur le sort de la Manufacture; éest seulement en effet le 19 aoùt 17:33 qu'un nouvel arrèt lui donna une organisation régulière par la transmission du privilege à une nouvelle compagnie. "Le " privilige de fabriquer toules sortes d'ouvrages at pièces de poree"laine peintes ou non peintes, dorées ou non dorées, unies ou de " reliefs, en seulpture on en fleurs, appartiendra à Éloy Brichard " pour en jouir privativement et exelusivenent à tous autres dans " Toute l'étendue du Royaume... ) Une interdiction absolue fut faite, sous les peines les plus sévères, de fabriquer ou d’introduire en France des porcelaines, et la Compagnie Éloy Bricharl ob!nt la jouissance 
de tous les bâliments du château de Vincennes servant à l'exploitation de la Manufacture " et ee, jusqu’à ce qu’elle puisse être trans" porlée dans le nouvel établissement qui doit être fait au village " de Sìres ". Enfin l'établissement reçut le titre de "Manufacture royale de porcelaine » et l'arrêt spéeilia que toutes les pièces fabriquées par elle seraient « marquées d’une double L entrelassée en forme de chiffre ». D'autres articles de l'arrêt firent aux ourriers de la Manufacture une situation particulière, les exemptant d’impôts, de logement des gens de guerre, mais maintenant pour eux l'interdiction de quitter l'établissement sans avoir oblenul'autorisation qu'ils devaient solliciter six mois d'avance. En échange des avantages aceordés à la Compagnie, le Roi devint possesseur de tous les seerets de composition que possédait la Manufacture et se réserva le droit de désigner l'homme chargé de la préparation des pâtes et couleurs.

Une société se forma immédiatement pour l'exploitation de ce privilège. Elle comprenait seize associés, choisis, comme ceux de la Compagnie Charles Aram, parmi les intéressés aux fermes; quelques-uns d'entre eux d'ailleurs avaient fait partie de la précédente société et l'on y retrouvail les noms de II. de Verdun, de Bonfils, de Bouillard, l'ancien taissier. Ils décidèrent, avant même la publication de l'arrêl, de faire un premier appel de fonds de 800000 livres, divisé en 80 actions, "tant pourl'exploitation de la Manufacture que pour la construction des bâtiments à édifier à Sèvres ». Sur cette somme, le Roi s'inscrivit pour 20 actions et devint ainsi intéressé pour un quart dans l'exploitation de l'établissement. Les versements devaient ètre faits à raison de 1000 livres par action au fur et à mesure des besoins : au cours de la première année, trois versements furent demandés aux associés, représentant une valeur de 240000 livres.

Dès cette époque, il estfacile d'apprécier quels étaient les projets de la Compagnie : elle youlait faire grand et ses premiers actes montrèrent 
qu'elle n’hésitait pas à engager de nouvelles dépenses. A còté de Boileau, inspecteur depuis 17:.1, appointé à 4000 livres, on nomma un con-

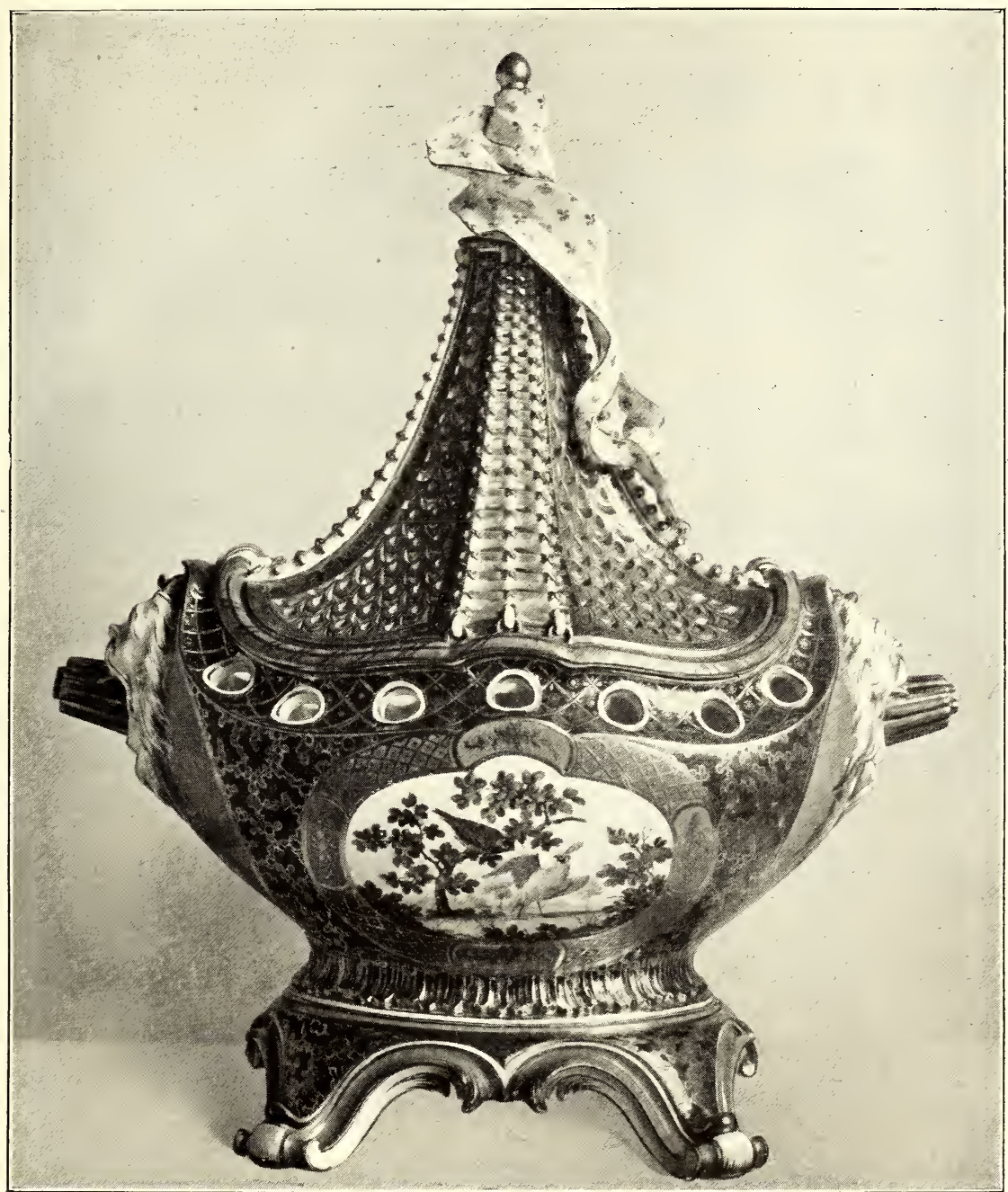

Fabrication de Vincennes, vers 17วั̆. - Vase “Vaisseau à mat » à fond bleu vermiculé, et cartels decorés d'oiseaux. (Musée Wallace.)

tròleur à 1800 livres; puis, comme la Compagnie avait son bureau à Paris, rue de Gaillon, elle engagea un préposé pour la correspondance à ce bureau. Pour l'emploi dont le Roi s'était réservé de nommer le 
titulaire, M. de Machault désigna en novembre 1753 Hellot, chargé deux ans plus tôt de réunir et de contrôler les formules des compositions employées à Vincennes. Les résultats de ce travail, terminé en 17\%2, avaient été consignés dans un registre spécial. C'est pourquoi le brevel de nomination indiquait que : " le sieur "Helot continuera le Mémoire en forme de procès-verbal de toutes " les connaissances acquises jusqu’à ce jour, dont l'original est " porté sur un registre de maroquin bleu. Le sieur Helot fera une " copie du dit registre plus détaillée que celle des mémoires qu’il a " déjà remis, laquelle copie sera déposée dans un coffre qui sera établi

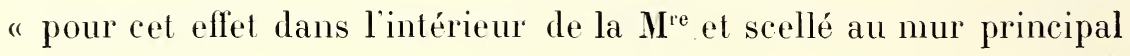
" du lieu qui lui sera destiné. »

A ce moment, la principale préoccupation de la nouvelle compagnie venait de la décision prise de transférer l'établissement à Sèvres, point admirablement choisi à égale distance de Paris et de Versailles, tout proche du château de Bellevue que $\mathbf{I}^{\mathrm{me}}$ de Pompadour avait édifié trois ans plus tôt el où elle réunissait tant de ehefsd'ourre des arts de son temps. Les terrains, achetés 18000 livres au nom de $\mathrm{M}$. de Verdun, avant même la publication de l'arrêt de 1753, comprenaient le domaine du château de la Guyarde, ancienne propriété du musicien Lulli, situé à mi-côte sur le chemin de Meudon à Sèvres : d'un côté, une large terrasse dominait la vallée de la Seine, tandis que le reste du domaine s'étageait sur les coteaux de Bellevue. Des bâtiments anciens de la Guyarde, il ne subsiste aujourd'hui qu'un petit pa villon du $x{ }^{\mathrm{e}}{ }^{\mathrm{e}}$ siècle, que la tradition fait encore appeler le pavillon de Lulli, mais que les parchemins contemporains désignent sous le titre plus original de (l’Opéra »: c’est, a vec des proportions restreintes, un modèle de simplicité élégante et d'harmonie de lignes; il s'élìve à l'entrée du pare de l'ancienne Manufacture, devenue l'École normale supérieure de jeunes filles. Les plans de la construction furent établis par l'architecte 
Lindet, et les travaux commeneèrent en septembre 1793, sous la haute direction de Perronnet, ingénieur et inspecteur général des Ponts et Chaussées. L’ordonnance générale des bâtinients comprenait un corps de logis principal se développant parallèlement à la route de Paris à Versailles : c'était une grande construction, haute de quatre étages, longue de 130 mètres environ, dont la façade banale n’était ornée que par un pavillon central et deux pavillons d'angle sans grand caractère. Aucune décoration n’en égayait les lignes monotones, car le grand motif exposé au Salon de 173̈. par Edme Dumont et représentant le buste du Roi supporté par Minerve d'un côté et par la France de l'autre, ne fut jamais placé dans le fronton du pavillon central pour lequel il avait été commandé. A l'intérieur, on trouvait en sous-sol les pièces de réserve des pâtes et terres; au rez-de-chaussée, les dépôts de matières prenières, les locaux destinés au séchage des moules, ete.; au premier étage, les ateliers des mouleurs en terre et en plàtre; au second, ceux des tourneurs, des mouleurs-répareurs, ainsi que les magasins de vente, isolés et dépourvus de toute communication avec les ateliers; au dernier étage enfin, les ateliers des peintres, des doreurs, et les laboratoires pour la préparation des couleurs, des émaux, de toutes les compositions secrètes de la maison. En arrière du bâtiment principal s'élevaient les fours et les services qui en dépendent.

Cela constituait l'usine proprement dite, d'où on avait écarté toute préoccupation de luxe ou d'élégance. Mais à l'une des extrémités de ces constructions on en édifia une autre, de moindre importance, orientée vers la Seine et à laquelle on accédait par la route de Meudon à Sèvres. La Compagnie avait réservé de ce côté un large espace pour y installer autour de la Cour Royale l'appartement du Roi et les services de la direction. Ce logis richement décoré de sculptures, relié aux salles d'expositions et à une réserve où l'on mettait à part pour Louis XV les eréations 
récentes, était composé d'une salle des gardes, de deux antiehambres, d'un salon ayant vue sur Paris et d'une chapelle. Au-dessus, des appartements avaient étédisposés pour le logement éventuel des associés ou des artistes appelés, comme Bachelier et Duplessis, à séjourner parfois à Sèvres. Enfin un troisième corps de logis contenait les appartements du Directeur.

La construction de cet immeuble considérable ne dura pas plus de trois années, pendant lesquelles on dépensa la somme énorme de 991.86 livres, à laquelle il convient d'ajouter pour l'installation intérieure plus de 300000 livres dépensées dans les années suivantes. Cependant, même avant d'ètre terminés, les bâtiments donnèrent de sérieux mécomptes. Bachelier affirme que l'architecte Lindet était un simple toiseur, incapable de mener à bien un ouvrage de cette importance, et ce jugement sévìre semble a voir trouvé sa confirmation dans les diffieultés que l'on rencontra au cours même des travaux. Avant la fin de la eonstruetion, on avait dù en consolider certaines parties, et des lettres du temps nous font savoir que le Roi hésita longtemps àvenir à la Manufacture, " ayant appris l’insolidité de l'ouvrage ». Au point de vue de la disposition intérieure, l'édifice présentait de graves défauts : le transport continuel des pièces à travers les quatre étages de cette grande maison faisait courir à celles-ci de forts risques de casse, et peut-être les critiques contemporaines n'étaient-elles pas eomplètement injustifiées lorsqu'elles prétendaient que l'on avait sacrifié la partie utile à l'agrément des intéressés de la Compagnie et du directeur.

L'installation dans ce nouveau logis se fit en 17306 : elle fut assez longue et l'on sait par des témoignages très préeis qu’elle était à peine terminée lorsque le Roi vint pour la première fois à Sèvres, en 1737. La Manufaeture trouvait enfin là une installation définitive et en rapport avee le développement qu'elle avait pris, et le transfert à Sèvres marque, à n’en point douter, le commencement de la 
période la plus brillante el la plus féconde de son existence : fondée depuis près de vingt ans, elle avait déjà montré des pièces admirables, mais sa production n'avait pas encore alteint la perfection matérielle et l'originalité de conception auxquelles elle parrint pendant le quart de siècle suivant.

Au point de vue de la fabrieation, nous arons indiqué qu’Hellot avait la charge de toutes les manipulations ef de toutes les recherches. A partir de 1757 , un autre savant, membre également de l'Académie des Sciences, Macquer, lui fut adjoint ef travailla des lors avec lui au perfectionnement constant de la pâte et des couleurs. A leur's côtés des hommes de métier, Bailly, chargé de la préparation des couleurs, Millot, chargé

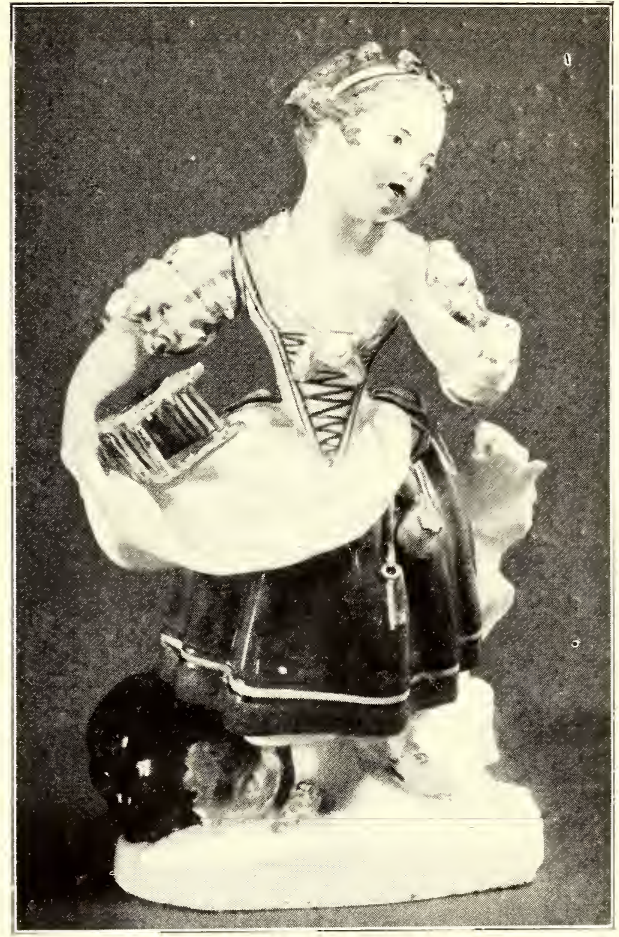

La porteuse de cage. -- Modèle de 1752. Porcelaine peinte et émaillée. Haut. 0,20, Larg. 0,11. Musée de Sèvres, no 10446.

de la conduite des fours depuis l'origine, donnèrent tous leurs soins à l'amélioration des procédés. Leurs cahiers d'expériences journalières, dont quelques-uns sont parvenus intacis jusquà nous, montrent l'effort convaincu de ce groupe de travailleurs et témoignent de la collaboration de tous à l'curre commune. Chaque artiste donnait la formule des couleurs dont l'emploi lui avait fourni les meilleurs résultats, augmentant par ses observations personnelles la quantité des secrets de la Manufacture : dans les petits livres 
de Macquer et de Millot, on trouve ainsi la composition du jaune de Morainville, de celui de Bailly, de celui de Massue, du jaune jonquille de Gravant, et il en va de même pour chaque couleur. Certains ne négligeaient pas, il est vrai, de tirer profit de leurs petites découvertes, mais l'exemple leur en éta it donné par Bachelier lui-même qui, ayant trouvé en 1753 un " jaune doré très fixeau feu », n'hésitait pas à le vendre à la Compagnie à raison de 50 livres l'once.

Hellot avait dû porter toute son attention, dès son arrivée, sur les pâtes livrées par Gravant. Celui-ci en effet continua à fournir à la compagnie Éloy Brichard les pâtes et les couvertes aux conditions fixées par son traité de $174: \ddot{~ a r e c ~ l e s ~ a s s o c i e ́ s ~ d e ~ C h a r l e s ~ A d a m . ~}$ Mais il ne faisait pas toujours, semble-t-il, les préparations avec un soin irréprochable et ces inégalités de la matière première produisaient un déchet considérable dans la fabrication. Afin de remédier à cet état de choses préjudiciables, Hellot établit en 1752 un ordre très rigoureux pour la réception, l'essai et l'examen des produits que la Manufacture achetait tout préparés. D'autre part, n’oubliant pas que le but primitif des fondateurs de Vincennes avait été l'imitation des porcelaines de la Saxe, et mieux averti que qui que ce soit des défauts de la pâte tendre, si belle et si riche qu'elle fût au point de vue du décor, il persista dans la recherche d'une pâte possédant toutes les qualités des porcelaines allemandes.

Une occasion sembla se présenter en 17.53 d’acquérir le secret de la composition de ces dernières. L’année précédente, la Compagnie, forte de son privilège, a vait intenté une action pour obtenir la fermeture de la seule usine de porcelaine dure existant en France à cette date, celle de Paul IIannong, à Strasbourg. Celui-ci comprit immédiatement combien il lui serait difficile d'entrer en lutte avec la Manufacture royale, et il conçut le projet de sauver son établissement en apportant à Boileau le secret de ses compositions. Mais sa tentative ne pouvait donner de résultats, puisqu’il n’était pas en mesure d'indiquer en 
même temps où trouver en France les matières premières qu’il employait : sa proposition fut done repoussée et il se vit obligé, en 17.34, d'abattre ses fours de Strasbourg et de transporter son industrie à Frankenthal, dans le Palatinàt.

Quelques mois plus tard, deux ouvriers chassés de cettefabrique, Busch et Staldmayer, proposèrent eux aussi de vendre les secrets

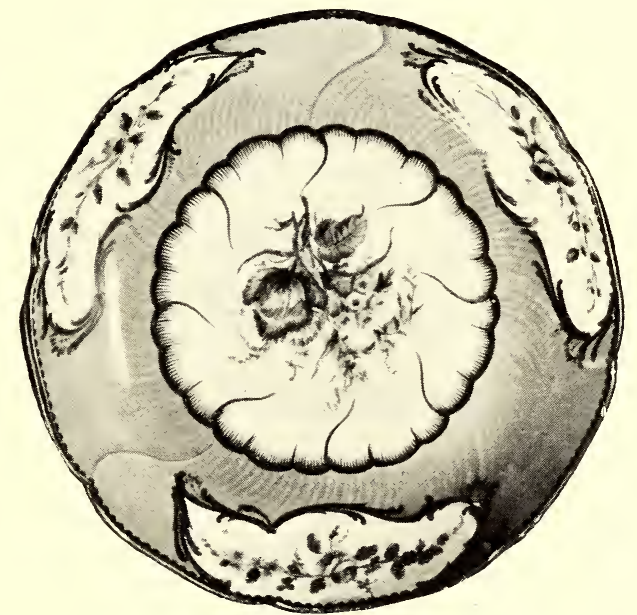

Porcelaine tendre de Sèvres, 1736. - Compotier, fonıl turquoise. Décor par Binet. (Musće de Sèvres, $n^{\circ}$ 4387.)

de la manufacture dans laquelle ils travaillaient et l'on n'hésita pas à les faire venir en France. Pour permettre au premier d'entreprendre le voyage, il fallut d'abord payer les dettes qui le retenaient à Strasbourg; puis, lorsqu'il eut installé à Paris sa femme et ses enfants dans une maison louée à son usage, il retourna à Baden sous le prétexte de ehercher certaines terres, tandis qu'il en envoyail d'autres de Strasbourg à grands frais. Revenu enfin à Sèves, il construisit successivement cing fours, quatre pour la peinture et un pour le biscuit, prolongeant pendant plus de dix mois des essais infruetueux qui eouterent à la Compagnie la somme de 12000 livres. Bien des années d'ailleurss devaient encore s'éeouler 
avant que la fabricalion régulière de la porcelaine dure pût être réalisée en France!

Du moins, si la Mlanufacture n'était pas encore en possession de tous les moyens d'action dont elle disposa plus tard en ce qui concerne la matière même de la porcelaine, elle parvint à cette époque à une production artistique d'une extraordinaire richesse. D'un côté Duplessis avait déjà donné, depuis 1748, par un concours presque quotidien aux travaux de la maison, une quantité considérable de dessins de vases ornés, de jardinières, de pièces de service, landis que d'un autre còté le groupe de jeunes artistes, que Bachelier s'était appliqué à former, apporlail des idées nouvelles dans la composition des déeors el aussi des procédés d'exécution mieux appropriés à la matière.

Hulst, dont nous arons indiqué l'influence décisive sur les tendances arlistiques de la Manufacture, avait en outre demandé à Bachelier de compléter son enseignement par la fourniture de modèles destinés à prendre place dans les ateliers des décorateurs. C'est ainsi que chaque année, à partir de 17302 , celui-ei fournit de 20 à 30 tableaux d'études, de projels de déeor's; Genest, chef des ateliers de peinture, contribua de la même façon à affiner le goût des exécutants placés sous ses ordres. Parmi ceux-ci une sélection s'élail déjà opérée : les uns étaient de simples praticiens chargés de la décoration des pièces courantes et peignant d'après des modèles graphiques; les autres étaient des artistes instruits, d'un goût souvent très personnel el dont les eompositions élaient assez originales pour désigner à première vue leur auteur. Ces hommes ont fait la véritable force et la valeur artislique toute spéciale de Sèvres, en créant et en eonservant jusquà la fin du xvme siècle une tradition d'art dans la maison. Beaucoup d'entre eux, Caton, Cornaille, Dodin, Levé, Parpette, les Pithou, entrés à Vincennes entre 174.̆ ct 1750, demeurèrent à la Manufacture royale pendant quarante ou cinquante ans; chacun possédait ses 
secrets, ses formules de couleurs, ses procédés de cuisson, et ils attachaient notamment à cetle dernière opération une importance assez grande pour que deux d'entre eux, et non des moindres, Capelle et Armand l’aîné, aient élé chargés, pendant le demi-siècle qu'ils passèrent à la Manufaclure, de la cuisson des pièces décorées.

Les dimensions des objels qui sortaient des atelier's élaient encore très restreintes à celte époque; cependant la variété des formes, la diversité des ornements étaient déjà devenues l'un des caraetères de la production. Les formes, simples d’abord, s’élaient eompliquées peuà peu, à mesure que la fabrication plus régulière permettait d’obtenir des pièees plus ornées à côté des vases à dauphins, des vases hollandais, des cases à oreilles, apparurent alorsle case Duplessis, l'urne Pompadour, les vases éléphants dent les anses élaient constituées par les têtes de ces animanx, ot enfin cette pièce d'une si extraordinaire ingéniosité décorative, le Pot-pourri à vaisseau, dont un admirable spécimen fait eneore partie des collections royales de Windsor : e'était une espèce de grand brûle-parfums en forme de navire, dont le couvercle représentail la mâture el les agrès d'un vaisseau. Une autre caractéristique de la production de ce temps fut la quanlité de petits objets d'usage courant que l'on fabriqua à Sèrres sous l'influence de la cour élégante de Louis XV, des grands seigneurs qui demandaient sans doute à la Manufature Royale de leur fournir les précieuses inutilités par le choix desquelles ils pouvaient. faire preuve de goût et d'esprit. Ce ne furent alors que bordures de miroirs, manches de couteaux, lorgnetes, arrosoirs, bénitier's, lanternes, tabatières, voire mème des lables en plusieurs morceaux, comme eelle qui fut exécutée pour le Grand Ture en 17ö3. Les genres de décoration colorée, très peu variés arant 1730 , présentèrent au contraire, dans les dix années qui suivirent, une originalité dont il faut sans doute rendre hommage à Bachelier. Beaucoup d'objets étaient eneore ornés de fleurs, de guirlandes, d'animaux, surtoul 
d'oiseaux, qui rappelaient l'origine des peintres ayant travaillé, soit à Chantilly, soit dans les ateliers d'éventails. Mais de plus en plus on vit se développer alors deux genres nouveaux : les paysages en une seule couleur, le pourpre généralement, et les jeux d'enfants inspirés des compositions de Boucher. Ces divers modes de décoration furent également employés dans des cartels réservés en blanc sur un fond coloré de l'une des trois teintes qui jouissaient alors d'une vogue particulière : le " bleu ancien » ou bleu turquoise découvert par Hellot, le rose du peintre Xhrouët, et le vert.

La fabrication des pièces dites de service s'accrut notablement, mais si les objets d'usage courant, tels que les plats ou les assiettes, prirent une certaine place dans cette production, il est certain que l'on vendait surtout les ustensiles, à la fois d'utilité et d'ornement, dont les formes multiples donnaient aux artistes l'oceasion de compositions originales et variées, particularité qui s'explique facilement par l'emploi de la vaisselle d'argent sur les tables prineières. Ainsi les seaux à bouteilles, les seaux à verres semblent avoir été au nombre des premières pièces dont on acheta de grandes quantités à la Manufacture : certains étaient "peints à Chinois ", indication qui montre suffisamment que les traditions primitives de Vincennes ne se perdirent pas immédiatement à Sèvres mème; d'autres étaient " peints à paysages ". Les déjeuners aussi, souvent de prix élevés, furent très appréciés, sans doute pour plaire au Roi qui en faisait l'objet principal de ses acquisitions. Par contre, des services de table complets furent rarement fabriqués à la Manufacture à cette date, et il faut peut-ètre en trouver la raison dans les prix énormes auxquels montaient detels services. Le goût des amateurs devait naturellement se porter plus volontiers vers des objets d'une valeur moindre et dans lesquels les modeleurs de Sèves avaient pu cependant faire preuve de facultés d'invention personnelle. Pour un mème objet, il n'était pas rare de trouver alors six ou huit formes différentes, el e'est ainsi qu'il y 
avait le gobelet forme du Roi, le gobelet à la Reine, le gobelet d'après le Saxe, le gobelet Hébert, les compotiers en forme de coquilles, les jattes feuilles de chou, les écuelles ornées de motifs en relief, etc. Toutes ces pièces recevaient des décors du mème genre que ceux des objets dont nous avons déjà parlé : il faut cependant y ajouter une ornementation fort appréciée et qui consistait en des dentelles et des frises d'or appliquées sur les bords des pièces.

On imagine volontiers quel armirable ensemble devait présenter l'exposition que chaque année le Roi autorisait la Manufaeture à organiser dans la salle à manger de ses appartements, ̀̀ Versailles. La coutune était d'y présenter les

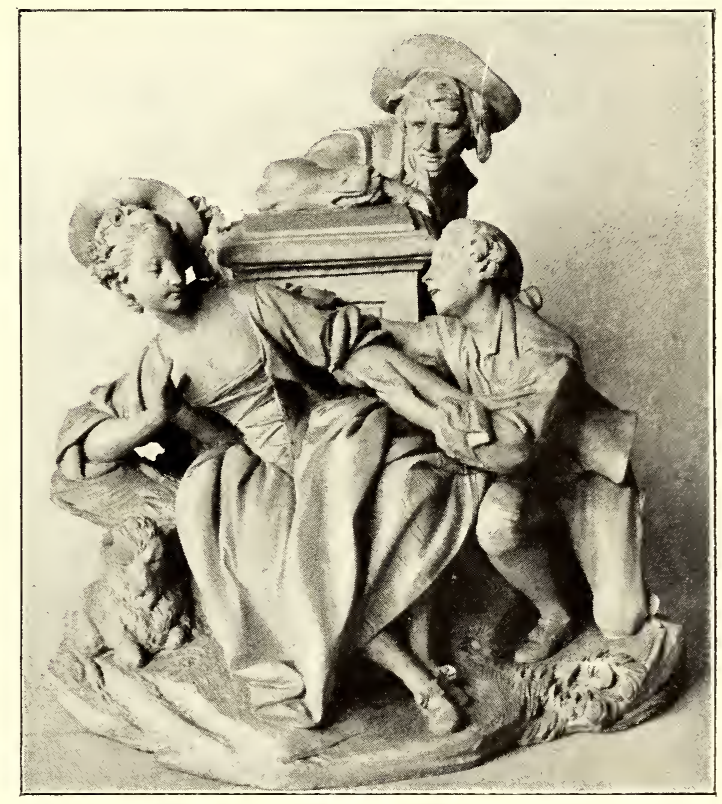

Groupe “ du Jaloux ». - Nodèle de 17ว20 (H., 0,25). pièces nouvelles, et l'on sait que le Roi ne craignait pas de se faire parfois le vendeur des précieux produits de Sèves: là, bien souvent, s’il faut en eroire les mémoires du temps, les courlisans se décidaient à acheter, moins par un eaprice de leur goùt que sur un encouragement impératif du maitre. Tous ces objets aux couleurs vives, aux formes harmonieuses, devaient se marier d'une façon charmante avee la sculpture, sous les deux aspeets qu’elle présentait eneore à celle époque, soit recouverte d'émail et colorée, soit en biscuit. Le succès de cette matière en effet ne fut pas immédiat, et bien des gens lui préférèrent 
longtemps les figures et les petits groupes mis en couleurs à la façon des statuettes de Saxe.

Avant 17:57, la sculpture comme la peinture était sous la direction de Bachelier ; mais sans diminuer en rien le rôle considérable que celuici eut certainement dans le développement de Sèvres, il faut encore

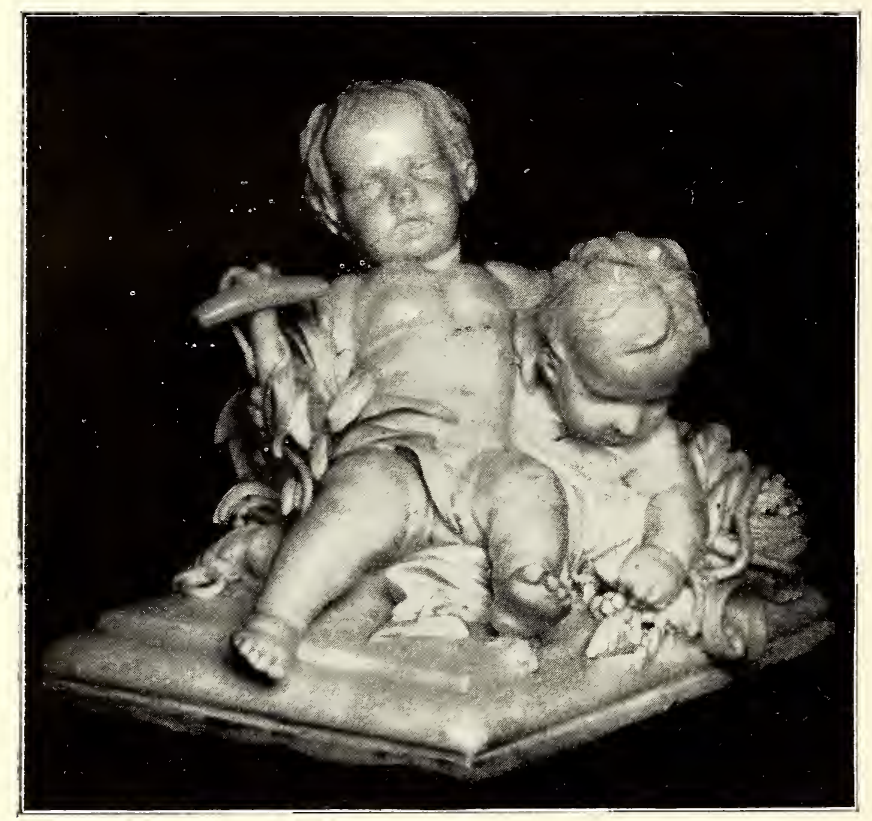

Groupe d'Enfants. - Modèle de La Rue, 17ว̈́t. - Porcelaine tendre émaillée de Vincennes. (Collection de Chavagnac.)

rappeler ici le nom de Duplessis qui était, nous l’avons vu, chargé des «formes et modèles ». La complication ingénieuse de certaines de ces formes, par exemple l'arrangement de girandoles où se mêlaient les fleurs de Vincennes, les figurines peintes, les feuillages vernis au naturel, les garnitures de bronze doré, ne permettent pas de négliger son influence lorsqu'on examine १a production sculpturale de la Manufacture durant la période qui nous occupe. Toutefois il est certain que, pour tout ce qui concerne la figure, les modèles étaient choisis par Bachelier lui-même et exécutés sous sa direction, et c'est 
sans auem doute à lui que l'on doil la collaboration de Francoiss Boucher aux travaux de Vincennes et de Serves. Il lui demanda fréquemment à eetle époque de fournir des dessins dont s’inspiraient tout à la fois les peintres et les seulpteurs : c’étaient d'un còté des figures familières telles que le Jardinier, le Marchand de gíteaux, la Batteuse de beurre, la Laitière, la Marchande de crème, des petits groupes d'une coneeption gracieuse comme le Joueur de flute, le Groupe du jaloux, des compositions allégoriques, litgriculture, l'Astrologie, les Quatre parties du monde, entin de nombreuses statuettes d'enfants. Pour traduire en terre ces compositions, Bachelier fit appel à de jeunes arlistes étrangers à la maison, Blondeau, qui semble aroir modelé principalement des liğurines d'enfants, Fernex, dont il existe encore au musée de sèves deux modìles signés (le Tailleur de pierres et la Blanchisseuse), La Rue enfin qui, avant de partir pour Rome, exéeula quelques pièees ormées de figurines d'enfants d'un joli sentiment - plaques à papier, vase soutenu par trois enfants marins, groupe de trois enfants dont un monté sur une panthère.

Toutes ees ceurresd’inspiration aimable et d'exécution gracieuse, composées par Boucher lui-mème ou par des artistes de tendanees identiques, eurent un réel sucè̀s, et il est juste de reconnaître qu'elles étaient merveilleusement appropriées à la décoration intérieure du temps. Elles se prètaient également bien à la reproduction en biscuit et en poreelaine émaillée, chaque natière leur dommant un charme partieulier: et il faut bien reconnaître que si, dans la suite, la découverte de la pàte dure permit d'exéeuter des pièces de dimensions beaucoup plus importantes, cette matière plus siehe, plus froide de ion, trop roisine du marbre par son aspeet, ne put jamais rivaliser avee la finesse de grains et la coloration légèrement ambrée des biscuits de pàte tendre.

En 17:57, celle partie de la produetion artistique de Sevres reçut une 
orientation nouvelle. Bachelier qui, depuis son arrivée dans la maison, était chargé de l'ensemble des travaux d'art, s'occupa seulement depuis lors des ateliers de décoration et principalement de l'école de peinture, tandis que Falconet fut appelé par le Roi à diriger la partie sculpturale. Académicien depuis 175̆4, adjoint à professeur, dans la pleine maturité de son talent, Falconet était particulièrement désigné pour marquer d'une empreinte personnelle les travaux qui s'exécutaient dans les ateliers de la Manufacture. Pendant dix années, il occupa auprès des modeleurs de Sèvres une situation de tous points semblable à celle de Bachelier auprès des décorateurs, chacun d'eux venant un jour par semaine surveiller les travaux, et recerant pour ce déplacement une somme de 48 livres. Falconet poussa la conscience plus loin, et l'on sait que, sans y être obligé, il fit travailler fréquemment les sculpteurs de Sèvres sous ses yeux dans son atelier de Paris : c'est sans doute à ce fait que l'on doit de retrouver intactes, dans beaucoup de modèles de cette période, les conceptions du grand artiste, tout imprégnées encore de son esprit et de sa gràce. En un passage du mémoire que nous avons déjà si fréquemment cité, Bachelier dit que « ce genre (les compositions de “ Boucher) eut le plus grand succès jusqu’à ce que M. Falconet “ portât dans la sculpture un genre plus noble, d'un goût plus " général et moins sujet aux révolutions de la mode », et il affirme que presque tous les sujets exécutés entre 1737 el 1766 furent composés par Falconet lui-même, assertion qui semble justifiée par l'examen des comples de dépenses de cette période. En effet, au contraire des années précédentes, on ne trouve plus alors trace de paiements à des artistes du dehors. Falconet avait demandé à la Manufacture d’engager certains de ses élèves, Duru et Le Riche entre autres, et il est à penser que ceux-ci terminaient sous ses yeux les maquettes ébauchées par lui et leur donnaient la précision de forme indispensable pour la reproduction en porcelaine. D'ailleurs, même avant 
d'être atlaché à Sèvres, Falconet avait fourni à la Manufacture des réductions de certaines de ses ceurres : l'Amour, conmandé par $M^{\text {me }}$ de Pompadour et exposé en $175 \%$, était en vente à Sèvres deux ans plus tard; de même en 17988 apparut la célèbre Baigneuse qui avait figuré au Salon précédent sous le titre de "la Nymphe qui descend au Bain ». En dehors de ces ourres, vulgarisées depuis par tous les modes de reproduction, Falconet s'attacha particulièrement à la création de petits groupes allégoriques destinés souvent à la décoration de la table du Roi et disposés pour ce motif de façon à offrir un aspect agréable sous toutes leurs faces. Les plus remarquables sont peut-être la Pếche et la Chasse, composés chacun de deux figures de femmes d'une grâce et d'un arrangement exquis. Il faudrait citer encore dans le mème ordre d'idées les groupes d'Hébé, d'Érigone, de Silène, etc. Cette production, tout à fait appropriée au talent de Falconet, ne l'empêcha point de composer aussi des sujets empruntés à la vie familière, qu’il marqua d'un sentiment très personnel et d'un goût trìs sûr : le groupe de la Curiosité, celui de la Loterie, ceux du Chien qui danse, de la Vache appartiennent à celte catégorie très partieulière de l'œuvre de Falconet.

Si l'on considère le développement pris par la Manufacture entre 1753 et 1760, il semble bien qu'elle soit parvenue alors au moment le plus brillant de son existence. A l’intérieur, la fabrication était devenue aussi parfaite que le permettait la matière délicate de la pâte tendre; les peintres, les sculpteurs avaient acquis sous limpulsion des meilleurs artistes une habileté extraordinaire, en mème temps qu’une science de la composition qui faisait défaut à leurs prédécesseur's : déjà les ateliers de Sèvres occupaient plus de 2.00 personnes. Au dehors, le Roi donnait à la Manufacture d'incessantes preuves de son intérêt; il y venait fréquemment, et l'on a vu quelle part il avait prise dans les frais d'établissement de la eompagnie Éloy Brichard. A cette époque, il la combla encore de nouvelles libéralités, d'abord en abandonnant 
la Verrerie Royale de Sèves pour servir de logement aux ouvriers, ensuite en accordant à titre de secours permanent à la Manufacture les sous-fermes de la 'marque d'or et d'argent du Royaume et les droits sur les suifs de la Ville de Paris, dont le revenu annuel était de 100000 livres environ. En $17: 58$ enlin, Louis XV vint en aide à la Compagnie par un don spéeial de 100000 livres. Malgré eela, la situation financière de l'établissement ne fut jamais plus critique qu’à eette époque. La Compagnie était ruinée par les constructions de Sevres et aussi, il faut bien l'avouer, par une administration souvent imprévoyante. Boileau, dans les nombreux mémoires qu’il rédigea alors, se plaignait des dépenses qu’entrainait trop souvent l'ignorance des associés de la Compagnie qui, pour se concilier la bienveillance du ministre, ordonnaient des essais rarement suivis d'un résultat utile, mais toujours fort coûteux. Aussi le registre des délibérations de la Compagnie à cette époque offre-t-il le témoignage des préoccupations que l'impossibilité de satisfaire leurs créancierss eausait aux eautions d'Éloy Brichard. Le compte de 17906 dépassa douze cent mille livres, tandis que le chiffre des ventes n'atteignait mème pas trois cent mille! On fut sur le point d'employer les moyens extrèmes pour sortir de cette situation : il fut ainsi question de licencier la moitié des ouvriers, et Boileau ne parvint à éviter cette mesure qu'en montrant la faible économie qui en résulterait. Entre 1736 et 17:39, la Compagnie ne persista qu'au moyen d'emprunts successifs qui ne lui permettaient même pas de payer les entrepreneurs des bàtiments. A la lin de cette période, elle était obérée de plus de 500000 livres de dettes: les ouvrier's n’avaient reçu que des acomptes; on devait 10000 livres à Gravant pour fourniture de pâte, pareille somme au marehand d'or ; Falconet et. Bachelier n'avaient encore touché qu'une fạible part de leur traitement de l'année précédente. Par surcroît, les créanciers, las d'attendre, firent saisir toutes les porcelaines déposées chez les négociants et s’ins- 
tallèrent au bureau mème de la Compagnie, à Paris, pour s'emparer des rentrées de fonds qui pourraient y ètre effectuées.

Les cautions d'Éloy Brichard, sentant qu'une solution favorable n’était plus à espérer, adressèrent en avril 17.99 un mémoire

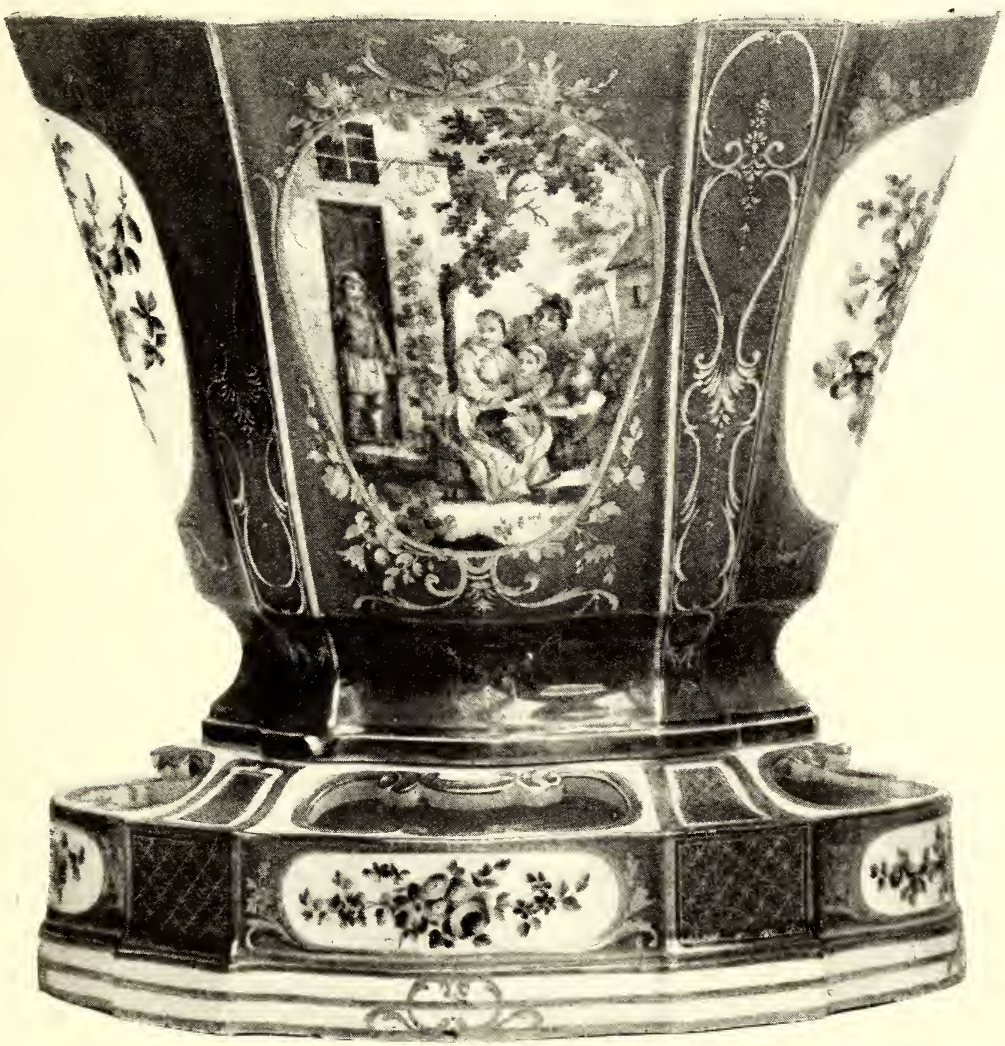

Fabrication de Sèvres, 1759. - Jardinière en poreelaine lendre. Fond vert. Cartels à personnages. (Victoria and Albert Museum.)

au Koi, le priant de racheter les bàtiments en échange de l'abandon des cinq années de privilège qui restaient à courir. Un mois plus tard, les créanciers devenant ehaque jour plus menaçants, les associés ne demandèrent plus qu’à ètre déchargés du privilège et indemnisés, s'en remettant à la justice du ministre pour fixer le taux du remboursement de leurs actions. La décision royale tardant 
encore à venir, ils en arrivèrent au mois d'août à solliciter seulement que l'on suspendit pour un temps l'effet des poursuites intentées contre eux par les créanciers, sur le point d'obtenir l'autorisation de faire vendre les meubles et effets de la Manufacture royale!

Pour tout dire, la gravité de la situation fut peut-être aggravée encore par le désir qu'avait Boileau d'échapper à la tutelle d'une compagnie et de rentrer dans le domaine du Roi. L’incompétence des associés l'empèchait d'établir dans la maison l'ordre et la régularité qu'il souhaitait, et d'un autre côté il craignait de voir s'élever des concurrences fâcheuses eapables d'entraver le développement de la Manufacture : ses appréhensions, peut-être justifiées, et qu’il exposa dans un mémoire adressé à $\mathbf{M}^{\text {me }}$ de Pompadour, avaient pour point de départ le projet prêté au comte de Brancas-Lauraguais, et à quelques-uns de ses amis, de fonder un établissement pour la fabrication de la porcelaine. Il est certain que tous ses efforts tendirent à la dépossession de la Compagnie Éloy Brichard.

La solution si impatiemment attendue fut donnée par le Roi le 17 octobre 1759: un arrêt du Conseil d'Élat du 17 février 1760 la confirma ensuite. Aux termes de ces décisions, la Manufacture cessa d'être la propriété d'une compagnie et passa entièrement sous l'autorité du Roi, moyennant une somme de quatorze cent mille livres représentant le capital et les intérêts des versements faits par les intéressés. Ceux-ci gardèrent à leur charge toutes les dettes de la Manufacture et abandonnèrent par contre au Roi toutes les créances recouvrables. Le bénéfice de la ferme de la marque d'or' el d'argent fut remplacé par une incription annuelle de 96000 livres sur le Trésor Royal. Enfin confirmation fut donnée des privilèges de 1745 et 1753 , tandis que des dispositions, plus favorables encore que les précédentes, assuraient la siluation du personnel des ateliers.

La Compagnie Éloy Briehard fut liquidée et sa dernière réunion eut lieu le 21 novembre 1761 . 


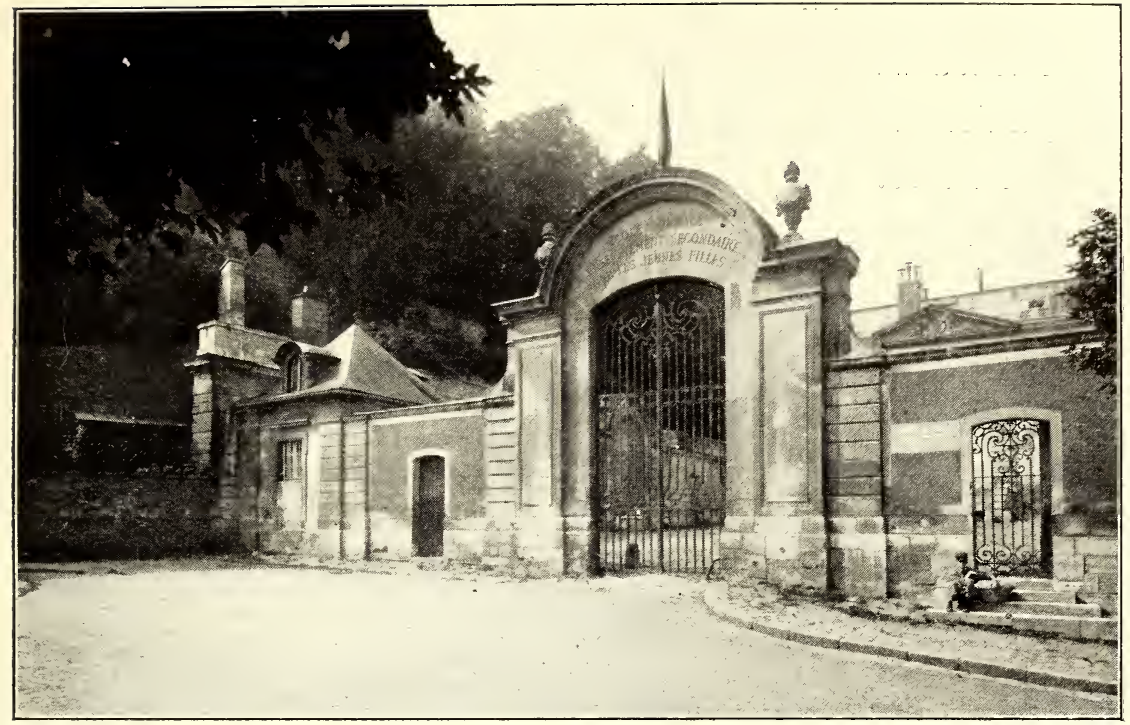

Ancienne Manufacture de Sèvres. — Entrée de la Cour Royale.

\section{III}

LA MANUFAGTURE, PROPRIÉTÉ ROYALE : DIREGTION DE BOILEAU LA DÉGOUVERTE DE LA PORGELAINE DURE (1759-1772)

La date du $I^{\text {er }}$ octobre 1739 marque l'époque à laquelle la Manufacture devint propriété royale: elle ne cessa de l'être que pour rentrer plus tard dans le domaine de l'État. Il n'en faudrait pas conclure qu'elle se trouva dès lors à l'abri des vicissitudes financiòres qui, à tant de reprises, avaient eompromis son existence au cours des vingt premières années de son établissement : elle conserva en effet son autonomie financière, el si, tant que régna Louis XV, une subvention royale lui permit chaque année d'équilibrer son budget et même de constituer un capital important, elle devait dans la suite voir s'aggraver sans cesse des diffieultés qui faillirent amener sa ruine totale à l'époque de la Révolution. Toutefois les années qui vont de 17.59 à 1772, dont nous avons à nous occuper et qui eor- 
respondent à la direction de Boileau, ne connurent point ces embarras et apparaissent comme la période la plus prospère de l'existence de la Manufacture.

Administrativement, elle fut placée sous l'autorité de Bertin, contròleur général des finances depuis 17\%9. M. de Courteille demeura jusqu’à sa mort, en 1767, commişsaire du Roi auprès de la Manufacture, emploi qu'il occupait depuis dix ans déjà, et dans lequel il ne fut pas remplacé. Lorsqu’il disparut, le détail des affaires fut traité directemént par les bureaux du contròleur général qui semble s'ètre occupé lui-mème très activement de tout ce qui concernait l'établissement royal. C'est à l'influence de Bertin certainement que les associés de la Compagnie Éloy Brichard avaient dù le remboursement intégral de leurs avances, et c'est lui qui plus tard remit chaque année entre les mains du caissier de la Manufacture un don de 96000 livres, en un temps où l'argent n'était pas toujours facile à faire rentrer dans les caisses du Roi. Les nombreuses notes manuscrites qu’il a laissées, les décisions qu’il a prises, montrent dans quel esprit libéral il s'efforça de développer la Manufacture sans nuire cependant aux progrès de l'industrie privée. Pour la direction de Sèvres, il accorda sa pleine confiance à Boileau, dont la fortune apparaît vraiment extraordinaire. Cet homme, entré à Vincennes comme garde-magasin avec 1000 livres d'appointements, était, quinze années plus tard, un personnage considérable, reçu à la Cour et ami de Collin, le secrétaire de $\mathbf{M}^{\text {me }}$ de Pompadour; aux huit mille livres de traitement qu’il s'était fait allouer en 1760, s'ajoutaient les arantages du logement, une importante gratification annuelle, des frais de représentation élevés, et enfin une retenue sur le chiffre des ventes qui, en certaines années, dépassa 20000 livres. Il obtint plus encore, lorsqu'à la fin de sa carrière il demanda au Roi de doter sa belle-soeur en récompense des services rendus par lui, faveur qui lui fut accordée et qui valut à $\mathbf{I}^{1 \mathrm{le}}$ Briais, en 1770 , au 
moment de son mariage arec M. de Léviston, une somme de 40000 livres et un brevet de rente viagere de 4000 livres.

Cette confiance extraordinaire en Boileau, cette libéralilé à son endroit se trouvaient en partie justifiées, il est vrai, par les résultats heureus de sa gestion. Profitant du succis de la Manufacture, il sut lui constituer d'importantes réserves sous deux formes, numéraire et pièces fabriquées, el ces réserves représentaient en 1772 un capital considérable, malgré des charges qui ne firent que s'accroître constamment à cette époque. Le budget des dépenses courantes, qui ne représentait que 310000 lives en 1761 , absorbait dix ans après 500000 livres. Le personnel, considérablement augmenté - il comprenait 250 jer-

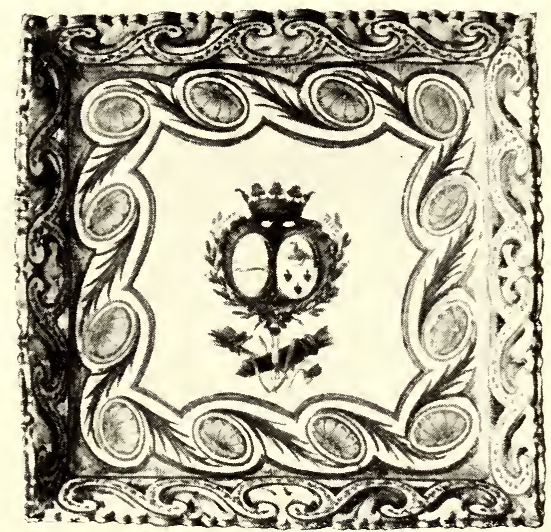

Cendrier carré.

Porcelaine tendre 1763. - Largeur 0,11. (Iusée de Sèvres, no 8853 .)

somnes au moment de l'acquisition par le Roi, et $3 \breve{0}$ au moins à la mort de Boileau - exigeait une rémunération plus forte et coutait 213000 lirres en 1772 au lieu de 140000 en 1760. Une progression identique s'affirmait dans les acquisitions de matières premières, de pâtes que les Gravant fournissaient encore au prix fixé en 174 , d'or, de combustible, et cette dépense s'élera dans le mème laps de temps de 74000 livres. Seul le haut personnel ne vit pas sa rémunération augmenter dans les mêmes proportions : directeur, sousdirecteur, inspecteur, commis coûtaient de 18 à 20000 livres; les artistes principaux, Bachelier, Falconet, Duplessis, 8000 livres; les " académiciens chimistes » Hellot, Macquer, de Montigny, 2 700 seulement.

Il faut dire, d'ailleurs, que les reeeltes s'accrurent d'une façon 
considérable et passèrent en dix ans de 320000 à 540000 livres. Les acquisitions du Roi - en moyenne 2.000 livres par an - celles de $\mathbf{M}^{\text {me }}$ de Pompadour et plus tard celles de $\mathbf{I}^{\mathrm{me}}$ Dubarry - encore plus élevées - entraìnèrent à des dépenses inouïes tous ceux qui voulaient faire leur cour à Louis XV ou à ses maîtresses, et ainsi l'exposition annuelle de Versailles rapporta à la Manufacturejusqu’à 80 et 100000 livres. D'autre part, la coutume d'envoyer aux souve-

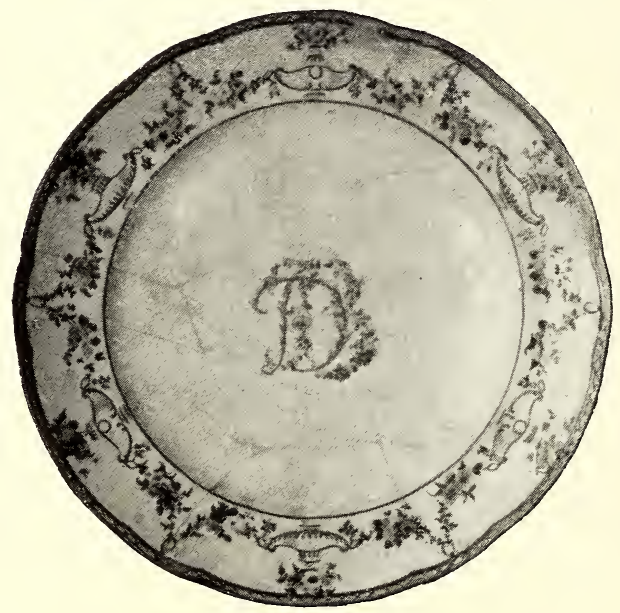

Assiette du service de Mme du Barry.

Porcelaine tendre 1770. - Décor de Catrice. (Musée de Sèvres, no 9109.)

rains étrangers de riches présents de poreelaine devint pour Sèvres une nouvelle source de revenus. Et le malheur même des temps, qui força beaucoup de grands seigneurs, suivant l'exemple du Roi en $170 ̈ 9$, à porter à la Monnaie leur vaisselle d'or et d'argent, fut l'occasion de commandes importantes : on remplaça sur les tables princières les belles pièces de service envoyées à la fonte, par des objets luxueux eneore, mais d'une moindre valeur intrinsèque. En dehors de ces ventes faites directement, la. Manufacture avait alor's de nombreux dépòts à Paris, en province, et mème à l'étranger : elle abandonnait aux marehands 12 p. 100 sur les porcelaines prises en compte ferme et 9 p. 100 sur celles prises à condition. 
Le public s'adressait volontiers à ces intermédiaires dont les noms reparaissent constamment sur les lives de vente; les principaux, après la mort de Duvaux, furent Sayde, la veuve Lair, Tesnières, Bailly, Bachelier lui-mème, dont la mère tenait au Palais-Royal un magasin de porcelaine, l'orfèvre Duplessis, dernier acheteur de ces délieats objets qui avaient décidé de la fortune de Vincennes - les fleurs de porcelaine - et qui, fabriqués maintenant à bas prix dans toutes les manufactures, ne donnaient plus lieu à Sèves qu’à des ventes insigniliantes. Les uns et les autres vendaient surtout des pièces de services, tasses, assiettes, seaux à glace, ete, et des objets de toilette.

A la datede 1760, la Man ufacture était parvenue, comme nousl'avons indiqué, à une grande perfection dans le façonnage et la décoration de la porcelaine tendre, et cela, non plus au moyen de coûteux achats de procédés comme aux débuts de son existence ${ }^{i}$, mais grâce à la 'remarquable habileté aequise par les ouvriers qu'avaient instruits Bachelier et Duplessis. Lorsque l'on se rend compte de la diffieulté que devait présenter la fabrieation des pièces conpliquées, ornées de trophées, de sujets en relief, de parties découpées, qui sortirent de Sèvres à ce moment, on reste émerveillé de la prodigieuse sûreté de main des mouleurs et des répareurs quï,maniaient avec tant de succès la pàte tendre. Il est malheureusement difficile de voir en France les plus beaux spécimens des produits de la Manufacture à cefte époque : nos musées en contiennent fort peu, et leur pauvreté s'explique d'abord par l'envoi de beaucoup de ces pièces rares à des princes étrangers, ensuite par la vente de celles appartenant à des familles de l'aristocratie française au moment de l'émigration : r'est ainsi qu'a été eonstituée la plus belle colleetion de

\footnotetext{
' On ne trouve guère comme procédés nouveaux que celui apporté en 176' par l'apothicaire Cadet qui découvrit le moyen d'empècher la chaux contenue dans la pàte de se revivifier et de détériorer les pièces : cela diminua singulièrement la quantité des pièces de rebut qui auparavant étaient inutilisables.
} 
vases de Sèrres anciens qui existe sans doute au monde, celle de S. M. Édouard VII.

La production présenta à cette époque une extrême variété, mais si les pièces d'usage furent d'une fabrication plus courante, le grand intérêt devait aller aux pièces d'ornement, aux vases, aux cassolettes, aux pots-pourris, aux jardinières. Dans ces objets, quirestaient toujours de dimensions restreintes, puisque la pâte tendre ne se prêtait pas au façonnage de pièces considérables, l'ornementation modelée prit une importance de plus en plus grande. Les formes n’eurent plus la gracieuse simplicité des petits vases tulipes ou des vases à oreilles de 17.30 , et souvent elles disparurent sous un amoncellement de guirlandes, de médaillons et d'ornements; quelques dénominations en peurent dire à ce sujet plus long que toutes les descriptions: vases à têtes de bouc, vases à la corne, vases grecs à médaillons, vases à serpents. Certaines peuvent même nous apparaître aujourd'hui comme des erreurs de goût, le vase en forme de ruche, le vase éléphants où les trompes de ces animaux se terminent en candélabres, par exemple ; mais, pour porter un jugement équitable sur des formes d'une fantaisie aussi caractérisée, il serait nécessaire de les replacer dans le milieu auquel elles étaient destinées et de les voir, non plus dans une vitrine de musée ou de collection, mais dans un de ces boudoirs élégants où les artistes de ce temps purent parfois donner libre cours à leur imagination pour la composition d'un décor. C'étaient d'ailleurs là des exceptions, et l'on retrouve bien les belles traditions de Duplessis dans des formes telles que le vase de Fontenoy, ou vase à cartels, aux lignes purẹs et si bien appropriées au genre de décoration employé alors.

Une égale diversité existait dans les mennes pièces de service qui représentaient à elles seules les trois quarts des ventes de la Manufacture et qui, plus que toute autre chose, étaient appréciées à la fois par la Cour et par les acheteurs plus modestes : elles composaient 
presque entièrement la vente des marchands, et le Roi lui-mème n'acquérail en général qu'un petit nombre de pièces d'ornements et de sculpture, employées surtout à titre de complément dans la eomposition de riches services de table. Les grandes commandes faites à la Manufacture - cadeaux diplomatiques ou achats de particuliers s'appliquaient souvent aussi à des objets d'usage : nous citerons seulement pour exemples le service du duc de Praslin en lapis cailloulé (รّ̋0 piicess : 28000 livres), le service du prince de Staramberg eomposé de 540 pièces toutes différentes (30624 livres), ceux offerts au roi de Danemark en 1768 , et au roi de Suède en 1770 (4.1664 livres), ou encore le service commandé par le prince de Rohan, en bleu céleste avee cartels d'oiseaux et chiffres. A côté de ces services, d'une valeur énorme, puisque chaque assiette valait en moyenne de 40 à ö0 livres,

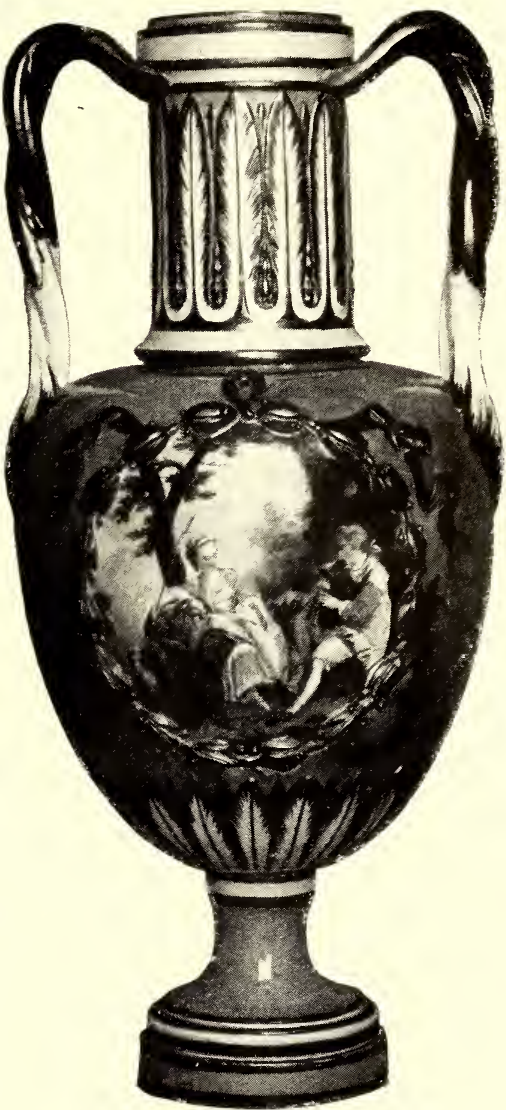

Porcelaine tendre. Haut. 0,35. Vase à anses torses à cartels. (Musée des Arts décoratifs.) la Manufacture produisail une quantité de pièces, gobelets, tasses, plateaux à huîtres, marronnières, etc., dont on s'étonne de voir les prix élevés : une jalte à punch et son mortier, un pot à oille se vendaient couramment 600 lirres, une saucière 120. Il en étail de même des objets de toilette, dont la mode se continua longlemps et passa des menus ustensiles aux pièces importantes, comme les cuvettes ou les brocs. 
En 1763, ${ }^{\text {me }}$ "le Pompadour acquit une “ cuvette à masques » pour 528 livres, tandis que le Roi payait une boîte à éponge 240 livres ; à la mème époque un plat à barbe était vendu 48 livres! Et cette exagération de valeur ne nuisait mème pas au suceès des objets de fantaisie que l'on fabriquait depuis Vincennes, tabatières, bobèches, œufs, manches de couteau ; au contraire, les mêmes tendances de goùt trouvèrent leur application dans des pièces importantes, telles que les écritoires - le Roi en paya une 960 livres en 1760, — les pendules, les " bras de cheminées » qui se vendirent fréquemment à partir de $176 \%$.

A cette date, on chercherait en vain, dans la déeoration peinte de tous ces produits, - qu’il s'agisse de vases, de pièces de service ou d'objets de fantaisie - les traces de l'influence orientale ou le souci d'imiter la porcelaine saxonne qui caractérisèrent longtemps la fabrication antérieure. Les pièces à fond blane devinient alor's très rares, et on tendit de 'plus en plus à employer dans l'ormementation les cartels réservés sur des fonds de couleurs vives d'une variété et d'une qualité de tons que l'on ne retrouva plus dans la suite. C'est l'époque où l'on se servit avee un égal succès du rose, du bleu de roi, du vert, du jaune, du violet, a vec l'adjonction fréquente de jeux de fonds vermicellés ou ceil de perdrix, destinés à donner au fond lui-mème toute sa valeur. Dans les cartels, les pièces de prix moyen étaient fréquemment ornées de fleurs, de guirlandes, d'oiseaux, traités dans une manière reconnaissable entre toutes par la légère diffusion des couleur's dans l'émail de la porcelaine tendre. Lorsqu'il s'agissait de pièees plus importantes, les décors se composaient généralement de paysages ou de scènes empruntées aux genres les plus divers : sujets galants où l'on sentait encore l'influenee immédiate de Boucher, motifs mythologiques, et de plus en plus scènes militaires et marines, eompositions exécutées avec une rare habileté par des artistes absolument spéeialisés dans ee genre. Les ors ajou- 
taient aux pièces leur éclat particulicr, et, travaillés en épaisseurs diverses, modelés, gravés, brunis "à l'effet », ménageaient une transition harmonieuse entre les fonds aux couleurs vives et les cartels constituant la décoration principale : loutefois cet usage des métaux précieux présentail de graves ineonvénients lorsqu'ils étaient employés sans modération, et Bachelier avait parfaitement raison d'en signaler l'usage exagéré, sur les pièces de service notamment, où le frottement ne lardait pas à faire disparaître les légers dessins tracés daus l’or.

L'habileté professionnelle des artistes de Sèves trouva une nouvelle oceasion de se manifester dans les tableaux sur plaques de porcelaine, dont le goùt se développa entre 1760 et 1770 , et à l'exécution desquels les meilleurs peintres de la Manufacture se consacrèrent à cette époque. Les premiers furent des portraits du Roi : on en trouve un livré en 1761 au due de Choiseul, un autre à une marchande l'année suivante, un troisième à Bachelier ên 1763. Ensuite apparurent des lableaux " de soldats " dont les prix atteignaient déjà de 600 à 1000 livres, puis, bientòt après, les copies directes de tableaux : ainsi le cadeau fait au roi de Danemark en 1768 comprit deux plaques, l'une d’après le Sacrifice à Pan de Pierre, l'autre d'après des Amours de Van Loo. Ce furent les premières manifestations d'un genre de décoration absolument faux au point de vue céramique et dont le goùl, malgré tout, devait persister longtemps. Jusquà nos jours les meilleurs artistes ont consacré beaucoup de talent à la peinture de véritables tableaux sur porcelaine, méconnaissant ainsi la destination réelle de cette matière.

La direction de tous les travaux de décoration demeura pendant toute cette période confiée à Bachelier, mais, à partir de 1766 surtout, son influence semble avoir été moins directe sur les artistes de Sivves, et cela pour plusieurs raisons : d'un còté sans doute, la fondation à cette date de l'Ecole gratuite de dessin qui est devenue 
l'École nationale des Arts décoratifs absorba une partie de son temps, tandis que d'autre part, à la Manufacture même, il reprenait par suite du départ de Falconet pour la Russie, la direction de la sculpture. A côté de lui, Duplessis continua à fournir les modèles et les formes, et fut en outre occupé à orner de riches garnitures, des socles en bronze ciselé et doré “ d'or moulu », les vases et les pièces d'ornement que fabriquaient les ateliers.

On penserait volontiers, en présence d'une production si intense de poreelaine décorée, que le biscuit dût tenir une place importante dans les ventes de la Manufacture. La renommée de certains des modèles composés dans cette période donnerait à penser que le goût de la sculpture en biscuit fut général, tandis que, en réalité, si l'on parcourt les livres de vente de 1760 à 1770, on est frappé de la faible quantité des pièces modelées qui entraient dans les acquisitions du Roi comme dans celles des marchands ou des particuliers. Les pièces de la période précédente élaient déjà tombées en discrédit et, lorsque par hasard on en vendait, on prenait soin d'inscrire sur les livres la mention " produits de Vincennes », leur attribuant une valeur à peine plus élerée que celle des objets de rebut. De la fabrication antérieure à 1760 , deux genres de modèles semblent avoir seuls conservé la faveur arec laquelle on les arait accueillis : ce sont d'un côté les enfants d'après Boucher et ceux d'après Falconet, modèles que leur appellation commune ne doit pas laisser confondre les uns arec les autres, ce titre s'appliquant pour Falconet aux petites figures gracieuses telles que le Flüteur, la Joueuse de guitare, la Fille au nid, la Montreuse de cornes, l'Iorogne, - et d'autre part, quelques groupes d'inspiration identique, entre autres celui du Jaloux qui resta de vente courante. La mode alla surtout aux conceptions nouvelles de Faleonet. Son oeurre personnelle, mise au point arec le coneours de certains de ses élères comme Duru qui ne resta à la Manufacture que pendant le temps où son maître y fut attaché, comme 
Le Riche demeuré au eontraire jusqu’à la fin du xvin sièele le premier modeleur de Sères, se présente sous deux formes assez différentes. On troure d'abord des petits groupes d'allure familière, le Gourmand, le Sabot cassé, la Feuille à l'envers 1760), le Buiser donné et le baiser rendu, les Trois contents, la Balançoire, la Féte du

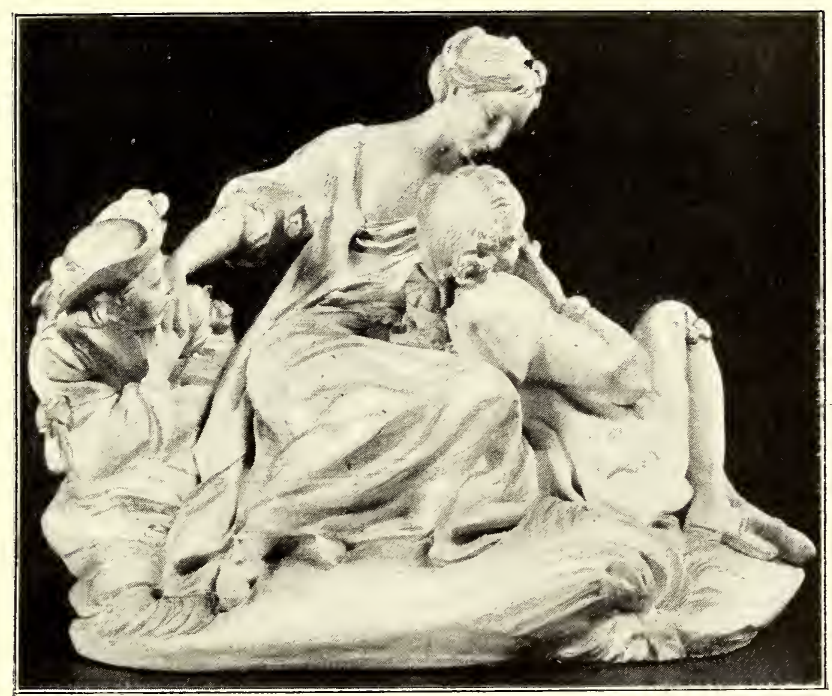

Les Trois Contents. - Modèle de 1765. (II. 0,20).

chàteau, ete., curres d'une conception gracieuse, légèrement libertine parfois, traitées dans le mème esprit quue les meilleurs modèles de la fabrication de Vincennes, mais avec une supériorité de goùt et une seience de la eomposition qui les mettent hors de pair. Puis on rencontre des modìles d'une inspiration plus élevée, au premier rang desquels il faut mettre le Pendant de l'amour de Falconet, et surtout l'admirable groupe de Pygmalion qu'une inexplicable tradition de la Manufacture a persisté à attribuer à Duru, bien que l'origine n’en soit pas douteuse, Falconet ayant exposé son Pygmalion au Salon de 1763. Dans la mème catégorie d'ouvrages, on peut eertainement faire rentrer aussi les figures d'Hébé, de Flore, et celle 
de l'Amitié où l'on a vu, sans doute avec raison, un portrait de $\mathbf{1}^{\mathrm{me}}$ de Pompadour. Un certain nombre d'œurres, moins directement inspirées peut-âtre par Falconet, parurent encore avant 1766 : le Maitre et la maitresse d'école, Annette et Lubin, plus proehes des tendanees de Boucher, enfin les Groupe de chasse, d'après Oudry. Cet ensemble d'ouvrages - assez peu nombreux en somme, puisqu'ils représentent une production moyenne de quatre modèles nouveaux chaque année - contribua certainement à assurer la supériorité artistique de Serres sur toutes les autres manufactures. Les artistes excellents à qui elle demandait ses modèles donnèrent à ceux-ci une valeur d'art à laquelle ne pouvaient être comparées les compositions sans finesse de Meissen par exemple; et d'autre part, la matière même du biscuit permettait de traduire les eonceptions les plus variées avec une délieatesse impossible à atteindre en porcelaine émaillée.

Après le départ de Faleonet pour la Russie en 1766, Caffiéri sollicita l'emploi devenu vacant. Le ministre ne prit pas de déeision immédiate, mais tinalement rendit à Bachelier la direction des ateliers de sculpture à laquelle il arait renoncé depuis dix ans. Tout en restant dans la tradition de Falconel, relui-ei apporta une variété plus grande dans le ehoix des modèles. Il eut l'idée de demander aux meilleurs artistes de son temps des réductions de leurs œurres et ainsi furent reproduits à Sèves l'Amour et le Mercure de Pigalle, l'A mour de Bouchardon, le Faune de Salis. II fit encore modeler d'après Van Loo la Conversation espagnole, composée de trois groupes principaux et d'un certain nombre de figures accessoires parmi lesquelles figure la Cantatrice du Barry. Le goût de l'antiquité qui se développait depuis quelques années devait avoir aussi son influence sur le choix des sujels, et certaines des œuvres qui parurent à Sèvres entre 1767 et 1772 marquent nettement ce retour vers le passé : en dehors des copies directes de chefs-d'ceuvre de l'art ancien tels que la 
Vènus de Médicis, la Manufacture produisit alors ces groupes si manifestement inspirés par la littérature contemporaine et qui avaient pour titre les Nymphes à la Corbeille, le groupe des Nä̈ades, le groupe des Sirènes, celui de la Naissance de Bacchus, l'autel de l'Amitié, le groupe

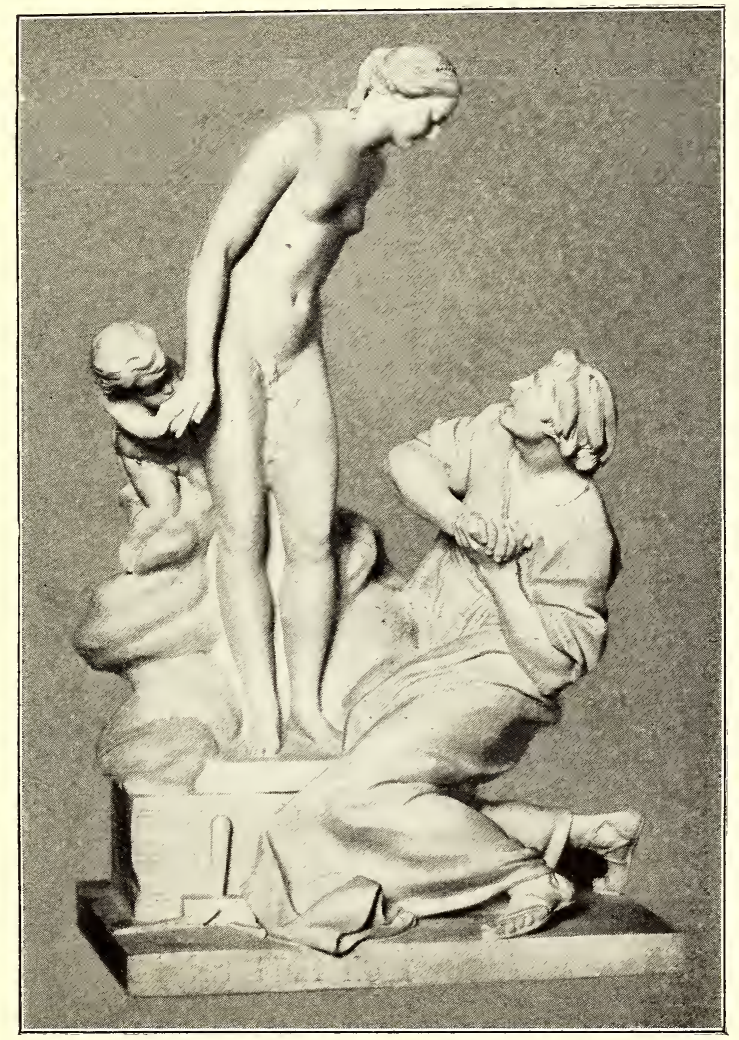

Groupe de Pygmalion, d'après Falconet. - Modèle de 1763. - H. 0,7̄. L. 0,45.

des Vestales, où la pensée antique se revèt d'une gràce toute moderne. En dehors de ces ouvrages où la ligure tient la place prineipale, le biscuit trouva un emploi nouveau dans des pièces d'ornement, dont la plus importante fut le grand surtout eomposé par Bachelier pour le banquet offert à la Cour, à l'oceasion du mariage du Dauphin avec Marie-Antoinette en 1770. C'était, d'après la deseription du Mercure 
de France, un grand portique dorique, dont le modèle fut donné par le sculpteur de Mouchy, au centre duquel s'élevait la statue du Roi d'après Pigalle, et que complétaient des groupes d'enfants et des fontaines. Sur la frise couronnant le monument, alternaient le chiffre du Roi, les armes de France, celles de l'empire d'Autriche et celles du Dauphiné. L'ensemble, de dimensions considérables, puisqu'il oecupa le centre d'une table de 10 mètres de long sur $4^{\mathrm{m}}, \breve{50}$ de large, ne comprenait pas moins de 56 colonnes, ornées de six mille cinq cent soixante-seize fleurs de poreelaine disposées en guirlandes et en bouquets aux tons éclatants. Ce surtout fut payé par le Roi 11164 livres.

Dès ce moment la Manufacture fut appelée à reproduire à un grand nombre d'exemplaires les effigies de la famille royale et des grands personnages. Trois bustes différents de Louis XV furent exécutés avảnt 1763 : un, faisant pendant avec eelui de la Reine, devait ètre dé petites dimensions, car son prix n'était que de 24 livres ; un autre, très rarement fabriqué, était l'œuvre de l'abbé de Bertin. Mais le plus important reproduisait le marbre de Lemoyne : e'est cette effigie qui semble avoir fixé tout à la fois les dimensions et le prix de tous les bustes de personnages de la Cour que la Manufacture exécuta dans la suite et qui étaient vendus uniformément 144 livres. Vers 1766 parut le buste du Dauphin, et en 1771 celui de Marie-Antoinette dont cette image charmante est demeurée comme le type idéalisé ${ }^{\text {. }}$ Le premier exemplaire de ee buste, que l'on hésite à attribuer à Lemoyne ou à Pajou, fut acquis par $\mathbf{I}^{\text {me }}$ du Barry, qui elle-mème commanda l'année suivante son effigie, d'après l'original de Lemoyne.

On a vu qu'en dehors des bustes, la statue du Roi par Pigalle avait été reproduite à Sèvres en 1770 ; avant cette date se rencontre l'indication d'une autre statue de Louis XV exécutée à Sèrres, mais

${ }^{1}$ Une épreuve ancienne de ce buste, réparée en 1852 par la Manufacture de Sèvres, est placèe dans les appartements du Putit Trianon. 
peut-ètre n'était-ce qu'une réduction de celle de Pigalle, car elle valait seulement 72 livres. Le désir de mettre en vente le portrait du Roi à un prix moins élevé que celui des bustes conduisit enfin à la fabrication courante des médaillons; celui du Roi parut en 1766, en mème temps que celui d'Henri IV : il valait 18 livres et fut remplacé quatre ans plus tard par un autre modele, sans doute plus grand, du prix de 30 livres.

Enfin deux bustes de grands hommes sortirent des ateliers de Sèrres au cours de cette période, ceux de Voltaire d'après Lemoyne et de Rameau.

Cette nomenclature un peu brève des principales variétés de la production au cours de la période qui commence au moment de l'aequisition de la Manufac-

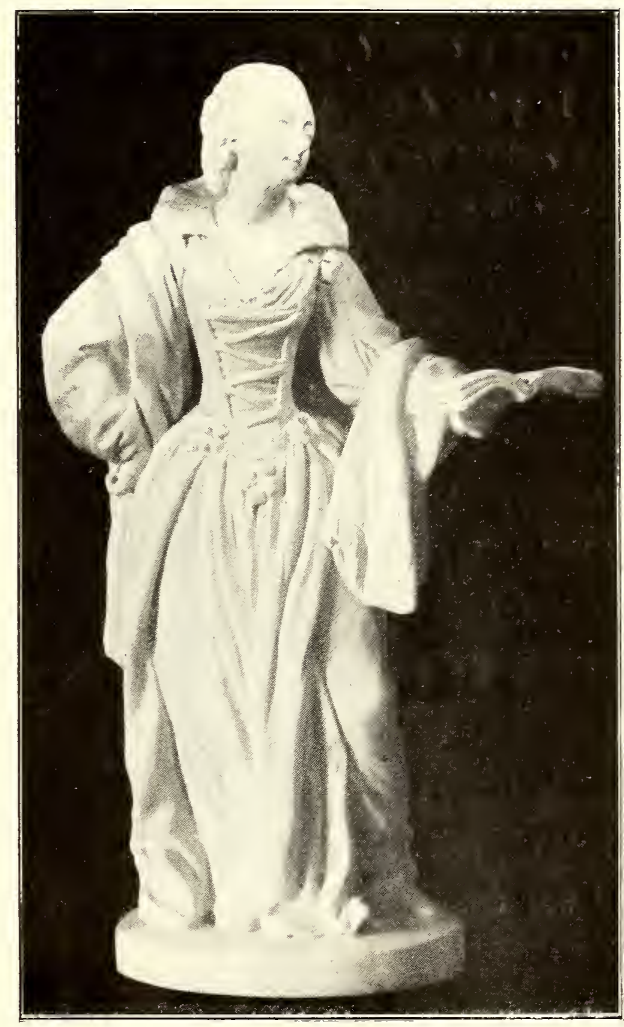

La Cantatrice du Barry. - Modile de 1772. (H. 0,23 ).

ture par le Roi, suffit pourtant à montrer quel développement et quelle richesse artistique elle atteignit à cette époque; et ces douze années constituent un ensemble d'autant plus caractéristique que la date de 1772 marque réellement le terme d'une première phase dans l'existence de la Manufacture.

Jusqu'alors, en effet, la pâte tendre fut seule employée à la fabrication de la porcelaine et du biscuit, tandis que, à partir de 1768, la 
découverte du kaolin de Saint-Yrieix vint peu à peu modifier les conditions d'existence de l'établissement par l'introduction de procédés d'exécution beaucoup plus sûr's et par l'emploi simultané, jusqu’à la fin du xviII ${ }^{e}$ siècle, de la pâte tendre et de la pâte dure.

C'est à cette époque que fut établie définitivement la composition de la pâte dure, vainement cherchée depuis tant d'années. On n’a pas oublié les sacrifices faits par la compagnie Éloy Brichard pour acquérir les secrets de la porcelaine allemande, sacrifices demeurés inutiles surtout par le fait qu'on ignorait la présence de gisements de kaolin dans le solfrançais. Des particuliers avaient poursuivi le même but de leur côté : à l'exemple du duc d'Orléans, le comte de Brancas-Lauraguais étudia en 1752 diverses terres et pensa avoir découvert le véritable kaolin aux environs d'Alençon. A Sèvres, le chimiste Macquer, adjoint depuis 1757 à Hellot, dont le ròle semble a voir été très peu actif depuis cette date, s'était appliqué inlassablement à de nouvelles expériences avec l'aide de Millot, chef des fours. Les cahiers où l'un et l'autre notaient au jour le jour leurs essais nous révèlent qu’en six années ils entreprirent plus de douze cents expériences sur des échantillons de matières qu'on leur adressait ou sur des mélanges qu'ils espéraient toujours plus semblables à la porcelaine véritable.

D'autre part, le ministre Bertin et le directeur Boileau n'avaient pas renoncé à enrichir la Manufacture des procédés de la pâte dure par le coûteux moyen des achats de procédés. Dans un rapport daté de 1759, Boileau avait insisté à nouveau sur l'intérèt que présenterait la porcelaine dure pour la fabrication des pièces de service, tandis que la pâte tendre « servirait à la partie de l'art, de la perfeetion et " du goût », et il avait signalé la porcelaine de Frankenthal comme réunissant les qualités les plus nécessaires de résistance à la chaleur, de simplicité de composition, de facilité de travail et de cuisson. Justement, en 1760, Paul-Adam Hannong, avee qui l'on n'avait pu 
s'entendre en 1793, mourut en laissant deux fils : à l'aìné revint la Manufacture de poreelaine de Frankenthal, tandis que le seeond prenait la direction des faïenceries conservées par son père à Strasbourg et à Haguenau. Certaines difficultés s'étant élevées entre les deux frères, M. Bertin pensa qu'il y avait peutêtre là une oecasion d'aequérir à bon compte le secret tant convoité, et, sans plus tarder, il enjoignit à Boileau de se rendre à Frankenthal pour engager des pourparlers avec l'aìné des Hannong. Celui-ci, ou bien ne voulut pas se dessaisir de son secret, ou bien émit des prétentions exagérées. Boileau revint vers Strasbourg sans avoir rien conclu, mais il rencontra dans cette ville le second fils, Pierre-Antoine Hannong, qu'il n'eut pas de peine à séduire et qui s'engagea à

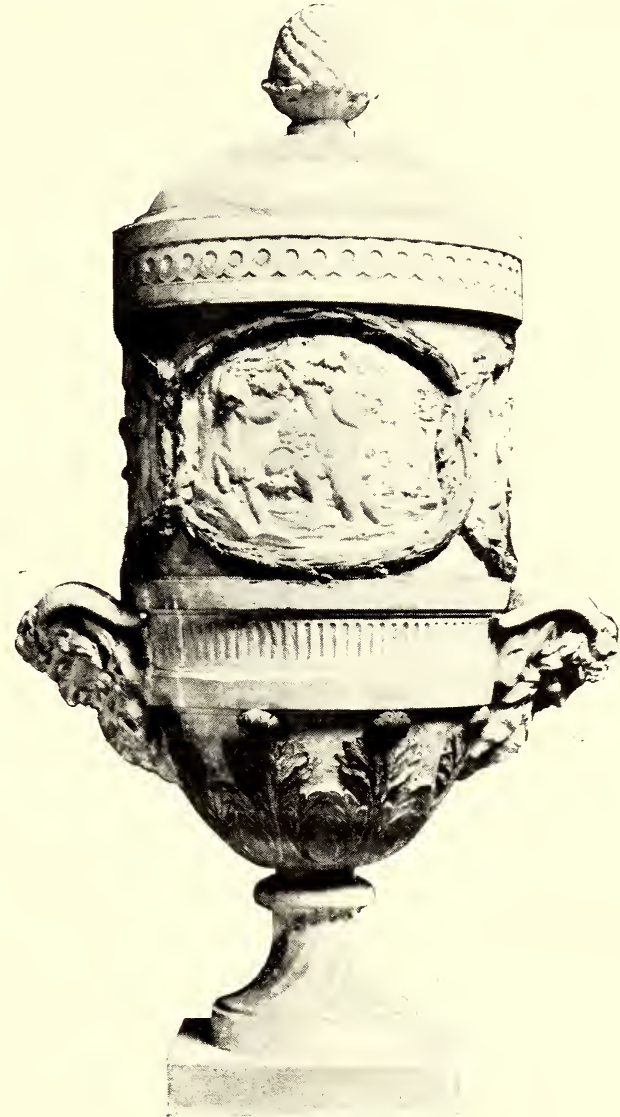

Vase des Saisons (H. 0,7วั). Modèle de Bachelier (1767). vendre au Roi les secrets de Frankenthal, moyennant une somme de six mille livres eomptant et une rente viagère de trois mille livres. Une convention fut passée avec lui aux termes de laquelle il devait venir à Sèvres faire l'essai de ses procédés en présence d'Hellot et de Maequer, chargés d'en consigner la description sur les registres de la Manufaeture. Hannong se mit une première fois 
en route au mois d'août 1760 , mais une série de démêlés avec son frère, la saisie des terres expédiées par lui de Strasbourg avant son départ, la vente enfin de la Manufacture de Frankenthal à l'Électeur Palatin ne lui permirent pas de faire avant 1763 des expériences concluantes. A cette époque, il remit à Boileau un cahier contenant les secrets de la porcelaine dure, avee les indications nécessaires à la construetion des fours et à la préparation des couvertes et des couleurs. Cela ne l'empêcha point de poursuivre des essais au terme desquels, deux ans phus tard, un procès-rerbal fut dressé, constatant qu’il “ n’avait pas une connaissance exacte des secrets, eompositions et manipulations ». Pourtant ses indications devaient avoir une cerlaine valeur, car le Roi lui accorda, en juin 1763, une rente viagère de 1200 livres, pour témoignage de la " satisfaction de ses travaux dans la Manufacture de poreelaine de Sèvres ». Ces expériences avaient coûté à l'établissemènt royal plus de 14000 livres.

D'un autre côté, au moment mème où Hannong achevait ses travaux, M. d'Aigremont, ambassadeur de France à Coblentz, prévenait Bertin qu'un Saxon, alors directeur de la manufacture de Kelsterbach, se montrait disposé à apporter à Sèvres ses procédés de fabrication. II. de Courteille, consulté sur le point de savoir l'intérêt que pouvait présenter cette proposition, manifesta dès l'abord à l'égard de cette offre une défiance justifiée. Malgré son avis, on appela cet étranger; et ainsi l'on vit arriver à Sèvres, en août 1764, Busch qui, dix ans plus tôt, avait vécu aux dépens de la Manufacture pendant plus d'une année, sans lui apporter les secrets dont il se prétendait dépositaire. Il reçut un accueil peu encourageant; pourtant on l'autorisa à faire, à ses frais, des essais dans l'établissement. Il construisit d'abord un four, puis, sous prétexte d'attendre des matières premières qui n’arrivèrent jamais, il trouva le moyen, malgré les résolutions prises, de vivre encore quelques mois des subsides de la Manu- 
facture. Ses essais n’eurent pas plus de résultats que ceux de 1733.

En réalité la difficulté à laquelle on se heurtait était toujours la mème et les tentatives de ce genre ne pouraient ètre couronnées de succès. Les fabricants allemands n'apportaient que des formules connues depuis longtemps, tandis que le véritable but des reeherches devait être la découverte dans le sol français des matières premières de la porcelaine. Certaines personnes, il est vrai, étaient eonvaincues d'avoir trouvé des gisements de kaolin et de petunsé au centre mème de notre pays : la preure en est dans la eurieuse diseussion qui éelata en 1764 entre le comte de Brancas-Lauraguais et le géologue Guettard, aneien collaborateur du due d'Orléans. II. de Lauraguais ayant fait à eelte époque une série de communications à l'Académie sur la porcelaine qu’il avait fabriquée avee des matières premières provenant de Maupertuis, près d'Alençon, et l'Académie ayant reconnu que sa poreelaine "était aussi belle que celle du Japon s, Guettard protesta contre l'affirmation par laquelle II. de Lauraguais s'attribuait la priorité de déeouverte du kaolin français. Il prélendit avoir établi dès 17300 l'identilé des terres de Maupertuis avee les échantillons que le due d'Orléans a vait fait venir d'Extrème-Orient et il assura avoir fait part de cette découverte à l'Académie dès ce moment. La question ne fut jamais complètement élueidée; toutefois on peut penser que Guettard a vait effectivement trouvé assez tòt les gisements de Maupertuis sans avoir su en tirer un parti satisfaisant, tandis que M. de Lauraguais parvint avec les mèmes matériaux à fabriquer une porcelaine de qualité inférieure, mais présentant beaucoup des caractères de la véritable porcelaine. A la mème date, Macquer prétendit, lui aussi, avoir fabriqué à Sèvres une poreelaine aussi belle et résistante que celle de Itannong avee des produits naturels uniquement français : il en envoya des éehantillons à II. de Courteille, en lui demandant que les registres relatant ses expériences soient 
déposés dans l'armoire des secrets de la Manufacture, et en sollicitant de plus l'autorisation de faire connaître sa découverte à Boileau et à Villot, afin qu’en toute concurrence le bénéfice en soit assuré à la fabrique royale.

Ces essais, ces recherches actives, le mémoire lu par Guettard à l'Académie sur la découverte " faite en France des matières propres " à faire de la porcelaine », eurent du moins le grand avantage de diriger les travaux dans la voie où ils avaient chance d'aboutir, et d'encourager les fabricants provinciaux à introduire le kaolin dans leur fabrication. Beaucoup de ceux-ci pensèrent bientôt avoir atteint le but, et de nombreuses demandes d'autorisation de fabriquer la porcelaine - entre autres, celle de Sary à Marseille et celle de Hannong qui, après son échec à Sèvres, a vait obtenu de s’installer dans les bâtiments de l'ancienne Manufaeture royale à Vincennes - attirèrent l'attention de Bertin sur l’interprétation généralement erronée que l’on donnait de l'arrêt de 1760 , concernant le privilège de la Manufacture. Dans un esprit libéral que l'on ne saurait trop louer, il entreprit la rédaction d'un arrêt nouveau, spécifiant que tous les fabricants avaient le droit de fabriquer de la porcelaine et que le privilège de la Manufacture s'appliquait seulement à la sculpture et aux ourrages dorés ou peints de couleurs variées. Ses idées sur l'utilité d'un établissement comme celui de Sèrres nous sont connues par la réponse qu'il fit à $\mathbf{M}$. de Laborde, valet de chambre du Roi, qui avait pensé lui faire sa cour par un mémoire sur les moyens de rendre la Manufacture Royale productive. "De toutes les pro" positions cy-contre, dit-il, il n'y a donc rien qui puisse être d'une " certaine utilité à l'objet d'État que le Roy se propose en montant " et entretenant une pareille Manufacture, que celuy de cuire dans " un four des trois quarts moins dispendieux. Mais quand le Roy “ l'aurait aujourd'huy, ce serait pour perfectionner le modèle de "fabrication que son intention est de donner, mais ce ne serait 
" pas pour en faire un objet de profit; ce point de vue contrarie" rait au contraire les vues que le Gouvernement s'est proposé, en " ce que le Roy concentrerait dans sa Manufacture les gains et les " profits d'un commerce « qui n'est fait que pour “ ses sujets; plus il retar“ derait l'établissement " de cette fabrication en “France, plusil découra" gerait tous ceux de ses " sujets qui tenteraient de " s'y adonner. Ceux qui " sont chargés de la Ma" nufacture de Sèvres et " qui la conduisent pour " le Roy doivent done " chercher à la perfec"tionner sur tous les " points, mais ils doivent " en même temps encou" rager les établissements " de pareille manufacture " partout où on voudra " en entreprendre, loin

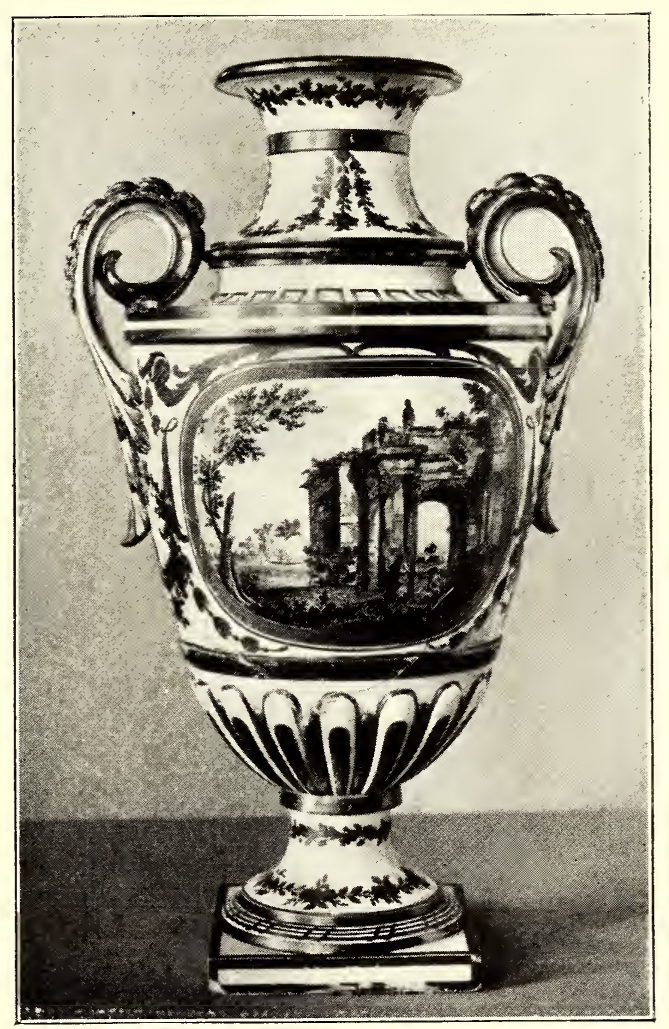

Vase en porcelaine dure. (Haut. 0,48). Décor de Philippine (1776). - Musée de Sèvres, nº 8081.

" de les gêner ou empêcher. Ce point de vue est une base dont " il ne faut jamais se départir et elle est telle que, quand mème " le Roy pourrait se flatter de fournir de ses Manufactures toute " la porcelaine à l'Europe, il devrait laisser cette branche de " commerce à ses sujets avec tous les autres. " Un arrêt fut rendu le 15 février 1766, en conformité avec les vues de Bertin, pour aider au développement des fabriques de porcelaine dans le royaume 
" où l'abondance des matières qui se trouvent propres à cette fabri" cation semble si favorable à l'industrie ». Cette décision renouvelait l'autorisation de faire les porcelaines à l'imitation de la Chine " avec des pàtes composées de telles matières que les entrepreneurs "desdits ouvrages jugeront à propos »; mais elle imposait aux fabricants l'obligation de " peindre, graver ou imprimer au revers de " chaque pièce les lettres initiales de leur nom ou toute autre marque " dont ils auront fait le dépôt entre les mains du Lieutenant de Police. " La décoration en couleur et en or, la sculpture restaient réservées à la Manufacture Royale en exécution “ des privilèges que la supério" rité de ses ouvrages lui a mérités ». Copie de cet arrêt fut adressée à lous les Intendants du royaume avee un certain nombre d'exemplaires du mémoire de Gucttard, destinés à faire connaître de tous côtés les caractères des argiles propres à la fabrication de la poreelaine.

Malgré les termes de cet arrêt qui considérait la question de la découverte de la pàte dure comme résolue, la Manufacture, aussi bien que les fanricants, fut forcée de reconnaître que les produits obtenus avec les terres de Maupertuis étaient fort inférieurs comme qualité et surtout comme beauté à la porcelaine japonaise ou allemande. Les recherches continuèrent donc, aussi actives que par le passé, et, à Sèvres notamment, une nouvelle impulsion leur fut donnée par M. de Montigny qui succéda à Hellot, décédé en 1767.

Cependant les expériences antérieures, la certitude que tout le secret résidait dans la pureté des argiles blanches employées pour la porcelaine, n’empèchèrent pas Bertin d'accueillir encore une fois avec confiance les offres de procédés que lui firent en 1767 Limprunn, directeur de la manufacture de Nymphenbourg et le comte de Gronfeld, propriétaire de la poreelaine de Weesp, en Ilollande. Le premier entra en relations avec le ministre par l'intermédiaire de l'agent diplomatique français à Munich, Iubert de Folard, qui envoya à 
Sèvres divers échantillons de porcelaine kaolinique; ceux-ci furent soumis à Macquer et à de Montigny qui déclarèrent cette matière aussi belle que la porcelaine de Frankenthal, mais dénoncèrent en même temps comme inutile l'achat de cetle composition, si Limprunn ne pouvait indiquer où trouver en France les matìres premières nécessaires à sa fabrication. Des raisons du mème ordre firent repousser par la Manufacture les propositions du comte de Gronfeld qui désirait vendre au Roi son usine de Weesp : il avait envoyé à Sèrres son directeur, un sieur Picot qui, lui aussi, fit en présence des chimistes des essais coneluants. Macquer saisit. cette occasion pour demander que l'on ne consacràt plus d'argent à l'acquisition de procédés, mais que bien plutòt on encourageât les naturalistes à rechercher en France les terres dont

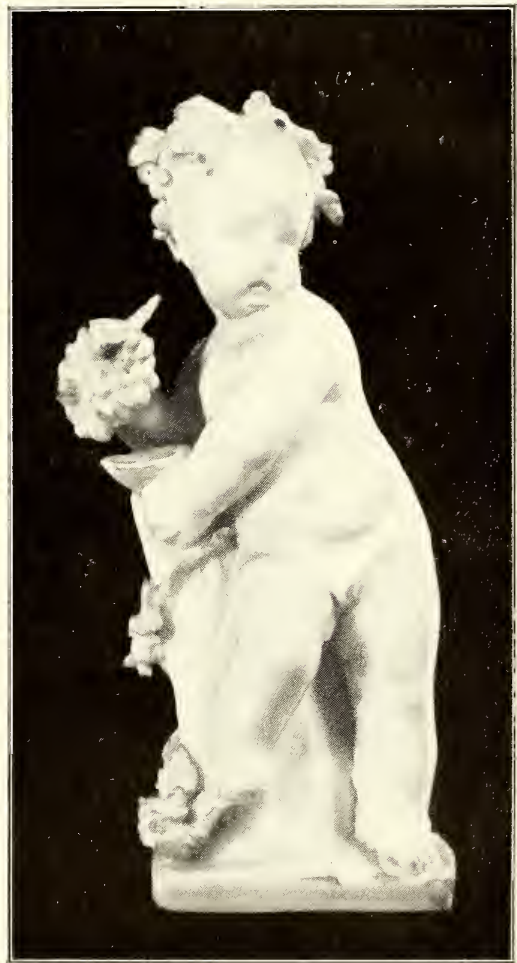

Bacchus enfant (H. 0,08). '- Premier essai de porcelaine dure émaillée (1760̈). (Musée de Sèvres, n 1830.) on avait besoin : e’était, à n'en pas douter, la voie la plus sùre pour parvenir au but et bientòt la découverte des gisements de Saint-Yrieix allait lui donner pleinement raison.

Si l'on s’en rapporte au réeit de Millot, l'archevèque de Bordeaux, lors d'une visite faite à la Manufacture en 176:3, s’était vivement intéressé aux recherches si patiemment poursuivies par les chimistes de la maison sur la fabrication de la porcelaine dure. Hacquer qui 
ne négligeait aucune occasion d'étendre ses investigations pour atteindre au but lui confia un fragment de kaolin chinois, en le priant d'examiner s'il ne trouverait pas d'argile de même nature dans l'étendue de sa résidence. Revenu à Bordeaux, l'archevêque n'oublia pas la demande de Macquer et chargea de cette enquête un apothicaire de la ville, nommé Villaris, qui connaissait bien la constitution géologique de la région. Celui-ci, muni du précieux échantillon, parcourait, sans succès d'ailleurs, les Cévennes et les Pyrénées, lorsqu'il eut l'idée d'adresser un fragment de kaolin à un chirurgien du Limousin qui était de ses amis, le chevalier Darnet, établi à Saint-Y rieix. Celui-ci ne tarda pas à lui faire parvenir quelques livres d'une terre identique, comme aspect, à l'échantillon. Expédiée à Sèvres, lavée, amalgamée à deux autres corps que Millot se garde bien d’indiquer dans son mémoire, l'argile de Villaris se transforma après euisson en une porcelaine, immédiatement reconnue en tous points semblable à celle du Japon : la première pièce de porcelaine dure sortie des ateliers de Sèves fut un petit Bacchus émaillé que l'on conserve précieusement au Musée Céramique.

Le problème était résolu, et il semble que rien ne devait plus manquer à la Manufacture pour établir définitivement la fabrication de la porcelaine nouvelle. Pourtant de nouvelles difficultés surgirent, lorsque Boileau roulut se procurer des quantités de kaolin plus considérables. Villaris, en effet, avait pris grand soin de laisser ignorev l'endroit d'où il avait extrait la précieuse argile et il se refusa à l'indiquer, avant qu'on lui eût assuré la récompense à laquelle il jugeait avoir droit pour sa découverte. Les pourparlers furent longs et, pour mettre fin à celte situation, Bertin déeida d'envoyer Macquer et Millot eux-mêmes en Gascogne et en Guyenne à la recherehe des terres. Ils se mirent en route le 22 août 1768 , emportant avec eux un certain nombre d'échantillons du kaolin, de la pâte et de la couverte employés à Meissen, destinés à leur servir de points de 
comparaison. Aux différentes étapes de leur voyage, à Orléans, à Blois, à Tours, à Angoulême, ils remirent des fragments de ces diverses matières aux géologues des régions traversées, promet-

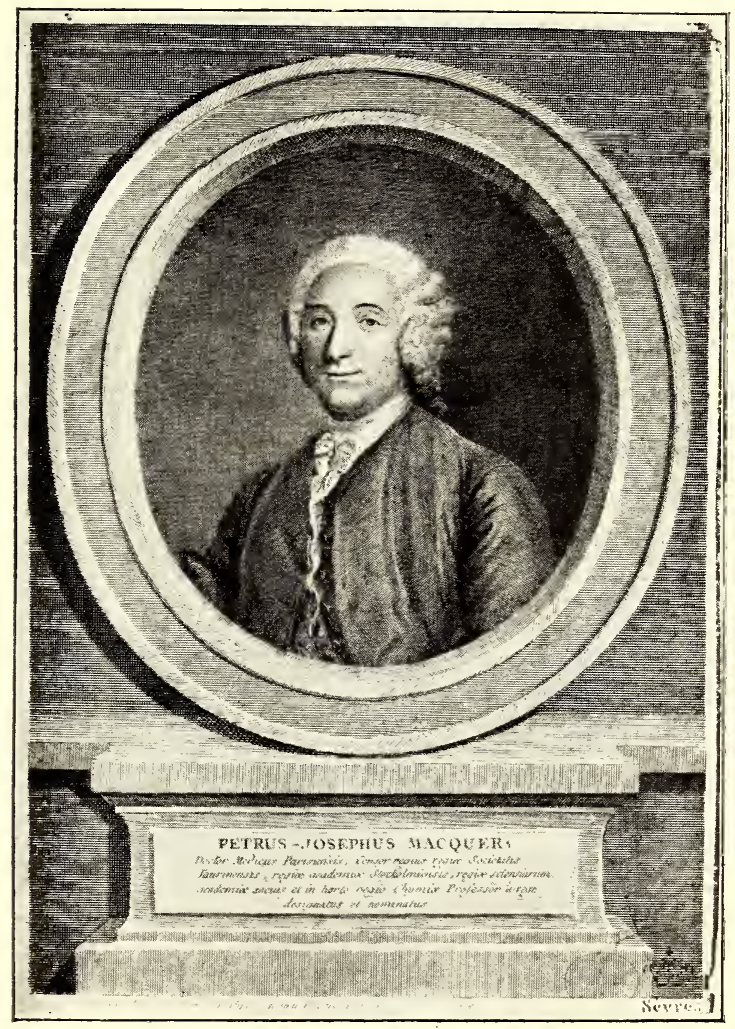

Portrait du chimiste Macquer (1718-178ł́). (Bibliothèque de la Manufacture.)

tant une récompense à ceux qui leur présenteraient des produits de même nature au moment de leur retour. A Bordeaux, Villaris persista dans sa méfiance et Macquer dut attendre pendant plusieurs jours la décision du ministre à qui il avait demandé quelle somme il pouvait promettre à Villaris en échange de ses indications. La réponse de Bertin fut catégorique : toutes relations devaient ètre immédiatement rompues avec l'apothicaire, et Macquer était invité à 
entreprendre par lui-mème, aux environs de Bordeaux et de Bayonne, la recherche des gisements de kaolin.

Les deux envoyés de la Manufacture Royale se rendirent tout d'abord à Biarritz, et ils y passèrent huit jours en courses inutiles; de là ils se dirigèrent vers Dax où leur séjour dura un mois. Le récit de leurs expériences dans cette petite cité pyrénéenne témoigne des difficultés qu'ils rencontrèrent à chaque pas, et il leur fallut certes une grande persévérance pour arriver à un résultat : c'est ainsi qülls navaient à leur disposition pour cuire leurs essais qu'une forge rudimentaire de serrurier! Cependant une terre des environs leur ayant paru satisfaisante, ils reprirent le chemin de Bordeaux, munis de nombreux échantillons et d'une quarantaine de livres de l'argile qui leur avait donné de bons résultats. Ils revirent alors Villaris "qui, raconte Millot, sest trouvé bien sot de " voir après son refus que nous avions trouvé le kaolin comme lui; " il n’était pas si fier que lorsque nous sommes arrivés à Bordeaux; “ il nous a offert tous ses services et mème qu’il allait nous conduire " sur le lieu où était le kaolin, en disant que le ministre lui donne" rait ce qu il voudrait pour ses peines ". Ils se rendirent done à Saint-Yrieix, se dissimulant autant que possible afin de n'ètre pas aperçus de Darnet, a vec qui Villaris ne tenait pas à partager la récompense tant convoitée. Par des chemins encaissés, ils purent atteindre sans être vus le champ où se trouvait le kaolin; mais, tandis qu'ils fouillaient la terre, le propriétaire survint et, afin d'éviter un mauvais parti, Macquer fut contraint de faire eonnaitre la mission dont il était chargé pour la Manufacture du Roi. Tout s'arrangea alors : après avoir expédié à Sèvres 400 livres de terres " tout ce qu’il y avait de plus blane », Macquer et Millot reprirent le chemin de Paris; ils étaient rentrés à la Nanufacture le 8 novembre 1768.

La matière première définitivement conquise, les études portèrent sur la facon de cuire la porcelaine dure et un temps assez long se 
passa encore avant l'établissement d'un four construit de façon à obtenir une égale répartition de la chaleur en tous les points. C'est en juin 1769 seulement que Macquer el de Montigny déposèrent à l'Aeadémie un mémoire où, après avoir rappelé leurs longues expériences et les résultats incomplets qu’ils avaient précédemment

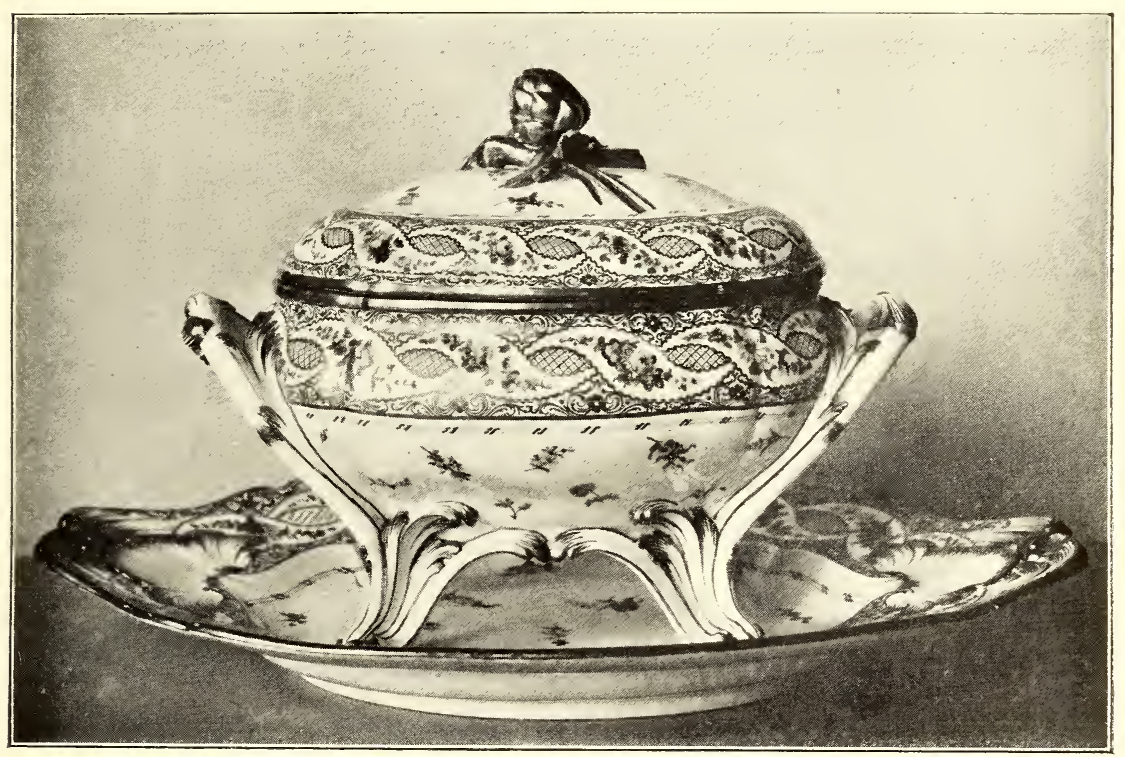

Soupière et son plateau en porcelaine tendre. - Décor de Le Bel jeune (1772). (Long. 0,48) (Musée de Sèvres, no 4408).

obtenus, ils résumaient ainsi les principaux caractères de la nouvelle porcelaine: “ Elle est entièrement et uniquement composée de maté" riaux qui se trourent en France. Il n’y a dans sa pàte et dans sa " couverte aucune fritte, aucun sel, rien qui vienne du plomb, ni d'au" cune autre matière métallique ou saline... Elle se travaille égale" ment bien sur le tour à la manière des poteries communes et dans " les moules où elle est susceptible de prendre toutes les formes " qu'on reut lui donner. Elle ne peut être euite qu’à un feu de la der" nière violence el la couverte exige le mème degré pour se fondre... 
"Elle est infusible au plus grand feu des fourneaux et peut servir de " creuset dans lequel on vitrifie complètement toutes les porcelaines " de fritte et de marne... Elle résiste aussi bien qu'aucune des porce" laines connues de la plus excellente qualité à l'impression subite " et alternative du chaud et du froid...; sa blancheur et sa demi-trans" parence sont pour le moins égales en beauté à ces mêmes qualités " dans les porcelaines de l'ancien Japon et de la Saxe... "

Duhamel du Monceau et Jussieu, chargés de faire subir à la porcelaine de Sèvres diverses épreuves, rendirent compte peu de jours après à l'Académie des résultats de leur enquête : après avoir reconnu l'exactitude des allégations de Macquer, ils avaient constaté que sa porcelaine "fait feu avec le briquet eomme un silex; elle " résiste au feu au point de servir de creuzet pour fondre et vitrifier " l'ancienne porcelaine de Sèvres; qu'elle va au feu sans se rompre, " qu'elle passe de mème, sans soutfrir aucune altération, du chaud " au froid ». Et ils ajoutaient : "Encore une chose très intéressante " pour le bien public, c'est que les travaux qu'on a faits sur la " porcelaine mettent sur la voye d'en faire à un prix modique, " de moins belle à la vérité que celle de Sèvres, mais qui aura toute " la solidité qu'on peut désirer. ”

La nouvelle porcelaine, qui reçut le nom de porcelaine royale (le titre de porcelaine de France continuant à désigner la pâte tendre), fut présentée au Roi à l'exposition annuelle de Versailles, en décembre 1769. "Le jour de la Saint-Thomas, raconte Macquer, à huit " heures du matin, je suis parti avec M. de Montigny pour Versailles. "A onze heures et demie, M. Bertin qui était allé ehez le Roy nous " a envoyé chercher pour nous eonduire dans les appartements où "l'on avait exposé la porcelaine de Sèvres comme à l’ordinaire, et " sur une table était la nouvelle poreelaine, toute en blanc et or... Il " y avait là une casserole de la même matière qui était sur un réchaud "à l'esprit de vin dans laquelle l'eau commençait à bouillir. Mais 
"elle s'est cassée un instant après, en présence de Sa Majesté qui “ s'est mise à faire un éclat de rire en reculant et nous disant : "Mon“ sieur! Monsieur! » Après quoi, elle est sortie pour aller à la messe... » Ce petit accident bouleversa Maequer; par bonheur, Louis XV devait, pour revenir de l'office, suivre le même chemin; à son retour, l'expérience fut tentée à nouveau devant lui et, cette fois, elle réussit pleinement.

A l'époque d'ailleurs où la poreelaine dure parut pour la première fois à Versailles, on était bien certain à la Manufacture, malgré la lenteur des reeherehes, de l’identité absolue de la pâte fabriquée à l'aide du kaolin de Saint-Yrieix avee la porcelaine orientale. La preure en est dans l'acquisition décidée, au cours de l'année 1769, des terrains où Darnet avait découvert les gisements : la rente, enregistrée au nom de Villaris, assura au Roi moyennant 3000 livres la propriété des terres de $\mathbf{I}^{\mathrm{me}}$ du Montais, à Saint-Yrieix. Cette mème année et la suivante, Villaris reçut la récompense qu'il avait, à tant de reprises, eru voir échapper : 15000 livres versées en plusieurs fois. Alors s'organisa enfin la préparation régulière de l'argile qui devenait nécessaire à la Manufacture: la surveillanee de l'exploitation, de l'extraction, du lavage sur place et de l'acheminement vers Sèvres des matières premières, fut eonfiée à Darnet à partir de 1770 , moyennant des appointement annuels de 600 livres.

C'est done à partir de 1770 seulement que la porcelaine dure cessa d'ètre un objet d'études pour devenir de fabrication industrielle; et, si l'on y regarde de près, il faut mème arriver jusqu’à 1772 pour trouver, dans les ateliers de la Manufacture, une organisation régulière, capable de produire en quantité appréciable la nouvelle porcelaine ${ }^{1}$. On ne doit done pas hésiter à reeonnaître que, si Sèvres fabriqua, dans la suite, des pièces indiscutablement supérieures à

\footnotetext{
${ }^{1}$ C'est à cette époque que parurent les premiers biscuits de pâte dure, dorés sur. biscuit : un groupe de Castor et Pollux, deux Divinités et un groupe de Fontaines, surmonté de l'Amour Falconet.
} 
celles des autres établissements, il serait injuste de la considérer absolument comme une devancière; car, à la date où la production de la porcelaine dure y devint courante, d'autres fabriques en offraient déjà depuis quelque temps au public. On a vu que l'arrèt de 1766 avait provoqué de nombreuses demandes de privilèges particuliers s'appliquant à la fabrication de la porcelaine dure. Hannong, il est vrai, fut forcé, cette année-là même, sur la demande de Boileau se plaignant qu’il débauchait les ouvriers de la Manufacture Royale, d'abandonner son établissement de Vincennes; mais sa fabrique persista, et sous la direction de Maurice des Aubiez, passa aux mains du comte de Laborde, déjà possesseur de la Manufacture de Vaux. Cette mème manufacture ne craignit pas en 1769 d'entrer en lutte directe avec Sèvres, par l'autorisation que sollicita son propriétaire " de fabriquer de la sculpture en biscuit, peinte en couleurs variées " et ornée de filets d’or ». Boileau protesta avee énergie contre cette prétention, accusant, avec quelque raison peut-être, M. de Laborde de s'être procuré le secret des compositions de Sèvres, grâce à la trahison d'un compagnon de Macquer pendant son voyage à travers le Limousin. La demande de M. de Laborde ne fut pas accueillie, mais elle montre que, dès cette époque, la Manufacture de Vaux fabriquait de la porcelaine dure semblable à celle de Sèvres. Elle n'était pas la seule : à Orléans, à Paris même, au Gros-Caillou, à Niderviller, s'étaient établies avant 1770 des usines ayant pour objet la fabrication de la porcelaine kaolinique. D'autre part, des dérogations commencèrent alors à ètre admises au privilège de la Manufacture Royale, telles que l'autorisation accordée en 1769 à Cyfllé, le fabricant de Lunéville, de faire de la figure avec ce qu’il appelait “ la pâte de marbre », à la seule condition que ses ouvrages continueraient à ètre vendus sous la dénomination de «terre-cuite ». En 1771, enfin, s'ouvrit à Limoges la manufacture de Grellet et Massié。 
A dire vrai, l'arrêt de 1766 et la découverte du kaolin de Saint-Yrieix, en ourrant un large champ d'action à l'industrie française, allaient peu à peu enlever toute valeur aux privileges de la Manufacture Royale; et l'on peut, des 1772 , entrevoir les premiers aetes de la lutte incessante qu'elle eut à soutenir jusqu'à la fin du xrin ${ }^{e}$ siècle pour la défense de ses droits. T'outefois, il faut reconnaître qu’elle étail à cette époque dans un état de singulière prospérité. Riche, malgré les malversations du caissier Schonen qui eut le tort de convertir en prescriptions une somme de 286133 livres appartenaut à l'établissement, elle fabriquait la plus belle poreelaine connue el elle possédait enfin la formule de la porcelaine orientale. Ses décorateurs, ses sculpteurs faisaient preuve d'un goût el d'une habileté incomparables. Il semblait qu'elle n'eût plus qu’à profiter de l'expérience acquise et à vire sur sa réputation. Pourtant lheure la plus brillante de son histoire s’acherait; l'ineapacité, l'avidité de sess administrateurs, jointes aux éléments de décadence que l'on voit déjà apparaître, devaient bientòt la faire déehoir de la situation éminente qu'elle avait eonqquise.

Boileau mourtit à la fin de 1772. Aussitôt son suceesseur Parent, chargé depuis longtemps dans les bureaux de II. Bertin de tout ce qui eoncernait la Manufacture, vint à Sèves pour " la recherche et " perquisition des cahiers el papiers où sont transerits les secrets et "procédés de la pàte de porcelaine el des couleurs lines et autres " achetées de différents particuliers, et transportés au dépôt des "Archives par le sieur Hellot et sous son eachet. Il devra, après " inventaire, les remettre audit dépòt, dans le coffre de fer à ee "destiné ». Cette besogne accomplie, Parent prit possession de son nouvel emploi. 


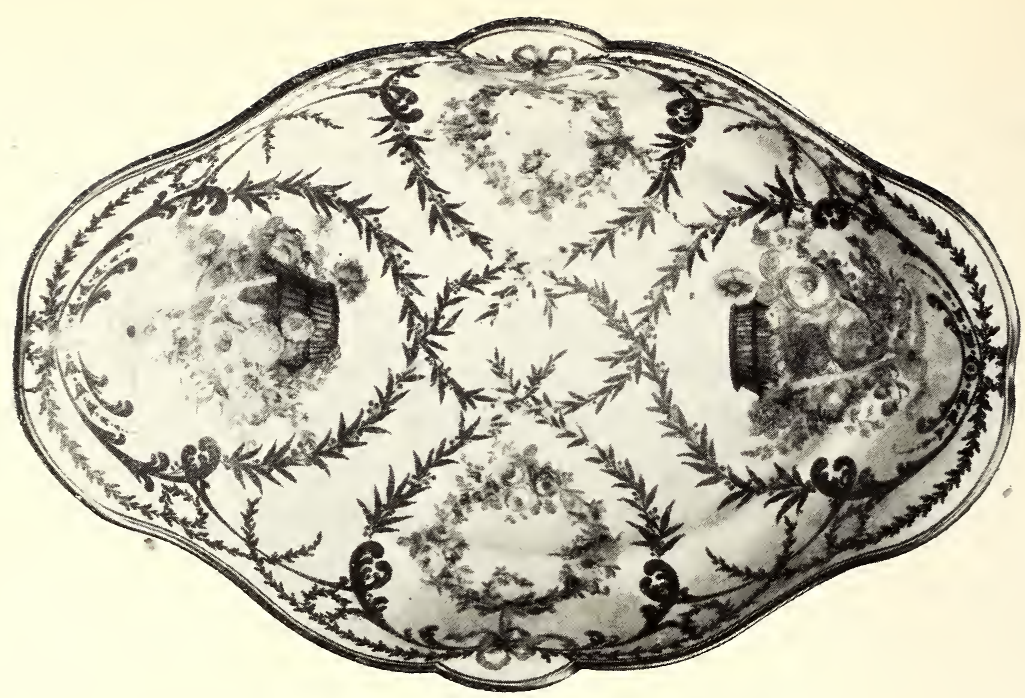

Cuvette en porcelaine dure. - Décor de Dubois (1777).

(Musée de Sèvres, nº 9ö68.)

\begin{abstract}
IV
LA MANUFAGTURE DE 1772 à 1789 : DIREGTIONS PARENT ET RÉGNIER. L'INFLUEINGE DE D'ANGIVILLIERS
\end{abstract}

Parent, lorsqu'il fut appelé à la succession de Boileau, était dès longtemps au fait de l'administration de Sèvres par l'emploi de premier commis " chargé de tout le détail des affaires concernant la Manufacture » qu'il oceupait dans les bureaux de Bertin. Il prit d'abord le titre d'Intendant avec des pouvoirs beaucoup plus étendus que ceux de son prédécesseur, puis, profitant de la confiance absolue que Bertin avait en lui, il fit accorder à son fils le poste de premier commis devenu vacant. Cet arrangement explique l'absolue liberté arec laquelle il put se livrer, pendant plusieurs années, à des malversations éhontées, sans qu'aucun avertissement ait été capable d'ouvrir les yeux du ministre sur l'infidélité de son agent.

Son administration se signala par un effroyable gaspillage dont il est mème difficile de mesurer l'étendue, par suite de la suppression 
de toute comptabilité régulière qu'il imposa à la Manufacture. Pour opérer sans eontrôle, il commença par éloigner tous les anciens employés dont la présence aurait pu le gèner, et il donna la place de caissier à un nommé Roger, très probablement fils de l'agent sous le nom duquel il se livrait à des affaires louches, jeune homme incapable à ce point de gérer une comptabilité qu’il ne put établir avant 1776 le compte de l'année 1773. Alors les dépenses du directeur se multiplièrent et, tandis que sous Boileau elles n’atteignaient pas 10000 livres, elles en coùtèrent bientòt 100000 . Un des procédés les plus courants de Parent pour se créer des ressources illieites était d'inserire sur les états mensuels de paiement le ehiffre intégral du salaire de chaque ouvrier et d'en retrancher, à l'heure de la paye, la valeur des absences faites par celui-ci dans le mois échu. Avec de telles pratiques, si l'on considère que l'emploi d'Intendant représentait une trentaine de mille livres de revenus réguliers, on s'explique sans peine que Parent se soit trouvé à la tète d'une fortune mobilière considérable. Peut-être ses malversations auraient-elles pu se prolonger longtemps eneore, s'il n'avait eommis l'imprudence d'engager les fonds de la Manufacture dans des spéculations hasardeuses. Lorsqu'en 1778, on examina entin sa gestion el celle du caissier Roger, ils furent accusés de faux, de banqueroute, de soustractions d'effets, incarcérés à la Bastille et reconnus solidairement redevables d'une somme de 247000 livres qui manquait dans la eaisse : depuis un an et demi, les artistes principaux, les chefs d'atelier', les fournisseurs n’avaient touché que de faibles acomptes!

Cela eréait une situation singulièrement difficile à Régnier qui, contrôleur de la Manufacture depuis 1774, fut appelé à la direetion le 20 décembre 1778. A còté de lui, Bertin nomma caissier un nommé Barrau, dont la mission première fut de faire rentrer au plus vite les fonds nécessaires au payement du personnel qui faisait entendre des plaintes de plus en plus vives. 
Cette mauvaise gestion fut d'autant plus regrettable qu'à certains points de vue Parent fit œurre utile. Ainsi l'on doit reconnaître l'heureuse impulsion qu’il donna à la Manufacture en organisant de façon définitive la fabrication de la pâte dure. Celle-ci, établie depuis trois ans déjà, s'était trouvée arrêtée dans son développe-

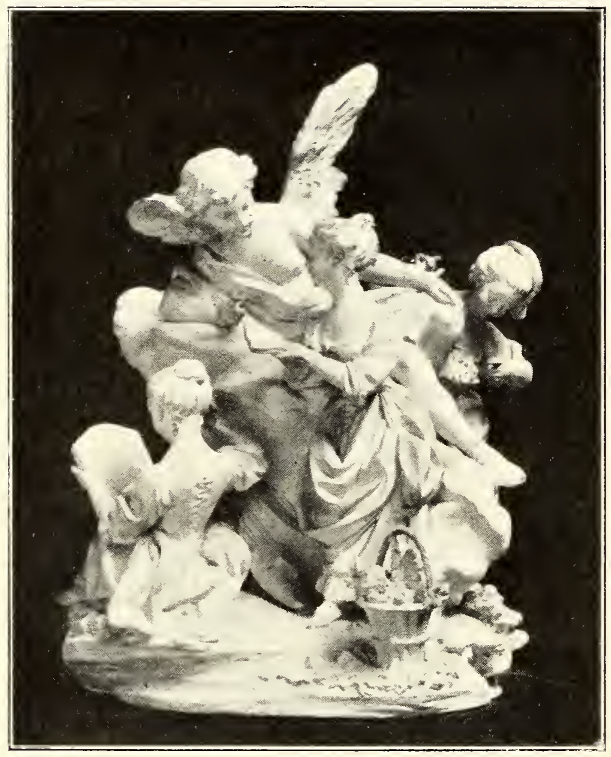

L'Éducation de l'Amour.(H. 0,31). — Modèle de 1773.

ment par des difficultés d'ordres diverss, provenant d'un côté des dépenses que devait entraîner l'installation d'ateliers nouveaux et, d'un autre côté, de l'incapacité des ouvriers de la pâte tendre à employer convenablement la nouvelle matière. Boileau, fatigué, malade, avait négligé de faire l'effort indispensable pour organiser la production courante de la pâte dure. Parent, dès son arrivée, vit que là était l'œurre utile et profitable à entreprendre et, sans plus tarder, d'accord d'ailleurs avec les intentions manifestées par le Roi, il fit transformer divers locaux en ateliers où purent facilement prendre place 12 tourneurs et 40 répareurs, décuplant 
presque le personnel altaché à cette fabrication. Il ulilisa une parlie de la foree motrice du moulin réeemment installé à Sèvres pour préparer le kaolin et broyer les pàtes; puis, afin de donner à cet élément

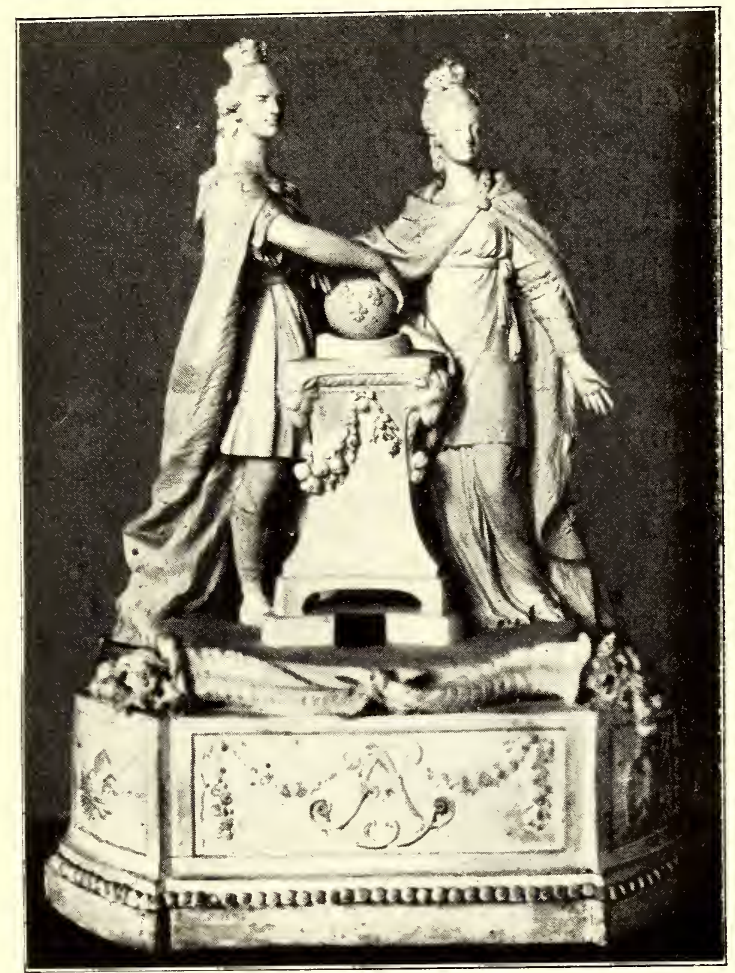

L'Autel Royal. Groupe allégorique du Couronnement de Louis XVI et MarieAntoinetle. Modile de $177 \%$ (Haut. 0,42). (Musće du Petit Trianon).

nouveau une importance plus grande encore, il groupa les ateliers de pâte dure en une manufacture presque indépentante, dont il confia la direction à Millot, chargé aussi, à partir de 1772, de la préparation de la pàte tendre qu'avait fournie sans interruption les Gravant depuis la fondation de Vincennes. A Bailly, "chef de la chimie », il demanda de déterminer la eomposition de couleurs appropriées à la décoration de la porcelaine dure. Aidé de ces eoncour's éclairés, Parent se trouva bientòt à mème d'établir une fabrication plus économique, 
plus sùre, et l'on peut le croire, lor'squ'il dit que dès 1773 la plus grande partie de la sculpture fut exécutée en porcelaine dure, “ce qui fit “ une économie considérable de la pàte ancienne, à cause de la “ perte des pièces qui n'a plus lieu avec la nouvelle, qui d'ailleurs " n'a pas besoin d'étays ». Toutefois cette organisation complète ne s'acheva pas sans entraîner de sérieuses dépenses d'aménagement d’abord, de personnel ensuite, car on n'hésita pas à faire venir des ourrier's d'Allemagne pour enseigner aux gens de Sèvres la manipulation de la pâte kaolinique. C'est à cette époque que la Manufacture compta le plus grand nombre d'ourriers qu'elle ait jamais employés : tout près de 400, dont les deux tiers attachés à la fabrication de l'ancienne porcelaine tendre.

Au dehors, Parent fut contraint de reprendre, presque au lendemain de sa nomination, la lutte contre les manufactures particulières dont le nombre s'était singulièrement multiplié depuis la découverte des kaolins français. Une concurrence effrénée était faite à la Manufacture, principalement par quelques industriels qui avaient été assez habiles pour s'assurer la protection d'importants personnages de la Cour, et qui ne se gênaient nullement pour décorer la porcelaine en or et en couleurs variées. Pressé par la direction de Sères, le lieutenant de police de Sartines se décida alors à rappeler les fabricants au respect des prescriptions de 1766 , mais son intervention fut d'autant moins efficace que les contrevenants trouvèrent en Necker un protecteur décidé el que Bertin lui-mème sentit combien la défense trop rigoureuse du privilège de la Manufacture était en désaccord arec ses idées libérales. Pour motiver son intervention, il allégua le désir de mettre les entrepreneurs en garde contre leur propre imprudence et de leur éviter des mécomptes, leur laissant espérer une liberté sans réserves lorsque leur production aurait atteint un certain degré de perfection.

La concurrence d'ailleurs ne nuisait pas encore au développement 
de la Manufacture : à aucune époque peutètre elle ne reçut des commandes aussi importantes el n'eut à exécuter des travaux aussi somptueux que sous l'administration de Parent. Celui-ci, laissant à Bachelier la direetion plus nominale qu'effective de la peinture. jugea nécessaire de charger un nouvel artiste de la conduite des sculpteurs que Falconet avail inspirée pendant dix ans. Boizot, élève de Michel-Ange Slotz, grand prix de Rome en 1762, âgé alor's de trente ans, prit en mains celte partie de la direction artistique qu'il devait conserver jusqu'en 1802. Artiste habile, sans génie peut-être, mais capable de conceptions originales et gracieuses, il n'occupe pas dans l'art du xrmi siècle la place à laquelle il aurait droit. Cela tient en partie à ce que bon nombre de ses ceurres rentra dans la production anonyme de la Manufacture, et aussi à la facilité trop

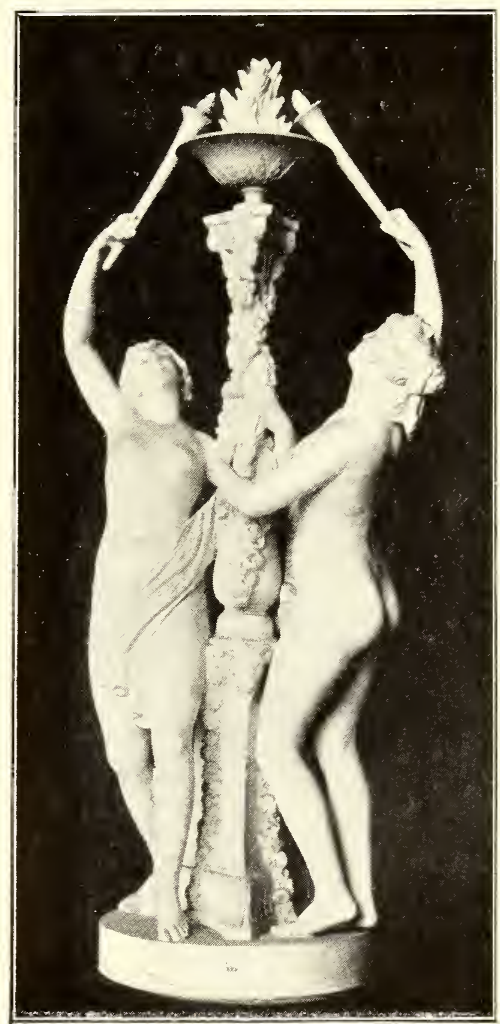

Girandole Boizot. — Modèle de 17íx. grande avec laquelle il s'adapta aux idées et aux goùts du moment, modelant tour à tour et avee une habileté égale de gracieuses girandoles dans l'esprit de Clodion ou des allégories compliquées comme la Raison terrassant l'Hydre de la Tyrannie.

Le style des décorations aussi bien que la forme des pièces commencèrent à se modifier à celte époque et se conformèrent de plus en plus au goût antique. Toutefois il y a lieu de noter eombien, à ce 
point de vue, la Manufaeture fut en retard sur l'ensemble des arts mineurs. Le style Louis XV y régnait encore en maître, et cela s'explique sans doute par la faible part d'influence que Parent laissa aux artistes du lehors, et surtout par le mode de recrutement des ateliers de Sèves où il était d'usage constant de donner aux fils l'emploi oceupé par leurs pères. Une des caractéristiques de la production de cette époque fut le développement donné à la fabrication des grands services de table. En 1773, les artistes de la maison venaient de terminer ceux de $\mathbf{I}^{\text {me }}$ du Barry et du prince de Rohan, et travaillaient, en dehors des commandes royales, à des services considérables commandés souvent par des étrangers, le due de Spencer, le prince des Asturies, le marquis Felino. Ces services valaient en général de 12 à 20000 lirres et presque tous étaient décorés de fleurs, de guirlandes, d'oiseaux, de dentelles en or, se détachant sur des fonds de couleur, détail qui révèle leur exécution en pàte tendre, car à ce moment les fonds de couleurs ne réussissaient que sur cette matière.

Le service le plus extraordinaire qui sortit alors de Sèvres est celui commandé en 1777, au nom de Catherine II de Russie, par son ambassadeur le prince Bariatinski, et composé de 744 pièces : il coûta à la Manufacture la somme rraiment énorme de 226124 livres et fut vendu 328188 livres. Chaque assiette revenait à 242 livres, les sucriers à 1410 , les seaux à liqueur à 2236 livres. Toutes les formes avaient été établies spécialement, avec la préoccupation de revenir aux lignes simples de l'art antique. Quant aux décors, ils étaient composés de sujets mythologiques, peints dans des cartels réservés sur un fond bleu turquoise : au milieu, le chiffre de l'impératrice en fleurs naturelles, surmonté de la couronne impériale; sur les bords, des camées imitant la pierre représentaient des têtes antiques et alternaient avec de petits bas-reliefs en agathe-onyx enchâssés dans la porcelaine, pour la gravure desquels la Manufacture avait dû monter un atelier de lapidairerie complet; enfin l'espace 
laissé libre entre les imilations de camées el les pierres était occupé par une frise d'or dont le molif élait empruntéau théàtre de Marcellus à Rome. Selon la coutume d'alors, ce service de table était complété par un certain nombre de pièces de sculpture, comprenant toutes les dernières créations de la Manufacture. Un seul groupe fut fait spécialement pour servir de motif central au surtout ainsi constitué : il eut pour sujet «les Arts et les Sciences présentant leurs hommages à l'Impératrice de Russie », sous la forme de figures symboliques entourant le buste de Catherine II. L’esquisse en a vait élé donnée par Boizot, dont Le Riche et son atelier traduisirent fidelement la conception tout imprégnée d'esprit classique.

Quant aux pièees d'ornement, aux vases ${ }^{1}$ notamment, le nombre des formes nouvelles fut très restreint à celte époque : la raison en est probablement dans la disparition en 1774 de l'orfévre Duplessis, qui depuis trente ans a rait exécuté presque tous les modeles nouveaux de ce genre. Là aussi il faut noter la part de plus en plus considérable faite à l’imitation de l’antique. Ainsi, dans une lettre de 1773, Parent indique quil fait exécuter douze vases noureaux, dont quelques-uns sur des dessins choisis dans ce "que l'antique a de plus élégant », et à cette date Boizot composait des vases ornés de - bas-reliefs d'un sentiment délicat. Les sujets de peintures se modifièrent suivant une évolution identique, et aux pastorales de Boucher, aux sujets militaires et aux marines, on vit alors sucéder les seènes mythologiques. Enfin les portraits devinrent un motif d'ornementation chaque jour plus fréquent. D'ailleur's l'habitude, fàeheuse en son principe, d'employer la porcelaine comme un simple support pour une peinture se développa singulièrement ì eelte époque et les sujets reproduits sur plaques devinrent d'une dirersité infinie :

\footnotetext{
${ }^{1}$ Les pièces exécutées en pàte dure reçurent depuis cette époque une marque un peu différente de celle des pièces en pàte tendre; les deux L entrelacées surmontées de la couronne royale.
} 
tableaux de fleurs, natures mortes, scènes à personnages, comme " l'Empereur de la Chine ", ou encore copies d'œuvres connues, tel " le Concert du Grand Seigneur » dont on décora une table vendue 3000 livres en 177\%. Dans le même genre, un des objets les plus curieux qui sortirent alors de Sèvres dut être la boîte montée en or, sur laquelle avaient été peints tous les portraits de la famille royale, boîte qui figure au compte du Roi pour une somme de 2800 livies.

La sculpture reçut, elle aussi, grâce au perfectionnement de la fabrication de la pâte dure, des applications extrêmement variées, et pour la première fois il devint possible d'établir des pièees de grandes dimensions. Antérieurement au motif central du service de Catherine II dont nous avons parlé, on avait vu paraître plusieurs surtouts de caractères très différents, au premier rang desquels il faut citer cet ensemble d'un si bel effet décoratif, le Triomphe de Bacchus, qui est demeuré aujourd'hui encore un objet de fabrication courante. On manque de renseignements précis sur l'auteur de cette curre gracieuse qui comporte un groupe principal, deux groupes de còté et huit personnages isolés, mais le style des figures comme la beauté de la composition permettent de croire que les modeles en furent donnés par Pigalle. Boizot en effet semble s'être moins régulièrement que Faleonet astreint à fournir lui-même la maquette de tous les ourrages qui s'exécutaient alors, et fréquemment il laissa les sculpteur's de Sèvres reproduire les modèles de ses confrères ou s'inspirer de compositions des peintres contemporains. C'est ainsi qu'on exécuta l'Amour d'après Van Loo, l'Enfant à la cage de Pigalle, enfin l'important surtout dit des Chasses d'après Oudry, comprenant la Chasse au Cerf, la Chasse au Loup et la Chasse au sanglier.

Parmi les cuvres diverses qui virent le jour entre 1773 et 1778, il est intéressant de discerner les influences qui s'exerçaient con- 
curremment alors sur les artistes de la Manufacture. La sensibilité

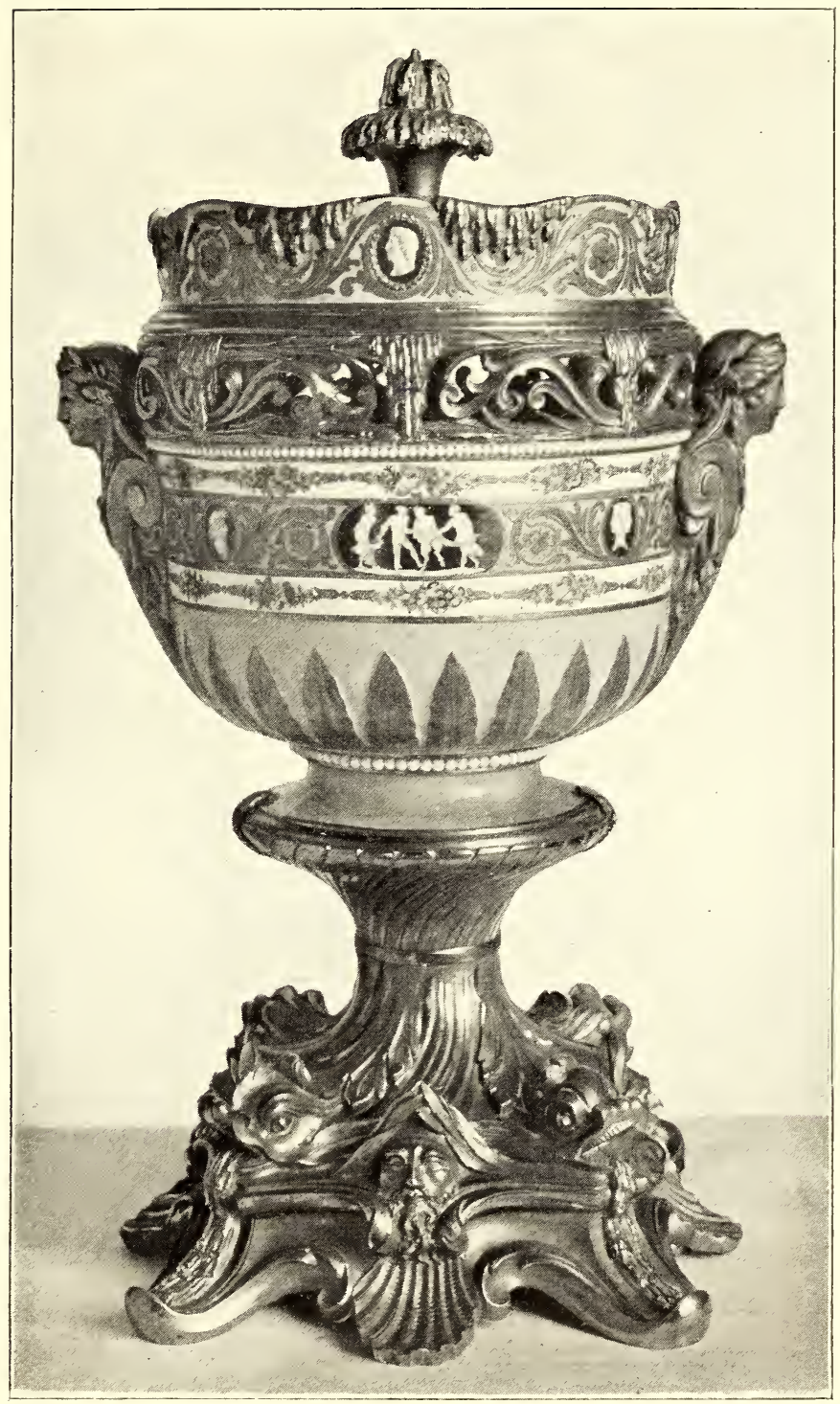

Cassolette du service de Catherine II, impératrice de Russie (17i7). Porcelaine tendre. Fond bleu turquoise. (Musée Wallace.)

à la mode, qui devait nécessairement se retrouver dans l'art délicat 
et un peu mièvre du biscuit, se manifesta par des groupes comme la Féle des Bonnes Gens ou le Couronnement de la Rosière (1770), en mème temps que les tendances, si accentuées déjà dans tout ee qui touchait à la décoration intérieure, vers l'imitation des formes de l'art romain trouvait son expression dans des compositions - les plus parfaites sans doute de cette période - comme l'Amour porté par les Graces, Bacchus porté par les Bacchantes, Jupiter et Léda, l'Autel de l'Amour, l'Autel de l'Hymen, ou encore les Nymphes et les Girandoles de Boizot. C'est dans ce genre, croyons-nous, qu'il faut chercher l’inspiration personnelle de Boizot à cette époque, bien plutòt que dans les aurres d'un earactìre intime, où l'on verrait volontiers la suite des séries de personnages familiers, créés autrefois à l'imitation de Boucher ou sous la direction de Falconet. Pour ceux-là, que ce soient de pelits groupes comme la Toilette, le Déjeuner, la Nourrice, ou des gens de métier comme le Marchand de colifichets, on peut penser que beaucoup sortirent des mains de Le Riche, cet artiste trop peu connu dont les comptes d'alors nous montrent le véritable ròle comme premier modeleur.

Boizot ful appelé peu de temps après son arrivée à Sèvres à composer un groupe de dimensious moyennes, destiné à commémorer le couronnement de Louis XVI : e'est le groupe de l'Autel Royal dans lequel il représenta le Roi et la Reine unissant leurs mains sur un globe orné de trois fleurs de lis royales et posé lui-mème sur un autel où se lisent gravés les mots : “Au bonheur public ». On n'exécuta qu'un très petit nombre d'exemplaires de cette ouve, trois ou quatre semble-t-il, et pour cela il faut nous féliciter d'en retrouver un absolument intact dans le salon de musique du Petit Trianon. C'est une composition simple, qui ne manque point de grandeur et qui donne, malgré ses dimensions restreintes, des effigies intéressantes du Roi et de la Reine à l'époque de leur couronnement ${ }^{4}$.

${ }^{1}$ On a longtemps donné pour titre à ce groupe “ L'Allégorie du mariage de Louis XVI 


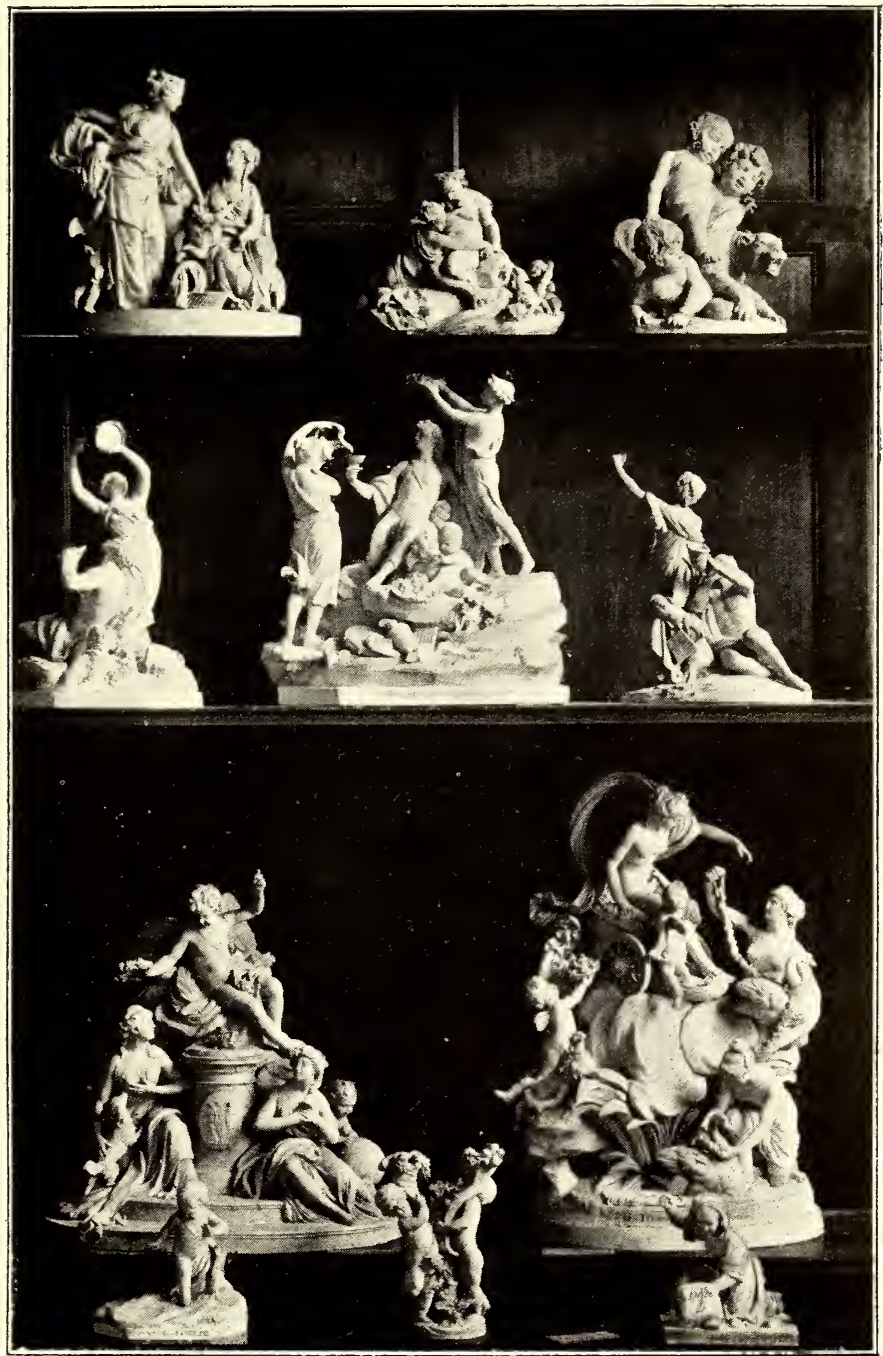

Modèles originaux en terre-cuite) de biscuits du xvil ${ }^{\mathrm{e}}$ siècle.

La Nourrice (1770). - Faune et bacchante (1773). - Les Enfants à la panthère (175\%). Surtout de Bacchus (1773-1774).

Les Cymbales. - Le Triomphe de Bacchus. - Le Tambourin.

L’Amour couronnant la Fidélité (1757). - Le Triomphe de la Beauté (1777).

L'Enfant au scarabée (1783). - Les lnfants aux cornes d'abondance (1773). - La Blanchisseuse (1736). (Musée de Sìrres.)

et de Marie-Antoinette » et il a été parfois reproduit avec cette désignation erronée: l'époque à laquelle il parut, aussi bien que le fait pour les personnages de porter la couronne royale, aurait dû suffire à lui conserver son titre ancien (roir figure page 8.ّ.). 
La Manufacture aurait, en fait, été loin d'un état précaire au moment où furent découvertes les malversations de Parent et Roger, si d'autres causes n'avaient singulièrement accru le malaise dont elle souffrait. Les ventes en effet avaient suivi une progression constante et étaient passées de 500000 livres en 1772 à 780000 en 1778; mais l'argent rentrait fort mal alors et la gestion de Parent avait eu par surcroît ce défaut de ne jamais proportionner les dépenses aux recettes. Parent avait multipliéles travaux extraordinaires, doublé la production de la sculpture qui, coûtant 50000 livres par an, n’en rapportait cependant pas la moitié, et ainsi avait encombré les magasins de Sèvres de marchandises représentant une valeur supérieure à un million. Bertin entreprit, avec le concours de Régnier, de donner à la Manufacture une meilleure orientation et, tout d'abord, il fit renouveler par un arrêt, daté de 1779, la défense faite aux İabriques particulières de vendre les ouvrages réservés à la Manufacture du Roi. Le Directeur reçut l'autorisation de faire procéder à toutes les visites et saisies qu'il eroirait nécessaires. Quelques poursuites furent effectivement engagées contre ceux qui violaient d'une façon trop apparente le privilège de Sèvres, poursuites qui aboutirent à la condamnation de Catrice et Barbé, deux peintres de la Manufacture établis l'un à Saint-Cloud, l'autre à Paris, qui décoraient la porcelaine par tous les procédés interdits. On apprit à l'occasion de leur procès que dès cette époque les fabricants n'hésitaient point à acheter à Sèvres des pièces blanches et à les couvrir d'ornements en or ou en couleurs, allant même jusqu'à contrefaire les deux L entrelacées, marque de la Manufacture Royale. Mais, dans l'application, l'arrêt de 1779 ne fut pas plus efficace que les précédents, par ce fait que la lutte était presque impossible contre les fabriques parisiennes qui toutes avaient pris soin de se placer sous la protection d'un grand seigneur : la fabrique de la rue Thiroux s'appelait Manufacture de la Reine, celle de Clignancourt était la Manufacture de Monsieur, 
celle de Sceaux portait letitre de Manufacture du duc de Penthièvere.

D’ailleur's les idées régnantes étaient de moins en moins favorables aux privilèges industriels et l'on ne savait plus guère quels motifs invoquer pour leur maintien. Bertin lui-mème reconnaissait qu’il était " juste et convenable de laisser Sceaux travailler en couleurs “à cause de son antériorité; cela annoncera, disait-il, à toutes les « autres qu'on leur accordera des permissions semblables lorsqu'elles « se seront soutenues un temps.convenable en fabriquant des ouvrages “ en bleu, blanc et camayeu, et des choses usuelles ». Dès l'instant où le Commissaire du Roi près la Manufacture admettait des exceptions au privilège de la maison, il devenait singulièrement diffieile d'en requérir l'application rigoureuse lorsque cela devenait nécessaire, et cette indulgence ne fut peut-ètre pas étrangère à la décision que prit le Roi de retirer à Bertin la direction de la Manufacture, pour la confier à d'Angivilliers, directeur général des bàtiments. Cette mesure fut prise le 24 septembre 1780 : pendant les douze années qui s'écoulèrent jusqu'à la chute de la royauté, d'Angivilliers demeura le grand maître de la Manufacture Royale et parvint à lui rendre un incontestable éclat, gràce à une administration régulière et à une orientation nouvelle de la production artistique. Il fut pendant ce temps remarquablement secondé par le premier commis du service des Bâtiments, M. de Montucla, voyant tout par lui-mème, inspirant les recherches qu'il jugeait utiles, examinant le détail des ventes ou des commandes aussi bien que la conduite des travaux: on peut dire qu'au cours de cette période, pas un ouvrier ne fut engagé, pas une œuvre ne fut exéeutée sans qu’il en ait été averti ou sans qu'il eùt fourni son opinion sur le projet.

Dès 1780, M. d'Angivilliers inaugura un sévère régime d'économies qui lui permit de combler en moins de trois années le déficit laissé par la gestion de Parent et de Roger. Il eut à cela d'autant plus de mérite que, à partir de 1778, la pénurie du Trésor contraignit 
le Roi à supprimer l'allocation annuelle de 96000 livres qu'il versait à sa Manufacture depuis 1760. Pour atteindre son but, il diminua notablement le nombre des ouvriers - trois ans après son arrivée le personnel ne comprenait plus que 274 membres. Dans ce travail de relèvement financier, il fut aidé par le caissier Barrau qui, nommé en même temps que lui, s'employa à faire tout d'abord rentrer le plus d'argent possible sur les ventes à erédit des années écoulées.

D'Angivilliers s'efforca de tirer le meilleur parti du personnel dont il disposait : et à ce sujet son attention se porta tout d'abord sur la direction artistique de la Manufacture. Nous avons déjà signalé que, sous Parent, l'autorité de Bachelier et de Boizot s'était peu à peu singulièrement amoindrie : ils pouvaient alors paraître assez inutiles pour que d’Angivillierss ait hésité à les conserver. Sa décision, il est rrai, fut favorable à leur maintien; mais il exigea d'eux une présence absolument régulière à Sèvres chaque lundi, entre huit heures du matin et sept heures du soir, et il spécifia que l'un et l'autre auraient à fournir par an 2.3 modèles pour lesquels ils recerraient une somme de 600 livres. Afin de rétablir leur autorité, il avertit les peintres et seulpteurs de la Manufacture d'a voir à se conformer d'une façon absolue à la direetion des deux artistes qüll leur donnait comme chefs, et sans l'approbation desquels il n'admettrait plus la mise en train d'aucun ouvrage important. Lne de ses plus grandes préoccupations dans la suite fut d'orner les ateliers de modèles fréquemment renouvelés, et dans ce but Bachelier fut appelé plusieurs fois à fournir des études pour remplacer les compositions dénodées et les estampes dont on se servail depuis trop longtemps. Un souci du même ordre le conduisit à arljoindre à Bachelier un artiste plus jeune, de tendances mieux adaptées aux aspirations de l'époque : Lagrenée le jeune, professeur à l'Académie, fut désigné pour cet emploi en 178ว et ses avis semblent avoir eu dès lors une sérieuse valeur. La même année, d'Angivilliers fit encore l'acquisition pour la Manufacture d'un 
lot considérable de peintures, d'esquisses, de croquis de Desportes,

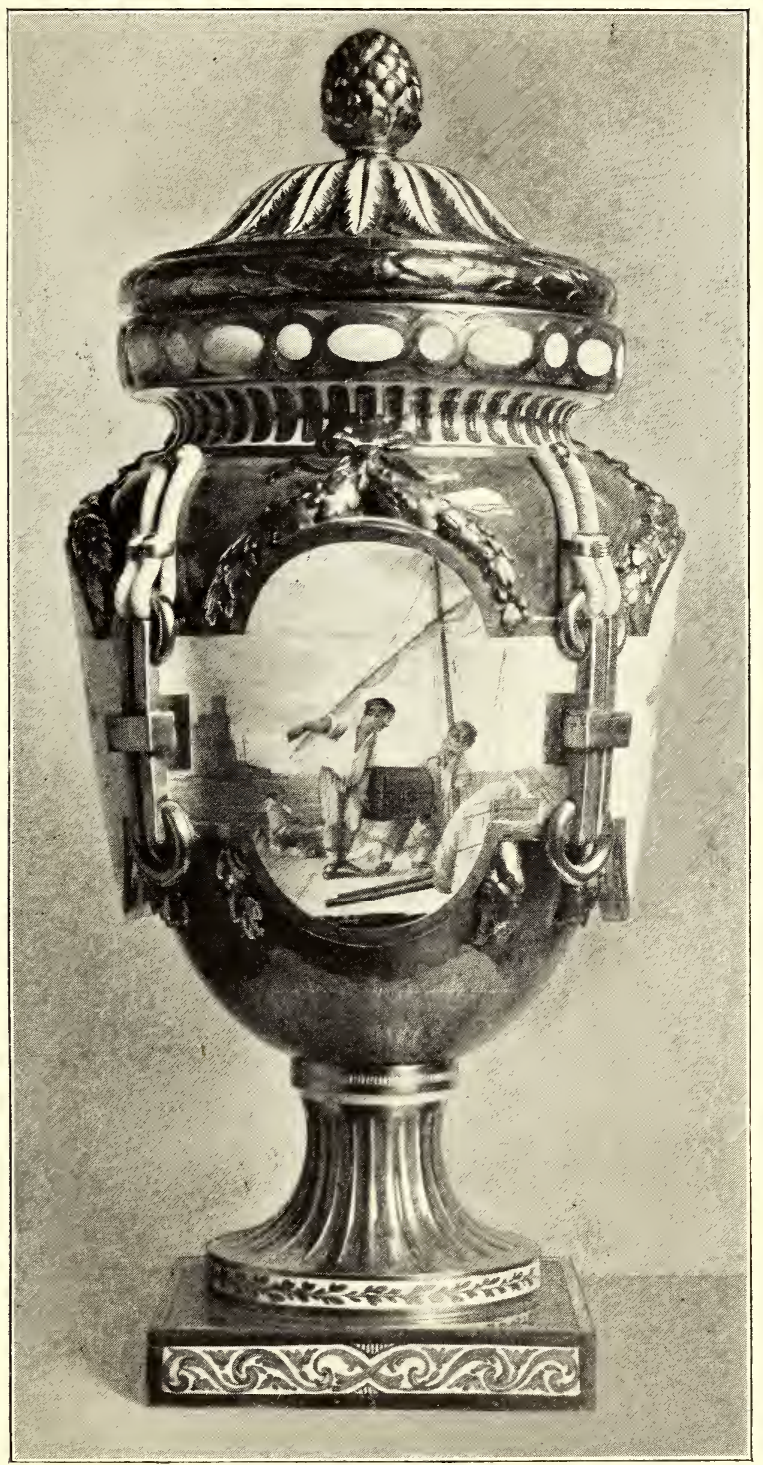

Vase à quatre cartels, à fond bleu ct ceil-de-perdrix. — Sujets de marine. Porcelaine tendre, 177̈. (Muséc Wallace.)

parmi lesquels Bachelier choisit les pièces qui pouraient ètre mises 
le plus utilement sous les yeux des ariistes de la Manufacture ${ }^{1}$. En 1786 enfin, il fit déposer dans l'établissement de Sèvres une partie des vases étrusques recueillis par Denon et achetés au nom du Roi, avec la pensée que certaines formes pourraient être employées avec profit par les artistes.

Dans un autre ordre d'idées, d’Angivilliers considéra, comme une des cuvres les plus urgentes à entreprendre, la codification des procédés employés à la Manufacture. Il en chargea tout d'abord les académiciens-chimistes Macquer et de Montigny, mais ceux-ci étant morts, l'un en $\mathbf{1 7 8 2}$, l'autre en $\mathbf{1 7 8 4}$, cette besogne se trouva confiée à leurs successeurs Darcet, Cadet et Desmarets, tous trois membres de l'Académie des Sciences. Il semble bien que l'influence du premier ne fut pas étrangère, - non plus que celle d'Hettlinger, nommé en 1784 inspecteur et adjoint au Directeur ${ }^{2}$, - à l'acquisition par la Manufacture de Sèvres de la fabrique de porcelaine dure fondée en 1784 à Limoges par Grellet et Massié. On fut amené à cette opération, désastreuse dans la suite, par l'espoir d'organiser la fabrication des pâtes à proximité des carrières de kaolin, de profiter aussi du bas prix de la main-d'œuvre en province pour fabriquer des pièces blanches qui auraient reçu seulement un décor à Sèrres, de s'assurer enfin la propriété de certaines carrières appartenant à Massié et Grellet. Darcet fut chargé de prendre possession au nom du Roi de leur installation qui fut payée comptant 142000 livres, et d'organiser la production en conformité a vec lebut poursuivi. Mais l'exploitation, au lieu de donner les bénéfices que l'on a vait escomptés, accusa dès le début un déficit inquiétant : au bout de deux ans, les carrières, constituant l'intérèt principal et la raison d'ètre de l'acquisition,

\footnotetext{
' Cette série si importante d'œuvres de Desportes est encore aujourd'hui à Sèvres et nous aurons l'occasion d'en parler en décrivant les collections artistiques de la maison.

" Hett!inger, né en 1734, était de nationalité suisse. Chirurgien de son état, il s'intéressa à la géologie et devint directeur des mines de cuivre de Baygorry, en Navarre ; il occupait cet emploi lorsque d'Angivilliers l'appela à Sèvres.
} 
se trouvèrent épuisées, tandis que la plupart des fabricants français ou étrangers qui auparavant achetaient leur kaolin chez Grellet cessaient de s'adresser à l'entreprise devenue royale. Quant aux pièces fabriquées, elles parurent, après examen, de qualité si médiocre que jamais on ne put les utiliser à Sìves! Malgré tous les efforts, la Manufacture de Limoges ne se releva jamais et créa de multiples difficultés

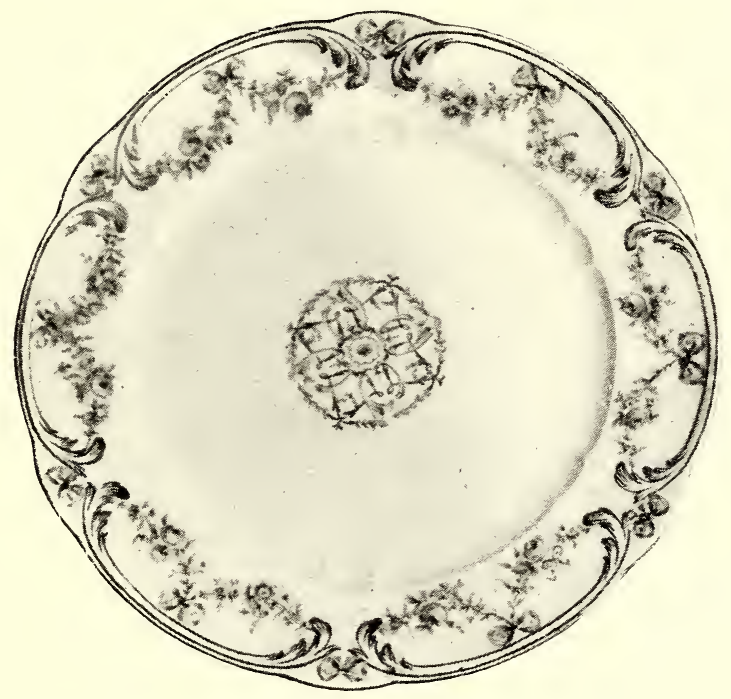

Assiette en porcelaine tendre à décor polychrome (1786).

à celle dont elle devait en principe faciliter les opérations : à l'époque de la Révolution, d'Angivilliers regrettait encore amèrement cette spéculation malheureuse qui avait coûté à la Manufacture royale plus de 200000 livres.

Sil'on examine les œuvres sorties de Sèvres entre 1780 et 1790, l'esprit d'initiative et l'intervention journalière du Directeur général des Bàtiments apparaissent d'une façon aussi caractérisée que dans la direction administrative. L'une des plus eurieuses tentatives de ce temps fut certainement celle qui eut pour point de départ le désir de frapper les esprits par la fabrication de pièces de dimensions inusitées. Ėn 1783, 
en effet, d'Angivilliers invita les artistes de Sèvres à étudier, en vue de la prochaine exposition de Versailles, la fabrication d'un vase de proportions considérables : et c'est à la suite de ce concours que fut exécuté le vase de Médicis orné de bronzes de Thomire, qui figure aujourd'hui encore au Musée du Louvre. La forme et la décoration de cette piècè de deux mètres de haut furent étudiées par Boizot qui fit adopter un projet de vase à fond bleu, orné d'un large bas-relief eirculaire en biscuit, représentant d'un côté Diane et ses suivantes s'exerçant à l'arc, de l'autre Diane surprise par Actéon, et complété par deux figures de bronze formant anses et soutenant des guirlandes de fleurs. Boizot se réserva l'exécution de la frise et des figures, et c'est à l'occasion de la fonte de ces dernières que Thomire, déjà connu par la ciselure de certains bronzes de Houdon, fut introduit à la Manufacture où il devait bientòt être chargé, par suite de la mort du fondeur Duplessis, de tous les travaux du même genre. La réussite de cette pièce fut l'événement important de la vie de la Manufacture à cette époque, et l'intérêt qu'y attachait d'Angivilliers se rérèle par les nombreuses lettres qu'il échangea en 1783 avec Régnier au sujet du "grand vase ». Malgré toutes les difficultés de fabrication auxquelles on se heurta, il fut en état de figurer à l'exposition de fin d'année dont il constitua le principal attrait : son pendant fut terminé l'année suivante. Mais on dut s'arrêter dans cette voie, car de telles pièces revenaient à des prix énormes, moins encore par le coût de la porcelaine que par celui des bronzes : pour les deux vases, la note de Thomire s'éleva à 107703 livres, et cette dette de l'année 1784 pesa lourdement, elle aussi, sur les finances de la maison qui n’acheva de s'acquitter envers le ciseleur que vingt ans après, en 1805. Du moins, les grands vases eurent cet avantage de déterminer la composition d'une pâte nouvelle que l'on obtint par l'addition à la pâte dure ordinaire d'une certaine quantité de terre de Dreux et de kaolin passés au feu de dégourdi. 
Au nombre des créations dues à l’initiative personnelle ded'Angivillier's, il faut encore citer les réduetions qu’il fit exécuter à Sèves des statues de grands hommes dont la commande se poursuivait à raison de quatre par année depuis 1777. Dans les contrats passés avec les sculpteurs, d'Angivilliers avait en effet slipulé que chacun deux serait tenu de fournir un modìle réduit de son aeuve, pour lequel il recerrail 1000 livres de la Manufacture; gràce à ce procédé, quatorze figures avaient été exécutées avant $1784^{2}$ et étaient mises en vente au prix de 600 livres. Chose curieuse, malgré l'intérèt que devait susciter cetle série d'oeuvres remarquables, elles ne furent l'objet que d'une euriosité vite salisfaite of l'on n'en vendit pour ainsi dire aucune à ce moment-là, bien que leur prix ait été abaissé a 300 livres. Au commencement du $x^{2}{ }^{e}$ siòcte, au contraire, elles furent très justement appréciées et devinrent de fabrieation courante.

Par d'autres ceuves la Manufacture parlieipa alors à Lous les événements qui marquèrent une date dans la vie de la Cour. Louis XVI manifesta toujours un goût très vif pour les produits de sevres et l'on sait quaux expositions qui avaient lieu au moment de Noël dans ses appartements de Versailles, il aimait à se faire le vendeur des produits de sa Manufaeture. D'Angivilliers, avee son habileté coutumière, ne manqua d'ailleurs jamais d'entretenir ce goût par des altentions de nature à toucher le cœur du monarque. Ainsi, en 1781, à l'oecasion de la naissance du Dauphin, Pajou reçut la commande d’une allégorie destinée à ètre reproduite en biscuit et dont le sajet était Vénus sortant de l'onde apportant un Dauphìn à la France. L'exécution de celte cuvre, dans laquelle l'artiste sut éviter la banalité trop fréquente des commandes officielles, dut ètre relardée, par ce que Pajou avait donné à la déesse les traits de la

\footnotetext{
' C'étaient celles de Corneille et Moliire (Caffieri) ; Pascal. Descartes, Bossuet, Turenne (Pajou) ; d'Iguesseau (Berruer) ; Montausier et Sully (de Mouchy); LiHopital (Goix); Fénelon (Le Comte); Montesquieu (Clodion); Tourville (Ioudon); Vauban (Bridan).
} 
Reine : celle-ci, avertie, demanda une modification grâce à laquelle cette œuvre charmante nous a été conservée sous deux aspects

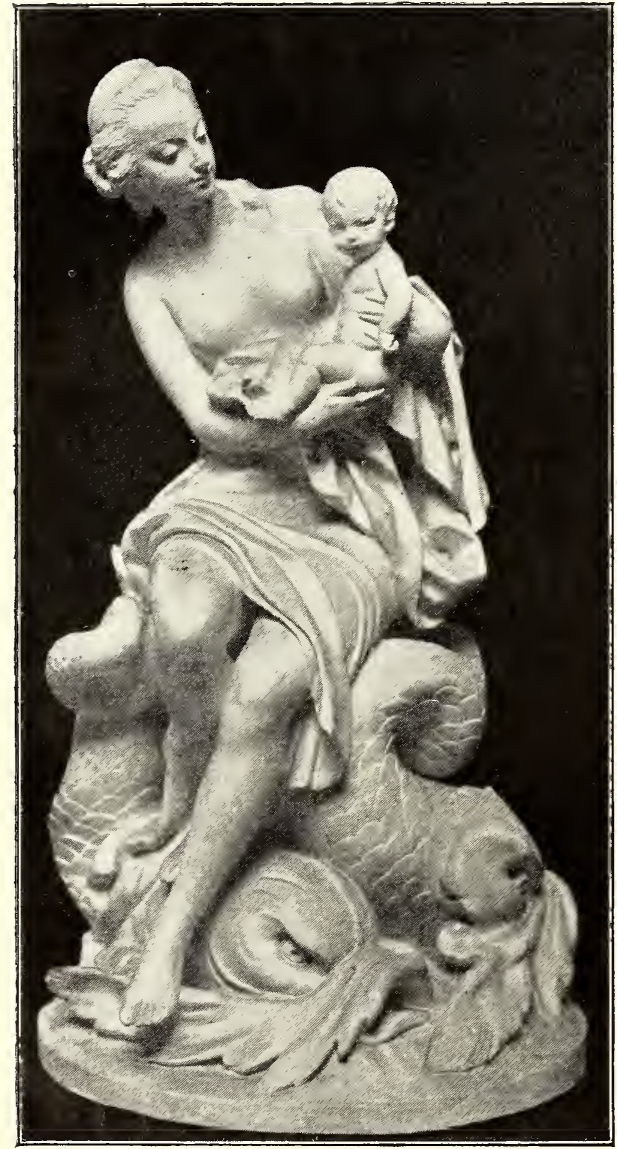

Allégorie de la naissance du Dauphin. Modèle de Pajou. (1781). (H. 0,40). différents. En 1785, lors de la naissance du duc de Normandie, Boizot à son tour composa un groupe représentant la Monarchie francaise sur laquelle le Génie de la fécondité place un troisième rejeton. Pour son hommage personnel à la Reine, d'Angivilliers fit décorer à eette occasion un gobelet orné d'un cartel où figuraient les armes du Dauphin et la couronne royale, entourées par un serpent qui se mord la queue, symbole de l'élernilé. Le présent de la Manufacture fut complété par deux pièces dont la décoration a vait été demandée l'une à Bachelier, l'autre à Lagrenée. Le premier choisil pour sujets les Parques filant les heureux jours de l'enfant et Thétis plongeant son fils dans les eaux du Styx; quant à Lagrenée, il peignit sur une écuelle des figures symbolisant le bonheur de la France.

De plus en plus, d'ailleurs, la Manufacture fut chargée de reproduire l'effigie des princes de la famille royale et des monarques amis 
ou hôtes de la France à celte époque. Boizot en 1785 modela deux bustes nouveaux du Roi et de la Reine: peu de temps auparavant avaient paru Madame Royale jouant sur son coussin, le groupe de Monseigneur et Mademoiselle, les bustes du Comte et de la Comtesse du Nord, et enfin la spirituelle statue équestre du roi de Prusse dont un exemplaire — sans doute celui vendu 960 livres à Louis XVI en 1784 - est préeieusement conservé au Musée de Versailles.

Comme décorations peintes, la Manufacture entreprit encore quelques grands services, dont les plus importants furent celui destiné au Roi - chaque assiette coûtait 480 livres $^{1}$ - et celui, commandé par la Reine en 1784, qui prit le nom de service "Arabesque » : l'arehitecte Masson en avait établi le dessin d'après les ornements des fresques de Raphä̈l on y travailla avec ardeur, mais il ne semble pas qu'il ait été complètement terminé diss ce

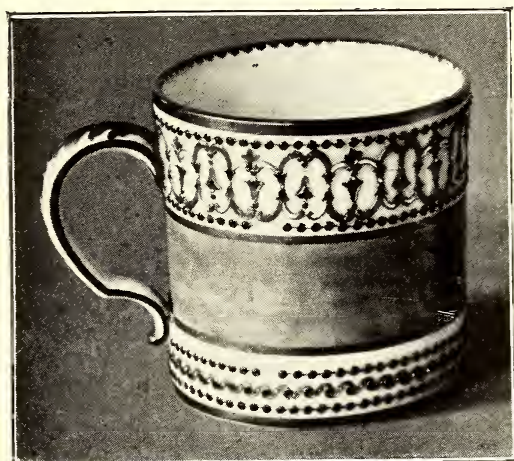

Tasse décorée d'émaux, par cotteau. Porcelaine tendre (1783). (Musée de Sèvres, nº 8999.) moment. De cette époque datent aussi les pièces composées pour l'ameublement des laiteries de Trianon et de Rambouillet et conçues dans le style pompéien.

Il semble que les artistes de Sères résistèrent parfois à cette modification absolue de la décoration qu'on leur imposa alors : “ Je " sais, écrivait d’Angivilliers à Régnier, que vous n’avez pas encore " le goût étrusque et que je vous parais un peu barbare, mais il

\footnotetext{
${ }^{1}$ La décoration de ce service était entièrement formće de sujets empruntés à la mythologie : au fond de chaque assiette itait peinte une scène principale, tandis que quatre cartels réservés dans le marli à fond bleu donnaient encore place à de petites compositions.

Ln 1790, le service du Roi ne comprenait encore que 42 assiettes, 10 seaux à verre, autant de compotiers, $1^{\prime}$ tasses et dix salières. Le soin de décorer ces pićces navait élé confié qu’aux meilleurs artistes de la maison, qui ne livrèrent jamais plus de six assiettes chaque année.
} 
" faudra bien que nous nous y accoutumions tous... ), faisant allusion au goût du Roi pour l'art antique. Et éest sans doute le désir de faire pénétrer cet esprit nouveau dans les ateliers de Sèvres qui valut à Lagrenée la situation prépondérante qu’il ne tarda pas à occuper à la Manufacture. Celle-ci avait terminé en 1782 une des pièces les plus curieuses qu'elle ait produites : la toilette offerte au cours d'une visite à Sèvres, le 13 juin, à Marie Feodorovna, femme de celui qui devint plus tard Paul $I^{\text {er }}$ de Russie. Ce magnifique présent de Marie-Antoinette comportait eomme pièce prineipale un grand miroir, supporté par des figures allégoriques dues à Boizot, et garni de montures d'or ainsi que les moindres ustensiles qui avaient été dessinés spécialement. Le parti général de la déeoration consistait en des cartels ornés de figures "étrusques" ; mais la grande nouveauté de cette somptueuse toilette résidait dans l'emploi des émaux sur or qui entraient dans son ornementation. Depuis 1780 l'émailleur Cotteau ${ }^{1}$, reprenant un procédé en usage à l'aneienne manufacture de Saint-Cloud, était parvenu à fixer sur la porcelaine des gouttelettes d'émaux colorés supportées par des paillons d'or. Les quelques pièces qu'il avait produites avaient eu un grand succès et on jugea convenable de lui donner une part dans la décoration de la toilette de la comtesse du Nord. Le prix de cette pièce merveilleuse dépassa tout ce que l'on avait fait jusqu'alors, ear elle figure au compte du Roi pour 73000 livres: les sommes déboursées par la Manufacture avaient atteint 5932 livres pour le miroir, plus de 3000 pour la cuvette seule...

D’autres présents eonsidérables de poreelaines furent faits à cette époque, au prince Henri de Prusse en 1784, aux ambassadeurs de

\footnotetext{
${ }^{1}$ Cotteau reçut en 1780 la somme de 1817 livres, sans doute en paiement des deux vases " en émaux " qui furent livrés à la Rèine la même année; ses travaux montèrent à 2794 ìvres en 1781, à 16000 livres en 1782 , à 4 5200 livres en 1784 . Il sollicita son admission définitive à la Manufacture, mais ne fut pas agréé, d'autres peintres de la maison étæ̈nt parvenus à exécuter avec succès des travaux de mème nature qut les siens.
} 
Tippoo-Saïb en 1788 : pour le présent remis à ce dernier, on s'appliqua à fabriquer des pièces rappelant certaines formes de vases indiens, dont le modiele fut emprunté au cabinet d'un amateur. Il est à noter d'ailleurs que les directeurs d'art de la Manu-

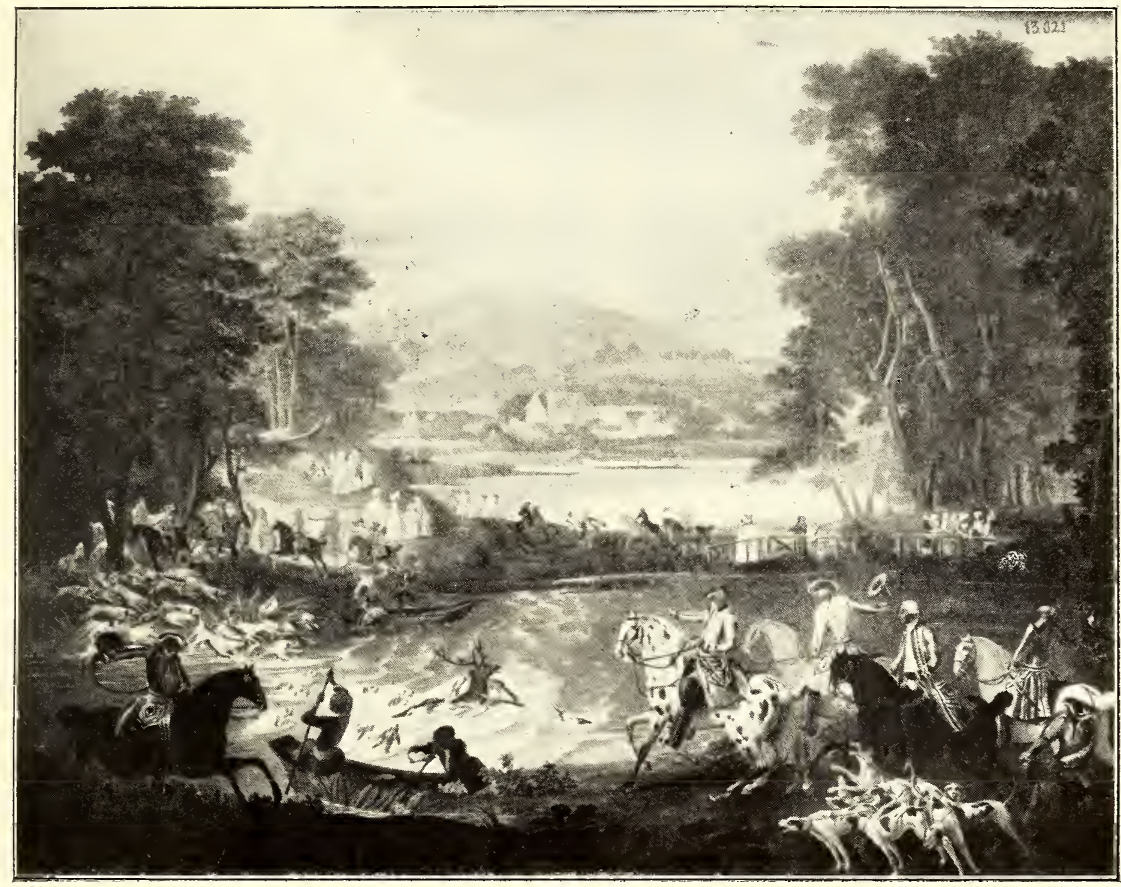

Plaque de la série des "Chasses du Roi », d'après Oudry. - Peinture d'Asselin sur porcelaine tendre (1781). Haut. 0,39əั, Larg. 0,495. (Musée de Sèvres, no 13021.)

facture manifestaient alors un souci d'exactitude bien différent de la fantaisie qui avait jusque-là caractérisé les décorations céramiques ; ainsi, aux oiseaux un peu conventionnels que l'on peignait depuis quarante ans sur les serviees de table, les artistes substituèrent la copie exacte des oiseaux représentés dans les ouvrages de Buflon et reproduisirent constamment entre $\mathbf{1 7 8 2}$ et 1798 le "service de Buffon ».

Si cette époque fut celle des grandes décorations deslinées à la table, elle pourrait également être caractérisée par le dévelop- 
pement donné à la peinture, sur plaques de porcelaine, de sujets empruntés aux artistes célèbres. Seule la pâte tendre se prêtait à cet usage, car on était encore loin de posséder la palette de pâte dure qui ne fut définitivement établie que sous Brongniart : les compositions était done de dimensions restreintes et il semble bien que les spécimens les plus parfaits de ee genre soient les neuf plaques, dont les plus grandes mesurent $0^{\mathrm{m}}, \breve{50} \times 0^{\mathrm{m}}, 40$, qui constituent la série des "Chasses du Roi », exécutée de 1779 à 1781 pour la salle à manger des petits appartements de Versailles, d'après les cartons qu'Oudry arait fournis aux Gobebins. Les meilleurs artistes de la Manufacture y travaillèrent pendant deux années et parvinrent à créer un ensemble harmonieux que l'on peut retrouver aujourd'hui à la place même pour laquelle il a été conçu, puisque $\mathrm{M}$. de Nolhac a eu la bonne fortune de pouvoir, après un siècle d'oubli, les exposer dans leur cadre prinitif. Elles sont d’une exécution très soignée, toute différente de la manière mesquine el presque trop parfaite des copistes habiles qui se livrèrent à des travaux du même genre, sur pâte dure, au début du xix ${ }^{\mathrm{e}}$ siècle. L'emprunt de modèles aux Gobelins était d'ailleurs fréquent à cette époque : ainsi, en 1784, la Manufacture employa dans ces conditions quatre tableaux de Van Loo, représentant des scènes de la vie du sérail; en 1785 , c’est dans les collections royales que Bachelier chorsit, pour être eopiés sur plaques, le tableau de Boucher "Renaud et Armide " et celui de Brenet “ les Honneurs funèbres rendus à du Guesclin ».

Quant à la seulpture, sans entrer dans le détail des ceurres de plus en plus nombreuses que produisit la Manufacture à partir de 1780, on peut discerner facilement l'orientation que d'Angivillers, toujours soucieux de se conformer aux aspirations de son temps, donna aux seulpteurs de Sèvres et à Boizot en particulier. Les sujets mythologiques occupèrent la première place, et c'est dans ce genre que l'on rencontre les groupes les plus importants, chargés de nom- 
breux personnages, et dont la valeur atteignail souvent 600 livres : parmi ces sujets, il suffit de citer le Jugement de Päris, la Toilette de Vénus, Diane et Endymion, la Naissance de Bacchus, Apollon et Daphné, l'Enlèvement de Proserpine, l'Enfance de Silène. Beaucoup de figures isolées, d'un style élégant, un peu mièvre parfois, accusaient encore, par les souvenirs de l'antiquité qu'elles éroquaient, la formule dominante : la Santé, la Fidélité, la Sagesse, la Beuuté, les Muses, eurent alors un extraordinaire succès. Les pastorales de jadis par contre avaient presque entièrement disparu de la fabrication courante, el arec elles eet art d'une grâce unique qui donnait tant de charme aux groupes délicals de 17̣60; ou du moins elles affectèrent une forme différente et s'adaptèrent, elles aussi, au goût ré-

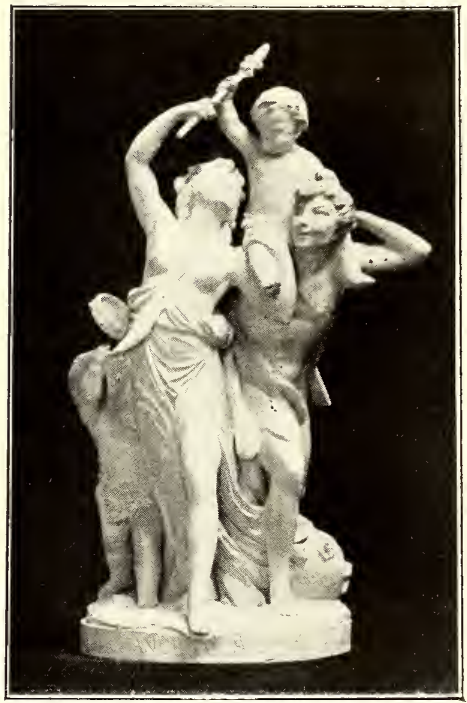

L'enfance du Silène. - Nodèle de 178s. (I1. 0,35). gnant : il n'élait plus question de bergers, ni de bergères, mais de l'Amour conduit par la folie, de l'Amour esclave de la beaulé, de l'Hyménée... représentés par des personnages vêtus à la romaine. A còté de cela, un certain nombre de pièces se rattachant à la vie contemporaine ligurèrent des scènes inspirées sourent par la littérature sentimentale : la Fête des bonnes yens où l'on voit couronner un vieillard entouré de sa famille, la Rosière de Salency, sont des sujets caracléristiques de celte manière. D’autre part le théâtre donna l'occasion de modeler des personnages représentant les acteurs célèbres dans leurs meilleur's ròles : la Thalie, qui parut en 1786 , reproduisait les traits de $\mathbf{I}^{\text {Ile }}$ Contat, le Figaro, le Crispin, ceux de l'acteur. Volanges. En dehors des portraits, quelques 
curres nous ont d'ailleurs conservé le souvenir des suceès de la scìne à ce moment, et la Belle Provençale rappelle la pièce du même nom jouée en 1778, tandis que les groupes de Persée et d'Andromède, d'Iphigénie en Tauride consacrent le succès des opéras de Lulli et de

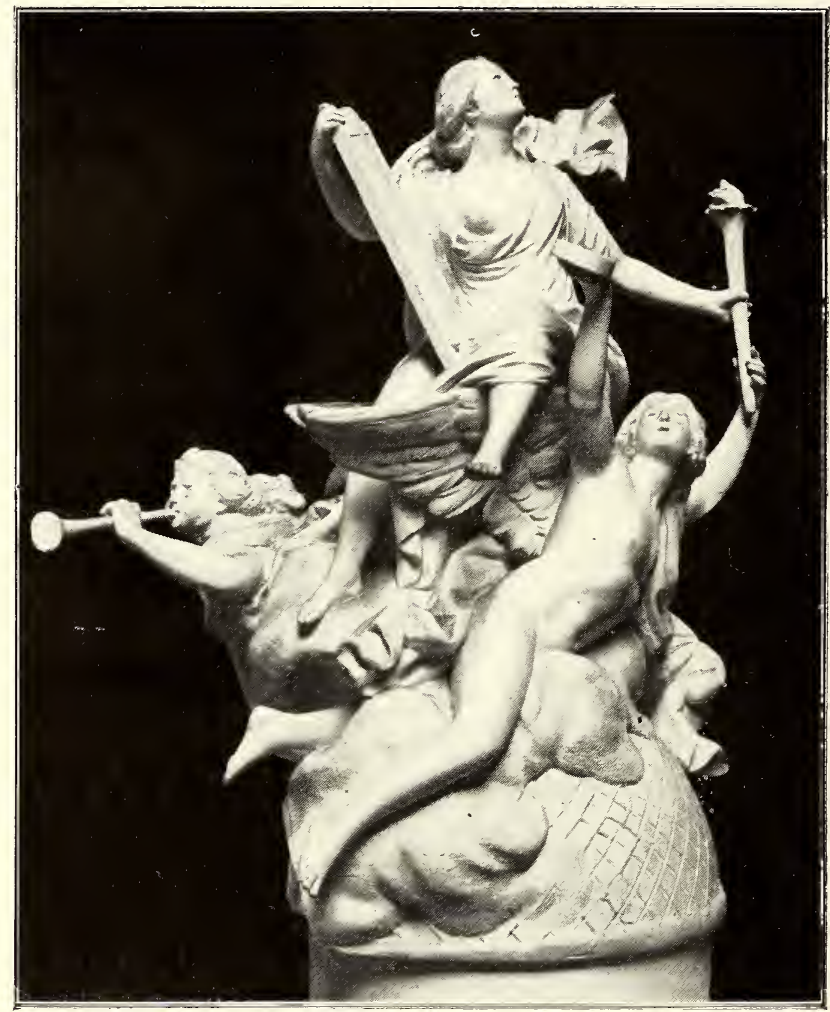

Groupe du Ballon. - Modèle de 1786. (H. 0,40).

Gluck. Enfin, à eòté de quelques personnages grotesques comme Eustache Pointu, le docteur Fagon ou le capitaine Laroche, ehef des basses-cours royales, on vit reparaitre des figurines de gens de métier, semblables à celles composées quarante années plus tòt par Boucher. Cela fut fait sur les indications de d'Angivillers lui-mème qui a exposé son idée dans une lettre commandant en oetobre 1788 le Marchand de tisane : "Je voudrais, disait-il, que vous fissiez faire à 
" la Mre une petile bambochade dans la proporlion des figures de " cheminée; c'est un de ces vendeurs de tisane d̀ la fraîche qui veut "boire, qui la portent sur leur dos avec un gobelet qui pend à " une petite chaine. Je voutrais que cela fùl fail pour les étrennes. "Ils ont quelquefois une petite lanterne à leur bonnet sur la tète. " M. Boizot pourrait faire un autre cri de Paris pour pendant aree (celui-là..."

Ainsi le Directeur des bâtiments ne cessait de s'intéresser de toutes les façons aux destinées artistiques de la maison qu'il avait entrepris de régénérer : aucun détail ne lui apparaissait trop mesquin pour mériter son attention, et c'est sans aucun doute à lui que l'on doit les grandes et belles choses quilurent faités à Sìvres à cette époque. Là ne s'arrêtèrent point les services qu'il s'efforģa de rendre à la Manufacture, et son rôle fut aussi actif dans la lutte que l'établissement eut encore à soutenir contre les falsriques particulières. Il eut le sentiment très net de la résistance générale qu’il rencontrerait, s’il prétendait réta!blir le priviligge de la Manufaelure dans son intégralité, et son ambition fut de lui conserver une place prépondérante dans l’industrie, moins par de nouvelles prohibitions contre ses rivales que par une supériorilé arlistique incontestable.

Les contrôleurs généraux des linanees s'élaient depuis longtemps déclarés hostiles au privilège exelusif de Sirves et répondaient mollement aux demandes de poursuites que, de temps en temps, le directeur Régnier sollicitail d'eux à l'égard de contrefacteurs trop audacieux. En 1782, Joly de Fleury alla plus loin et, dans une affaire de cette nature, fit savoir qu’il élait nettement opposé au maintien de tout privilège, que d'ailleurs diferses autorisations partieulieres avaient déjà élé données à des fabriques ef invoqua, à l’appui de sa thèse, les réeentes décisions royales par lespuelles avaient été abolis un grand nombre de privileges. Il n’y a done pas lieu de s'étonner 
que l'arrèt rendu deux ans après - le 16 mai 1784 - ait été, malgré sa forme prohibitive, considéré comme un succès par les détracteurs de Sèvres. Cette décision, après a roir dans ses premiers articles consacré à nouveau le principe du privilège, lui portait ensuite une atteinte grave en donnant aux particuliers l'autorisation de faire " tous objets " du genre moyen destinés à l'usạge de la table, d'y appliquer de " l'or en bordure et de les peindre de fleurs nuancées de toutes cou" leurs ». La seule mesure favorable à Sèrres que contînt l'arrêt était l'obligation imposée à tous les entrepreneurs, ceux de Sceaux et Chantilly exceptés, de transporter leur établissement à quinze lieues au moins de Paris. Signifié un mois après sa promulgation aux principaux fabricants, il ne fut pas plus efficace que ceux qui l'avaient précédé, et d'Angivilliers dut mème, en 1785, donner à Régnier l'ordre officiel de suspendre toutes poursuites. Par contre, cet arrèt eut pour la Manufacture Royale le fàcheux résultat de faciliter l'exode des ouvriers qui, mal rétribués à Sèvres et presque certains de l'impunité, n’hésitèrent plus à s'engager dans les fabriques particulières où on leur offrait des conditions meilleures.

En réalité, dès ce moment, ceux qui avaient la responsabilité morale de la Manufacture saraient combien serait inutile tout effort pour faire revivre les privilèges dans leur esprit ancien, et leurs protestations apparaissent comme de pure forme. La suppression progressive de tous les avantages accordés par Louis XV à sa Manufacture dut être considérée comme le triomphe définitif des principes des contrôleurs généraux et de M. Calonne en particulier qui avait inscrit dans le plan de réformes proposé à l'Assemblée des notables la suppression de tous les privilèges d'État. Aussi la dernière décision prise par Louis XVI le 17 janvier 1787 au sujet des fabriques de porcelaines, ne fit-elle que confirmer des libertés acquises en fait depuis plusieurs années. Par cet arrèt, que l’on a justement qualifié de « charte d'émancipation des porcelainiers », les manufactures de la 
Reine, de Monsieur, du comte d'Ariois, du due d'Angoulème, furent autorisées à fabriquer les objets antérieurement réservés à Sìves, sauf les ouvrages à fond d'or ou de grand luxe, tels que les tableaux sur porcelaine. Pour les autres établissements, les interdictions anciennes ne demeurèrent effeclives que jusqu'au jour où ils auraient fait constater, dans un eoncours ouvert chaque année à cet effet, la perfection de leur fabrication. C'était là une protection illusoire pour la Manufacture Royale, et M. de Calonne, qui avait rédigé l'arrèt, put penser que son but était définitivement atteint. Une curieuse lettre de M. de Montucla à Régnier montre d'ailleurs clairement dans quel esprit la décision avait été prise. "On ne “ nous a pas fait l'honneur, écrit-il le 6 mars 1787, de nous " envoyer encore un seul exemplaire de l'arrèt du Conseil relatif " aux manufactures de porcelaine. M. Régnier devrait en faire prendre " une demi-douzaine d'exemplaires pour voir ce qu’il chante. Enfin, “ si nous perdons ce procez, à quoi je m'attendais bien, ce n'a pas été " sans beaucoup écrire, car j’ai bien fait la valeur d'un volume in"quarto d'écritures faites, refaites, corrigées, augmentées; mais les " idées actuelles de liberté devaient prévaloir. "

D'Angivilliers s'efforça, nous l'avons dit, de pallier l'effet de ces mesures par un redoublement d'activité. Au lendemain de la promulgation de l'arrèt de 1787, il ne se découragea pas, et la correspondance de cette époque le montre renouvelant l'assortiment des pièces exposées chez les grands marchands de Paris, obtenant mème du Roi l'abandon de l'hòtel de Ménars pour y établir un dépôt central, projet qui d'ailleurs n’eut pas de suites. Ni la fabrication, ni les ventes ne cessaient d'être actives, et pourtant la situation allait toujours s'aggravant, car, si l'on achetait encore, on ne payait plus. Les gens de la Cour arguaient des retards apportés par le Trésor royal au règlement de leurs pensions pour demander un crédit presque illimité. Chaque mois, les mèmes difficultés renaissaient, en raison de 
la pénurie de fonds qui ne permettait mème pastoujour's de distribuer quelques acomptes aux ouvriers : en 1789, M. de Montucla dut personnellement avancer 3000 livres au eaissier pour donner à Thomire un peu d'argent sur la dette contractée envers lui cing ans plus

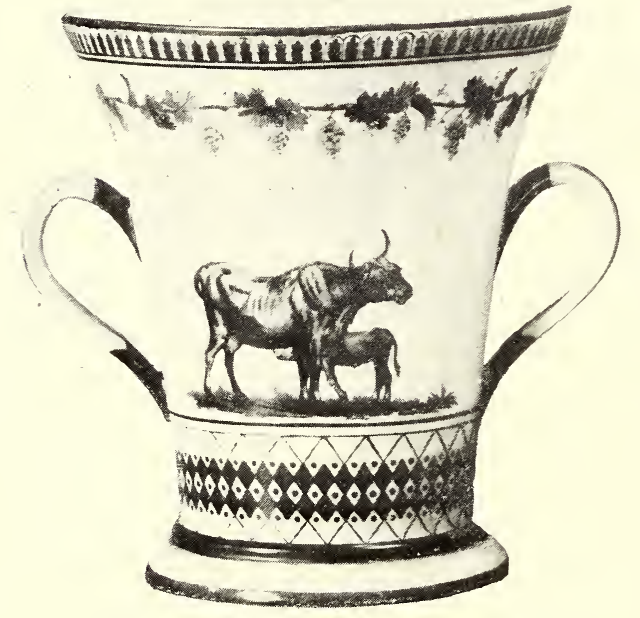

Gobelet à anses de la laiterie de Rambouillet. Peinture d'après Lagrenée. - Pàte dure (178s). Haut. 0,11. (Musée de Sèvres, no 6795.) tôt. Rien d'ailleurss ne saurait mieux faire eomprendre l'inquiétude dans laquelle vivait le personnel, que le mouvement de révolte dont le caissier Barrau faillit être luimême la vietime en novembre 1789 : à l'avis qui leur fut donné à cette époque d'attendre jusqu'au mois suivant le paiement des travaux arriérés, les ouvriers furieux répondirent en détachant une des lanternes de la potence qui la soutenait, et peu s'en fallut que Barrau n'y fùt pendu! Le problème du maintien de la Manufacture devenait chaque jour plus difficile à résoudre farorablement, car les essais de réorganisation économique devaient aroir pour résultat immédiat de eondamner une partie du personnel à une misère plus terrible eneore. La seule réforme efficace eût été de trouver des acheteurs solvables, et celle-là seule était impossible en ce temps où, selon le mot de Montucla, "tout "ce qui tenait au luxe es! sabré pour longtemps. Paris s’anéantit " peu à peu, écrivait-il alors; tous les gens opulents s'en vont " planter leurs choux dans leurs terres ».

Malgré celte situation pénible, Louis XVI ne put se résoudre à abandonner la Manufacture de Sirres. En 1790, un groupe de 
financiers lui ayant offert d'acquérir l'établissement dans des conditions avantageuses, il consulta d'Angivilliers sur l'opportunité d'une mesure aussi grave. Le Directeur des Bâtiments n'eut pas de peine à lui persuader que “ sa dignité exigeait qu’il essayât, au moins " pendant quelque temps, de maintenir la Manufacture », et le Roi écrivit aussitôt au bas du mémoire qui lui était présenté, les lignes suivantes: “Je garde la Manufacture de Sèrres à mes frais; mais " je veux qu'on en diminue el règle la dépense, de façon qu'elle ne "dépasse pas 100000 écus; et que les mois des ouvriers, à dater " de la fin de cette année, ne passent pas 12000 livres... On paiera " les dettes sur les produits des ventes, et je ne veux pas qu'il y en " ait, ce qui est très facile au moyen que je fais fournir les fonds sur " les dépenses de mes bâtiments... ». Quelle valeur pratique pouvaient avoir des instructions de ce genre, nous pensons l'avoir suffisamment montré : il était également impossible au Trésor royal de fournir des fonds pour payer les ouvriers et au caissier de liquider les dettes sur le produit des ventes. Ce geste de Louis XVI sauva du moins la Manufacture de la destruetion, et le décret rendu par l'Assemblée Nationale le 26 mai 1791 spécifia que ni Sèrres, ni les Gobelins ne seraient confondus avec les biens nationaux, mais qu'ils resteraient à la charge de la liste civile du Roi. 


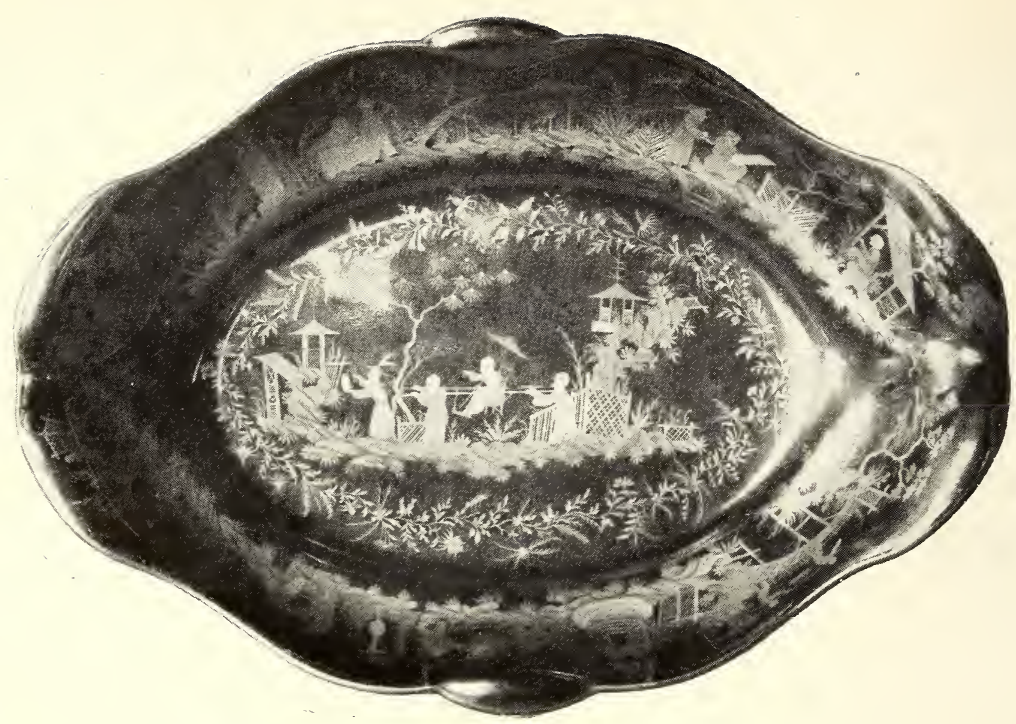

Guvette décorée en or sur fond noir imitant la laque, par Le Guay. Porcelaine dure (1791). (Musée de Sèvres, n 5291.)

\section{$\mathrm{V}$ \\ LA MANUFAGTURE PENDANT LA RÉVOLUTION \\ (1790-1800)}

La Manufacture fit partie du Domaine de la Couronne jusqu'au 12 août 1792 , date à laquelle le ministre des Contributions publiques fut chargé de l'administration des Domaines et Bàtiments de la Liste civile. Pendant les deux années précédentes, l'établissement avait pu, malgré l'abaissement continu du chiffre des ventes, se soutenir grâce à quelques maigres subsides accordés de temps en temps par le Roi. Mais déjà la direction avait perdu presque toute autorité en raison de l'importance prise à Sèvres par un club, composé en majeure partie d'ouvriers de la Manufacture, qui montra tout d'abord son activité en jetant la suspicion sur les chefs de la maison. En mai 1793, ce club provoqua un violent incident par la dénonciation à l'Assemblée Nationale du directeur Régnier, coupable, assurait-il, d'avoir brûlé quelques jours auparavant dans les fours 
de la Manufacture les fameuses "arehives du Comité autrichien », affaire qui eut son écho dans les délibérations de l'Assemblée el qui avail rraisemblablement pour point de départ la destruction du mémoire scandaleux de $\mathbf{I}^{\text {me }}$ de Lamotte contre Narie-Antoinette.

Après la chute de la royauté, une mesure immédiate fut prise, qui montre combien on croyait encore à cette époque aux secrets si jalousement défendus de la fabrication de la pàte tendre : sans plus tarder, en effel, on apposa les scellés sur les manuscrits décrivant les procédés, et l'on interdit à quiconque de les ouvrir hors la présence du commissaire des Manufactures que devait incessamment désigner le ministre Clavière. Pour remplir ces fonctions, on nomma bientòt un ancien administrateur de salines, nommé Haudry, qui établit tout d'abord une sorte deconseil composé des chefs d'atelier et chargé de l'administration intérieure de la Manufacture : Nous avons six " ateliers, disait le manifeste qu'il publia à celte occasion, et nous " devons les regarder comme six frères que nous adoptons pour " chérir avec nous notre vertueux père Roland et notre bonne mère "Patrie. ) Cette organisation n'eut d'autre résultat que d'enlever aux administrateurs demeurés en fonctions, Régnier et Hettlinger, le semblant d'autorité qui leur restait encore et de laisser le champ libre à quelques meneurs, à la tète desquels se signala le chef des fours, Ilenri-Florentin Chanou. Au début de 1793, IIandry, effrayé, semble-t-il, par les diffieultés qu'il rencontrait dans l'accomplissement de sa mission, abandonna définitivement l'administration de la Manufacture, qu’il laissa dans un état d'anarchie inquiétante et de plus dans une situation financière d'où il semblait impossible de sortir sans un secours inespéré. A cette date, on devait aux académicienschimistes et aux artistes principaux leur traitement depuis le mois de juillet 1791; quant aux ouvriers, ils recevaient, au hasard des rentrées de fonds, des acomples d'autant plus insuffisants que la cherté des vives grandissait sans cesse. Tous les moyens parurent 
bons, en ces temps désastreux, pour se procurer quelques subsides. Dans le but de suppléer autant que possible aux ventes annuelles de Versailles et des Tuileries, des loteries, des ventes aux enchères furent organisées, mais l'argent était aussi rare chez les particuliers que dans les caisses de l'État et ces expédients n’apportèrent pas un soulagement appréciable à la misère des artisans de Sèvres. Des mesures radicales furent prises, et c'est à ce moment que, par économie, on supprima les emplois de Bachelier, de Desmarets, de Darcet, conservant seulement Boizot et Lagrenée. La pénurie était au point que, pour exécuter les travaux urgents, on alla jusqu’à dédorer des pièces anciennes richement décorées!

Sur ces entrefaites, Garat devenu ministre prit la Manufacture dans ses attributions : un redoublement de zèle révolutionnaire se manifesta aussitôt dans les Comités qui exigèrent tout d'abord l'abandon de la marque aux deux L entrelacées, en usage depuis quarante années. Par une anomalie assez singulière, en effet, l'emploi des initiales royales s'était perpétué jusqu'alors, et c’est le 17 juillet 1793 seulement que Garat preserivit de substituer dorénavant à l'emblème choisi par Louis XV, le mot “Sèvres » accompagné des lettres initiales R. F. "République Française ». Peu après, le ministre trouva une nouvelle occasion de signaler l'ardeur de son zèle révolutionnaire, en invitant Régnier à réparer au plus vite la négligence dont il s'était rendu coupable par la conservation à Sèvres des bustes de la famille royale et de certaines pièces allégoriques du régime déchu. Au reçu de cet avis, Régnier entrevit certainement les conséquences fâcheuses que pourrait avoir pour lui tout délai dans la destruction de ce qui avait trait à " l'histoire des tyrans » : aussi, le soir même du jour où cet ordre lui élait parvenu, adressa-t-il au ministre la note suivante : "Sept personnes occu" pées sans relâche depuis quatre heures sont occupées à casser et “ à briser, et j'espère que demain matin, après a voir fait la plus scru- 
" puleuse recherche avee les chef's Le Riche, Roguier et Chanou, " il ne restera plus rien." - Il ne resta plus rien en effel à Sìvres des précieuses efligies qu'a vaient modelées Le Moyne, Pajou, Boizol, ele..., et ces quelques heures de vantalisme nous ont privés d'une partie certainement curieuse de la production de la Manufacture au xvm $^{\mathrm{e}}$ siècle. Ce geste un peu tardif ne sembla d'ailleur's pas aux plus violents parmi les orvriers une garantie suff:sante du loyalisme de Régnier, et lo Comilé de Sùreté Générale de Sèvres requit peu après le ministre d'avoir à exéculer la loi, à l'égard des membres de l'administration auxquels il refuserait le certifieat de civisme. Composé pour les deux tiers d'ourriers de l'ancien élablissement royal, ee Comité s'empressa de signaler comme suspects les direc-

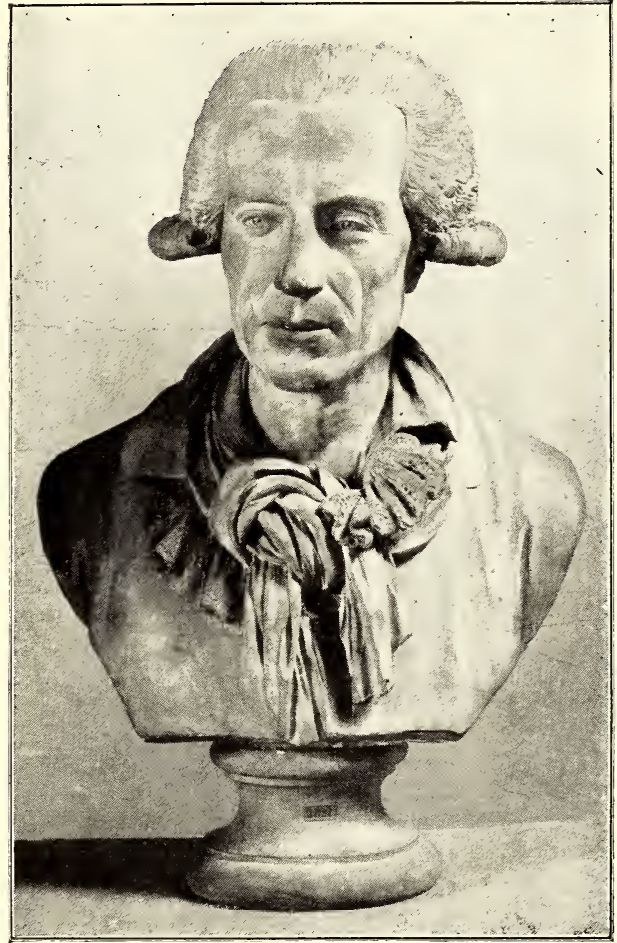

Buste d'flettlinger, par Roguier, sculpteur de la $\mathrm{M}^{1}{ }^{\circ}$. - Terre cuite. (Musée de Sèvres.) teurs Régnier et Itetllingèr, le caissier. Salmon et le chef des ateliers de peinture Caton, qui furent sans délai incarcérés à Sainte-Pélagie. Dans d'aussi déplorables conditions d'existence, la maison était, on le eonçoit sans peine, de plus en plus désorganisée. Pour y rétablir un peu d'ordre, la Convention nomma le député Battelier commissaire de la Manufacture; mais celui-ci se montra vite faligué des incessantes réclamations du Comité de Sèrres et pensa ne pou- 
voir y échapper sûrement qu'en déléguant ses pouroirs à l'un des membres les plus turbulents de ce Comité, Chanou, dont nous avons déjà cité le nom. L’administration de celui-ci, qui dura plus d'une année, peut ètre considérée comme la crise la plus dangereuse qu'ait subie l'établissement: ouvrier habile, mais faible de caractère, au surplus illettré et manquant de toutes les qualités nécessaires dans un emploi aussi difficile, Chanou se fit l'instrument des rancunes de ses anciens camarades et signala son passage par un retour aux plus regrettables errements de l'administration royale. A l'imitation des anciens directeurs, il usa bientôt de la Manufacture comme d'une propriété personnelle, dont il s'eflorça de tirer le plus de profits possible. Ses dilapidations finirent par attirer l'attention du Comité : deux délégués envoyés à Sèvres pour vérifier la caisse constatèrent un déficit important. Attaqué déjà par les artistes las de sa tyrannie et par Itettlinger enfin sorti de sa prison, il se défendit avec arrogance et commit la maladresse de menacer, si l'on persistait à demander sa destitution, de détourner les secrets dont il arait la garde. Cette attitude acheva de le perdre, et le Comité de l'A griculture et des Arts n’hésita plus à envoyer l’un de ses membres, Lhéritier, pour constater la présence des précieuses pièces et pour signifier à Chanou son renvoi définitif.

Un mois après, le 13 pluviôse an III, un arrèté du mème Comité modifia de fond en comble l'organisation de la Manufacture, qui fut confiée à trois directeurs disposant d'une autorité égale et recevant un traitement de 6000 francs. Hettlinger, Salmon l'aîné, François Meyer, chimiste distingué qui s’était fait connaître par ses études sur la préparation des couleurs, formèrent le Conseil de direction. tandis que Lagrenée et Boizot, éloignés un moment par la fantaisie de Chanou qui avait voulu leur substituer Wicart, l'élève de David, reprenaient leurs fonctions anciennes avec le concours nouveau du peintre de fleurs van Spaendonck. 
Si on excepte Meyer qui démissionna presque immédiatement, l'autorité demeura entre les mêmes mains jusqu’à la fin du siècle, détenue en fait par Itettlinger, très supérieur par l'intelligence el par les connaissances à son collègue Salmon. La première mesure prise fut de demander à Berthollet un plan complet de travaux : malheureusement la bonne volonté des directeurs, leur désir de rétablir l'ordre dans les ateliers se heurtèrent à des difficultés matérielles sans cesse renaissantes el à l'absence toujour's complète de numéraire dans les caisses de la Manufacture. On en était arrivé à cette époque à distribuer des secours en nature, pain, viande, chaussures, aux artistes et aux ourriers les plus nécessiteux : “Tous les ouvriers " sont épuisés par les besoins, souffrants et malades, éerivaient “ les directeurs; ils ont sacrifié la plupart tout ce qu’ils possédaient “ pour se procurer des vivres; quelques jours encore et ils seront “ forcés malgré leur attachement, leurs longs services, de quitter la " maison pour chercher ailleurs le pain qui leur manque... La direc" tion demande qu’il soit attribué à l'Élablissement National des " porcelaines de Sèrres une quantité suffisante de grains ou farine “ pour la nourrilure par jour de plus de 200 ouvriers. ” En réponse à cette supplique, le Comité de Salut Public décida que 60 quintaux de farine "pris dans les magasins de Franciade " seraient délivrés tous les mois au Directeur. Mais celle mesure de générosité n’était point suffisante, el le ministre de l'Intérieur Bénézecli put constater en thermidor an IV “ que la misère des artistes était telle que beaucoup avaient à rougir de leur nudité ». Prenant en main la cause de ces malheureux et rappelant tout ce que la Manufacture avait déjà livré à la République pour cadeaux diplomatiques ou autres, il réussit à obtenir du Directoire un secours extraordinaire de 207000 franes qui permit au personnel d'attendre des jours meilleurs, sans lui rendre toutefois la sécurilé que lui avait enlevée une longue période de misère. 
Il est d'ailleurs permis de se demander si cette somme fut intégralement versée à la Manufacture, car il apparaît bien que la détresse des ouvrier's fut à son comble en l'an VII, à l'époque où Dubois, chef de la $4^{\mathrm{e}}$ division du ministère de l'Intérieur, dut faire appel à la complaisance d'un banquier pour obtenir une avance

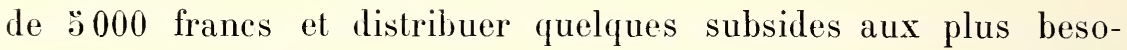
gneux. Alors la question se posa une fois de plus, à propos d'une pétition déposée au Conseil des Cinq Cents par le personnel de la Manufacture, de savoir si l'État devait conserver Sèvres. Les commissaires chargés de formuler un avis rédigèrent à cette occasion un chaleureux plaidoyer en faveur de la glorieuse fondation de Louis XV et firent des artistes un émouvant éloge. " G'est le pain " quotidien, dirent-ils, que réclament les artistes et ouvriers de la “Manufacture, et ce n’est qu'aubout de sept mois qu'ils font entendre " leur voix plaintive. Pendant ce long intervalle, ils ont vécu souvent " de la vente d'un modique mobilier et presque toujours sur un " crédit qui honore également les habilants de la commune de Sèvres " et les artistes dans lesquels ils ont eu confiance; elle prouve la " bonne conduite des uns et la bienfaisante humanité des autres. » Les commissaires conclurent nettement en faveur du maintien de la Manufacture comme propriété nationale, souhaitant qu'elle devînt de plus en plus un laboratoire d'essais appliqué au perfectionnement de l'industrie, devenue si réellement française, de la porcelaine. A la suite de cette enquête, les bureaux du ministère de l'Intérieur étudièrent un nouveau plan de réforme complète qui devait avoir pour premières conséquences la limitation du nombre des ouvriers et la nomination, à la tête de la Manufacture, d'un directeur énergique, capable d'enrayer la désorganisation croissante. Hettlinger, malade, vieilli par les circonstances, sembla incapable d'assumer cette lourde tâche; Salmon, honnête homme, mais sans initiative, était encore moins désigné pour mener à bien l'œuvre de rénovation que l'on 
projetait d'aecomplir à Sèvres. C'était done hors de la Manufacture qu’il fallait trouver un homme assez audacieux pour affronter tant de difficultés réunies. Berthollct, consulté sur ce choix délicat, proposa un jeune homme de trente ans, Alexandre Brongniart, le fils de l'architecte de la Bourse, inspecteur des Mines et titulaire depuis trois ans de la chaire d'histoire naturelle au College des Quatre-Nations. Lucien Bonaparte ratifia le choix de Berthollet, et le 25 floréal an VIII, Brongniart fut officiellement appelé au poste qu’il allait oceuper pendant quarante-sept années, jusqu’à sa mort.

Est-il besoin de dire que la production de ces années troublées se ressentit du désordre croissant et accusa une déeadence profonde dans l'art de la porcelaine? Sans parler des déplorables conditions matérielles dans lesquels ils vivaient, les artistes de Sèvres, incertains du lendemain, mal payés, ne trouvaient mème pas alors l'occasion d'employer leurs talents, car on ne leur demandait plus de déeorer, comme au temps de Louis XV, de somptueux services, mais seulement de produire hàtivement des pièces quelconques, destinées à satisfaire le goùt des exportateurs. Hettlinger arait jugé très nettement la situation, lorsquien 1793 il proposa au ministre, pour conserver la Manufacture, de se séparer des meilleurs artistes, de ceux qu'il appelait " les matadors en peinture et en sculpture », faisant valoir que leurs ouvres délicates n’étaient plus en harmonie a vee le goût du temps, et de se consacrer à une production moyenne qui s'adresserait surtout aux marchands et aux étrangers. L'exode des vieux artistes. de ces hommes qu’un séjour prolongé dans les ateliers de Sèves avait faits les dépositaires des traditions de la Manufacture, se réalisa d'ailleurs par le fait mème des eirconstances. Le manque de travaux en chassa un certain nombre, mais ils s'éloignèrent surtout à cause des persécutions dont ils furent l'objet de la part des comités révolutionnaires : leurs longs services 
dans un élablissement royal avaient suffi à les rendre suspects d'attachement au régime déchu, et les vexations, les menaces d'incarcération même dont quelques-uns furent l'objet, effrayèrent les autres qui préférèrent chercher ailleurs une existence plus calme.

Pendant ces années, le chiffre des rentes alla toujours en décroissant depuis 1792 jusqu'en l'an VII, où elles n’atteignnirent même pas 42000 francs. Tant que la Cour subsista, le Roi et son entourage firent encore, chaque année, quelques acquisitions - limitées à des pièces de service - soit dans le cours de l'année, soit à l'exposition de Noël transférée, à partir de 1791, de Versailles aux Tuileries. Mais, après la chute de la monarchie, la Manufacture n'eut plus à compter que sur les ventes aux marchands, et ceux-ci, achetant la plupart du temps pour l'étranger, appréciaient médiocrement les décors nouveaux, sans stỵle et mal exécutés, qu’on leur proposait alors et portaient leur choix sur des porcelaines d'ancienne fabrication, décorées dans la manière traditionnelle de Sèvres et appropriées par là au goût de leurs clients. Quant aux commandes officielles, elles cessèrent presque complètement jusqu’à la formation du Directoire; mais il semble qu’à ce moment, après les jours d'épreuve que l'on venait de traverser, les hommes en place aient ressenti le besoin de connaître tous les raffinements du luxe et de goûter un peu la douceur de la vie d'autrefois. En une seule commande, 102941 francs de porcelaine el de biscuits - cotés en valeur de 1789 - furent choisis pour l'ornementation des salons et de la table des Directeurs; et à la mème date les ministres, eux aussi, emplirent de pièces somptueuses et de sculptures dans le goût de Louis XVI les palais qui venaient de leur être affectés. De grands cadeaux diplomatiques, enfin, composés presque uniformément d'un service de 24 couverts et d'un surtout plus ou moins important, furent faits au nom de la République aux ambassadeurs des puissances voisines avec une prodigalité qu'a vait toujour's ignorée la royauté. Nalheu- 
reusement toutes ces livraisons n'eurent, pour la Nanufacture, d'autre effet que de dégarnir complètement les magasins sans faire rentrer dans ses caisses la valeur des pièces sorties, car le gouvernement s'accorda un crédit illimité, et Talleyrand, entre autres, se refusa absolument à payer les 290000 francs de porcelaines qu il arait reçues au
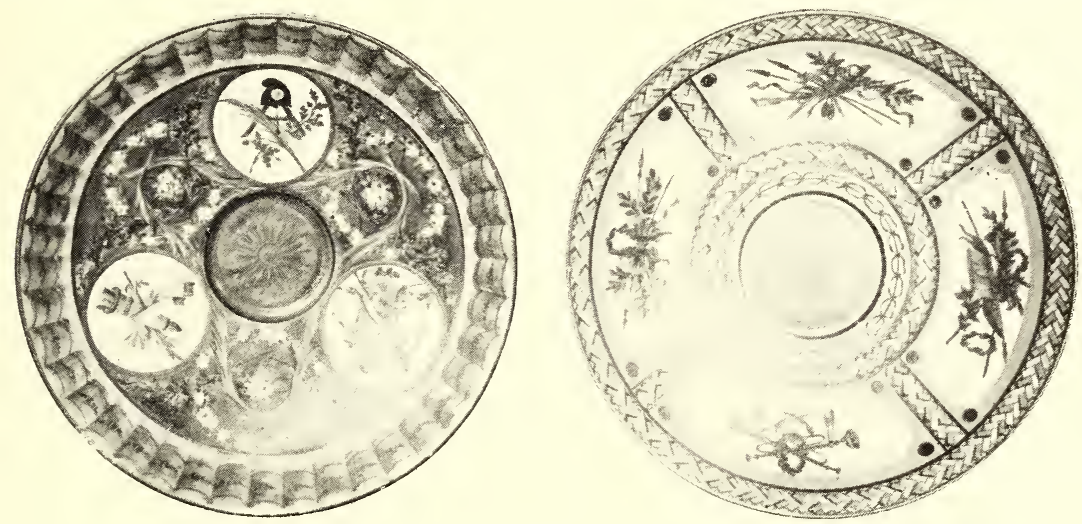

Assiettes décorées d’emblèmes rérolutionnaires (1793-1795). (IIusée de Sèrres, $n^{05} 8068$ et 9319.$)$

compte du ministère des Affaires étrangères. On essaya bien de relever d'une façon factice le ehiffre des ventes en organisant à plusieurs reprises, entre 1793 et 1800 , des ventes aux enchères ou des loteries: ainsien 1793, deux vacations eurent lieu dans les magasins de Daguerre et Lignereux, les dépositaires de la Manufacture, et produisirent 90000 franes, représentant au plus le tiers de la valeur des pièces vendues; mais on s'aperçut vite que les acheteurs étaient tous des marchands qui s'étaient préalablement entendus pour empêcher les objets d'atteindre des prix raisonnables. Quant aux loteries organisées au château de Saint-Cloud dans le but de venir en aide aux ouvriers de Sèvres, des Gobelins et de la Savonnerie, le maigre produit qu'elles donnèrent se trouva absorbé par les frais d'installation et par les prélèvements au profit des entreprencurs. On en arriva alors à des mesures dont les conséquences devaient ètre plus graves et se pro- 
longer jusqu’à nosjours : car c'est à ce moment que la Manufacture se vit contrainte, afin de se procurer quelque argent, d'aliéner pour une somme de 33000 francs une énorme quantité de pièces de rebut, qui servirent dans la suite à faire ce genre de contrefaçon qu'on nomme le surdécor, d'autant plus difficile à reconnaître que la matière est bien de la véritable poreelaine de Sèvres, et que seuls le caractère des ornements ou la maladresse de l'exéeution permettent d'établir l'origine véritable des pièces.

De toutes les ventes, on vit disparaître peu à peu les objets de haut luxe ou d'élégante inutilité qui avaient caractérisé la production de Sèvres sous la monarchie : vases décorés et sculpture devinrent très rares, jusqu'en 1796 tout au moins. Et, à ce sujet, il n'est pas inutile d'indiquer que la seulpture révolutionnaire de Sèvres, dont on a beaucoup parlé, se réduisit en réalité à un petit nombre de groupes et de figures qui sont demeurés connus beaucoup plus en raison des titres sonores qu'on leur avait donnés que de la fréquence de leur reproduction. Il est certain que la Manufacture fabriqua alors, sans doute d'après des maquettes de Boizot, des groupes comme la France gardant sa constitution, la France libre, la France guidée par la raison, la Liberté présentant les vertus civiques; il est établi aussi que la Convention commanda à Sèvres un surtout de dimensions colossales, dont le sujet était le Despotisme jeté à bas de son piédestal et entrainant la noblesse dans sa chute; mais ces pièces de circonstances, dont certaines n'étaient peut-être qu'un gage de loyalisme offert par les ouvriers au gouvernement, ne pouvaient devenir un objet de vente; elles ne pouvaient davantage entrer dans la composition des services offerts par la République aux souverains ou à leurs représentants. Cette sculpture, par son caractère mème, ne convenait absolument qu’à la décoration des palais des ministres : or ceux-ei semblent avoir manifesté un goût beaucoup plus vif pour la sculpture du temps de 
Louis XV et de Louis XVI, que pour ces allégories compliquées et froides. Dans l'énorme quantité de pièces qui fut attribuée aux membres du Directoire en 179.9, trois groupes seulement représentaient la production contemporaine, et lorsqu'à la fête commémorative de la fondation de la République en l'an VI, on distribua des biscuits de Sèvres à titre de prix, les sujets choisis furent le Triomphe de la Beauté et le Sacrifice d'Iphigénie. Par un extraordinaire retour vers le passé, on vit alors les ceuvres des périodes antérieures retrouver le succès qui les avait accueillies à leur apparition, et entre 1796 et 1800 on mit en vente, avec un égal succès, les groupes et les figurines des caractères les plus différents. Si l'on voulait trouver dans la production de la Manufacture la trace des événements actuels, il faudrait plutôt la chercher dans la reproduction des effigies contemporaines que dans les groupes ou les figures symboliques. Ainsi, en 1792, on fabriqua encore les bustes du Prince Royal et de Madame Royale; tandis que l'année suivante les personnages représentés furent Bıutus, J.-J. Rousseau en romain, Danton, Marat, Lepelletier Saint-Fargeau, Robespierre; deux ans plus tard, la Manufacture reproduisit les traits des jeunes héros des guerres de la République, Bara et Viala, et à partir de ce moment, les préoccupations guerrières de la fin du siècle se révélèrent par la commande faite à Boizot des bustes des généraux vainqueurs, Joubert, Marceau, Hoche, Bonaparte enfin. Le premier portrait de eelui-ci exécuté en biscuit parut à l'oecasion de la grande fête donnée en son honneur par le Directoire, le 20 frimaire an VI ; on en offrit alors un exemplaire à tous les ministres, aux ambassadeurs, aux représentants des puissances étrangères. A cette réception solennelle, d'ailleurs, la Manufacture avait apporté un concours effectif par le prêt d'énormes quantités de porcelaines demandées pour le banquet offert au triomphateur.

Une remarque du mème ordre peut s'appliquer à tout ee qui 
concerne le style des décorations peintes, et il n’y a guère entre les ornementations des dernières années de Louis XVI et celles de la période révolutionnaire d'autre différence que celle d'une exécution

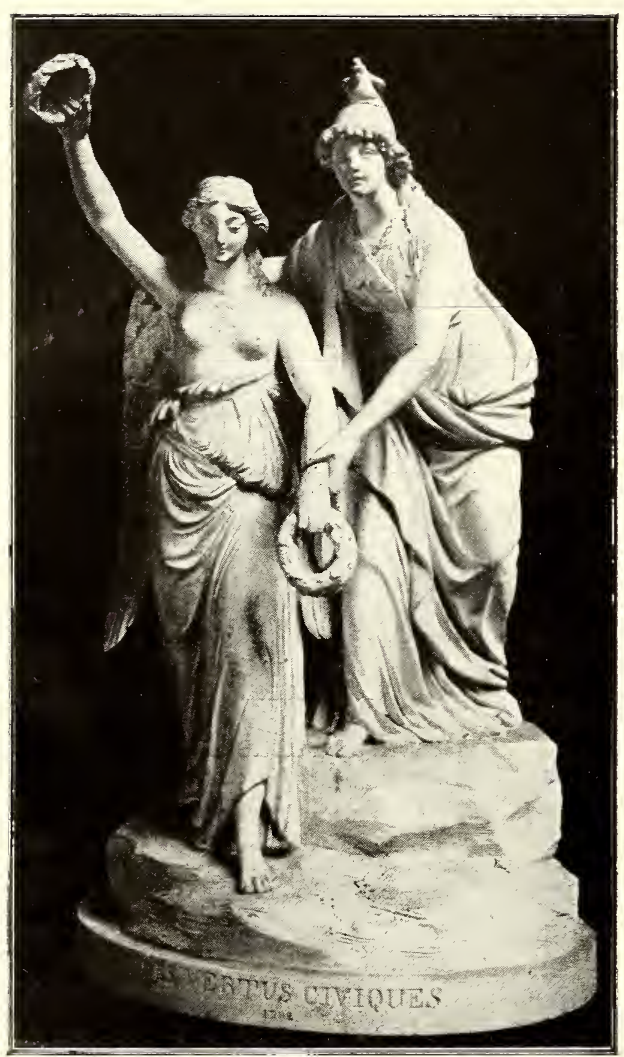

La Liberté présentant les vertus civiques. Modèle de 1792. (Haut. 0,50). médiocre après 1790 et excellente auparavant. Nous avons indiqué plus haut les causes réelles de cette décadence qui s'étendit jusqu'à la fabrication même des pièces : à aucune époque, la porcelaine ne montra tant de défauts, une matière aussi grossière, une couverte aussi terne et sale. La formule de décoration des pièces de service - qui représentèrent alors la part la plus considérable de la production - presque toujours la même, fut caractérisée par une utilisation mesquine des éléments em. ployés auparavant : sur les assiettes, des guirlandes ou de minces rubans de couleurs vives courant sur le marli, alternaient avec de légères fleurettes, roses, jonquilles, bleuets ou pensées. D’autres services présentaient des zones de diverses couleurs, bleu, jaune ardent, vert céladon, ornées aussi de bouquets ou de semis de fleurs. Ce retour au décor floral s'explique fort bien d'ailleurs, non seulement par le goùt des acheteurs, mais par l'habileté médiocre des décorateurs demeurés dans les ateliers de Sèvres; 
et, lorsqu'on lit qu'en 1793 le Comité de Salut publie fit don au ministre du Roide Prusse d'un service valant 47600 francs et décoré d'après les arabesques de Raphä̈l, il ne faut pas attribuer le choix de cette ornementation aux artistes contemporains, mais se rappeler que les dessins de ce service avaient été faits dix ans plus tòt sous la direction de l'architecte Masson; la peinture mème des pièces datait peut-ètre de la période royale.

Entre 1790 et $179 \%$, les emblèmes rérolutionnaires, faisceaux de licteurs, cocardes tricolores, bonnets phrygiens, se mèlerent maladroitement aux ornements demeurés de style Louis XVI, et il y a lieu de remarquer ici combien peu les artistes de Sèrres s'assimilèrent la formule de l'art contemporain. Leur éducation, faite pour la plupart à la Manufacture mème, ne leur permetlait guère de s'adapter aux conceptions nourelles, et c'est ainsi que, la tourmente passée, ils revinrent tout naturellement, pendant les dernières années du siècle, au genre de décors dont ils avaient l'habitude. Dans les grandes pièees cependant, vases ou objets d'apparat, l'influence de plus en plus forte de l'antiqquité greeque et romaine se marqua fortement, laissant préroir le triomphe des tendances qui s'affirmèrent sous l'Empire : la raison en est dans le fait que, pour les objets importants, la composition, au lieu d'ètre abandonnée à l'inspiration d'un peintre quelconque, était presque toujours établie par Lagrenée le jeune, sur des formes que dessmait Boizot. Quant aux quelques essais curieux qui datent de cette époque, tels que les décors en ors de divers tons se détachant sur un fond noir imitant la laque de Chine, ils eurent tous pour auteurs quelqu'un de ces vieux artistes dont l'ingéniosité et le goùt avaient assuré, depuis un demi-siècle, la supériorité de la Manufacture.

A les considérer dans leur ensemble, ces dix années ne présentent aucun progrès, aucun effort nouveau; bien au contraire, elles portent tous les stigmates d'une décadence profonde de la valeur 
artistique comme de la main-d'œuvre. Lorsque l'on voit à quel point en était arrivée la production de Sèvres en l'an VII, on comprend mieux encore les raisons qui conduisirent Berthollet à proposer Brongniart pour diriger la Manufacture. Seule une énergie jeune, une activité puissante pouvaient tenter de relever l'établissement désorganisé par l'absence de toute administration régulière. Lt l'on s'explique aussi comment les tendances autoritaires du nouveau directeur, l'absolutisme parfois étroit de ses idées, furent peut-être les leviers qui lui permirent de faire rentrer la Manufacture dans une voie normale. 


\section{I}

\section{LA MANUFAGTURE DE SĖVRES AU XIX SIÉGLE}

(1800-1876)

Brongniart fut appelé à la direction de la Manufacture par une lettre de Lueien Bonaparte, ministre de l'Intérieur, en date du 2.3 floréal an VIII (14 mai 1800). Cette nomination complétait le plan de réforme absolue proposé peu auparavant par Costaz, chef du bureau des Arts et Manufactures, dont l'influence eut alors une action décisive sur les destinées de Sèvres. Nous avons vu combien, jusqu’à ce moment, le gouvernement était demeuré indifférent aux justes réclamations des ouvriers de la Manufacture : tout récenment encore les pétitions adressées, l'une au Conseil des Cinq-Cents, l'autre au Premier Consul lui-même, avaient donné lieu à une enquête sans résultats. Il fallut l'initiative de ce modeste agent du ministre de l'Intérieur pour laisser entrevoir enfin l’issue de la crise redoutable que la Manufacture traversait depuis dix ans. Costaz, après une étude approfondie de la situation linancière de l'établissement, avait reconnu que la première mesure à prendre était le lieenciement d'un grand nombre d'ourriers qui, vieillis, devenus incapables d'un travail régulier, grevaient lourdement le budget de la maison, la coutume s'étant perpétuée de leur payer leur traitement complet jusqu'à leur mort, quelles que fussent d'ailleurs la quantité et la valeur de leurs travaux. D'autre part, ayant constaté l'absence de tous progrès récents dans la fabrication, il insista pour que la direction de la Manufacture fùt eonfiée à un chimiste, de qui 
l'on pourrait exiger, en dehors de ses attributions administratives, des recherehes de laboratoire s'appliquant à l'ensemble des matières céramiques et vitriques. Par là il voulait donner à Sèvres un caractère déterminé de " conservatoire des arts céramiques ». Berthollet avait approuvé complètement les propositions hardies de Costaz, et e'est ainsi que, à la date même où Brongniart arriva à Sèvres, 159 ouvriers, sur 220 qu’occupait alors la Manufacture, furent licenciés. Ceux-là seuls qui, âgés de soixante ans, avaient vingt ans de présence dans la maison, furent admis au bénéfice d'une modeste pension annuelle. A la direction, on laissa, en raison de leurs services passés, Hettlinger avec le titre d'administrateuradjoint, Salmon dans l'emploi de caissier; mais dés ce moment toute l'autorité appartint dans la maison à Alexandre Brongniart, et à lui seul.

Le premier souci du nouvel administrateur fut de rétablir le plus rapidement possible les finances de la Manufacture : en 1800, le passif s'élevait à 202001 franes, dont les trois quarts étaient dus aux artistes et aux ouvriers sur leurs traitements des dernières années. Quant à l'actif représenté par les porcelaines décorées ou en cours d'exécution, Hettlinger et Salmon lui avaient donné, d'après les prix marqués sur les pièces, une valeur de 947761 francs; mais. Brongniart, désireux avant tout de connaître la valeur marchande de cette énorme quantité de marchandises, s'empressa de faire procéder à une expertise dont le résultat fut de diminuer de plus de moitié le chiffre annoncé par les anciens directeurs. Pour obtenir immédiatement quelques fonds, Brongniart donna tout d'abord son approbation à l'arrangement qui venait d'ètre pris avec les banquiers Lemercier et $\mathrm{C}^{\text {ie }}$ en vue de l'exportation en Russie et en Anglelerre de 100000 franes de porcelaines, cédées par la Manufacture avec un rabais de 30 p. 100 . Puis il obtint l'autorisation de faire au Louvre, du 2:3 fructidor an VIII au 8 vendémiajre an IX, une 
vente aux enchìres qui, tous frais payés, laissa 3.3000 francs dans la caisse de l'établissement. Celte somme, jointe aux 15000 franes que remit alors le Gouvernement, permit déjà de distribuer quelque argent aux fournisseurs ot aux ouvriers les plus nécessiteux.

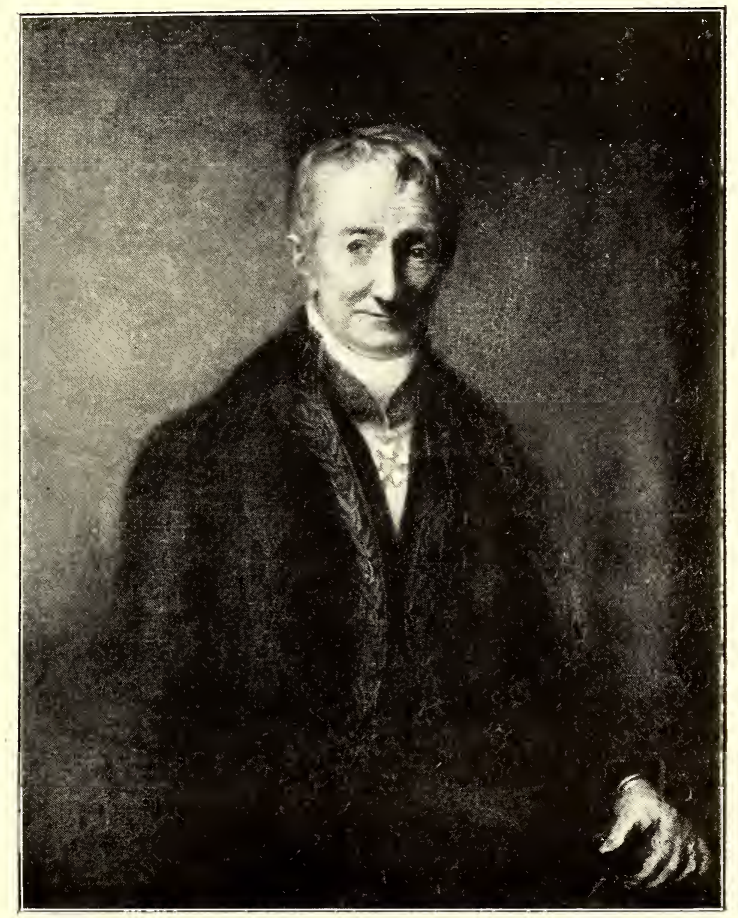

Alexandre Brongniart (1770-18'7), par E. Wattier. (Musée de Sèvres.)

L'année suivante, Costaz assura à la Manufacture une allocation mensuelle de $\$ 000$ franes, mais par contre il ne voulut jamais reconnaitre la légitimilé de la dette contractée par le Directoire, qui s'était fait livrer 376000 franes de porcelaines sans verser la moindre somme en paiement. L’impossibilité de réeupérer ces créances anciennes explique comment Brongniart, malgré son ordre et son économie, ne parvint que trìs lentement à éteindre les dettes de la Manufacture: au $1^{\text {er }}$ vendémiaire an XIII, époque à laquelle Sèvres fut rattachée à 
la liste civile de l'Empereur, elles s'élevaient encore à 109000 francs, qui furent payés en bons de la Caisse d'Amortissement.

Depuis lors, la Manufacture a vécu, jusqu'en 1870, subventionnée par les listes civiles, sauf en 1848 où elle rentra pour quelques années dans le domaine de l'État, qui assura son fonctionnement normal par l'inscription d'un crédit annuel au budget. La direction financière de Brongniart apparaîlrait comme un exemple d'administration remarquable, s’il n’avait recouru, à plusieurs reprises, à un genre d’opérations désastreuses par la dépréciation dont elles frappent les produits : c'est le système des ventes aux enchères et des ventes globales moyennant un prix d'ensemble. De telles mesures étaient encore admissibles en 1800 , car à ce moment il fallail trouver de l'argent ou renoncer à l'exploitation de la Manufacture; mais Brongniart les renouvela de 1816 à 1819, quand il vendit pour 50000 francs à Irlande, Perez et Jamar une énorme quantité d'objets de pâte tendre, en biscuit, en train d'être décorés ou terminés. Plus tard, en 1826, à l'occasion du transfert du dépôt que la Manufacture avait depuis huit ans $5 \%$ rue Sainte-Anne, il organisa une vente aux enchères de " pièces de rebut ou démodées 》 qui produisit 35000 franes, accusant une perte de 79 p. 100 sur les prix véritables des objets. Enfin, en 1840, après avoir demandé l'autorisation de supprimer le dépôt de Paris qui, en fait, n’avait jamais été qu'une charge pour la Manufacture, il organisa une dernière vente aux enchères : cette fois la perte fut de 84 p. 100, le produit ayant été de 20299 franes pour 126777 franes de marchandises !

On s'explique difficilement les raisons qui déterminèrent Brongniart à aliéner dans d'aussi mauvaises conditions les produits de la Manufacture, et sans doute obéit-il simplement au désir d'éliminer de temps en temps ce qu’il considérait comme inparfait. Mais cette pratique a eu pour effet inmédial de créer dans le public une confusion préjudiciable à la fois à la vente et au bon renom de Sèvres. 
Brongniart, d'ailleurs, apporia, dans la direction générale donnée à la maison, des idées très différentes de celles du xvir ${ }^{\mathrm{e}}$ siècle, idées que l'absenee de toute préoceupation financière lui permil de réaliser en grande partie. N'ayant plus, gràce aux subventions des listes civiles, à couvrir les dépenses par le produit des ventes, il s'efforça de donner à la Manufaclure ce caractère de « conservatoire des arts céramiques et vilriques » qu'avait préconisé Costaz dans son rapport à Lueien Bonaparte. Il n'aceorda jamais qu’une importance secondaire au point de vue commercial, et on ne saurait mieux définir ses idées sur eette question qu'en citant ees deux phrases écrites par lui en 1830 : “Ce n’est pas par la porcelaine " que la Manufacture meltra dans le commercequ'elle conservera son " influence sur l'industrie: elle la conserverait encore, lor's mème " qu'elle n’y meltrail pas une piece; il suffit qu’elle fasse du bruit “ en Europe par ses produits de luxe, par ses grandespièces, pour " que sa réputation s'attache à toute la porcelaine française. C'est " ainsi que la Manufacture de Sères, en faisant des pièces que per" sonne n’achète, a rendu de grands services au commerce de la por" eelaine. " Ces quelques mots constituent toul un programme et délerminent le ròle d'utilité générale que Brongniart a vait assigné à l'établissement qu'il dirigeait. Tous ses efforts devaient tendre vers les progrès industriels, et c'est pour bien marquer celte orientation nouvelle qu'en l'an IX il modifia l'organisation intérieure de la maison, en créant à còté des "départements " de la fabrieation el de la décoration, celui de la "chimie », chargé de la préparation des couleurs el de la euisson des peintures. Il ne négligea d'ailleurs rien pour pousser ses collaborateurs dans la roie des recherehes, el à plusieurs reprises il accorda des encouragements à ceux qui réussirent. Ainsi, en 1802, Benoîl Chanou reçut 200 franes pour ses découvertes de la pâte imilant le bronze et du procédé d'application du bleu de pâte tendre sur la porcelaine dure: l’année suivante, le 
chimiste Méreaud fut gratifié d'une somme égale à la suite de ses recherches sur les couleurs de peinture sur verre.

Surtout il convient de parler ici des travaux personnels de Brongniart à Sèrres, travaux qui eurent tous pour objet le perfectionnement de la pâte dure, puisque, peu après son arrivée, en 1804, il avait décidé d'abandonner complètement la fabrication de la porcelaine tendre dont l’infériorité au point de vue chimique lui arait peutêtre trop facilement fait oublier la réelle valeur artistique. Ses recherehes, dans lesquelles il fut aidé successivement par les chimistes Laurent, Malaguti et Salvetat, aboutirent à la publication de deux ourrages considérables, le Traité des Arts Céramiques et le Catalogue du Musée Céramique, qui sont demeurés les livres fondamentaux sur ces matières. En ce qui concerne la porcelaine même, il établit la formule définitive de la composition de la pàte dure, formule qui, aujourd'hui encore, est généralement employée pour la fabrication des pièces de service; il substitua à la glaçure ealcaire dont elle était recouverte jusqualor's la pegmatite qui, se vitrifiant à une température plus élevée, acquiert par là une résistance supérieure. D'autre part, il composa une palette de couleurs vitrifiables extrèmement riche, qui permit d'exécuter avec une scrupuleuse exactitude les copies de tableaux dont le succès fut considérable entre 181 ŏ et 18000 . Ces travaux de Brongniart se combinèrent avec les nombreuses études quil fit en même temps comme géologue, et les voyages qu'il entreprit successivement à travers tous les pays d'Europe eurent tous un but scientifique, qui était de recueillir des données précises sur la constitution du sous-sol dans les régions qu'il traversait, et un but pratique qui était de noter les procédés dont il constatait l'emploi dans les usines eéramiques.

Au point de vue purement administratif, Brongniart organisa chaque chose avec la précision que l'on retrouve dans tous ses actes. Son souci de l'ordre le conduisit à l'élaboration pour chaque service 
de règlements particuliers dont beaucoup sont demeurés en vigueur jusqu’̀̀ nos jours. Parmi ses innovations, l'une des plus utiles fut sans doute l'institution en 1806 de la "Conférence hebdomadaire » dans laquelle il appela tous les chefs à rendre compte de la marche des services placés sous leurs ordres, voulant ainsi créer un lien

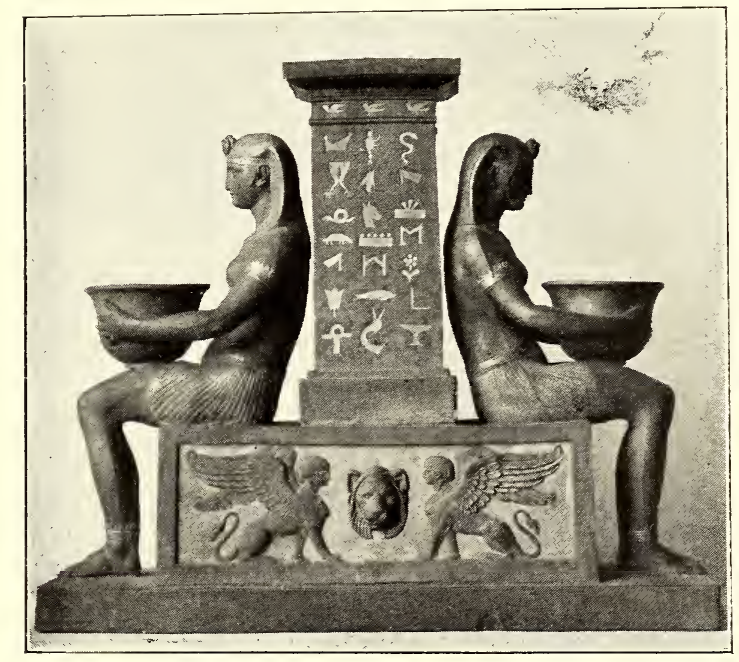

Encrier en pâte de biscuit imitant le bronze, avec ornements eñ or.' (II. 0,22). Porcelaine dure (1802). (Musée de Sèvres, n²648.)

entre les divers éléments de la maison et stimuler l'activité de chacun par une mutuelle appréciation des travaux entrepris.

Dans ses relations arec l'autorité supérieure, Brongniart demeura l'exéeuteur fidèle des instruetions qu’il reçut des divers régimes aux: quels il fut soumis, pendant les quarante-sept années de son administration. Peut-être, dans cet ordre d'idées, est-il permis de regretter que cet homme, si ferme dans la conduite intérieure de l'établissement, ait fait preure d'une obéissance trop absolue dans l'exécution de certains ordres et qu'il ait parfois trop eomplètement oublié les bienfaits du régime précédent. Certainement, si en 181 ว il arait opposé quelque résistance au ministre de la Maison du Roi, nous n’aurions 
pas à déplorer aujourd'hui la destruction, à laquelle il se prêta, de tous les modèles, bustes, figures, médaillons, vases en train d'être décorés, dont le sujet avait trait à la famille de Napoléon. Un tel acte de vandalisme peut encore s'expliquer en 1793, sous la domination des

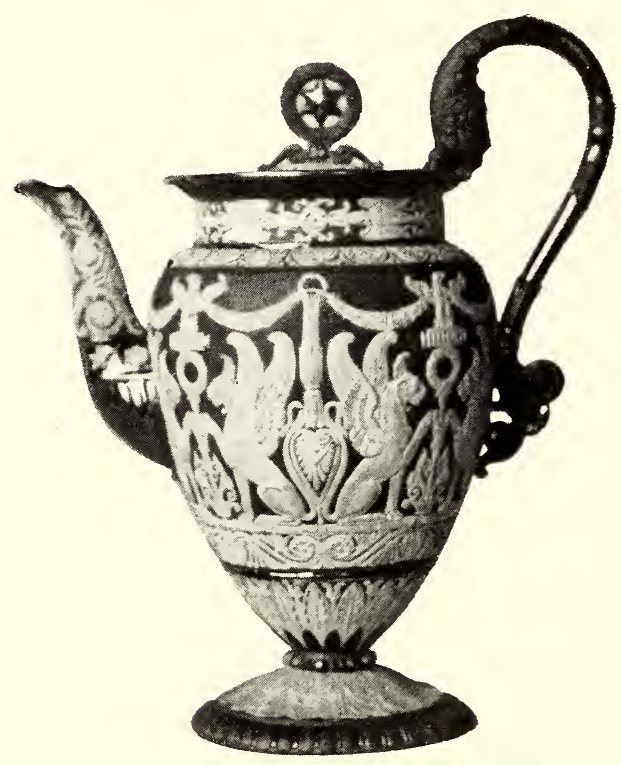

Théière décorée de sujets en biscuits sur fond d'or, d'après Régnier. - Porcelaine dure 1812. (Musée de Sèvres, nº 6160.) Comités révolutionnaires, mais il prend un caractère particulièrement odieuxlorsqu'il est le fait d'un gouvernement régulier. Brongniart, personnellement, devait beaucoup à Bonaparte et l'on eût souhaité trouver chez lui une protestation contre cet acte brutal au lieu de la soumission passive dont il fit preuve dans ces circonstances.

Quant aux ceuvres que produisit la Manufacture pendant la longue période qui va de 1800 à 1847, il faut reconnaître que la remarquable perfection matérielle à laquellè la science de Brongniart permit d'atteindre ne s'appliqua généralement qu’à des œuvres d'une valeur artistique tout à fait contestable et n'aboutit jamais à la création d'un style caractérisé, comparable à celui de Vincennes et de Sèvres au siècle précédent. Autant il était nécessaire, sous Louis XV et Louis XVI, d'étudier les œuvres dan's leur infinie diversité, autant à cette époque l'ensemble de la production peut être caractérisée par quelques formules, à peine modifiées pendant un demi-siècle. Dès le début de l'Empire, les formes gracieusés du xvmr siècle furent abandonnées de parli pris, et remplacées par l'art rigide et froid qui 
triomphait alors. Le blanc de la porcelaine, suivant une tendance qui s'accentuait depuis un certain temps déjà, disparut complètement sous des fonds de couleurs, des compositions ou de lourdes dorures, auxquelles une exécution impeccable ne parvint pas à donner une réelle valeur artistique. Enfin, une nouvelle génération de décorateurs ne tarda pas à remplacer ceux qui, mème en pleine décadence révolutionnaire, avaient conservé quelque chose de l'esprit de l'époque monarchique et qui, du moins, avaient la pratique traditionnelle de leur métier. Les artistes que choisit Brongniart étaient, pour la plupart, des hommes de talent, instruits et habiles, mais peu avertis de tout ce qui avait trait à la technique de la décoration sur porcelaine. Les uns étaient des peintres de figures, les autres se consaeraient plus spécialement au décor floral ou ornemental, chaeun d'eux restant spécialisé dans un genre partieulier : ainsi se généralisa la déplorable méthode qui consiste dans l'emploi de plusieurs mains pour la décoration d'une mème pièce, sans se préoccuper de l'harmonie de l'ensemble, impossible à oblenir dans ces conditions. D'autre part, les hommes auxquels Brongniart demanda de nouvelles formes et des déeors originaux, Brongniart père, Percier, Isabey et autres artistes de grande valeur, étaient mal préparés à ce genre de travaux qui exigent une connaissance approfondie des ressources et des conditions d'emploi de la matière.

Les premières années de la période impériale furent marquées, nous l'avons dit, par un renouvellement général des formes, aussi bien pour les pièces de service que pour les vases. Les modeles du xvir e sicele, en effel, se prètaient mal au genre de décoration capable de satisfaire le goùt du public et surtout de répondre aux intentions de Napoléon, qui semble avoir vu très rapidement le parti qu’il pouvait tirer de Sèvres pour sa renommée. Pendant toule la durée de son règne, il condamna la Manufacture à retracer sans cesse, sur les assiettes aussi bien que sur les grandes pièces décoratives, les 
principaux faits de son existence. Les formes anciennes n'offraient pas aux décorateurs un champ assez vaste pour le but que se proposait l'Empereur, et c'est pour cela sans doute que l'on emprunta alors à l'art antique des formes très simples qui avaient du moins l'arantage de présenter de larges surfaces faciles à orner. Brongniart père fut appelé à donner ainsi dès 1801 le profil du vase Cordelier, puis avant 180 马 le vase OEuf, le vase Fuseau, le vase Floréal. A la mème époque, Percier dessina le vase qui a gardé son nom, tandis que, peu d'années après, parurent le vase étrusque à rouleaux (1809), le vase étrusque cylindré, le vase carafe étrusque (1810), déjà plus eompliqués et plus lourds. Sur ces formes d'une hauteur moyenne d'un mètre, entièrement couvertes de fonds assez ternes, verts, bleus ou brun écaille, surchargées souvent de bronzes, les meilleurs artistes de la Manufacture, Swebach, Georget, $\mathbf{I}^{\text {me }}$ Jacquotot, Béranger, Degault, etc... peignirent inlassablement, dans des cartels oceupant en général le tiers de la hauteur du vase, des seènes de la vie de l'Empereur : la bataille d'Austerlitz, la revue de l'Empereur sous les murs de Vienne, l'entrée de l'Empereur dans Berlin, ete. Ces pièces atteignaient souvent des prix énormes; pour n'en citer que deux, nous indiquerons que le vase représentant le “Mariage de Napoléon », d'après le dessin de Zix, fut compté 30000 francs, et celui représentant « les Trophées d'art de l'armée d'Italie apportés au Musée Napoléon du Louvre », peinture de Béranger, 40000 franes.

Les mèmes idées présidèrent au choix des sujets servant à l'ornementation des services de table. Les formes d'abord avaient été simplifiées autant que possible : uniformément rondes, sans aucun découpage venant rompre la ligne sèchedes bords, les assiettes, elles aussi, ne laissèrent plus rien transparaître de la blancheur de la porcelaine, des marlis de couleurs sombres, surchargés de dorures, entourant en général des seènes extrêmement réduites, des vues, des 
paysages. En 1803, par exemple, Swebach peignit la bataille de Marengo au centre d'une assiette dont le marli étail décoré de trophées par Percier, et à la même époque, il travailla avec Caron et

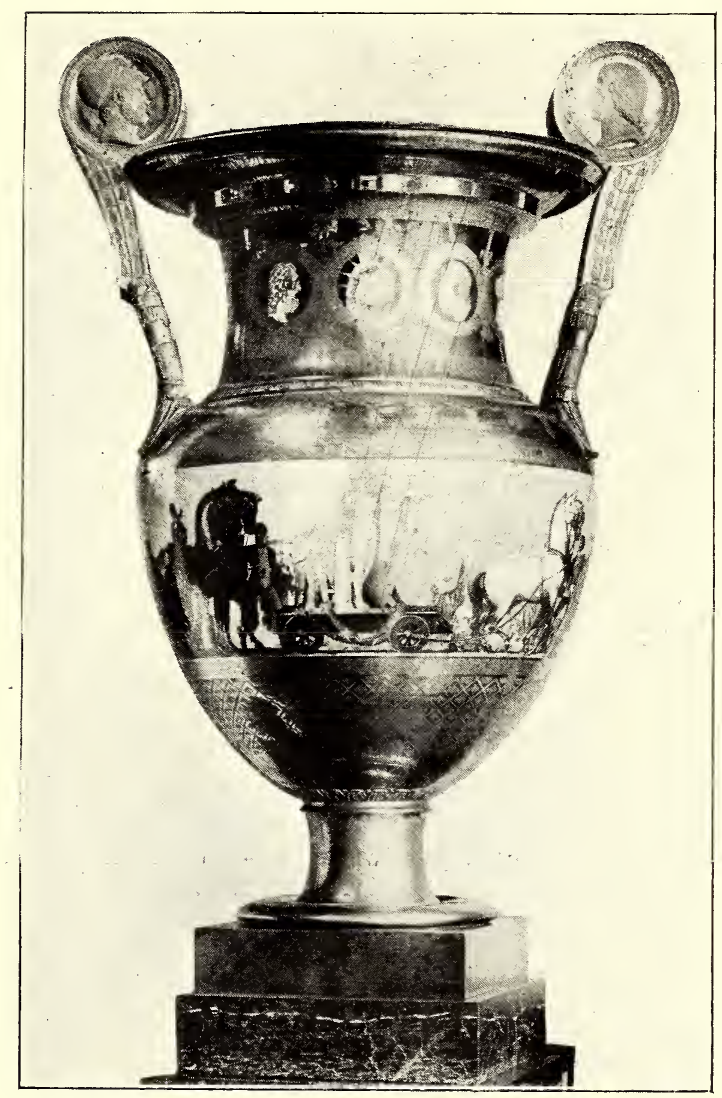

Vase "étrusque à rouleaux », représentant l'arrivée à Paris des objets d’art rapportés d'Italie. - Sujet principal par Beranger. - Porcelaine dure 1813. (Haut. 1 ${ }^{\mathrm{m}, 00)}$. (Musée de Sèvres, no 1823.)

Drolling à un service, destiné à l'Avoyer du canton de Berne, reproduisant des paysages contenus dans le livre de Delaborde. Quant aux pièces commandées pour la Maison de l'Empereur, elles furent, comme les vases, consacrées à la glorification du maître, et ornées de rues rappelant les faits guerriers, politiques ou administratifs de 
Napoléon. Le service égyptien, terminé en 1808, était décoré de vues d'Égypte d'après les dessins de Denon, et les bords d'assiettes représentaient des hiéroglyphes scrupuleusement dessinés d'après les originaux. Cette habitude de transcription remplaçant les compositions aimables du passé devint à ce point une règle dans la

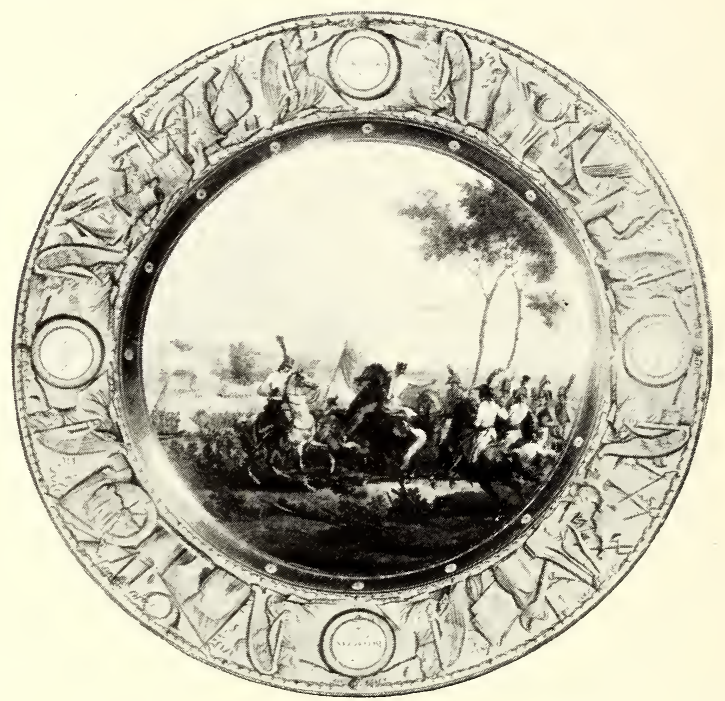

La bataille de Marengo, par Swebach. - Porcelaine dure (1803). (Musée de Sèvres, $\mathrm{n}^{\circ}$ 179..)

maison que le goùt de l'arrangement se perdit peu à peu et que les artistes les plus délicats devinrent de simples copistes, remarquables seulement par leur habileté.

Le succès des peintures sur plaques de poreelaines, que l'on a vu s'affirmer depuis 1780, aboutit sous l'Empire à un genre qui apparaît aujourd'hui comme une conception absolument fausse : celui des meubles ornés, en tout ou en partie, de porcelaines déeorées. Napoléon $\mathbf{I}^{\text {er }}$ semble avoir particulièrement apprécié les tables composées suivant ce principe, et e'est sur son ordre mème qu’en 1806 on établit le projet de trois meubles de cette espèce, dont l'un était consacré aux grands capitaines de l'antiquité, tandis que l'autre, 
demeuré le plus célèbre, devait immortaliser la gloire des vainqueurs de la campagne de 1805. La “ Table des Maréchaux », exéeutée de 1808 à 1810 d'après le projet de Pereier, représentait, sur une plaque ronde d'un mètre de diamètre, l'Empereur en grand costume occupant le centre d'une étoile, entre les rayons de laquelle étaient reproduits les traits des treize généraux ayant pris part à la eampagne. Pour cette ouvre considérable, Isabey, chargé de la peinture des portraits, reçut 9000 francs, et de plus on mit un appartement de la Manufacture à sa disposition pour qu'il pût travailler plus eommodément; les bronzes ciselés par Thomire coûtèrent 4000 francs, et la table, livrée en 1810 au Gouvernement pour 35000 francs, demeura aux Tuileries jusqu'à la ehute de l'Empire, époque à laquelle elle disparut dans des circonstances mal connues.

La sculpture, à celte époque, devait nécessairement - et plus directement encore que la peinture - ètre mise par Napoléon au service de sa gloire. Cependant, jusqu'au moment où Boizot quitta Sèves en 1809, la Manufacture produisit eneore quelques groupes, les Musiciennes entre autres, et des figures copiées ou inspirées de l'antique, qui rappelèrent la tradition ancienne de la maison. Boizol, avec son extraordinaire faculté d'assimilation, s'était adapté au goût du jour. Il exécuta aussi en 1802 un buste de Bonaparte au moment même où l'on modelait à Sèvres la « statuette équestre du Premier Consul », d'après Carle Vernet. Sous l'Empire, les effigies de Napoléon par Chaudet, le buste de Marie-Louise, la statuette du Roi de Rome couché, par Bosio, furent presque, en dehors de la froide composition des Trois Graces de Chaudet, les seuls ourrages d'auteurs modernes fréquemment reproduits pendant ees dix années. On ne saurait en effet comparer au biscuit ancien les grands surtouts de table que l'on exécuta pour compléter les services de table dont nous avons parlé, et dans lesquels le biscuit, souvent teinté en bleu, en noir, en couleur bronze, ne fut plus seulement employé, 
comme au xvIII $^{\ominus}$ siècle, à la reproduction de scènes ou de figures, mais servit de plus en plus à la composition de pièces décoratives.

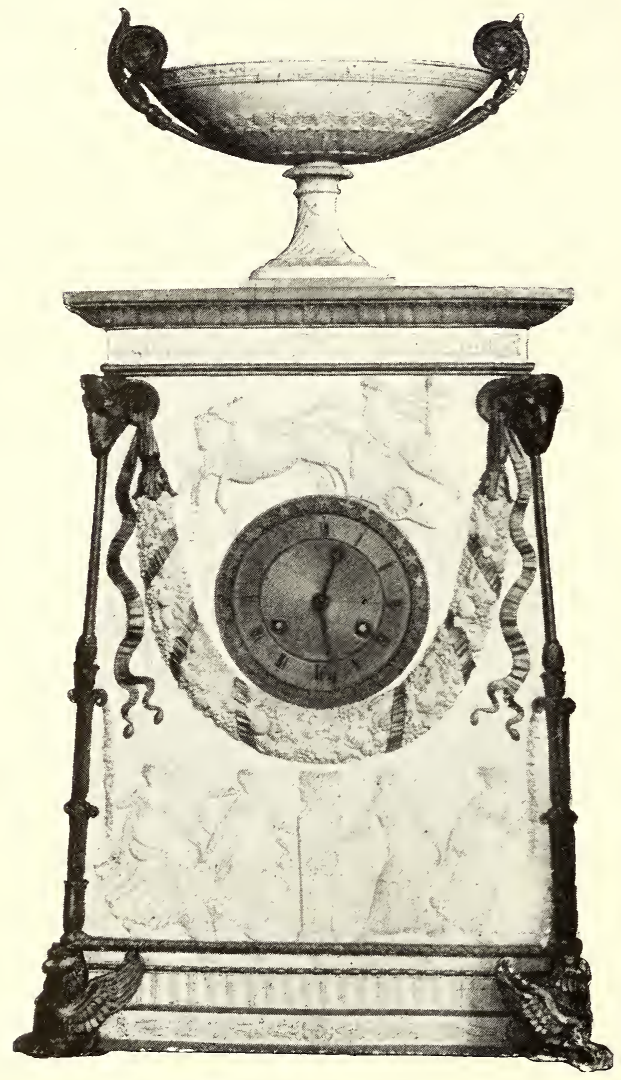

Pendule en biscuit avec parties dorées. (Haut. 0,56). - Modèle de Percier. (Musée de Sèvres, $\left.n^{\circ} 13022\right)$.
Les premières applications du biscuit à des objets de ce genre furent la " Pendule de Percier » de pur style Empire, et l'écritoire égyptien, en pàte colorée avec parties dorées. Mais bientòt, à còté de ces objets de dimensions moyennes, on vit paraître des pièces comme le surtout du Service olympique dont le motif central représentait Napoléon $I^{\text {er }}$ sur un char de triomphe trainé par quatre. chevaux; les figures secondaires étaient des réductions des principales statues antiques du Louvre. Plus bizarre encore fut le surtout du Service égyptien, directement inspiré par la

manie archéologique du jour : éétait une énorme eonstruction, longue de plusieurs mètres, représentant au centre le temple de Philæ, a uquel étaient reliés par des colonnades deux autres temples et deux mòles de même style; les espaces demeurés libres étaient ornés de figures de Memnons et de Sphinx ! Dans le mème ordre d'idées, il faut encore citer la Colonne Triomphale de la Grande Armée, et le Candélabre de l'Impératrice, haut de $2^{\mathrm{m}}, 33$, établi d'après les dessins de 
Brongniart père. Navait-on pas eu le projet, en 1806, de reproduire en biscuit le chàteau des Tuileries et l'Are de Triomphe de Fontaine? De semblables aberrations montrent la décadence profonde du goùt et sont les premières manifestations de la tendance à lapuelle la Manufaeture s'abandonna pendant tout le six $^{e}$ siecte, lorsqu'elle fit servir la porcelaine à des usages auxquels elle n'est point appropriée.

Cependant, malgré tous leurs défauts, malgré lear faible intérèt au point de vue purement artistique, les curres qui sortirent de Sevres entre 1800 et 1813 offraient du moins certaines qualités, gràce aux artistes qui avaient encore à cette époque une certaine influence. Leur imitation de l'antiquité égyptienne ou étrusquie n'eut certes rien de la gràce du xvmi sièele, mais elle se signala généralement par un certain souei d'exactitude qui conserve aux ouvres une valeur relative. D'autre part, le parti pris the faire servir toutes choses à la glorification de l'Empereur donna une orientation aux artistes, et il faut reconnaître, toutes réserves faites d'ailleurs sur le principe mème de la décoration céramique à cette date, que Swebach, Drolling et d'autres ont produit parfois des compositions heureuses. Enfin les meilleurs d'entre eux n'étaient pas encore constamment réduits à l'emploi de copistes qu'on leur imposa dans la suite, et pouvaient parfois faire preuve d'une certaine initiative ef de qualités personnelles.

La chute de l'Empire fut l'occasion pour la Manufacture d'une série d'incidents qui se rattachent à l'oceupation de Paris par les armées alliées en 1810 . A cette époque, en effet, l'armée allemande s'empara de l'établissement qui, d'abord transformé en ambulance, fut bientòt considéré comme prise de guerre par les Prussiens : un officier d'intendance en prit possession, avec l'ordre de saisir l'argent en caisse et de s'assurer au jour le jour du produit des ventes. Le dommage n’eùt pas été bien sérieux, s'il s'était borné à cela, mais 
l'armée avait besoin d'argent et l'état-major prussien pensa bientôt à tirer parti de son occupation. Brongniart fut brusquement avisé d'avoir à dresser l'inventaire exact de tous les objets en état d'être vendus et de les faire transporter à Paris pour être dispersés aux enchères. Il parvint heureusement à retarder l'exécution de cette mesure désastreuse, en faisant valoir le peu de bénéfices qui résulterait de eette opération dans un moment aussi troublé et il amena mème l'état-major prussien à accepter le principe d'une indemnité en argent, équivalente au produit que l'on pouvait escompter de la liquidation projetée. Après de longs pourparlers, le chiffre de l’indemnité fut fixé à 100000 franes, auxquels devait s'ajouter la valeur de toutes les pièces ayant trait à l'histoire de Napoléon, pièces dont le transfert à Berlin fut immédiatement effectué. A la suite d'interventions diverses, Brongniart obtint en définitive que la remise de la Manufacture au roi Louis XVIII aurait lieu contre le versement de 40000 francs en argent et de 10000 franes en porcelaines, sans déduction des 76000 franes de pièces que les offieiers prussiens avaient précédemment choisies pour leur usage personnel dans les magasins de Sèvres. L'établissement ainsi rançonné n’eut d'ailleurs point à souffrir autrement de l'occupation prussienne, et dès la signature de la convention, il rentra sous l'autorité du ministre de la Maison du Roi. Une sauvegarde lui fut assurée par M. de Müffling, gouverneur prussien de la Ville de Paris, jusqu'au moment de la libération complète du territoire, et Brongniart semble n'avoir eu qu'à se louer des procédés des officiers prussiens chargés d'assurer l'ordre à Sèvres; on peut même trouver qu'il leur manifesta sa gratitude d'une façon exagérée le jour où il adressa comme souvenir au baron de Müflling une tasse, sur laquelle il avait fait peindre le portrait du général Blücher. “ Le général Blücher est cher aux "Prussiens, lui répondit M. de Müflling en le remerciant, et les Fran" sais lui rendront justice un jour..." 
A partir de la Restauration, la corruption des styles qui avaient caraetérisé la période impériale s’accentua constamment, et un curieux indice de l'évolution qui se produisit alor's parmi les artistes de Sìves nous est fourni par des croquis conservés à la Manufacture et

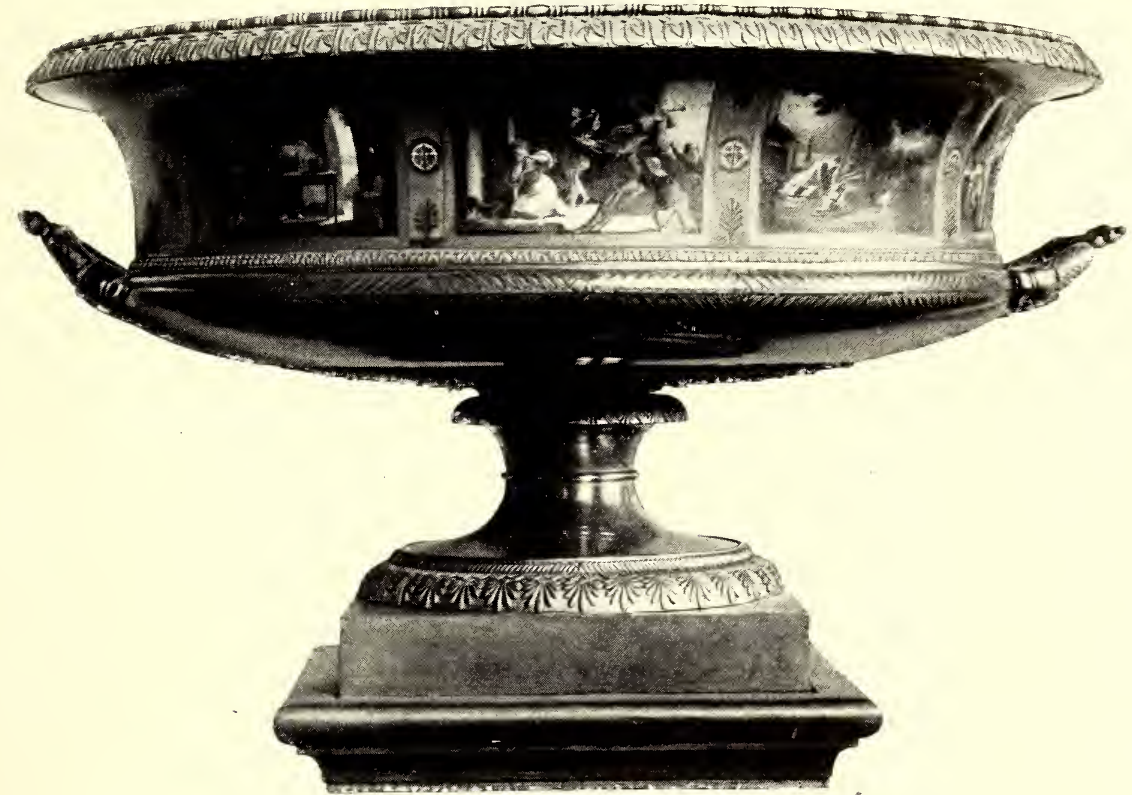

Coupe dite " des sens ». - Décor de Ilme Ducluzeau, d’aprés Alex. Érariste Fragonard.

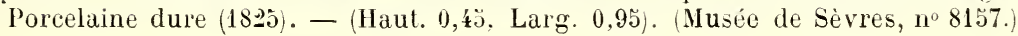

montrant l'arrangement des expositions quui, à l'exemple du xvin siècle, eurent lieu chaque année au Lourre depuis 1816. Dans les années qui suivirent la chute de l'Empire, le nombre des formes nouvelles fut tris restreint : parmi les vases, on ne peut guere citer comme pièces importantes que le vase Socibius et le vase Campanien de Luynes de 1826. Les décors se rattachèrent aux mèmes genres d'ornementation que précédemment, mais, lélément fourni par l'épopée napoléonienne faisant défaut, il fallut šngénier à découvrir sans cesse des sujets nouveaux, et e'est alors que se multiplièrent, dans la décoration des services notamment, ces suites de compositions 
bizarres, dont les spécimens qui nous restent font regretter que tant d'habileté n'ait pas trouvé un emploi plus judicieux. Le « service iconographique antique », par exemple, était composé d'assiettes au centre desquelles était peint en camée le portrait d'un homme illustre d'Athènes ou de Rome; le "Service des Oiseaux d'Amérique », celui des "Arts Industriels », celui des "Vues historiques de France » et tant d'autres, différents par les sujets représentés, restaient identiques par la disposition du décor. Le même genre d'ornementation s'appliqua plus fàcheusement encore à la décoration de certaines pièces dont le succès datait du $\mathrm{xvm}^{\mathrm{e}}$ siècle, les déjeuners, comprenant une tasse, une cafetière et un pot à crème réunis sur un plateau, que l'on couvrit à cette époque de peintures dont les titres suffisent à faire entrevoir le mauvais goût et l'adaptation ridicule à des pièces d'usage domestique : les "Peines el plaisirs de l'Amour ${ }^{1}$ ", l' "Apothéose d'Henri IV », l' "Allianee d'armes de Du Guesclin et d'Olivier de Clisson », ete... Des sujets du mème ordre - par exemple, Michel-Ange aveugle enseignant ses éleves au Vatican, - étaient reproduits sur les vases, à côté de quelques allégories politiques rappelant les compositions de la période antérieure, comme le "Retour de Charles X à Paris à la suite du Sacre » ou "Louis XIV prenant les rènes du char de l'État ».

Un développement considérable fut alors donné aux objets mobiliers formés de plaques en porcelaine, dont la production avait été jusque-là presque complètement limitée à des tables de dimensions diverses. Celles-ci d'ailleurs ne furent pas abandonnées et les plus importantes de cette période représentèrent la « Restauration du Musée

${ }^{1}$ La décoration du plateau de ce déjeuner est ainsi décrite dans le catalogue de l’Exposition de 1821: "Vénus envoie sur la Terre les Amours de différents caractères exer" cer sur les âmes leurs diverses influences. Les Amours sages sont blonds, n'ont au" cun instrument de tourments et sont principalement envoyés par les Gràces. Les "Anours violents sont bruns, emportent des chaînes pesantes et d'autres instruments " de tourments. Deux Amour's de caractères opposés veulent entraîner dans leur parti un jeune Amour encore sans caractère. Deux autres écrivent les noms des victimes " cle l'amour violent et des héros de l'anour réciproque... " 
Royal » et l' "Inauguration de la statue d'Henri IV ». Mais on semble avoir apprécié surtout les coffrets, les bureaux, les armoires à bijoux, les pendules enfin qui le plus souvent rappelèrent par

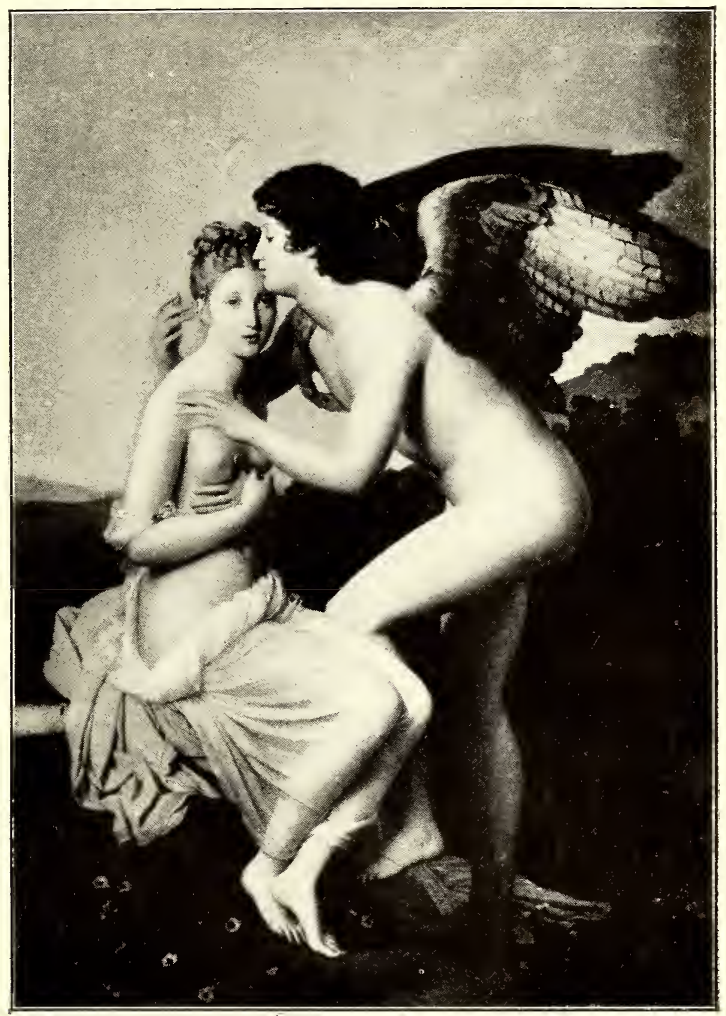

L'Amour et Psyché. - Peinture sur plaque par Mme Jacquotot, d’après le baron Gérard. Porcelaine dure (1S26). - (Haut. 0,60, Larg. 0,43). (Husée de Sèvres, no 72.59.)

leur forme générale la pendule de Pereier, exécutée non plus en biscuit avee des ornements en relief, mais décorée de sujets peints. L'une de ees pendules, vraiment monumentale par ses proportions, est demeurée célèbre sous le nom de pendule géographique : elle atteignait $2^{\mathrm{m}}, 20$ de haut, et son cadran tournant avait la forme d'un bouclier attaché à une gaine supportant les bustes d'Apollon et de Diane; ce bouclier représentait en douze tableaux les lieux de la 
terre où il est midi, quand il est deux heures, quatre heures, six heures, et॰., à Paris... Sa valeur était de 12000 francs!

Enfin il faut signaler, pour donner une idée complète de la production de la Manufacture entre 181 ğ et 1830 , l’importance prise à ce moment par les copies de tableaux sur grandes plaques de porcelaine. Les progrès de la fabrication ayant permis d'obtenir par le procédé du coulage des plaques absolument unies atteignant $1^{\mathrm{m}}, 60$ sur 1 mètre, les meilleurs artistes de la maison, Georget, Constantin, Béranger, Langlacé, surtout $\mathbf{I}^{\mathrm{me}}$ Ducluzeau ef $\mathbf{I I}^{\mathrm{me}}$ Jaquotot, ne furent plus occupés qu’à reproduire sur ces plaques les principaux chefsd'courre du Louvre, dans le but de conserver ainsi des témoins inaltérables d'ourres d'art appelées à être détériorées par le temps. Le premier grand travail de ce genre avait été la reproduction en grandeur naturelle du portrait de Napoléon I ${ }^{\text {er }}$ par Gérard; dans la suite, et jusqu'en 1830 , quelques copies de tableaux parurent chaque année aux expositions. En 1830 même, on n'lésita pas à envoyer Constantin à Rome, avec mission d'exécuter sur porcelaine une transcription fidèle de certaines ceurres des musées italiens. Il faut bien reconnaître que les artistes dont nous avons parlé apportèrent dans ces travaux une indiscutable perfection et firent preuve d'extraordinaires qualités d'interprétation consciencieuse : au point de vue de l'exécution, rien d'aussi parfait n'est peut-être sorti des ateliers de Sères, mais, pour en apprécier la valeur intrinsèque, il faudrait d'abord aceepter le principe décoratif dont ces oeures étaient la manifestation. Elles avaient d’ailleurs un autre grave défaut, qui était leur prix de revient, peu en rapport, semble-t-il, avec l'intérêt qu'elles pouvaient offrir : ainsi les copies des deux lableaux de Raphaël, la Messe de Bolsena, par Constantin, et la Vierge au Voile, par M' Jacquotot, coûtèrent l'une 27000 et l'autre 35000 franes!

Quant à la sculpture en biscuit, on assiste après l'Empire à la décadence définitive de cet arl, et la collection des statues équestres 
des Rois de France que Brachard, premier seulpteur de la Manufacture, modela presque entierement, nous apparaît aujourd'hui eomme une collection d'effigies parfaitement ridieules. La seulpture ornementale ne valut guère mieux et les grands surtouts d'alors, surchargés de palmiers, de lourdes guirlandes de fleurs et de fruits, ne présentèrent mème plus l'intérèt des motifs principaux du Service Olympique ou du Service Ég!jptien. L’influence romantique se marqua de bonne heure dans la composition de cerlaines pièces de style pseudlo-gothique, aussi fausses d'ailleurs par l'interprétation du style lui-mème que par l'adaptation que l'on en fit à des pendules, à des bibliothìrques ou à des coffres à bijoux.

A celte époque fut créé l'atelier de peinture sur verre qui devait fonctionner jusqu'en 1852. L'idée de cette fondation appartient à Brongniart qui, dans le programme de travaux

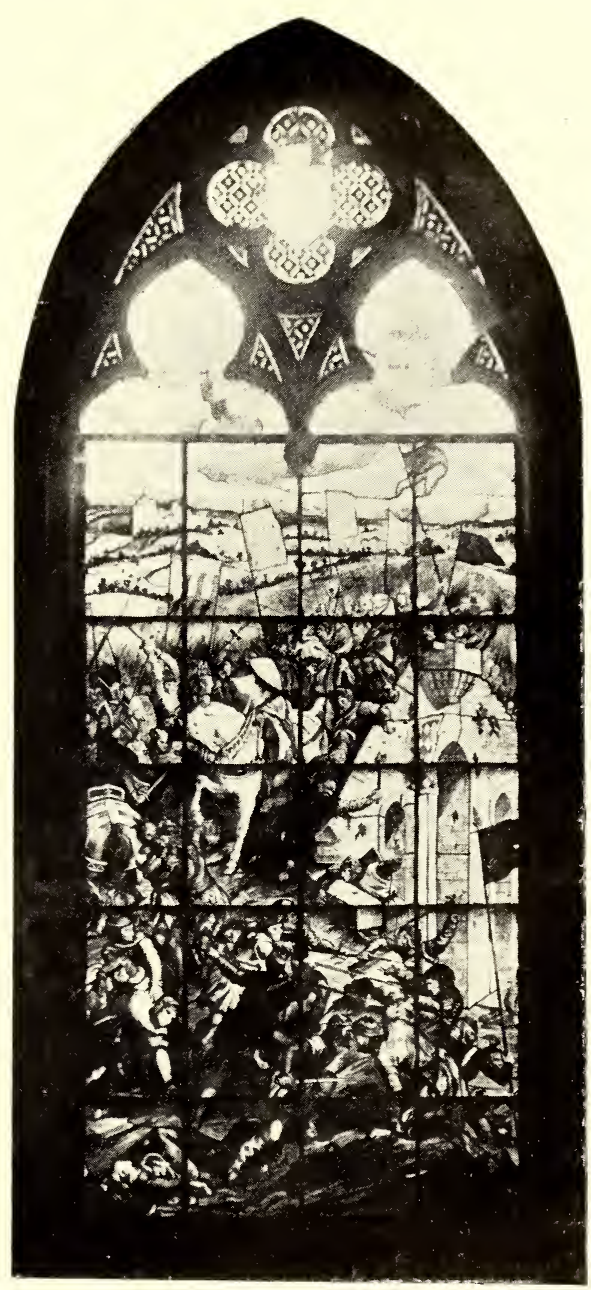

Saint Louis au pont de Taillebourg. - Composition d'Eugène Delacroix. - Vitrail de la chapelle de Dreux. adopté en 1800, avait inscrit l'élude des couleurs destinées à ce genre de décoration, en faveur duquel un essai de rénovation était tenté par quelques praticiens. Dès 1802, il s'était livré à diverses 
recherches à ce sujet et, lorsqu'il organisa le Musée Céramique, il prit soin d'y faire entrer des échantillons de toutes les matières employées dans la verrerie. Les procédés que lui apporta en 1824 un des décorateurs de la Manufacture, Pierre Robert, le conduisirent à l'organisation d'un atelier de peinture sur verre, dont les travaux parurent pour la première fois à l'exposition de 1827. On y put voir diverses glaces peintes depuis 1824 d'après les procédés de Robert, ainsi qu'un fragment de vitrail, copié sur une verrière de la SainteChapelle et exécuté, à la manière du xin ${ }^{\mathrm{e}}$ siècle, par juxtaposition de verres colorés dans la masse. A partir de 1828, l'atelier de peinture sur verre, placé sous la direction de Pierre Robert, puis en 1832 de Louis Robert, exposa chaque année d'importants vitraux destinés pour la plupart aux chapelles des résidences royales, Compiègne, Amboise, Randan, Eu, Carheil, aux caveaux de Dreux, au Musée du Lourre.

Les meilleurs artistes du temps de Louis-Philippe furent appelés à fournir des cartons à cet atelier : en 1830, l'architecte Le Bas établit ainsi un projet de vitrail pour Notre-Dame-de-Lorette; à la décoration du château d'Eu travaillèrent successivement Paul Delaroche, Chenavard, Wattier, Ziegler, Decaisne, Deveria; pour les vitraux de la chapelle de Dreux, on fit appel au talent de Delacroix pour les figures et de Violet-le-Duc pour les ornements ${ }^{1}$. Entre 1830 et 1840, Chenavard semble avoir été le principal artiste attaché à l'atelier de peinture sur verre, - c'est à lui notamment que fut demandée la composition d'une grande verrière $\left(6^{\mathrm{m}}, 6\right.$ s sur $\left.3^{\mathrm{m}}, 43\right)$ exécutée en 1838 pour montrer les ressources de l'art du vitrail et représentant le Renouvellement des Arts et des Sciences à l'époque de la Renaissance, - tandis qu'après 1840 les travaux importants furent confiés à Achille Deveria dont les meilleures ouvres en ce

\footnotetext{
${ }^{4}$ Beaucaup de ces cartons sont demeurés dans les collections de la Manufacture et constituent de précieux documents pour l'histoire de l'art de ce temps.
} 
genre sont peut-ètre l'Annoncialion et l'Assomption, placées lans l'église Saint-Louis de Versailles.

Cet atelier fut supprimé en 1832. Il n’y a pas lieu de le regretter, car la peinture sur verre de Sèvres ne correspondit jamais à un genre de décoration bien délini, et le jugement que M. de Lasteyrie porta en 1850 sur cette fabrication détermine ce qu'il y avait d'artificiel et d’incomplet dans cette création : "En reconnaissant à chacun “ son mérite, il nous est impossible, disait-il, de ne pas nous élever " contre cette peinture d'un genre bâtard qui veut tenir le milieu " entre le tableau à l'huile et le vitrail, sans pouvoir jamais atteindre " l'éclat de l'un ni les qualités de l'autre »...

Si l'on prétendait donner une idée de la production artistique de Sèvres entre 1830 et 1848, on pourrait presque se borner à reprendre l'énumération des pièces dont avons déjà parlé. Le caractère des décorations demeura le mème et les sujets n’offrirent d'autre particularité qu’une exagération des défauts déjà signalés. Toutefois le style général des pièces rendit plus manifestes encore la décadence du goût et la disparition de tout prineipe de composition; nous ne saurions mieux définir le caractère de cette époque qu’en citant ce jugement de Georges Vogt qui traduit excellemment l'impression donnée par les œuvres : « Sous le règne de Louis-Philippe, les vases sont “ surchargés des ornements les plus variés; des figures, des bas-reliefs, " des chimères, des animaux, des mascarons, des guirlandes de fleurs " et de fruits, des cabochons se heurtent sur leurs surfaces dans une “ ordonnance qui nous paraît aujourd'hui des plus étranges; toutes " les couleurs à la disposition de l'artiste se trouvent réunies sur la “ même pièce; il n’y a plus ni harmonie, ni unité dans la composi“ tion ni dans la coloration ${ }^{1}$ ». De plus en plus, la Manufacture s'en-

\footnotetext{
${ }^{1}$ Georgès Vogt. La Porcelaine. Bibliothèque de l'enseignement du dessin.
} 
ferma dans une imitation maladroite des styles du passé : Fragonard et Chenavard composèrent alors des surtouts, des meubles, des guéridons Renaissance, arabes, romans ou mauresques, pour aboutir à la création de pièces comme la pendule turque à musique! La sculpture ne trouva plus dans cette période d'autre emploi que l'ornementa-

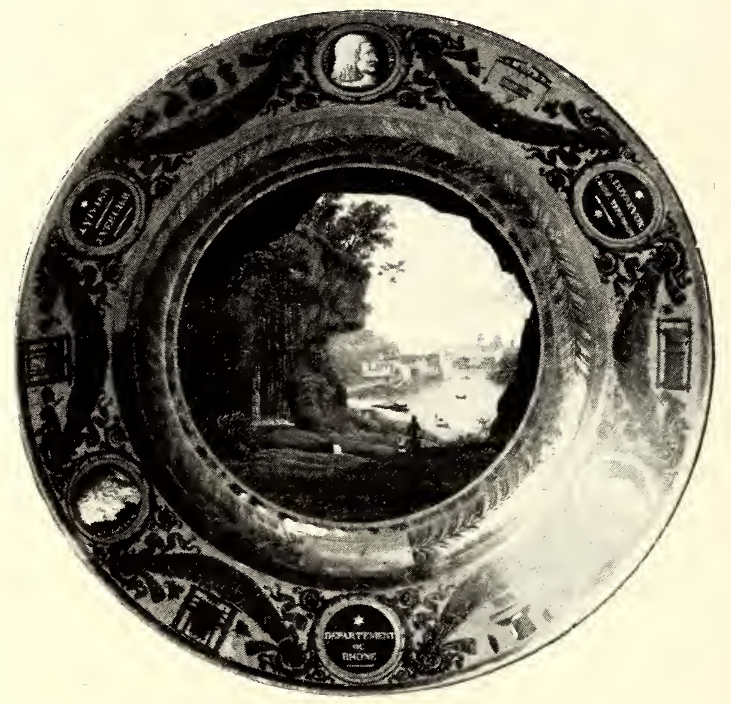

Assiette du service des Départements. - Porcelaine dure (18פS).

(Musée de Sèvres, no 12861.)

tion de grandes pièces telles que le vase de Phidias, haut de $2^{\mathrm{m}}, 38$, le Vase Renaissance de Fragonard, ou la Cheminée de Fontainebleau.

La direction de Brongniart apparaitrait donc dans l'histoire de la Manufacture comme un temps de véritable décadence si l'on bornait l'examen des ouvres à la valeur d’art qu'elles représentent; mais ses travaux eurent heureusement pour résultat des progrès considérables au point de vue de la fabrication. Nous avons eu occasion de signaler déjà quelques-uns des perfectionnements acquis grâce à ses patientes recherches : il faut ajouter à cette liste déjà longue l'emploi généralisé du procédé du coulage proposé vers 1820 par Régnier, chef des fours et pâtes, pour la fabrication des grandes plaques de por- 
celaine. A la collaboration de celui-ci avec Brongniart, on doil encore la construction des premiers tours à calibrer, employés au tournage des assiettes et des pièces de platerie ronde, ainsi que certains arrangements ingénieux d'encastage grâce auxquels il devint possible d'utiliser beaucoup mieux la capacité d'un four. Il convient aussi de signaler ici l'introduction dans la Manufacture de la fabrication de certaines poteries moins fines que la porcelaine, mais par cela mème mieux appropriées aux besoins de la production courante. C'est ainsi qu'en 1827 Brongniart accueillit M. de Saint-Amand, auteur de travaux sur la fabrication de la faïence fine à la manière anglaise; des locaux furent mis à sa disposition et, bien que ses essais fussent faits sous sa responsabilité personnelle, Brongniart tint à montrer toute l'importance quïl leur donnail en exposant les résultats

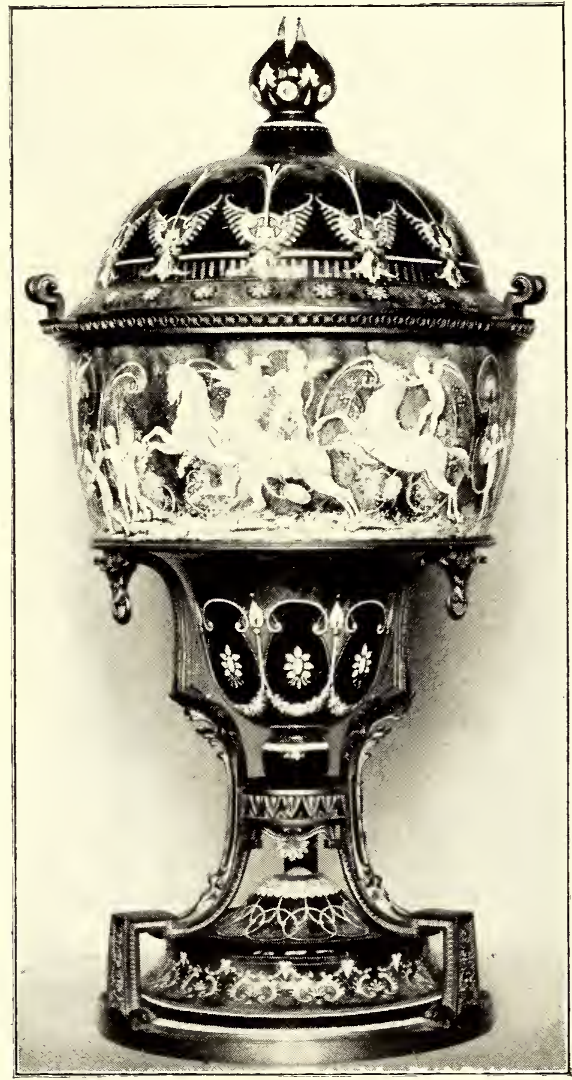

Atelier d'émaux sur métaux. - Cassolette décorée d'émaux sur cuivre, par Gobert. (Musée de Sèvres, n $7 \dot{j} 0$ tr) (Haut. 0,60).

obtenus, à còté des produits de la Manufacture. Avec le mème souci d'aider au développement de tous les arts du feu, il organisa en $184: 3$ un atelier d'émaillage sur métaux qui fonctionna jusqu’en 1872 et qui, sous la direction habile de Mayer, produisit des travaux intéressants à la fois par leur perfection technique et par 
leur's dimensions. Une des tentatives les plus curieuses qui soient sorties de cet atelier est certainement la décoration en émaux appliquée à des plaques de fer atteignant $1^{\mathrm{m}}, 30$ de hauteur et décorées de grandes figures comme les Quatre Évangélistes ou la Madone du Grand-Duc, peintes par Bonnet et Apoil.

Fidèle au but quäil s'était lui-même marqué, Brongniart voulut encore en 1820 compléter son œuvre d'enseignement industriel par la création d'une "École royale de peinture en couleurs vitrifiables ». Il avait formé le dessein de donner là à des jeunes gens déjà munis d'une éducation artistique assez conplète une instruction professionnelle qui les mît à même d'employer ces couleur's sur porcelaine, sur métal ou sur verre. L'expérience lui avait montré, en effet, combien l'absence des notions les plus élémentaires eoncernant l'usage de ces couleurs décourageait rapidement les meilleurs artistes, et il avait conçu l'espoir de préparer, pour le plus grand bien de l'industrie, une génération de jeunes artistes que ces difficultés techniques n'entraveraient plus. Une école fut done installée à Paris, à côté de l'atelier qui fonctionnait déjà au dépôt de la Manufacture, 18, rue de Rivoli; mais les élèves se présentèrent en petit nombre et l'institution ne donna jamais les résultats qu'on en pouvait attendre. Il y avait longtemps qu'elle avait cessé d'exister réellement, lorsqu'en 1840 Brongniart lui-mème proposa de la supprimer officiellement, en mème temps que le dépôt de Paris qui, lui aussi, n’avait été pour la Manufacture qu’une charge inutile.

Brongniart mourut à Sèvres en octobre 1847, mais il avail pris le soin de se préparer un successeur. Deux ans plus tôt, en effet, il avait fait nommer à l'emploi d'administrateur-adjoint Ebelmen, sạvant éminent sorti comme lui du corps des mines et déjà connu par des travaux remarquables. La Révolution de 1848 fit rentrer la Manufacture, rendue à l'État, dans les attributions du ministre de l'Agriculture 
et du Commerce dont le premier soin fut de nommer un Conseil de Perfectionnement des Manufactures nationales, ayant Albert de Luynes pour président et Fernand de Lasteyrie pour rapporteur. Sur les indications de ce Conseil, Ebelmen entreprit une réforme complète de la maison. Après la longue direction de Brongniart, il sembla

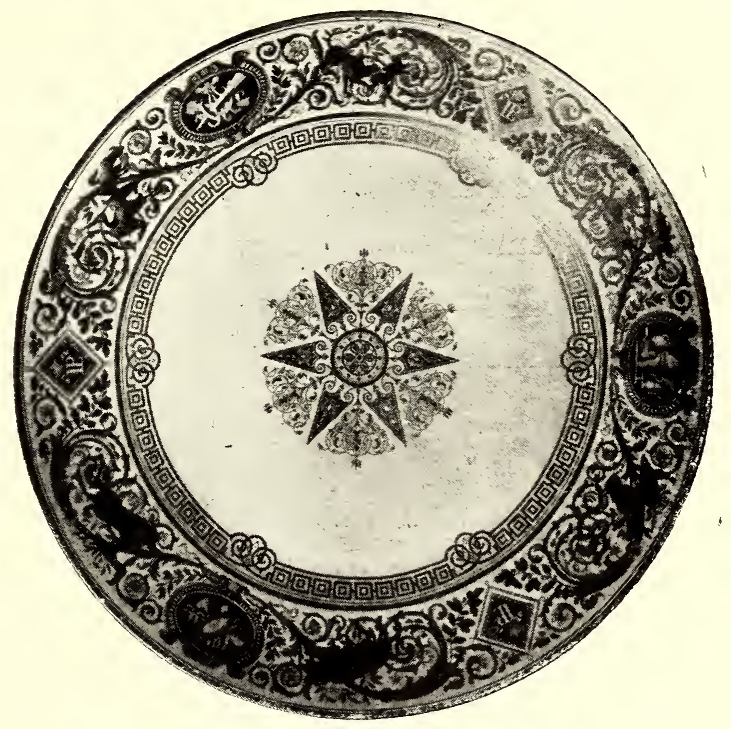

Assiette du service du chàteau de Fontainebleau. - Porcelaine dure (1838).

(Musée de Sèvres, 12כั41.)

urgent de faire tans le personnel une sélection semblable à celle réalisée en 1800. Régnier, le chef des fours et pâtes, fut remplacé par Vital-Roux dont le nom demeure attaché au perfectionnement des procédés de euisson de la porcelaine à la houille; Willermet, chef des ateliers de peinture, fut mis à la retraite el eut pour successeur Louis Robert, tandis qu'un emploi nouveau, celui d'artiste en chef, était confié au décorateur Diéterle. Beaucoup des peintres appelés par Brongniart à Sèvres furent, eux aussi, remplacés par une génération nouvelle d'artistes, Mérigot, Cabau, Hamon, Robert, Paul Avisse comme décorateurs, Klagmann à la sculpture. Malheureusement Ebelmen mourut en pleine activité en 18\%2, el ce qu'ilavait 
réalisé pendant les quatre années de sa direction fait doublement regretter sa fin prématurée, car il promettait de mener à bien de grandes choses. Au point de vue scientifique, ses travaux les plus importants portèrent sur des synthèses minéralogiques d'un intérèt considérable pour le développement de la décoration au grand feu. Il avait entrepris d'autre part de rétablir la fabrication de l'ancienne porcelaine tendre, abandonnée par Brongniart en 1804. Enfin, on lui doit le perfectionnement des procédés du coulage, employé seulement jusqu'alors à la fabrication des plaques et des instruments de chimie, et qu’il appliqua au façonnage de deux genres de pièces également difficiles à obtenir : les objets extra-minces, tasses, soucoupes, pièces découpées à l'imitation du Japon, et les pièces de grandes dimensions comme le Vase de Klagmann et la Coupe du Travail de $1^{\mathrm{m}}, 14$ de diamètre, de Feuchère.

Nous avons indiqué le concours prèté par le Conseil de perfectionnement des Manufactures nationales à l'ceuvre entreprise par Ebelmen. Le rapport rédigé par M. de Lasteyrie en 1890 paraìt en effet la critique la plus juste qui puisse ètre faite de la production de Sèvres pendant la première moitié du xixe siècle. A còté des éloges décernés à toutes les tentatives nouvelles, il avait signalé dès ce moment l'erreur fondamentale que constituait le fait de peindre un tableau sur la panse d'un vase et le non-sens que l'on commettait en dissimulant entièrement la belle matière de la porcelaine sous des fonds de couleur et sous des déeors opaques.

La Manufacture rentra en 1892 dans la dépendance de la maison de l'Empereur. L’illustre physicien Regnault, déjà membre à cette époque de l'Académie des Sciences et officier de la Légion d'honneur, fut nommé à l'emploi devenu vaeant par la mort d'Ebelmen; il conserva pendant tout le règne de Napoléon III la direction de Sèvres, jusqu'au jour où la mort de son fils, le peintre Henri Regnault, vint le frapper cruellement et le décida à abandonner toute fonction publique. 
Entre 1832 et 1870 , se place la période la plus criliquable de la production de Sèves. Regnault, absorbé par ses travaux de physique, parvenu à une situation considérable, se désintéressa constamment de la direction artistique qu’il abandonna à Diéterle d’abord, puis à Nicolle qui arriva en 18006 avec le titre d'administrateur-adjoint. Tout l'effort de Regnault, secondé par Salvetat, porta done sur des perfectionnements techniques qui furent d'ailleurs appréciables durant ces vingt années. A ce point de vue, il faut tout d'abord indiquer les nombreux essais tentés pour obtenir des décors de grand feu : on trouva alor's la formule d'un certain nombre decouvertes colorées capables de se développer au feu defour; surtout on perfectionna le procédé de décoration par les pâtes colorées. L’idée de ce procédé avait été domnée par Riocreux, le conservateur des collections : il consistait essentiellement dans le fait de mélanger à de la pàte une faible proportion d'oxydes colorants et de décorer la porcelaine crue en déposant cette matiere au pinceau en épaisseur variable suivant l’intensité des tons à obtenir. Ce procédé se prêtait à un genre de décoration imitant le camée - fréquemment utilisé depuis lors - que l'on obtient en dessinant des ornements ou des figures avee de la pâte blanche sur une pièce recouverte préalablement d'une couche de pâte colorée. Confiées à d'habiles praticiens comme Gély, Gobert, Cabau, Barriat, $\mathbf{I}^{\mathrm{me}}$ Escallier, les pâtes colorées donnèrent des effets agréables et les pièces décorées par ce moyen constituent le seul intérêt de la production à cette époque. On voulut aussi donner aux pâtes colorées une autre destination, d'un effet beaucoup plus contestable et qui rappelait les essais de biseuits colorés faits sous le premier Empire. Comme ceux-ci, les pâtes colorées dans la masse, initant le marbre ou certaines pierres, eurent le grave défaut de domner à la porcelaine un aspect douteux et de lui enlever les qualités qui font son charme.

Les essais de reeonstitution de la pâte tendre qu'avait entrepris 
Ebelmen furent continués sous Regnault qui s'efforça, non plus de retrouver la formule des anciennes porcelaines tendres, mais d'en

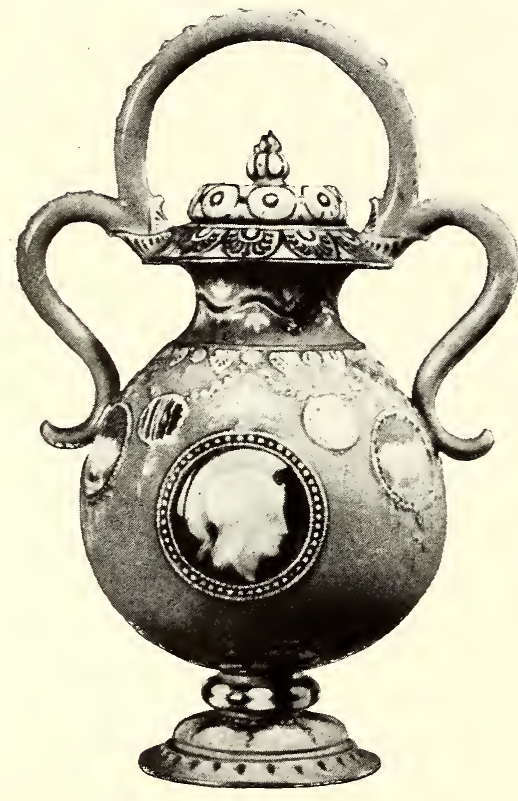

Vase “bijou » décoré en pâtes d'application, par Gély. (Musée de Sèvres, n 7596). Porcelaine dure (186j.) composer une nouvelle ayant des qualités identiques. Il fut loin de réussir dans cette voie et ce qui nous est resté des produits de ce genre montre avec quelle facilité les chimistes de Sèvres estimèrent avoir atteint le but. Jamais ils ne furent en état de reproduire le bel émail ancien, dans lequel les couleurs se fondaient si complètement, et leurs fonds roses, bleus ou verts ne rivalisèrent jamais avee les teintes limpides du $\mathrm{xvm}{ }^{\mathrm{e}}$ siècle.

Les études de Regnault et Salvetat portèrent encore - et c'est là un des résultats les plus intéressants de leur's travaux - sur les effets que peuvent donner les mèmes oxydes colorants suivant la composition chimique de l'atmosphère à laquelle la pièce est exposée pendant la cuisson : on sait en effet qu’un mème oxyde, cuisant en feu réducteur ou en feu oxydant, cuisant en courant d'air ou en gazette close, produit des colorations absolument différentes. L'observation de ces phénomènes, poursuivie avec grand soin depuis lors, a notablement étendu les moyens d'action dont disposent les décorateurs de grand feu.

Enfin, répondant au vœu du Conseil de perfectionnement, la Manufacture organisa un atelier de faïences qui fonctionna officiellement de 1852 à 1872. Sous Brongniart, à plusieurs reprises 
des études avaient été entreprises sur les matières céramiques autres que la porcelaine. La création de 1892 ne fut done en fait que la reconnaissance officielle du concours que la Manufacture devait prèter au perfectionnement de la céramique en général. Cet atelier produisit d'ailleur's des œuvres intéressantes, d'abord de grands objets comme le porte-bouquet dont nous domnons la reproduction, puis des terres cuites décorées d'engobes colorées et de nielles à la manière des fä̈ences d'Oiron. Il disparut en 1872, à l'époque où la nécessité de réaliser des économies se joignit au besoin de consacrer tous les efforts du personnel à une régénération devenue indispensable.

La Manufacture prit part sous le second Empire à de nombreuses expositions, à Londres en 1851, à Paris en $183 \%$, de nouveau à Londres en 1862, et à l'Exposition universelle de 1867. Par une tendance qui mérite d'ètre notée et qui montre à quel point les efforts étaient alor's uniquement tournés vers les perfec-

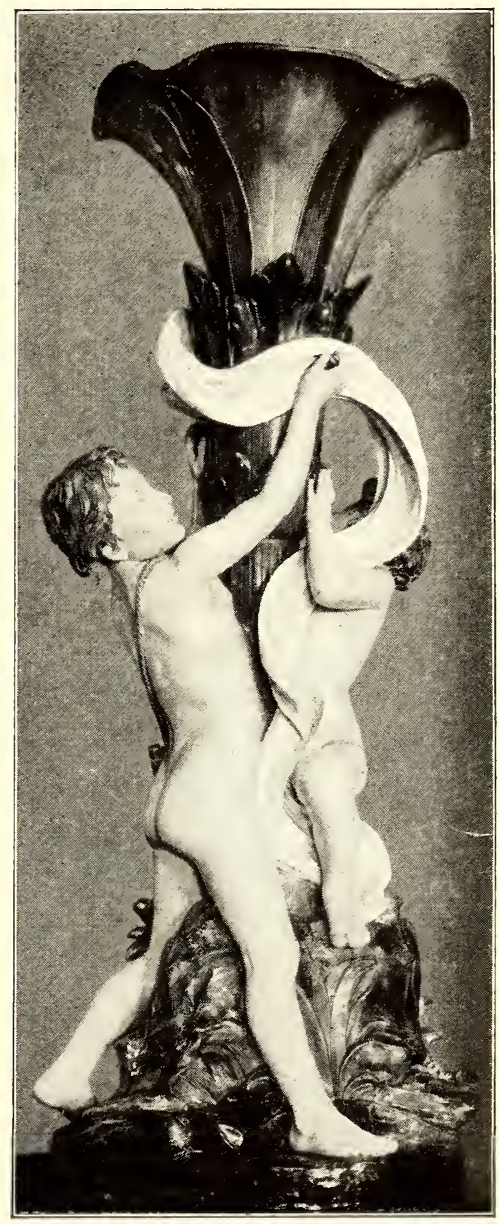

Atelier de faïence émaillée. - Enfants porte-bouquets, par Larue (1863). (Ilaut. 1,50) • (Mlusée de Sèvres, no 12991.) tionnements techniques, tous les rapports faits à la suite de ces expositions laissèrent de eôté la partie d'art, à laquelle seule on s'attachait un siècle auparavant. Celle-ci d'ailleurs manquait d'intérèt et, à ce point de vue, la Manufacture 
souffrit du malaise qui affecta tous les arts sous Napoléon III. Dans un remarquable rapport qui sert de préface au compte rendu des travaux d'art industriel exposés à Londres en 1862 , Prosper Mérimée a fait ressortir la faiblesse générale des productions artistiques à la date où il écrivait : il montrait la relation qui a existé de tout temps entre le "grand art » et les arts mineurs, et établissait un rapprochement curieux entre la pauvreté de conception des artistes d'alor's et le manque d'idées originales qui se manifestait dans l'ameublement, l'orfèvrerie, aussi bien que dans la céramique, etc... L’absence de style caractérisé, le goût eroissant des reconstitutions devaient conduire fatalement, selon lui, à un art de pure imitation, sans aucun profit pour l'École française.

Cet appaurissement de l'art français se marqua profondément dans les produits de la Manufacture et, devant les copies bâtardes de tous les styles antérieurs auxquelles elle se livra, on en vient à regretter presque les compositions de la Restauration ou de Louis-Philippe. A l'époque où nous sommes arrivés, à còté de la tendance de plus en plus marquée vers les tours de force de fabrication - pièces colossales ou objets tellement minces et fragiles que leur conception même semble un défi à la logique - on ne saurait guère citer de formes nouvelles, mais seulement la reprise de beaucoup de celles du xvin ${ }^{\mathrm{e}}$ siècle. Quant à la décoration en couleurs, on vit encore s'accentuer, s'il est possible, les défauts dont elle était marquée depuis le début du $\mathrm{xix}^{\mathrm{e}}$ siècle. Les mêmes traditions persistaient et l'on en était encore aux sujets plus ou moins haroques dessinés et peints sur la panse des vases; mais tandis que sous Brongniart ces compositions étaient franchement de petits tableaux limités par un encadrement, elles s'étalèrent alors sur toute la surface des vases, sans tenir compte de la forme, sans souci de l'harmonie que l'on doit toujours chercher entre les dimensions de la pièce et son décor.

Au lendemain de la guerre franco-allemande, Regnault fut rem- 
placé par Louis Robert, un des plus anciens praticiens de la Manufacture, successivement chef de l'atelier de peinture sur verre et chef de tous les ateliers de décoration. La Manufacture eul à subir presque aussitôt un assautredoutable, de la part de ceux qui voyaient dans sa suppression une sérieuse économie à réaliser, le budgel de Sèvres étant passé sous l'Empire de 330000 à 580000 francs. A ceux-ci se joignirent certains fabrieants de céramique qui demandèrent qu'une partie des fonds alloués à l'entretien de la maison leur fût distribuée pour leur permettre d'entreprendre des essais et de perfectionner par leurs propres moyens les procédés de fabrication et de décoration. Le gouvernement ne céda pas aux sollieitations intéressées des industriels, mais, fidèle à la tradition qui avait maintenu la Manufacture en 1793 et en 1848, il pensa qu'un nouveau plan de réformes devait ètre élaboré. Jules Simon, alors ministre de l’Instruction publique et des Beaux-Arts, nomma, le 26 juillet 1872, une Commission composée de Charles Blanc, de l'arehitecte Duc, de Guillaume, directeur de l'Éeole des Beaux-Arts, du peintre Mazerolle et d'Adrien Dubouché, qu'il ehargea de définir les principes fondamentaux de la décoration céramique. M. Duc, désigné comme rapporteurdecette commission, indiqua en premier lieu les vices dont souffrait la Manufacture. "Les produits actuels, dit-il dans ce premier rapport, " sauf quelques exeeptions qu'il serait injuste de ne pas noter, ne “ présentent pas non seulement les qualités de l’ancienne céramique " au point de vue déeoratif, mais attestent plusieurs défauts sensibles. “Les formes sont souvent languissantes, leur dessin ne faitpas suffi“ samment sentir ces oppositions fines, inattendues et originales qu’on " trouve si fréquemment dans la céramique antique, qu’elle soit de " style gree, indou, persan, chinois ou arabe. Pour la décoration " coloriée... elle est aujourd'hui absolument sans ordonnance; do " larges surfaces vagues sont abandonnées le plus souvent à des feuil" lages qui les couvrent sans aucune division ornementale. De là 
“ résulte un effet indéterminé qui n’apporte à la vue aucune jouissance " et la fatigue comme un effort impuissant et maladif ».

La Commission de perfectionnement, augmentée de plusieurs

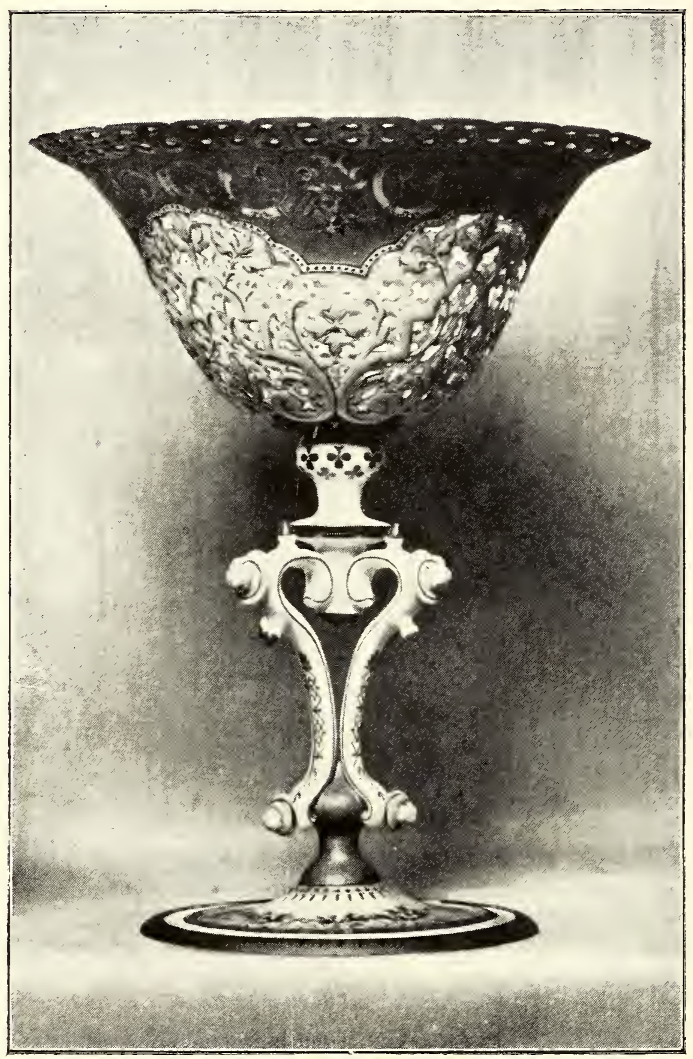

Coupe ajourée. (Haut. 0,22). - Porcelaine dure (1862). (Musée de Sèvres, no 7591.)

membres choisis parmi les céramistes et les décorateurs, se livra pendant trois années à un examen rigoureux des résultats obtenus el fournitd'utiles indications sur le but à poursuivre. M. Duc, chargé en $187:$ de rédiger le rapport définitif, résuma les observations formulées au cours des années précédentes. Deux critiques générales dominent cet important travail : "La science de la Céramique a moins de progrès à faire que l'Art. Les artistes, qui n'ont rien à 
gagner au point de vue du métier, manquent de l'instruclion générale qui leur ferait acquérir les notions de ce qui est utile à la décoration céramique. "La Commission proserivit tout d'abord d'une façon absolue tout décor où il serait fait emploi de la perspective, et ainsi se trouvèrent condamnés la plupart des genres enployés jusqu'alor's. Elle recommanda aux artistes l'étude des diver's arts anciens et modernes en leur signalant les qualités caractéristiqques de l'art de chaque temps. Elle établit cegrand principe, si complètement méconnu depuis trois quarts de siècle, que le décor doit loujours respecter la forme de la chose décorée, et demanda, pour assurer un recrutement d'artistes préparés à leur rôle, d'organiser dans la Manufaelure mème une école où des jeunes gens recerraient un enseignement spécial appliqué à la céramique.

Ayant ainsi assuré la formation de pratieiens habiles, la Commission pensa qu’il était aussi nécessaire d'activer l'échange des idées entre les artistes de la Manufacture et ceux du dehors, plus directement mèlés au mouvement de l'art : pour cela elle proposa l’organisation d'un prix de Sères qui, décerné tous les ans, devait donner lieu à un concours entre tous les artistes pour la eréation de la forme et du déeor d'un oljet déterminé. L’œuvre primée serait exécutée par la Manufacture. Comme complément de l’instruction esthétique des artistes, la Commission demanda enfin l'installation du Musée céramiquesuivant un prineipe un peudifférent de celuiadopté par Brongniart, quien avait plutôt fait une collection teehnologique qu'un musée, négligeant de parti-prisle point de vue esthétique pour donner toute l'importance au point de vue purement teehnique. La conclusion du rapport de M. Due vaut d'etre citée : "La "Manufacture de Sèves possìde dans son sein tous les éléments " nécessaires pour la maintenir au niveau desa réputalion européenne. “La fabrication est supérieure, la science est arrivée à un haut degré " de perfection et peut fournir à lous les besoins de l'art céramique 
" sous le double rapport de la matière, des émaux et des couleurs, " mais elle doit faire de nouveaux efforts pour l'avenir. Les artistes ".ont pour la plupart une virtuosité qui ne peut être surpassée. Ils " possèdent presque toutes ces qualités naturelles de goût, de grâce " et de délicatesse qui sont l'apanage de notre tempérament national. "L'éducation et l'instruction seules manquent à cet ensemble de "brillantes qualités : il y a beaucoup à faire dans ce sens."

Dans quelles conditions, dans quelle mesure les conclusions de la Commission de perfectionnement furent-elles suivies de résultats, c'est ce qui nous reste à indiquer en étudiant le développement de la Manufacture au eours des trente dernières années. Mais ici s'arr’ète, en réalité, la période historique de l'existence de cet établissement : les réformes profondes qu'on apporta à cette époque dans son organisation ont encore leur répercussion sur la production actuelle : celle-ci ne saurait donc être jugée au mème point de vue que les œuvres de la période antérieure. 


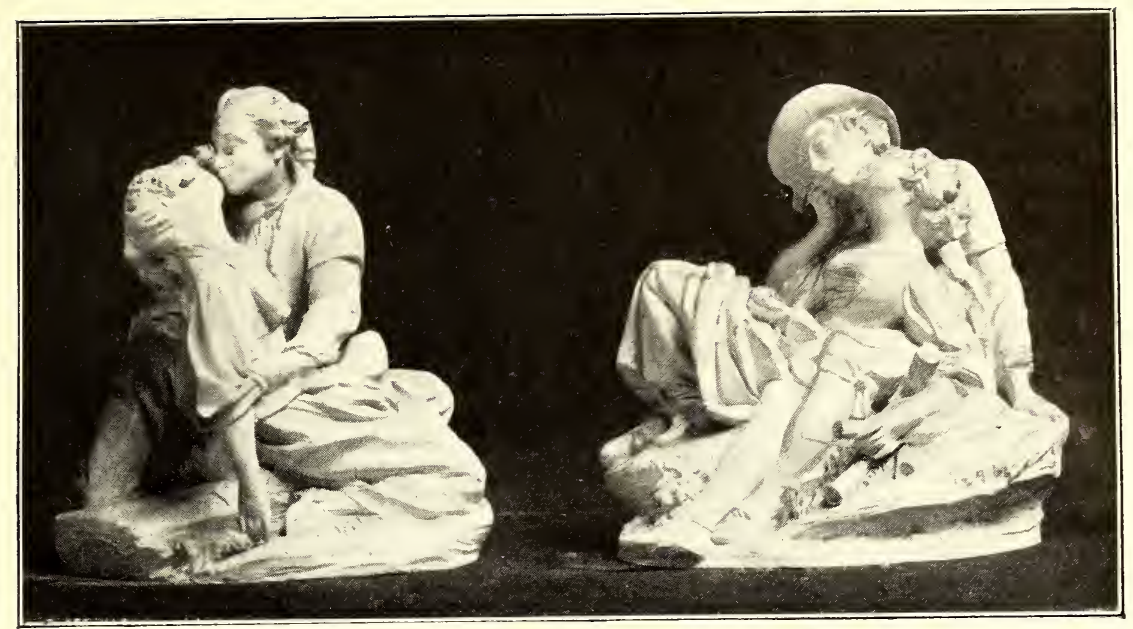

Le Baiser donné et le Baiser rendu. - Modèles de 176ว.

\section{TABLE DES GRAVURES}

Porcelaine tendre de Vincennes, $1^{\text {re }}$ époque. Boiles et étui . . . . . . . .

Porcelaine tendre de Vincennes. Jatte décorée d'une vue du chàteau de Vincennes

Porcelaine tendre de Vincennes, vers 1740-1750. Vase Médicis, a vec bouquet de fleurs peintes.

Porcelaine tendre de Vincennes, $1^{\text {re }}$ époque. Vase à oignon. Décor imité des Chinois . . . . . . . . . . . . . .

Porcelaine tendre de Vincennes, vers 1730. Vase "Pot-Pourri » ovale, à fond vert et cartels décorés d'amours, d'après Boucher. Convercle orné de fleurs en relief.

Porcelaine tendre de Vincennes, entre 1745 el 1753. Assietle décorée d'oiseaux et de fleurs en or. . . . . . . . . . . . . . . . . . . . 12

Porcelaine tendre de Vincennes, vers 17ă0. Broc à décor de paysages . . . 13

Porcelaine tendre de Vincennes. Salière trilobée à têtes de dauphin . . . . 17

Porcelaine tendre de Vincennes. Bouquet en porcelaine offert au Grand Electeur de Saxe, en 1748 . . . . . . . . . . . . . . .

Porcelaine tendre de Vincennes, vers 1745-1750. Saucière ornée de fleurs en relief. . . . . . . . . . . . . . . . . . . . 21

Groupe de Léda, d’après Boucher. Modele de 1745. . . . . . . . . . . . 23

Chien et canard, d’après Oudry. Modèle de 1732. . . . . . . . . . 25

Groupe de danseurs. Modèle de 1763. . . . . . . . . . . . . . . 27 
Fabrication de Vincennes, vers 1753. Porcelaine tendre peinte et émaillée . Vue de l'ancienne Manufacture de Sèvres (1756-1876). - Aquarelle de Troyon père

Porcelaine tendre de Vincennes, vers 1735. - Vase "Vaisseau à mat » à fond bleu vermiculé et cartels décorés d'oiseaux . . . . . . . . . . .

La Porteuse de cage. Modèle de 1752. - Porcelaine peinte et émaillée. . .

Porcelaine tendre de Sèrres, 1756. - Compotier fond turquoise. Décor par Binet. . . . . . . . . . . . . . . . . . . . .

Groupe " du Jaloux ». - Modèle de 1752 . . . . . . . . . . . . . . . .

Groupe d'enfants. - Modèle de La Rue, 173̆4. - Porcelaine tendre émaillée de Vincennes . . . . . . . . . . . . . . . . . . .

Porcelaine tendre de Sèvres, 1739. - Jardinière fond vert. Cartels à personnages

Ancienne Manufacture de Sèrres. - Entrée de la Cour Royale . . . . . .

Porcelaine tendre de Sèves, 1763. - Cendrier carré. . . . . . . . . . .

Porcelaine tendre, 1770. - Assiette du service de IIme du Barry. Décor de Catrice . . . . . . . . . . . . . . . . . 54

Porcelaine tendre de Sèvres. - Vase à anses torses à cartels . . . . . . . 57

Les Trois Contents. - Modele de 176̈ . . . . . . . . . . . . . . . . . 61

Groupe de Pygmalion, d'après Falconet. - Modèle de 1763 . . . . . . . . 63

La cantatrice du Barry. - Modèle de 17\%2 . . . . . . . . . . . . . . 65

Vase des Saisons. - Modèle de Bachelier (1767) . . . . . . . . . . . . . 67

Vase en porcelaine dure. Décor de Philippine (1776) . . . . . . . . . . . 71

Bacchus enfant. - Premier essai de porcelaine dure émaillée (1765) . . . 73

Portrait du chimiste Nacquer, 1718-1784 . . . . . . . . . . . . . . . 75

Porcelaine tendre. Soupière et son plateau. Décor de Le Bel jeune (1772). . 77

Curette en porcelaine dure. Décor de Dubois (1777) . . . . . . . . . . . . 82

L'Éducation de l'Amour. - Modele de 1773 . . . . . . . . . . . . . . 84

L’Autel Royal. Groupe allégorique du comronnement de Louis XVI et MarieAntoinette. - Modèle de 1775 . . . . . . . . . . . . . . . . . . 85

Girandole Boizot. - Modèle de 1774 . . . . . . . . . . . . . . . . . . 87

Porcelaine tendre. - Cassolette du service de Catherine II impératrice de Russie (1776). - Fond bleu turquoise . . . . . . . . . . . . . . . . 91

Modeles originaux de biscuits du xvint siècle . . . . . . . . . . . . . . 93

Porcelaine tendre. - Vase a quatre cartels à fond bleu et ail-de-perdrix.

Sujets de marine (1775). . . . . . . . . . . . . . . . . . . . . . . 97

Porcelaine tendre. Assiette à décor polychrone (1786) . . . . . . . . . . 99

Allégorie de la naissance du Dauphin. - Modèle de Pajou (1781) . . . . . 102

Porcelaine tendre. - Tasse décorée d'émaux, par Cotteau (1783). . . . . . 103

Porcelaine tendre. - Plaque de la série des "Chasses du Roi ", d'après

Oudry. Peinture d'Asselin (1781) . . . . . . . . . . . . . 10 כ

L'enfance de Silène. - Modèle de 1788. . . . . . . . . . . . . . . . . 107

Groupe du Ballon. - Modèle de 1786 . . . . . . . . . . . . . . . . . 108

f'orcelaine dure. Gobelet à anses de la laiteric royale de Rambouillet. Pein-

ture d'apres Lagrenee $(17 \times 8)$. . . . . . . . . . . . . . . . . . . . 112

Porcelaine dure. - Cuvette décorée, en or sur fond noir imitant la laque,

par Le Guay (1791) 
Busle d'Hellinger, par Roguier, sculpteur de la Manufacture. . . . . . 117

Ássiettes à emblèmes révolutionnaires (1793-1793) . . . . . . . . . . . . . 123

La Liberté présentant les vertus civiques. - Modele de 1792 . . . . . . 126

Alexandre Brongniart $(17 \pi 0-184 \pi)$. . . . . . . . . . . . . . . . . 131

Porcelaine dure. - Encrier en pite de biscuit imitant le bronze. Ornements

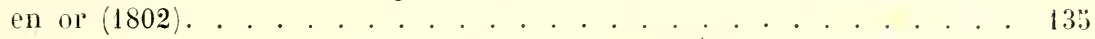

Porcelaine dure. - Théière décorée de sujets en biscuits sur font d'or, d'après Rég̨nier (1812) . . . . . . . . . . . . . . . . . . . . . . . 136

Porcelaine dure. - Vase " étrusque à rouleaux "représentant l'arrivée à Paris des objets d'art rapportés d'Italie (1813) . . . . . . . . . . 139

Porcelaine dure. - La bataille de Marengo, par Swebach (1803). . . . . . 140

Pendule en biscuit arec parties dorées. - Modèle de Percier . . . . . . . 142

Porcelaine dure. - Coupe dite " des sens ». Décor de Mme Ducluzeau daprès Fragonard $(1825)$. . . . . . . . . . . . . . . 145

Porcelaine dure. - L'Amour et Psyché. Peinture sur plaque par $\mathbf{I}^{\mathrm{m} s}$ Jacquotot, d’après le baron Gérard (1824). . . . . . . . . . . . 147

Saint Louis au pont de Taillebourg. - Composition d Eugène Delacroix pour les vilraux de la chapelle de lreux . . . . . . . . . . . . . . . 149

Porcelaine dure. - Issiette du service des départements (1828). . . . . . 152

Atelier d'émaux sur métaux. - Cassolette décorée d'émaux sur cuivre, par Gobert. . . . . . . . . . . . . . . 153

Porcelaine dure. - Assiette du service du chiteau de Fontainebleau (1838). 1\%3

Porcelaine dure. - Vase " bijou » décoré en pates d’application, par Gély $(1863)$. . . . . . . . . . . . . . 158

Atelier de fä̈ence émaillée. — Enfants porte-bouquets, par Larue (1863). . 159

Porcelaine dure. - Coupe ajourée (1862) . . . . . . . . . . . . . . . 162

Le baiser donné et le baiser rendu. - Modèles de 176ว . . . . . . . . 16 כ̆ 


\section{TABLE DES MATIÈRES}

Chapitre premier. - Les premières manufactures françaises de porcelaine. La fondation de la Manufacture de Vincennes. La Compagnie Charles Adam (1738-1732). . . . . . . . . . . . . . . . . . . 1

Chapitre II. - La Manufacture royale de porcelaine. La Compagnie Eloy Brichard (1752-1759). . . . . . . . . . . . . . . . . . . 31

Chapitre III. - La Manufacture, propriété royale : Direction de Boileau. La découverte de la porcelaine dure (1759-1772) . . . . . . . . . . . 51

Chapitre IV. - La Manufacture de 1772 à 1789 : Directions Parent et Régnier.

L’influence de M. d’Angivilliers. . . . . . . . . . . . . . . . . 82

Chaprtre V. - La Manufacture pendant la Révolution (1790-1800) . . . 114

Chapitre VI. - La Manufacture de Sèvres au xix e siècle (1800-1876). . . . 129 




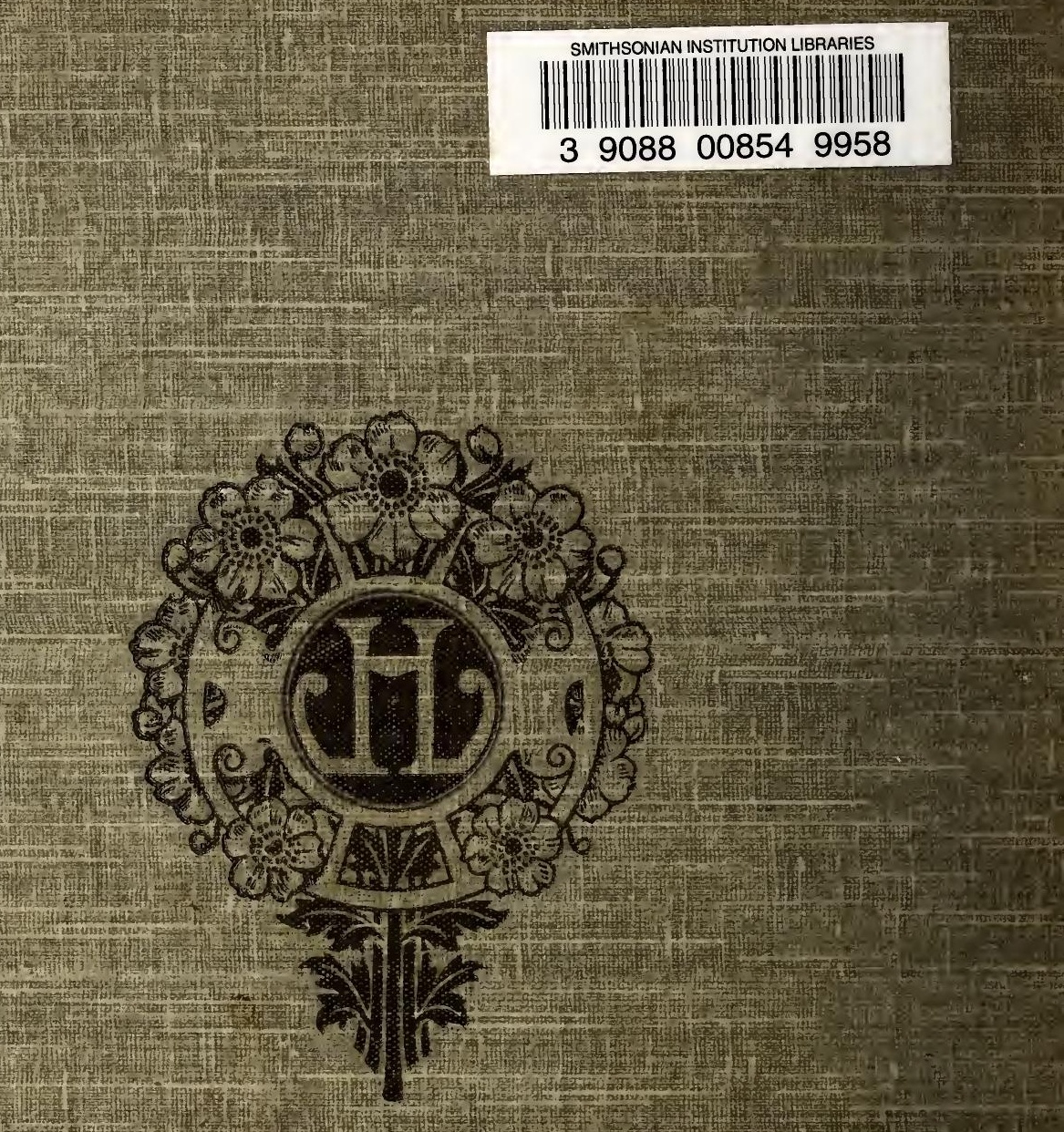

